\title{
Políticas públicas para el desarrollo y la competitividad en la industria manufacturera
}

Gerardo González Chávez cosodhoder 
Las pequeñas y modianas empresas generan gran parte de los empleos en los paises industrializados, sin embargo, la mayoria de los gobiemos muestran una gran falta de atención a las mismas, por considerarlas actividades poco importantes o de escaso aporte a sus economias. En México apenas se esta iniciando el debate entre gobernantes, politicos y grandes empresarios, sobre la función de las pymes. Entre las cuestiones principales que se discuten están: ¿cuall es la importancia real de su contribución al crecimiento económico de estos paises?, ¿son un motor clave en la creacion de emploo para las economias nacionalos?

En este contexto, la obra colectiva que ahora se presenta ayuda no solo a conocer las condiciones en que se han desemperiado las actividades (industriales) de las pymes en los últimos aifos, sino que refuerza el análisis de la problemática del sector manutacturero en México, asi como de las politicas instrumentadas por el aparato público en ese sector, principaimente para apoyar su compotitividad.

Se presentan también aportaciones individuales con estudios de casos sectoriales, como los de las industrias automotriz, textil, editorial y de la produccib́n de mezcal, además de que se destaca el efecto que ha tenido la introducción de nuevas tecnologias y apropiación de los mercados internacionales y domésticos, on las condiciones laborales y en los ingresos tanto de los empresarios pequenos y madianos, como de los trabajadores ocupados formalmente.

Políticas públicas para el desarrollo

y la competitividad en la industria manufacturera 


\section{UNIVERSIDAD NACIONAL AUTÓNOMA DE MÉXICO \\ José Narro Robles \\ Rector \\ Eduardo Bárzana García \\ Secretario General \\ Leopoldo Silva Gutiérrez \\ Secretario Administrativo \\ Estela Morales Campos \\ Coordinadora de Humanidades}

\section{INSTITUTO DE INVESTIGACIONES ECONÓMICAS}

Verónica Villarespe Reyes

Directora

Berenice P. Ramírez López

Secretaria Académica

Aristeo Tovías García

Secretario Técnico

Marisol Simón Pinero

Jefa del Departamento de Ediciones 


\title{
Políticas públicas para el desarrollo y la competitividad en la industria manufacturera
}

\author{
Gerardo González Chávez \\ (coordinador)
}


Esta investigación, arbitrada por pares académicos, se privilegia con el aval de la institución editora.

Políticas públicas para el desarrollo y la competitividad en la industria manufacturera / coordinador: Gerardo González Chávez. - Primera edición. - México, D.F. : Universidad Nacional Autónoma de México, Instituto de Investigaciones Económicas, 2014.

340 páginas: ilustraciones; $21 \mathrm{~cm}$.

Incluye bibliografías

ISBN: 978-607-02-5375-1

1. Industrias manufactureras - Aspectos económicos - México. 2. Competencia económica - México. 3. Industrias manufactureras - Innovaciones tecnológicas - México. 4. México - Política económica - Siglo XXI. I. González Chávez, Gerardo, coordinador. II. Universidad Nacional Autónoma de México. Instituto de Investigaciones Económicas.

$338.47670972-\operatorname{scd} 21$

Biblioteca Nacional de México

Primera edición, 12 de febrero de 2015

D.R. (C) Universidad Nacional Autónoma de MéXico

Ciudad Universitaria, Coyoacán, 04510, México, D.F.

InSTITUTO DE INVESTIGACIONES ECONÓMICAS

Circuito Mario de la Cueva s/n

Ciudad de la Investigación en Humanidades

04510, México, D.F.

Proyecto PAPIIT IN305610

"El desarrollo tecnológico y la competitividad

en la industria manufacturera 2010-2012"

ISBN: 978-607-02-5375-1

Diseño de portada: Itzel Flores Montes de Oca

Cuidado de la edición: Graciela Reynoso Rivas

Prohibida la reproducción total o parcial por cualquier medio sin la autorización escrita del titular de los derechos patrimoniales.

Impreso y hecho en México/Printed in Mexico 


\section{ÍNDICE}

Prólogo

Carlos Bustamante Lemus

Referencias, 15.

Introducción

\section{Capítulo 1}

Las políticas públicas para la competitividad industrial.....

Gerardo González Chávez

Introducción, 27; La economía con un Estado intervencionista, 28; El taylorismo-fordismo, 32; El patrón de acumulación intervencionista, 33; El modelo sustitutivo de importaciones, 35; Cambios a la política industrial del modelo intervencionista, 39; El cambio del modelo intervencionista, 41; El patrón de acumulación neoliberal, 45; El toyotismo o la producción flexible, 46; Las políticas públicas para la competitividad industrial en México, 50; La producción industrial en el siglo XXI, 58; Conclusiones, 60; Referencias, 61.

\section{Capítulo 2}

\section{El Estado, la empresa trasnacional automotriz}

y los trabajadores

Angelina Gutiérrez Arriola

Introducción, 67; Periodo de transición, 68; Consolidación de la fase flexible, 73; La nueva división técnica del trabajo, 80; Conclusiones, 86; Referencias, 88. 


\section{Capítulo 3}

\section{La participación del Estado en el desarrollo}

y la competitividad de la industria automotriz en México.

Luz María Jiménez Ramírez

Introducción, 91; Importancia del tema, 92; El Estado mexicano y la industria automotriz, 92; El desarrollo industrial y el sector automotriz, 95; La industria automotriz en México, 95; El proteccionismo económico y la industria automotriz, 97; Instituciones reguladoras de la industria automotriz, 101; Crisis de la ISI en la industria automotriz, 102; La apertura económica, 103; La industrialización orientada a las exportaciones en la industria automotriz en México, 105; El Tratado de Libre Comercio de América del Norte en la industria automotriz, 109; Efectos del TLCAN en la industria automotriz, 110; Nuevos decretos después del TLCAN, 112; Los decretos de 2009 y 2011, y los acuerdos complementarios, 113; Apoyos gubernamentales al consumo de automóviles, 115; El sector de autopartes, 116; Conclusiones, 118; Referencias, 118.

\section{Capítulo 4}

La industria manufacturera y su localización: el caso de la Ciudad de México entre 1993 y 2008

Roberto Ramírez Hernández

Introducción, 123; Antecedentes históricos: la Ciudad de México y su crecimiento industrial hacia la mitad del siglo XX, 125; Estructuras policéntricas y su identificación: el caso de la ZMCM, 129; Evolución de la estructura policéntrica industrial de la Ciudad de México en 2008, 139; Especialización en los centros industriales de la ZMCM, 140; Conclusiones, 145; Referencias, 145.

Capítulo 5

Competitividad de las pequeñas y medianas empresas en el sector manufacturero 
Introducción, 149; Antecedentes de las pymes, 151; Situación actual de las pymes, 156; Análisis de las pymes manufactureras, 163; Manufacturas, 167; Estudio de casos, 170; Conclusiones, 176; Referencias, 177.

\section{Capítulo 6}

Políticas públicas para la competitividad del sector textil en México en un entorno de libre comercio

Irma Portos Pérez

Introducción, 181; Evolución reciente del sector textil y sus perspectivas, 183; Continuidad y avances del nuevo gobierno (el discurso y los hechos), 188; La política sectorial textil actual, 189; Conclusiones, 191; Referencias, 192.

\section{Capítulo 7}

La manufactura de la confección en el Distrito Federal: el caso de las cooperativas de producción de uniformes escolares

María de Jesús López Amador

Introducción, 195; La industria de la confección y el vestido en México: problemas y retos para la competitividad, 199; Desarrollo tecnológico en la industria del vestido, 207; Breve panorama sociohistórico de las cooperativas en el Distrito Federal, 213; La política de empleo y de fomento cooperativo en el Distrito Federal: el caso de las cooperativas de confección de uniformes escolares, 217; La organización del trabajo y su efecto en la competitividad. Las cooperativas de producción de uniformes escolares, 224; Conclusiones, 233; Referencias, 236; Entrevistas realizadas, 239.

Capítulo 8

Políticas públicas para la innovación tecnológica en la industria mexicana del libro 
Introducción, 241; Historia de la industria editorial, 242; Perfil de la industria editorial en México, 247; Problemas de la industria editorial, 253; Innovación tecnológica en la industria editorial, 259; Políticas públicas culturales en materia editorial, 263; Conclusiones y propuestas, 270; Referencias, 273.

\section{Capítulo 9}

Una mirada a la industria del mezcal de Oaxaca

María Elena Lopes Pacheco

Introducción, 277; Principal productor de mezcal: Oaxaca, 279; Materia prima: agave, 280; Producción industrial y artesanal de mezcal, 281; La inversión privada y pública en las empresas productoras de mezcal, 285; Comercialización del destilado, 288; La denominación de origen, las regulaciones y acciones gubernamentales, 291; Conclusiones, 294; Referencias, 295.

Capítulo 10

Políticas públicas para el desarrollo de la innovación y la competitividad de la industria manufacturera

Gerardo González Chávez, Melissa Said Gayosso, Yarel Esparza García y Óscar Alejandro Gómez Romero

Introducción, 299; El papel del Estado liberal en la economía, 301; Algunos casos de éxito en el desarrollo industrial, 304; Crisis y participación del Estado, 321; Políticas públicas para el desarrollo, 325; Propuesta de políticas públicas para México, 327; Referencias, 334.

Conclusiones generales 


\section{PRÓlogo}

Es motivo de enorme gratificación prologar este trabajo, producto de un arduo libro de investigación colectiva y de coordinación por parte de Gerardo González Chávez. La obra adquiere, sin lugar a dudas, interés y relevancia, sobre todo porque atiende un campo de investigación de vital importancia no solo para México, sino para un gran número de países insuficientemente desarrollados llamados por muchos de manera eufemística "en vías de desarrollo", que requieren con urgencia cambios en su visión sobre el desarrollo económico y el bienestar social, además de que deben responder a los considerables impactos en sus respectivas economías nacionales, derivados de las crisis y recesión por las que atraviesan desde hace ya más de seis años los países industrializados.

Las pequeñas y medianas empresas (de cinco a 250 empleados) generan gran parte de los empleos en los países industrializados. Este es un hecho bien fundamentado en documentos oficiales y científicos de casi todo el mundo. Sin embargo, la mayoría de los gobiernos de países no suficientemente desarrollados muestran desprecio o, por lo menos, falta de atención a las pequeñas y medianas empresas, por considerarlas actividades poco importantes o de escaso aporte a sus economías y, con frecuencia, inclusive las califican como actividades marginales. En pocos de 
estos países, entre ellos México, apenas sí se está aceptando en los últimos 10 años abrir el debate entre gobernantes, políticos y grandes empresarios, sobre el papel que desempeñan las empresas pequeñas y medianas también en los países en desarrollo. Las preguntas principales que surgen entre ellos incluyen: ¿'son aportes importantes para el crecimiento económico nacional? y ¿son un motor importante en la creación de empleo también para sus economías nacionales o subnacionales?

Diversos documentos de organismos internacionales, como la Organización Internacional del Trabajo (OIT), además de investigaciones académicas más o menos recientes de países industrializados y en desarrollo, subrayan su importancia. Por ejemplo, Jan de Kok, Claudia Deijl y Christi Veldhuis-Van-Essen [2013] analizan alrededor de 50 estudios de investigación y concluyen que las pequeñas y medianas empresas (pymes) proporcionan dos terceras partes de todos los empleos formales en los países en desarrollo de África, Asia y América Latina, y $80 \%$ en los países de bajos ingresos, sobre todo en África subsahariana. Los autores enfatizan que existe la opinión generalizada de que las pymes no generan muchos empleos y que frecuentemente su ciclo de vida (en operación) es más corto; pero con su estudio muestran que $50 \%$ del total de la creación de empleos procede de las empresas con menos de 100 trabajadores y no siempre su operación o ciclo de vida es breve.

Más aún, otros estudios especializados [Geroski y Gregg, 1997], que basan su investigación en estudios empíricos de empresas industriales en Gran Bretaña, revelan la capacidad de adaptación de muchas de ellas a las crisis del sistema económico prevaleciente, para seguir operando y recuperarse de sus déficits temporales.

Muy recientemente se publicó otro estudio de la OCDE [2013], en el cual se destaca la importancia que el gobierno mexicano de los años recientes ha prestado a este asunto con una serie de políticas para la promoción de las pequeñas y medianas empresas y la iniciativa empresarial. Se ha formulado una serie de políticas de apoyo que favorecen el desarrollo de nuevos emprendedores, 
microempresas, pequeñas y medianas (mipymes), y sirven de vínculo entre ellas y las grandes compañías también llamadas empresas "tractoras". Además, se han logrado acuerdos de coordinación mediante las secretarías del gobierno federal y entre los gobiernos estatales y algunos locales, para aumentar la coherencia y la integración de sus programas.

En este contexto, la obra colectiva que ahora se presenta contiene una riqueza variada que ayuda a conocer las condiciones en que las actividades manufactureras se han desempeñado en los últimos decenios; más aún, refuerza el análisis de la problemática subyacente del sector industrial y manufacturero de México, y de las políticas puestas en marcha por el aparato público y el sector privado, al igual que permite reflexionar sobre los logros y limitaciones que se han presentado a la fecha.

Algunos de los trabajos individuales destacan los cambios que ha experimentado la economía mexicana desde los dos principales paradigmas del crecimiento económico del siglo xx: el modelo llamado fordista, o de producción en gran escala automatizada, acumulación de inventarios y establecimientos en plantas de crecimiento concentrado; y el modelo toyotista, o de producción flexible, con entregas just-in-time (justo a tiempo), sin acumulación de inventarios y procesos de producción desconcentrados, que también gracias a las grandes innovaciones tecnológicas en telecomunicaciones y transportación, ha dado lugar al modelo neoliberal y globalizador, así como a los efectos que dicho modelo ha tenido entre las empresas y en la clase trabajadora, tanto de países industrializados como de los menos industrializados.

Se presentan otras aportaciones individuales con estudios de casos sectoriales, como los de las industrias automotriz, textil, de la producción de mezcal y de la producción editorial, en los cuales se muestra el predominio de empresas con capital trasnacional, con un mínimo impacto favorable en unas cuantas compañías pequeñas y medianas que han logrado insertarse en algunos de los procesos intermedios de las grandes firmas, mientras que la mayoría de las empresas nacionales son desplazadas del mercado. Al mismo tiempo, se destaca el efecto que ha tenido 
la introducción de nuevas tecnologías y apropiación de los mercados internacionales y domésticos en las condiciones laborales y en los ingresos tanto de los empresarios pequeños y medianos, como de los trabajadores ocupados formalmente.

Dentro de las aportaciones individuales, resalta la que se ocupa del comportamiento económico y territorial del sector manufacturero en la Ciudad de México, capital alguna vez concentradora de más de $35 \%$ de la actividad industrial de todo el país y de cerca de $40 \%$ del empleo manufacturero nacional. Este trabajo expone en primer lugar, que la Ciudad de México, así como casi todas las urbes mexicanas, ha carecido de una planificación efectiva principalmente por el desconocimiento acerca de los diversos procesos de producción, de sus necesidades de localización, lo cual repercute en el diseño de políticas económicas equivocadas o por lo menos de escaso impacto en el crecimiento y en el bienestar de los pobladores. Con el empleo de técnicas como la del análisis espacial exploratorio de datos, se intenta demostrar el carácter policéntrico en el crecimiento de la Ciudad de México y su zona metropolitana, así como el proceso de desindustrialización que se presenta en el Distrito Federal, al tiempo que surgen nuevos subcentros cada vez más fortalecidos o consolidados.

De igual manera, las nuevas relaciones en el mercado internacional han profundizado la dependencia y subordinación de nuestro país al exterior, al encontrarse ante una competencia totalmente desigual e inequitativa, por tener un sector industrial sumamente fragmentado y graves problemas de atraso tecnológico en la mayoría de las empresas pequeñas y medianas, con escasa productividad tecnológica, y una clase trabajadora totalmente empobrecida, en constante zozobra por las nuevas condiciones laborales impuestas por el modelo de producción flexible y de empleo temporal.

En síntesis, los estudiosos que participan en esta obra colectiva destacan la estructura general de la producción, la falta de competitividad y de innovación tecnológica, y la ruptura en las cadenas de producción de un gran número de empresas industriales 
pequeñas y medianas, además de una debilidad por parte de los gobiernos mexicanos para atender todos estos problemas que aquejan al sector industrial de nuestro país. Con ello, se sientan las bases en el presente trabajo para proponer algunas políticas públicas que podrían dar un giro a la visión eminentemente exportadora que hasta ahora ha prevalecido desde los tomadores de decisión en el gobierno mexicano, de modo que se destaque la importancia del mercado interno para el desarrollo económico.

El presente libro concluye con una serie de propuestas al sistema político de México, para adoptar políticas públicas tendientes a reforzar y a dar un mayor impulso a la economía nacional desde su base productiva, en la que empresarios mexicanos, cualquiera que sea la escala productiva en la que se desenvuelven, puedan revitalizarse y facilitar un nuevo empuje al crecimiento y bienestar de la población de México.

Por las anteriores consideraciones, resulta más que gratificante y provechoso leer los trabajos contenidos en esta obra colectiva, la cual tiene entre sus objetivos principales crear conciencia y motivar a estudiantes, profesores, políticos y público en general, a fin de generar nuevos aportes al conocimiento de la economía mexicana y a la toma de decisiones para el diseño de políticas más acordes con nuestra realidad nacional.

\section{REFERENCIAS}

Geroski, P.A., y P. Gregg [1997], Coping with Recession. UK Company Performance in Adversity, UK, Cambridge University Press, The National Institute of Economic Research.

Kok, Jan de, Claudia Deijl y Christi Veldhuis-Van-Essen [2013], "Is Small Still Beautiful?", Literature Review of Recent Empirical Evidence on the Contribution of SMEs to Employment Creation, International Labour Organization and Deutsche Gesellschaft für Internationale Zusammenarbeit $\mathrm{GmbH}$, April 16, 68 pp. 
Organización para la Cooperación y el Desarrollo Económico [2013], Studies on SMEs and Entrepreneurship, Mexico, Key Issues and Policies, OECD Publishing, 9 de mayo, 258 pp. 


\section{INTRODUCCIÓN}

El presente trabajo es resultado de una investigación colectiva sobre la competitividad internacional del sector manufacturero mexicano, uno de cuyos factores es el incremento en la productividad ligado a la utilización de nuevas tecnologías en el sector industrial, la organización del trabajo y las ventajas proporcionadas por el Estado en la lucha competitiva. Por un lado, se busca entender los efectos de la innovación tecnológica y los cambios en la fuerza de trabajo en un entorno de mayor competitividad en el mercado internacional y con altos grados de dependencia del sector manufacturero nacional. Además, se propone establecer y analizar los vínculos entre la fuerza de trabajo y la tecnología, e identificar las políticas públicas y posibles limitaciones existentes en México para poder competir en un mercado globalizado.

Los estudios que conforman esta obra se enfocan en la estructura de la producción, la competitividad y el empleo en la economía nacional. En ellos se analizan factores como la movilidad de la fuerza de trabajo y la transferencia de conocimiento que conlleva la necesidad de apropiación de las nuevas tecnologías por parte de los trabajadores, mediante el aprendizaje, para optimizar su aplicación. Un elemento fundamental es el análisis de la política económica en materia de innovación tecnológica por medio de las políticas públicas encaminadas a la productividad, y sus efectos en el mercado de trabajo ante los cambios estructurales en las cadenas productivas, el empleo productivo y la movilidad salarial. 
Los productos de investigación individual de los académicos que participaron en el proyecto de investigación, enriquecen el texto en el aspecto de la participación estatal, la competitividad internacional, la innovación tecnológica, la economía del cambio tecnológico, la internacionalización de la producción y las políticas de innovación. Se caracteriza el perfil de la fuerza de trabajo calificada y la productividad por medio de la evaluación del impacto económico de la transferencia de conocimiento ligada al sector manufacturero. Asimismo, se destaca la importancia de la calificación del trabajo en la difusión del conocimiento, el incremento de la productividad y el crecimiento económico.

Esta investigación pretende contribuir al avance del conocimiento en un tema que se ha estudiado poco: la vinculación entre la tecnología y el trabajo; con este objetivo se aprovechó la confluencia de expertos en innovación tecnológica y estudios sobre el trabajo en la industria manufacturera.

Los resultados proporcionan elementos para comprender la manera en que la tecnología influye en la productividad y, en consecuencia, en la competitividad, además de sus efectos en la organización las condiciones de trabajo. Por otro lado, la movilidad laboral conlleva la transferencia de conocimientos a través de distintos espacios, de una industria a otra, de un país a otro, en un contexto de grandes transformaciones competitivas a escala mundial y de rezago económico de los países subdesarrollados.

Desde el punto de vista macroeconómico, esta investigación aporta una perspectiva amplia de la competitividad en el sector manufacturero, así como de las condiciones de atraso en que se encuentra México, lo cual es importante para plantear alternativas emergentes que amortigüen la crisis social que vivimos. Asimismo, se realizan algunas recomendaciones en materia de políticas públicas que propicien la cooperación y el apoyo a las empresas para el fortalecimiento de la productividad y que permitan disminuir la inequidad social.

Es un esfuerzo que se encamina a participar en la discusión con especialistas y generadores de las políticas públicas que definen el papel del Estado en todo el proceso, al diseñar las políticas de 
apoyo a la innovación tecnológica, el desarrollo de la infraestructura y las reformas aplicadas en la regulación laboral que impactan las condiciones de trabajo y de vida de los asalariados.

En el primer capítulo, Gerardo González Chávez ofrece una revisión de la participación del Estado en la economía como un factor esencial para entender la evolución de la producción industrial desde principios del siglo xx hasta nuestros días, tanto en su papel de interventor directo en la economía como indirecto. En la primera etapa el Estado desempeña un papel esencial en el establecimiento de las condiciones generales para la industrialización, con el modelo sustitutivo de importaciones por medio del proteccionismo, el fomento a la empresa privada y su participación directa en la construcción de infraestructura, así como la creación de las empresas estratégicas que el capital privado requería. En la segunda etapa analiza cómo el Estado aplicó una política pública encaminada a fortalecer los mecanismos del mercado y favorecer las exportaciones en un mercado globalizado. En este capítulo, el autor identifica ambos procesos para entender los cambios de las políticas públicas en el largo plazo y señalar los elementos para interpretar las formas competitivas de la industria manufacturera con la política industrial del modelo intervencionista, y el patrón de acumulación en el neoliberalismo con el toyotismo o producción flexible, a fin de entender el capitalismo de nuestros días.

En el segundo capítulo, Angelina Gutiérrez Arriola presenta los efectos de la globalización y la participación del Estado en la adecuación de las condiciones de apertura, desregulación y privatización de las empresas públicas para facilitar la libre circulación del capital, así como aquellas otras medidas económicas, políticas y sociales para atraerlo. Analiza la reestructuración del capital a escala mundial y cómo se expresa en la internacionalización de la producción y del trabajo mediante el fraccionamiento y la segmentación del proceso productivo, como una respuesta a la tendencia decreciente de la tasa de ganancia. Estudia los cambios que sufren la empresas trasnacionales, en particular la industria automotriz, cuya modernización ha sido posible dado el gigantesco 
desarrollo tecnológico y la apertura de fronteras que han facilitado la reorganización de su producción a escala global, mediante una red de cadenas de valor a las que son integrados proveedores especializados de diversos países y regiones, lo que da lugar a nuevas formas de organización de la producción y el trabajo.

El capítulo tercero, abordado por Luz María Jiménez Ramírez, también se refiere a la industria automotriz. La autora estudia las políticas públicas para el desarrollo tecnológico y la competitividad en este sector. Analiza el papel que el Estado ha desempeñado en el desarrollo de la industria automotriz mexicana, por lo que examina los diversos decretos y acuerdos emitidos por el gobierno desde la década de los sesenta hasta la firma del Tratado de Libre Comercio de América del Norte (TLCAN) y sus repercusiones actuales en la producción y distribución de automóviles en México. Destaca la forma en que la industria automotriz ha logrado fortalecer su competitividad mediante la implantación de estrategias vinculadas a la innovación tecnológica, pero también cómo su competitividad ha estado sustentada en los bajos salarios de la mano de obra calificada y las bajas restricciones a la inversión instrumentadas en México. La autora reflexiona en las transformaciones que ha sufrido el sector de las autopartes y la forma en que se ha desarrollado la producción automotriz en un mercado internacional altamente fragmentado y con una producción de lo que se conoce como el automóvil mundial.

El cuarto apartado, a cargo de Roberto Ramírez Hernández, da cuenta de la estructura económica de la industria nacional a escala territorial; específicamente, identifica las principales aglomeraciones de tipo industrial para el caso de la Ciudad de México y su zona metropolitana. Analiza los aspectos que conforman un sistema de subcentros de actividad industrial (sistema policéntrico), cuya principal función es la de abastecer el mercado interno de la ciudad con los productos manufactureros que generan. Asimismo, señala que la industria de la Ciudad de México no debe ser considerada parte de una etapa anterior del desarrollo económico urbano de la ciudad ni un centro generador de industria orientada exclusivamente al modelo de exportaciones de la apertura 
económica, adoptado en México a partir de los años ochenta del siglo XX, sino una zona de especializaciones de estos subcentros; muestra la manera en que estas juegan un papel fundamental en el suministro de productos manufactureros para la Ciudad de México y da pauta para entender los estudios de caso.

En el capítulo quinto, escrito por Evelia Rojas Alarcón, se hace un análisis crítico del papel que juega la participación del Estado en las pequeñas y medianas empresas y su importancia para la economía mexicana. Se consideran tres áreas de estudio: en primer lugar se establecen las condiciones bajo las cuales surgieron y se han mantenido estos actores del desarrollo nacional desde una perspectiva histórica; en una segunda instancia, se identifican las circunstancias actuales que los caracterizan, además de que se definen las nuevas condiciones que están haciéndose presentes en su actividad a medida que penetra la globalización en el comportamiento económico nacional; en el tercer apartado, se plantea un análisis empírico, por medio de entrevistas a los empresarios, con el fin de corroborar su conducta frente a los problemas de su iniciación, crecimiento y desarrollo, que permita entender la importancia de las políticas públicas para promover el financiamiento y destacar la falta de acceso a recursos financieros que prevalece en los programas e instrumentos de aliento a la inversión en este sector industrial.

El capítulo seis, escrito por Irma Portos Pérez, se refiere a la industria textil desde la perspectiva de las políticas públicas para la competitividad en un entorno de libre comercio. Es una revisión de las acciones de políticas públicas orientadas a la elevación de la competitividad del sector textil-confección en México. Destaca las medidas más recientes planteadas por el gobierno mexicano por medio de la Secretaría de Economía, cuyo eje más destacado parece ser su carácter defensivo frente al comercio desleal que ha dañado severamente la situación del sector textil local. En ese sentido, la autora menciona la perspectiva gubernamental para fortalecer la presencia de la industria textil en el mercado local e incrementar su competitividad frente al exterior, sin menoscabo del libre comercio; pero fomentando la innovación, 
combatiendo la ilegalidad y fortaleciendo la integración del sector que se compone por fabricantes de textiles diversos y productores de prendas de vestir. Plantea la necesidad de detener el grave deterioro de la cadena industrial, poniendo fin a las importaciones ilegales provenientes de China, además de ampliar el juego de posibilidades para elevar la competitividad de las empresas que integran la industria textil.

María de Jesús López Amador, en el capítulo siete, presenta un estudio sobre la industria manufacturera de la confección en el Distrito Federal. Atiende al sector de las cooperativas en la manufactura de prendas de vestir, que enfrenta un entorno de alta competitividad global en el que resaltan sin duda los aspectos de su desarrollo tecnológico y los niveles de competitividad que alcanza ante la diversidad regional, empresarial y de la generación de empleo de calidad que puede impulsar. Analiza el Programa de Fomento Cooperativo por parte del Gobierno del Distrito Federal y la Secretaría de Trabajo y Fomento al Empleo, ante el desafío de aminorar los efectos de la crisis del empleo y la precariedad laboral. El estudio de una empresa cooperativa que produce uniformes escolares, permite a la autora identificar las variables claves para la competitividad, como la innovación tecnológica, la organización del trabajo y la producción, desde una base cooperativa y de interés social que se inscribe en un conjunto de políticas de desarrollo local y de empleo vinculadas en las cadenas de producción y comercialización para el mercado interno. De esta manera logra una visión de las trabajadoras cooperativistas en relación con los obstáculos a sortear para mantenerse en el mercado local y las carencias que se tienen en materia de políticas para el financiamiento del sector.

Los siguientes capítulos presentan otros estudios de caso. Así, en el octavo capítulo, Graciela Reynoso Rivas analiza la importancia de la innovación tecnológica en la industria editorial en México, en la rama dedicada a la producción de libros. El desarrollo de las tecnologías de la información y comunicación afecta directamente a este sector, no solo en la modificación de los procesos de producción, sino también en los productos finales y 
en la manera en que son consumidos. Por otro lado, en virtud de que la utilidad de dichos productos excede la materialidad de sus insumos, y su consumo incide en el desarrollo cultural de la propia sociedad, los procesos de producción y de circulación comercial no pueden ser dejados a la exclusiva lógica del mercado, lo que determina la existencia de regulaciones y políticas públicas para su fomento. La sociedad le ha otorgado al libro un elevado papel simbólico que lo convierte en objeto de debate público y de regulaciones estatales. La industria del libro, además de compartir rasgos con las industrias culturales, posee algunas características propias. En primer lugar, produce un bien que para ser consumido requiere como condición la existencia de un público alfabetizado y otros elementos que la hacen sumamente importante para la economía en su conjunto.

Otro caso interesante de análisis se refiere a la industria del mezcal en el estado de Oaxaca, abordado en el capítulo nueve por María Elena Lopes Pacheco, quien nos proporciona un acercamiento al problema de las bebidas y un conocimiento somero de la situación de las empresas mezcaleras de dicha entidad, pues aun cuando el mezcal ha empezado a comercializarse a escala nacional e internacional, todavía se le ubica como una bebida de baja calidad y generalmente la comparan con el tequila, por lo que es de interés del estudio conocer la situación específica de esta industria. La autora plantea que el mezcal es una bebida de buena y mejor calidad cuando se exporta, pero se debe analizar de qué depende su exportación, si de la materia prima o del proceso de elaboración o si ha habido acciones gubernamentales que han impulsado el desarrollo de algunas de las empresas mezcaleras oaxaqueñas. Destaca que es una producción artesanal basada en microempresas con limitados niveles de innovación, pero que los alfareros del estado de Oaxaca han tenido que introducir cambios fundamentales para mantenerse en el mercado. En este documento se plantean con mucha claridad las políticas públicas para el desarrollo y conservación de un producto tradicional de gran relevancia para la cultura local y nacional. 
Finalmente, en el capítulo diez, el trabajo colectivo de Gerardo González Chávez, Melissa Saíd Gayosso, Yarel Esparza García y Óscar Alejandro Gómez Romero, rescata el debate de las políticas públicas aplicadas en el contexto del neoliberalismo en el ámbito internacional para lograr el desarrollo y la competitividad de la industria manufacturera. Los autores muestran las contradicciones de la política liberal, ya que mientras que en los países desarrollados se mantienen las barreras arancelarias proteccionistas, se proporcionan grandes subsidios públicos a la industria y se propicia una participación creciente del Estado en la gestión económica, la situación es muy diferente en los países subdesarrollados: a ellos se les pide la apertura; se critica y sataniza al Estado como interventor o participante directo de la gestión económica; se exige redistribuir el gasto público en lo social, la privatización y descentralización de los servicios de salud y seguridad; o se confronta la necesidad de rescatar las empresas para capitalizarlas y luego, nuevamente venderlas en tanto estimulan el traslado de recursos sociales hacia la acumulación y el incremento de las ganancias de las empresas trasnacionales. Con ejemplos concretos, los autores destacan por qué los países que no siguieron al pie de la letra los lineamientos de los organismos financieros internacionales obtuvieron mejores resultados en el desarrollo económico, y sugieren la necesidad de cambiar la política económica del Estado en un sentido similar a las aplicadas en economías que han logrado enfrentar en mejores condiciones la crisis económica. Son ejemplos de esta situación los casos de China, Corea, Brasil e India en contraste con México que, a pesar de contar con los elementos necesarios para el despegue industrial y productivo, no ha conseguido articular bases interinstitucionales sólidas que permitan conducir un desarrollo industrial en el sector manufacturero en el ámbito global.

Por último, en los diferentes capítulos se ofrecen recomendaciones que pueden servir de base para políticas públicas encaminadas a mejorar las condiciones de innovación y competitividad del sector manufacturero nacional, en un contexto de intensificación en la lucha por los mercados y con el predominio del capital 
financiero internacional y el dominio de las grandes empresas trasnacionales, pero también para llamar la atención en las políticas orientadas a disminuir los costos salariales y sus efectos sobre los trabajadores.

La elaboración de esta investigación no hubiera sido posible sin el Programa de Apoyo a Proyectos de Investigación e Innovación Tecnológica (PAPIIT) de la UNAM, que nos apoyó en la realización del Proyecto IN305610, "El desarrollo tecnológico y la competitividad en la industria manufacturera", en cuyo contexto se pudieron reunir voluntades para concluir la mayor parte de los estudios aquí presentados, por lo que expreso nuestra gratitud a las participantes y colegas invitados a colaborar en esta obra. 


\section{Capítulo 1 \\ LAS POLÍTICAS PÚBLICAS \\ PARA LA COMPETITIVIDAD INDUSTRIAL}

Gerardo González Chávez:*

\section{INTRODUCCIÓN}

La participación del Estado en la economía ha sido un factor esencial para entender la evolución de la producción industrial desde principios del siglo xx hasta nuestros días. Tanto en su papel de interventor directo como indirecto, el Estado desempeña un papel esencial en el establecimiento de las condiciones generales de la acumulación y la regulación de las contradicciones sociales entre los poseedores de los medios de producción y los trabajadores. Se identifican dos grandes patrones de acumulación. En el primero la participación directa del Estado es muy clara mediante el proteccionismo, el fomento a la empresa privada y la intervención directa en la economía a fin de crear las mejores condiciones para el proceso de industrialización, como generador

* Académico del Instituto de Investigaciones Económicas (IIEc) de la Universidad Nacional Autónoma de México (UNAM), coordinador del proyecto de investigación "El desarrollo tecnológico y la competitividad en la industria manufacturera" (Programa de Apoyo a Proyectos de Investigación e Innovación Tecnológica-PAPIIT IN305610). Correo electrónico: <gerardog@unam.mx>. 
de demanda por la vía de la masa salarial con la creación de empleos directos e indirectos por medio de la infraestructura, al igual que como el creador de las empresas estratégicas que el capital privado requería para la obtención de sus beneficios y la regulación de la tasa de ganancia.

El Estado le otorgó al capital las condiciones necesarias para el buen funcionamiento de la fuerza de trabajo, en un entorno de estabilidad social, con una política pública que propició altas tasas de crecimiento económico y grandes márgenes de ganancia capitalista. La segunda etapa del desarrollo del modo de producción capitalista estableció una política del Estado encaminada a fortalecer los mecanismos del mercado, como forma más eficiente de funcionamiento para el capital. Se transformó el modelo de industrialización sustitutivo de importaciones por otro que favorece las exportaciones en un mercado globalizado. Este patrón de acumulación señala que lo mejor para el sistema capitalista es la organización de la actividad económica mediante empresas privadas que operen en un mercado libre y que, al descentralizar el poder económico, el sistema de mercado compensará cualquier concentración de poder político. En este capítulo se identifican ambos procesos para entender los cambios de las políticas públicas en el largo plazo, que nos permitan demostrar la importancia del Estado -como un elemento esencial para mantener elevadas tasas de beneficio y proporcionar los elementos para evitar la caída de la tasa de ganancia en el mediano y largo plazo- e interpretar las formas competitivas de la industria manufacturera en el capitalismo de nuestros días.

\section{LA ECONOMÍA CON UN ESTADO INTERVENCIONISTA}

Desde principios del siglo xx, el funcionamiento del Estado fue por medio del patrón de acumulación con un Estado proteccionistakeynesiano, que permitió la creación de las condiciones para la expansión económica por medio de la protección, el fortalecimiento y la expansión nacional del capital privado. El Estado se 
constituyó en un agente de la acumulación cuya acción intervencionista, al contrario de lo que afirmaba la argumentación neoclásica, no solo no cuestionó el sistema de propiedad privada, sino que le abrió espacios y posibilidades de desarrollo con la inversión pública en infraestructura (electricidad, petróleo, ferrocarriles y otras comunicaciones básicas para el avance de la industria). El creciente desarrollo industrial en la esfera de la propiedad directa demandaba las condiciones más adecuadas para impulsar la producción en las áreas de interés del capital privado mediante créditos blandos, garantías a la propiedad, asistencia técnica, barreras arancelarias o facilidades para la importación y exportación de bienes y servicios [Ayala, 2001: 146 y 211]. La intervención del Estado se convirtió en el eje esencial del crecimiento económico, sobre todo después de la segunda guerra mundial, cuando muchos países se vieron obligados a ser cada vez más autosuficientes ante la reducción de la oferta externa de productos manufacturados, debida a los obstáculos que enfrentaba una parte significativa del comercio internacional.

El Estado se convirtió en el principal instrumento de apoyo para el conjunto de la clase propietaria al regular la posesión y los recursos a las empresas privadas, pero también al mantener las condiciones sociales adecuadas para la acumulación. ${ }^{1}$ Es decir, la intervención pública no consiste únicamente en socializar las pérdidas y privatizar las ganancias; también intenta paliar la incapacidad de la iniciativa privada de suscitar el desarrollo del espacio social [Lipietz, 1979: 169]. La participación del Estado se desplegó en acciones de política fiscal y gasto público favorables a la inversión privada: se cobraban bajos impuestos o una limitada progresión en las cargas tributarias, concesiones y subsidios; se aplicaban en forma laxa e indiscriminada facilidades para la

${ }^{1}$ En el transcurso de su acción, es frecuente que se llame al Estado para compensar desequilibrios muy irritantes o hacer frente a errores de funcionamiento de la máquina económica, ya sea aportando una ayuda a los capitalistas en dificultades o racionalizando las condiciones de la intervención privada, por ejemplo, mediante la organización de los mercados de ciertos productos y la difusión de informaciones y de previsiones económicas [Vincent, 1977: 114-115]. 
amortización acelerada y aranceles generosamente proteccionistas que resultaban estímulos a la producción de altos costos y baja calidad; y la orientación del gasto público en beneficio preferentemente de los grandes empresarios se traducía en crecientes compras de bienes y servicios a ciertas compañías privadas.

En contraposición con las afirmaciones de los neoclásicos, la presencia activa y múltiple del Estado en la acumulación de capital permitió ampliar, fortalecer y modificar los mecanismos de intermediación para asegurar que la burguesía nacional y extranjera, en particular el capital más poderoso, dispusiera de los recursos necesarios. "En otras palabras, cualquier Estado particular es hijo de la clase o las clases de la sociedad que se benefician del conjunto particular de relaciones de propiedad que el Estado tiene la obligación de hacer efectivo." [Sweezy, 1969: 268]. Su misión no era obstaculizar el proceso de acumulación de capital en el sector privado; por el contrario, siempre fue para estimularlo, darle facilidades a las empresas nacionales y extranjeras, así sea a un alto costo para el Estado, para las masas trabajadoras y para toda la nación [Carrión y Aguilar, 1977: 98 y 150].

La intervención directa del Estado fue necesaria en muchos sectores económicos, sobre todo en aquellos en donde la empresa privada por sí sola no podía asegurar un desarrollo mínimo estable al sistema; por esta razón, el Estado se hizo cargo de los programas y costos en infraestructura de comunicaciones telegráficas y telefónicas, caminos y puertos, transportes marítimos y aéreos, ferrocarriles, obras hidráulicas, obtención de energéticos baratos, escuelas, servicios de salud, etc. El mero hecho de que aun los más poderosos empresarios asignen al Estado la responsabilidad de "crear y mantener la infraestructura económica" demuestra que ellos son incapaces de hacerlo. Pero también sirve para regular la relación capital-trabajo por todos los medios a su alcance, a fin de que el capital disponga de las condiciones más propicias posibles para su desarrollo [Aguilar, 1983: 38, 198 y 212].

Las políticas públicas permitieron amortiguar el desempleo, generar contratos para el capital privado y estimular la demanda, 
para darle funcionalidad a la acumulación capitalista durante un largo periodo. Por ejemplo, se crearon importantes organismos para la atención de la salud: el Instituto Mexicano del Seguro Social, IMSS (1943), y el Instituto de Seguridad y Servicios Sociales de los Trabajadores del Estado, Issste (1949) [Aspe, 1993: 155]; asimismo, se amplió la inversión en el área de la educación, mediante la creación de universidades y otras instituciones responsables de la formación de los recursos humanos calificados requeridos en todas estas nuevas actividades [Hirschman, 1973: 59; Sunkel, 1993: 19]. Destaca la creación de grandes entidades, como Petróleos Mexicanos y paraestatales encargadas de la producción de bienes salarios [Valenzuela, 1990: 96; Aspe, 1993: 155]. Todo ello contribuyó al fortalecimiento de la industria nacional y al crecimiento económico con el incremento de las filas de la clase obrera y el fortalecimiento de la masa salarial. Se dio un notable aumento del peso específico, el nivel y la calificación de la fuerza de trabajo en la estructura general de población, al incorporar a sectores muy amplios como asalariados, hasta entonces considerados como "profesiones libres" (ingenieros, técnicos, médicos, profesores, entre otros), así como el incremento cuantitativo y cualitativo del trabajo femenino en la industria [Vizgunova, 1980].

Es importante destacar que la mayor parte de la población tenía alguna relación directa o indirecta con las empresas estatales (como proveedor, comprador, empleado, distribuidor, etc.), en la medida en que casi todo lo que se consumía o utilizaba era producido, subsidiado o adquirido por el Estado en prácticamente todos los sectores económicos (transportes terrestres y aéreos, teléfonos, telégrafos, energía eléctrica, combustibles, alimentos básicos y no básicos, telas de algodón y de otras fibras, ropa, aparatos domésticos, automóviles, ciertos medicamentos, aceros para construcción, cemento, maderas preciosas, etc.), pero también equipos y maquinaria, entre otros muchos [Rey, 1984: 22]. La producción se sustentaba en una organización del trabajo en forma de cadenas productivas denominadas tayloristas, con una producción masiva de alta parcialización del trabajo. 


\section{EL TAYLORISMO-FORDISMO}

La organización del trabajo del modelo intervencionista se basó en lo que el psicólogo industrial Frederick W. Taylor estableció como el sistema de tiempo/movimiento por medio de un cronómetro, midiendo en centésimas de segundo el tiempo que tomaba colocar un faro o un guardabarros.

Después de la segunda guerra mundial, el sistema de producción de Estados Unidos, Europa Occidental y Japón experimentó un régimen de acumulación fordista, ampliado por los principios tayloristas de organización del trabajo y racionalización en las manufacturas a través de una estandarización rigurosa de las prácticas de trabajo (intensidad del trabajo) y los productos, y una separación entre el concepto (ingeniería y diseño) del trabajo y su producción, incorporando los métodos más eficientes de producción (administración científica) [Sennett, 2001: 41].

Los principales elementos de la forma de organización fordista del trabajo son: 1) separación entre concepción y ejecución, 2) segmentación minuciosa del proceso de trabajo, 3) estandarización y simplificación de las herramientas y métodos de trabajo, 4) separación entre ejecución y supervisión, 5) división entre producción y mantenimiento, y 6) una cultura instrumental del trabajo; el conjunto de estos factores da lugar a una mecanización del taylorismo, en un proceso cuya velocidad es determinada por la cadena y no directamente por la suma de los tiempos de producción parcelados.

Es una forma de producción intensiva, caracterizada por la organización del trabajo a partir de una división minuciosa de funciones precisas de los puestos; separación entre producción y mantenimiento, entre supervisión y trabajo directo ordenado por las líneas de montaje, producción marginal en masa, consumo en masa y por la gestión estatal de la fuerza de trabajo mediante el sistema de contratación colectiva y el salario indirecto" [Sennett, 2001: 40 y 44]. 
El sistema fordista mostró un agotamiento y poca funcionalidad para los cambios que estaba sufriendo señaladamente el mercado competitivo mundial.

El taylorismo se asoció a fenómenos como el ausentismo, la rotación externa de personal, la drogadicción, el alcoholismo, paros locos, sabotajes, huelgas y el establecimiento de leyes laborales y contratos colectivos que impusieron límites sociales a los principios de la scientific management [De la Garza, 2006: 124].

Sin embargo, esta forma de organización y protección del trabajo funcionó durante toda la etapa del Estado intervencionista, con buenos resultados para la acumulación durante un largo periodo, como veremos más adelante.

\section{EL PATRÓN DE ACUMULACIÓN INTERVENCIONISTA}

La producción industrial con el modelo de acumulación intervencionista estuvo sustentada en el modelo de industrialización sustitutiva de importaciones (ISI), mediante un programa estatal de impulso a las industrias claves, particularmente de bienes finales de consumo directo e incluso intermedio y una proyección para la producción de bienes de capital. Se buscaba mejorar la eficiencia productiva y diversificar las exportaciones, a la vez que se desarrollaba el mercado interno para fortalecer la producción nacional. La política proteccionista fue esencial para el desarrollo del mercado interno, pues se abandonaron las prácticas del laissez faire para emprender acciones de intervencionismo dirigido a transformar al Estado en un actor fundamental para el proceso de acumulación, aunque con diversos matices en su forma de intervención.

La Comisión Económica para América Latina (CEPAL) desarrolló toda una teoría a favor de la intervención del Estado, con el fin de alentar el proceso de industrialización y crear un conjunto de instituciones reguladoras de los aranceles al comercio, el 
control de cambios y la política monetaria activa tras la creación de los bancos centrales [CEPAL, 1993: 7]. Se aseguraba que

El Estado debe planificar el desarrollo y, más específicamente, fijar los criterios de asignación de recursos entre la producción destinada al mercado interno y la destinada a las exportaciones; debe promover la planificación, la protección del mercado interno, la integración latinoamericana, la obtención de financiamiento externo y la asistencia técnica internacional [Guillén, 1997: 75].

Este proceso dio por resultado una mayor intervención del Estado en la economía, como inversionista y empresario, rector, planificador e impulsor activo del desarrollo, además de regulador de los mercados de bienes, servicios y trabajo, y como promotor del bienestar social mediante leyes laborales y agrarias e instituciones sociales de educación, salud y servicios básicos [Calva, 1995: 48].

El Estado se convirtió en el gran articulador del crecimiento económico, por medio de la protección de la naciente industria y del mercado interno con la imposición de altas y crecientes tarifas arancelarias, derechos de importación, tipos de cambios múltiples, subsidios e incentivos para promover las importaciones de bienes intermedios y de capital; además, se siguieron políticas de comercialización y financiamiento que, entre otros aspectos, fueron utilizadas para inducir y orientar la expansión del sector público que demandaba la industrialización sustitutiva de importaciones [Fajnzylber, 1983: 19]. Le compraba a los capitalistas sus productos, les vendía insumos subsidiados y les otorgaba las facilidades fiscales y crediticias para fomentar la exportación de mercancías y capitales, y cuidaba que los salarios no aumentaran más allá de ciertos límites; construyó una costosa infraestructura de servicios a favor principalmente de la oligarquía financiera; promovía e incluso se hizo cargo de la investigación tecnológica y científica; retenía y hacía suyas actividades riesgosas y de bajos rendimientos que en realidad no interesaban ya a los capitalistas y organizaba la explotación directa de grandes masas de trabajadores [Poulantzas et al., 1977: 16 y 17]. 
Muchas de las empresas públicas se ubicaron en actividades que no interesaban o que requerían enormes capitales a largo plazo y que los empresarios privados no estaban en posibilidades de invertir. La importancia de la acción del Estado en el desarrollo industrial fue cada vez mayor, pues generó gran cantidad de empleos ${ }^{2}$ y se movilizaron recursos para la industrialización y la modernización por medio del financiamiento de proyectos y programas de largo plazo con el fin de contar con un mercado financiero privado; la redistribución del ingreso con la creación y expansión de la infraestructura y de servicios en los "sectores sociales" mediante la inversión pública permitió la ampliación del mercado interno.

\section{EL MODELO SUSTITUTIVO DE IMPORTACIONES}

El desarrollo de la ISI se sustentó en una participación creciente del Estado como principal promotor de la acumulación de capital al transformarse en el articulador del crecimiento económico y ser el primer comprador de las mercancías producidas por el sector privado, contratista de montos crecientes de fuerza de trabajo o impulsor de la producción y el fortalecimiento de las empresas nacionales mediante la inversión en infraestructura, la expansión de los servicios sociales, la protección del mercado interno y proveedor de subsidios.

El Estado amplió significativamente su campo de acción y su intervención directa en los procesos económicos, con lo que marcó una nueva fase en el desarrollo capitalista, caracterizada por su mayor injerencia en la economía, sobre todo para impulsar

${ }^{2}$ El gobierno de Lázaro Cárdenas estableció las bases para el desarrollo industrial con la construcción de obras de infraestructura (caminos, obras de irrigación, etc.), ferrocarriles y la expropiación de la industria petrolera; destaca también la creación del banco de desarrollo (Nacional Financiera), el Banco Nacional de Comercio Exterior y de los bancos de crédito agrícola que configuraron junto con el Banco Central un sistema financiero importante. Asimismo, el surgimiento de la Comisión Federal de Electricidad y el desarrollo de la industria nacional del petróleo y permitieron orientar el sector productor de energía al proceso interno de crecimiento [Villarreal, 1988: 48]. 
las áreas económicas consideradas estratégicas y emitir leyes y reglamentos acordes con las nuevas necesidades. Se aplicaron políticas comerciales de fomento (tasa de cambio, aranceles y control cuantitativo) como instrumentos para la protección a la industria: los aranceles a la importación y los subsidios a las exportaciones, las licencias de importación (principal instrumento de protección y regulación de las compras en los mercados internacionales), los programas de fabricación y la política fiscal. Asimismo, se emitieron dos instrumentos para fomentar la inversión industrial y promover el proceso de sustitución de importaciones: la Ley de Industrias Nuevas y Necesarias y la Regla XV de la Tarifa General de Importación [Villarreal, 1988: 76]. Ambas políticas públicas estimularon la creación de empresas y la venta de insumos baratos producidos por las empresas estatales.

El resultado fue un clima favorable para la expansión industrial, que aseguraba un ágil proceso de formación de ahorro de capitales y atracción de capital extranjero, con una veloz expansión, pues el sector industrial no solo se transformó internamente, sino que además arrastró y modificó el resto de las actividades productivas: obtenía mano de obra del sector agrícola y le devolvía insumos y equipos para su modernización; generaba servicios requeridos para la producción, comercialización y financiamiento de los bienes industriales, los que a su vez retroalimentaban la expansión industrial; urbanizaba y modificaba indirectamente la infraestructura física y educacional mediante la transformación social inducida por el crecimiento, la cual se expresaba en los ámbitos sindicales, partidarios, regionales, de organización de consumidores y otras formas de agrupación que adquirieron particular importancia en la década de los sesenta y que contribuyeron a inducir y orientar la expansión del sector público [Fajnzylber, 1983: 19]. Buena parte del gasto gubernamental se dirigió al desarrollo de la infraestructura que demandaba el capital en su conjunto, de manera que el patrón intervencionista adquirió rasgos exitosos que se prolongaron por muchos años.

El modelo sustitutivo transitó por dos etapas. En la primera se impulsó la producción de bienes de consumo no durable, 
como ropa, calzado y enseres domésticos, y de sus insumos, como textiles, cueros y madera para la producción nacional, es decir, se buscó el reemplazo de productos no duraderos por bienes producidos internamente. Son sectores intensivos en mano de obra poco calificada porque no se requiere una tecnología muy sofisticada, ni una red de proveedores de partes, componentes y accesorios para las operaciones eficientes.

El reto de la periferia era integrar estas industrias con la economía nacional mediante los encadenamientos hacia adelante y hacia atrás, a fin de que impulsaran un desarrollo equilibrado que aprovechara la exportación de manufacturas y la obtención de recursos y alcanzara una competitividad aceptable, a pesar de que la prioridad fuera el desarrollo del mercado interno [Rivera, 2000: 130].

El fortalecimiento de la demanda interna de bienes de consumo propició el incremento de las importaciones de los bienes intermedios y de capital, así como la demanda de transporte; tal situación elevó los costos y favoreció un sensible incremento del déficit en la balanza de pagos en cuenta corriente. Por otro lado, aunque los subsidios fueron útiles como impulso inicial para la modernización de la economía, constituyeron un fuerte incremento del gasto.

Una práctica generalizada entre las empresas estatales fue la de vender sus bienes y servicios a bajo precio, con el propósito de reducir los costos de producción de las empresas privadas y, con ello, estimular la inversión. Aunada a los insuficientes ingresos tributarios y no tributarios del sector público, esta política de precios sirvió para transferir recursos a la industria privada [Huerta, 1995: 21].

Se produjo un continuo y permanente desequilibrio externo financiado con capital extranjero y un creciente déficit gubernamental (del gobierno federal y empresas públicas) costeado con endeudamiento interno y externo; todo esto propició una dependencia estructural de las importaciones de bienes intermedios y de capital, además de que las exportaciones se concentraron en 
unos cuantos productos primarios y no crecieron lo suficientemente rápido para financiar las importaciones necesarias en esta primera etapa [Villarreal, 1988: 16 y 95]. En estas condiciones:

La producción nacional aumentó con mayor rapidez que el consumo interno, ya que no solo satisfizo los incrementos del consumo sino que también sustituyó las importaciones de bienes de consumo por producción nacional lo que provocó una demanda creciente de bienes intermedios y de capital para la elaboración de esas mercancías [Balassa, 1988: 22].

La segunda fase del proceso sustitutivo de importaciones involucró una clara reestructuración del sector manufacturero en perjuicio de las ramas industriales mencionadas -primordialmente las textiles y la metalmecánica- y en favor de las ramas procesadoras de materias primas locales, como celulosa y papel, productos petroquímicos, siderurgia, aluminio, harina de pescado, minerales y aceites vegetales [CEPAL, 1993: 7-8]. También se registró un mayor contenido tecnológico en productos, entre los que sobresalían los de consumo duradero, los insumos industriales y algunos bienes de capital. Es decir, en la segunda fase de la sustitución de importaciones se consideró a muchos productos de demanda final, como insumos intermedios necesarios para las industrias que se encontraban en el mismo proceso (acero, papel, vidrio, productos petroquímicos): tendían a ser muy intensivos en capital y estaban sujetos a economías de escala y al tamaño eficiente de la planta, en contraste con las necesidades internas de la mayoría de los países en desarrollo, pues los costos se elevaban rápidamente con niveles de producción bajos [Balassa, 1988: 24].

Las políticas públicas intervencionistas permitieron garantizar la protección requerida para impulsar una industria naciente, orientada al mercado interno, que pudo satisfacer en una primera etapa la demanda nacional de bienes de consumo manufacturados e incluso proyectar la producción de bienes intermedios y de capital. Sin embargo, al mismo tiempo el modelo sustitutivo empezó a registrar un creciente aumento en los gastos del Estado, producto de la ampliación de sus funciones; también se dio un 
rápido incremento en las exportaciones de materias primas y alimentos, lo cual fortaleció considerablemente a la burguesía mexicana y favoreció el estrechamiento de las relaciones entre el gobierno y las empresas privadas, y entre los capitalistas nacionales y extranjeros [Carrión y Aguilar, 1977: 168], pero no siempre fue bien vista por el capital privado, sobre todo el capital trasnacional que buscaba la apertura económica como un mecanismo para la expansión y recuperación de la tasa de ganancia tan deprimida en el ámbito mundial.

\section{CAMBIOS A LA POLÍTICA INDUSTRIAL DEL MODELO INTERVENCIONISTA}

Las grandes empresas presionaron para cambiar el modelo de industrialización hacia adentro y modificar la política estatal, centrándose en tres críticas fundamentales:

[La primera señalaba que] al agotarse el periodo "fácil" de dicho proceso, la economía había heredado empresas industriales de costos relativamente altos y en condiciones más vulnerables de balanza de pagos, porque entonces empezó la importación de materias semiterminadas, refacciones y maquinaria, indispensables para mantener y aumentar la producción y el empleo; la segunda crítica afirmaba que las industrias que sustituían importaciones padecían una especie de inhabilidad congénita que les impedía convertirse en exportadoras, y la tercera indicaba que las exportaciones de las nuevas industrias eran inadecuadas para solucionar el problema del desempleo [Hirschman, 1996:503].

La crisis del patrón con un Estado intervencionista puso en evidencia diversos problemas: la agricultura había dejado de ser el canal de financiamiento interno y externo para la industria, por lo que ya no constituía un factor de estabilización de precios $y$, por el contrario, ayudaba a generar presiones inflacionarias por la relativa abundancia de mano de obra, fuerte contracción de los recursos financieros para el sector agrícola, un déficit público 
creciente y endeudamiento con el exterior, ante un aumento de la carga fiscal asociada a la expansión del sector público durante el periodo de crecimiento, saturación de los sectores que "arrastraban" al sector de la industria. Todos estos factores, en combinación con las precarias perspectivas de crecimiento, incrementaron los problemas del comercio internacional y sirvieron de base al cuestionamiento de las políticas proteccionistas.

Se diagnosticó que la IsI había provocado el endeudamiento externo pues había hecho surgir una planta fabril ineficiente, poco articulada en su interior e incapaz de cubrir con sus exportaciones el importe de sus bienes de capital e insumos; para mejorar la eficiencia competitiva de la industria nacional se debería impulsar las exportaciones con el fin de generar divisas suficientes que autofinanciaran el desarrollo industrial y evitaran el financiamiento externo [Fajnzylber, 1983: 84, 90 y 244].

Para el caso de México, el balance general de la ISI muestra un éxito relativo en el crecimiento promedio anual del producto interno bruto (PIB) de 6.5\% en el periodo 1940-1970. Aunque el problema estuvo en términos del “... desarrollo económico, pues el costo del crecimiento se manifestó en el aumento del desempleo, de la concentración del ingreso y de la dependencia externa tanto en términos directos como indirectos, es decir, inversión extranjera y deuda externa" [Villarreal, 1988: 119]. Con estos problemas se demostró la insuficiencia de la IsI; la falta de competitividad en el exterior, el cuestionamiento a la actuación del Estado en las políticas de incentivos, el excesivo grado de protección de las barreras arancelarias y no arancelarias y la carencia de disciplina en el manejo de los grandes agregados macroeconómicos dieron argumentos a la postura neoclásica para asegurar que todo el sistema mostraba la caduca injerencia estatal que había prevalecido en el modelo intervencionista y que se transformó en una traba para la ampliación de las inversiones. Asimismo, se señalaba que la participación de un sector público cada vez más intervencionista había destruido la prosperidad del sistema de libre mercado y atentaba contra la libertad humana, al ser el 
principal responsable de las interferencias en el sistema de mercado libre “(...) porque distorsiona el sistema de precios al imponer aranceles y otros obstáculos al comercio internacional, como la fijación de precios y salarios por el Estado" [Friedman y Friedman, 1980: 9, 17, 35-36 y 56]. Esta corriente de pensamiento considera al Estado ineficaz e incapaz para regular la economía y los mercados al provocar parálisis institucional, poca competitividad e improductividad; además, lo acusa de despilfarro de recursos, mala calidad de los servicios, burocratismo, corrupción, déficit permanente y crecimiento inestable, alteración en los procedimientos de fijación de precios, distorsiones en la aplicación correcta de los recursos y altos costos de funcionamiento.

\section{EL CAMBIO DEL MODELO INTERVENCIONISTA}

La transformación del modelo intervencionista por la corriente neoliberal planteó el retiro del Estado en la inversión productiva y la disminución de los gastos destinados a los aspectos sociales, así como una política de estabilización entre salarios y productividad, ${ }^{3}$ conocida como flexibilidad del trabajo. Para esta ideología los mercados son la base de cualquier economía próspera porque estos funcionan bien por sí solos, de modo que se pasó del fundamentalismo del Estado que todo lo puede al “... fundamentalismo de mercado -que los mercados son eficientes, que se corrigen por sí solos, y que por consiguiente lo mejor es dejarlos a su aire [sic] si lo que se pretende es maximizar el crecimiento y la eficiencia” [Stiglitz, 2010: 47 y 282].

Esta corriente de pensamiento dice que el Estado debe facilitar el funcionamiento del mercado, intervenir lo menos posible en la economía y limitarse a ser regulador, "observador" ${ }^{4}$

${ }^{3}$ Las modificaciones salariales estarían determinadas por el incremento de la productividad de la mano de obra (Banco de México, 1994: 24], con lo que se reforzaron los mecanismos para establecer los programas de flexibilidad de la fuerza de trabajo.

${ }^{4}$ El Banco Mundial define así las funciones fundamentales del Estado: mantener el orden público, salvaguardar los derechos de propiedad, encargarse de la gestión 
auspiciador de la producción; sus funciones serían, cuando más, coordinar y vigilar, no suplir a la empresa privada ni competir con ella. Debe garantizar al individuo libertad de acción en circunstancias específicas, pues solo el individuo puede conocer perfectamente las situaciones particulares que le permiten moldear su propia conducta. Es decir, esta ideología asegura que la sociedad podría funcionar mejor si cada individuo tuviera la posibilidad de actuar libremente en busca de su interés individual por medio del sistema de precios, mecanismo que desempeña su misión sin necesidad de una dirección centralizada, sin obligar a las personas a hablar entre sí o a que se gusten mutuamente. La función del Estado, según la percepción neoliberal, es entonces la de hacer “... cumplir la ley y respetar el orden, proporcionar los medios para definir las reglas de conducta, fallar en materia de litigios, facilitar los transportes y las comunicaciones y supervisar la emisión de moneda" [Friedman y Friedman, 1980: 56 y 57]. "Es una visión extrema particularmente violenta y agresiva frente a cualquier tipo de planificación, justicia social, racionalismo constructivo y toda aquella utopía que no esté basada en el mercado y sus mecanismos" [Dussel, 1997b: 24; Dussel, Piore y Ruiz, 1997: 57].

Se busca la disminución de los costos laborales y el aumento de la productividad con una ofensiva de gran envergadura del capital contra el trabajo, para contrarrestar la caída de los beneficios por medio de la modificación de los procesos productivos, la organización del trabajo y profundos cambios en las relaciones laborales. Se establece la flexibilidad laboral, el desmantelamiento de la seguridad social y de los sistemas de bienestar, la racionalización de los procesos de trabajo y la utilización de políticas de abatimiento de costos como el recorte de personal, la subcontratación o la precarización del trabajo. "Se trataba de encontrar nuevas vías a la reproducción del capital y de modificar las relaciones entre el capital y el trabajo, a favor del primero" [Guillén, 2007: 286-287].

macroeconómica, suministrar servicios sociales básicos y proteger a los indigentes [Banco Mundial, 1997: 180]. 
La política industrial se enfrenta a un crecimiento limitado y los grupos económicos internacionales más poderosos intensificaron sus presiones para liberar el mercado interno.

La política de industrialización fue centrada en la liberalización del mercado interno, se derribaron las barreras que impedían la circulación de mercancías a escala mundial, al tiempo que los países desarrollados impusieron nuevas formas de protección de sus propios mercados internos. ${ }^{5} \mathrm{~A}$ los países atrasados se les prescribe la apertura comercial, la orientación de sus manufacturas hacia las exportaciones y el saneamiento de sus finanzas públicas, en tanto que los países centrales establecen políticas restrictivas contrarias a estos principios.

Se busca el abatimiento de muchas de las conquistas obreras a fin de abaratar los costos de producción del sector manufacturero para la exportación. Es un proceso que se expandió rápidamente:

... los tres grandes países de América Latina -Argentina, Brasil y México- abandonaron el régimen de industrialización por sustitución de importaciones y abrieron su economía a la competencia externa. En dichos países la bajada de los aranceles fue acompañada por la liberalización de los mercados financieros, y en el caso de Argentina, por la flexibilización de las leyes laborales. Este tremendo cambio de política afectó la estructura de los sectores productivos y comerciales, cuyos efectos en el mercado de trabajo todavía no son bien entendidos [Dussel, 2004: 4].

Los organismos internacionales encargados de impulsar la "Reforma del Estado" fueron el Banco Mundial (вм), ${ }^{6}$ el Fondo Monetario Internacional (FMI), la Organización Mundial de Comercio (OMC) y otros organismos como la OCDE, la Unión Europea,

5 "Los críticos de la globalización acusan con razón a los países occidentales de hipócritas, pues forzaron a los pobres a eliminar las barreras comerciales, pero ellos mantuvieron las suyas con las que impiden las exportaciones de los países subdesarrollados” [Stiglitz, 2002: 31].

${ }^{6}$ El Banco Mundial y otras organizaciones internacionales "sugieren" programas para ayudar a los países, siempre y cuando, pongan en práctica reformas en las funciones del Estado orientadas a reducir su papel en algunas áreas de la economía y a encauzar los recursos así liberados hacia actividades básicas [Banco Mundial, 1997: 180]. 
etc., instituciones que sustentaron el modelo de Estado intervencionista o benefactor. Reducen la acción del Estado al mínimo y establecen políticas fiscales y monetarias restrictivas con una industrialización orientada hacia las exportaciones, por lo que promueven la apertura económica, la disminución de la participación directa del Estado en la economía (la privatización de las empresas públicas), ${ }^{7}$ el estímulo a la inversión privada y la regulación de la fuerza de trabajo. Aunque, como lo señalé antes, los principios liberales no se aplican de manera equitativa, ya que a las grandes empresas trasnacionales se les permitió el libre movimiento de bienes, servicios y capitales, pero no sucedió lo mismo con la fuerza de trabajo y muchos productos de exportación nacional de los países subdesarrollados que requerían autorización para su libre circulación, con diversos pretextos que impiden en los hechos el cumplimiento de los acuerdos signados por los países involucrados.

Es claro que esta política fue posible, como lo señala con mucha precisión Joseph E. Stiglitz, por el mecanismo que sugerían el FMI y el Tesoro estadounidense cuando algunos países acudían a solicitar financiamiento, ya que este se les condicionaba al impulso de políticas de desregulación, incluida la liberalización del mercado financiero y de capitales:

... bajo unas condiciones draconianas que en realidad no habían hecho más que agravar la crisis en los países afectados. Esas condiciones estaban más pensadas para ayudar a los acreedores occidentales a recuperar más dinero del que hubiesen recuperado sin ellas que a ayudar a los países afectados a fortalecer su economía. Las estrictas condiciones a menudo impuestas por el FMI han provocado disturbios en todo el mundo; los de Indonesia durante la crisis de Asia oriental son los más famosos [Stiglitz, 2010: 260].

7 "La ideología liberal considera que la economía debe ser regulada por ella misma, bancos, bufetes de abogados, agencias de rating y en reuniones de jefes de las naciones más ricas y gobernadores de bancos centrales. También a partir de esta ideología se inventó el concepto globalización. Por respuesta se asegura que está reviviendo en mayor escala el imperialismo, es decir, el predominio del capital financiero internacional sobre el industrial nacional" [Saxe-Fernández, 2002: 68]. 
Nada detendría esta política en beneficio de la expansión de las grandes empresas trasnacionales y financieras.

\section{EL PATRÓN DE ACUMULACIÓN NEOLIBERAL}

La coyuntura para establecer el modelo neoliberal en varios países del orbe fue la crisis del petróleo en los países desarrollados a principios de los setenta y el endeudamiento de los países subdesarrollados de mediados de los ochenta con la imposición de programas de choque como condición para obtener los créditos:

... la reducción de la intervención estatal en la producción, los precios y el comercio, la disminución de las tasas de impuestos a los ingresos más altos, la apertura externa de los mercados de mercancías y de capitales y el abandono del pleno empleo bajo la apariencia de la tasa natural [Palley, 2005: 144].

El éxito de estas políticas se debió a las necesidades de crédito de la mayoría de los países, a lo que se agregó la desregulación de los mercados financieros, la privatización de las empresas públicas, la erosión de las instituciones de seguridad social (sistemas de pensiones), el debilitamiento de los sindicatos y de las protecciones al mercado de trabajo. En el establecimienrto de políticas públicas:

El FMI rebasó su campo básico de competencia en macroeconomía hacia cuestiones estructurales, como los mercados de trabajo, las reformas de las pensiones, entre otras, para impulsar la nueva religión -el fundamentalismo del mercado- que reemplazó a aquella que había demostrado ser tan defectuosa [Stiglitz, 2002: 69 y 174].

El Estado debe alejarse “... desde las fábricas a la seguridad social, no dejar que el Estado participase en promover industrias; reforzar los derechos de propiedad; no ser corrupto. Minimizar la intervención estatal significaba bajar los impuestos -pero mantener equilibrados los presupuestos-" [Stiglitz, 2006: 55]. Se enfatiza la liberalización del comercio y del mercado de capitales 
(eliminando las barreras comerciales y los impedimentos a la libre circulación de capitales) y la desregulación (eliminando las normas de conducta de los negocios).

\section{EL TOYOTISMO O LA PRODUCCIÓN FLEXIBLE}

La forma de organización del trabajo que mejor se adapta a las condiciones del modelo de acumulación liberal es el toyotismo, la especialización flexible o el neofordismo, en la medida en que este sistema elimina los obstáculos que le impedían establecer los mecanismos del mercado para asignar precios y crear empleos en un mercado cada vez más competido. El fordismo se había convertido en una verdadera pesadilla para la dirección de la empresa porque había una "falta de cuidado" permanente en la producción que elevaba los "defectos de fabricación" y los "desperdicios". El ausentismo y la imposibilidad de rotar al personal también significaban trabas y constantes fricciones y resistencias en la fábrica. Muchas de estas acciones se debían a "actos voluntarios" resultado de la fatiga excesiva por los ritmos de trabajo o del "rechazo" al trabajo en cadena que trató de remediarse mediante la creación de todo un aparato de vigilancia y control que implicó costos y gastos suplementarios para la empresa. Así, se desarrollaron categorías como "controladores", "retocadores", "revisores", "reparadores", entre otros, y talleres de reparación en el interior mismo de las unidades de fabricación que "revisan" un número creciente de productos defectuosos mediante pruebas y reparaciones diversas incluso antes de que lleguen al público.

... Los problemas de la rutina y de la calidad de los productos se solucionarían con la aplicación de una estructura del trabajo distinta, que incorporara la nueva composición social y técnica de la fuerza de trabajo o los nuevos caracteres de las tecnologías basadas en el automatismo que desprende una nueva exigencia: la de una fuerza de trabajo "ágil" que otorgue flexibilidad a la fuerza de trabajo [Coriat, 2000: 129,163-164]. 
La producción en masa tradicional llegó a su límite y coincide con la emergencia del nuevo paradigma tecnológico en un contexto de predominio de una economía de variedad (clientes que exigen variedad y calidad en los productos).$^{8}$ La producción en masa es distinta de la producción flexible, porque en la primera la oferta moldea y homogeneiza la demanda, mientras que en la producción flexible del paradigma informático es la demanda la que orienta, moldea, segmenta y diversifica la oferta. Son dos lógicas distintas de toma de decisiones en relación con los mercados [Pérez, 2009: 34]. Con la introducción de la nueva forma de organización del trabajo se pudieron incorporar de manera más sencilla las innovaciones tecnológicas para disminuir costos, aumentar la productividad e incrementar la competitividad y las utilidades empresariales.

El toyotismo es una filosofía del ahorro del espacio, la eliminación de desperdicios y la utilización óptima del tiempo, el establecimiento de los círculos de control de calidad, equipos y células de trabajo, ${ }^{9}$ cero errores, control estadístico del proceso, entregas justo a tiempo (productos que se fabrican al tiempo en que el consumidor los demande), cero inventarios, control integral de $\operatorname{procesos}^{10}$ y manufactura flexible con la ... "calidad, flexibilidad, eficiencia y el constante aumento de la productividad como pautas fundamentales del desarrollo capitalista. Los países que sean más flexibles podrán beneficiarse más: no los más fuertes ni los más inteligentes sino que los más flexibles ganarán y sobrevivirán"

${ }^{8}$ La productividad en la economía globalizada se obtiene a costa de la degradación salarial, de la movilidad en el empleo, de la precarización de las relaciones laborales, de la informatización de la producción y de la consiguiente supresión de los puestos convencionales de trabajo [Hernández, 2010: 56].

${ }^{9}$ Son los llamados círculos de calidad total, con lo que se logra la organización de todo el personal de la empresa, desde el gerente hasta el obrero, para que los productos o servicios no tengan ningún defecto de fabricación.

${ }^{10}$ Es parte de la flexibilidad laboral, que implica que todos los empleados de la empresa tienen las mismas responsabilidades y deben intervenir directamente en todo el proceso, incluyendo la supervisión dentro de las tareas de los trabajadores directos. La empresa deja en manos de los mismos trabajadores la vigilancia de su trabajo. El obrero realiza varias funciones, con lo que desaparece un buen número de categorías laborales que antes se manejaban en la contratación colectiva o las relaciones de trabajo. 
[Holzmann et al., 2002: 5]. Se fomentan las labores multicalificadas en todos los niveles de la cadena de la producción y la ingeniería (Dussel, 1997a: 95-96). Las organizaciones sindicales perdieron la posibilidad de la negociación bilateral en la definición tecnológica y la reorganización del trabajo en las empresas lo que genera mayores facilidades para subcontratar funciones para otras empresas que realizarían tales actividades.

La intensificación de la subcontratación ${ }^{11}$ permitió que el proveedor le proporcione insumos a la empresa, de acuerdo con el diseño y la definición determinados por ella misma, con lo cual se extiende el control del proceso más allá de los límites del negocio. Se necesitan trabajadores que puedan ser contratados o despedidos a voluntad, además de poder moverlos de un sitio a otro dentro de la línea de producción sin que existan impedimentos para ello. Se plantea la reforma a la legislación laboral para adecuar aspectos específicos, como en el caso de la sustitución del criterio de antigüedad en el trabajo por el de aptitud para el desempeño del puesto o el aumento de los salarios vinculados a la productividad, la capacitación permanente, la posibilidad de mover a los trabajadores a los distintos departamentos en donde se les requiera (multifuncionalidad), entre otros mecanismos que formalizan ${ }^{12}$ la flexibilidad que es, sobre todo, interna, entre puestos, categorías, departamentos, turnos o de horario de trabajo; son elementos claros de la nueva forma de organización

${ }^{11}$ Nos referimos a empresas contratadas ex profeso para funciones productivas y de servicios como limpieza, mensajería y cobranza. La empresa se libera de toda relación con esos trabajadores y evita hacerse cargo de las "molestas revisiones contractuales y salariales", los pagos al seguro social o las prestaciones que en algún momento hubieran acordado con la empresa.

${ }^{12} \mathrm{El}$ concepto de producción flexible proviene de la idea inglesa del siglo Xv derivada de la simple observación de que el viento podía doblar un árbol, pero sus ramas siempre volvían a la posición original. Flexibilidad designa la capacidad del árbol para ceder y recuperarse, la puesta a prueba y la restauración de su forma. En esta perspectiva, la conducta humana flexible debería tener la misma resistencia a la tensión: adaptable a las circunstancias cambiantes sin dejar que estas la rompan. De aquí se deriva la expresión especialización flexible de la producción que no es otra cosa que la de conseguir productos más variados cada vez más rápido pero cambiando las tareas semanales, y a veces diarias, que los trabajadores han de realizar [Sennett, 2000: 47, 52-53]. 
laboral en que los criterios de ascenso estarán en función de la capacidad y no la antigüedad, y los incrementos salariales dependerán del aumento de la productividad.

Con este sistema, muchas actividades se transfieren a terceros y se puede establecer una producción en forma de red de productores y proveedores; por ello los empresarios la utilizan a favor de los intereses del capital convirtiéndose en un importante mecanismo adicional de control de los trabajadores. Se destruye la contratación colectiva y a los mismos sindicatos; con las negociaciones individuales se aleja la "molesta solidaridad entre los trabajadores". En estas condiciones se eliminan las trabas para el uso de la fuerza de trabajo y se establece una relación diferente entre trabajadores y supervisores en el proceso de producción, con capacidad de cambiar a voluntad el número de trabajadores, su uso de acuerdo a las necesidades de la empresa, sin restricciones, ajustando sus salarios a la productividad y la jornada de trabajo. Es un suministro del mercado de trabajo en condiciones de menor resistencia y mayor docilidad a la movilidad en cualquiera de las funciones que se requieren, por lo que es una constante la extensión de la jornada de trabajo, la mayor intensidad de los procesos, además de los bajos salarios y las deplorables condiciones de trabajo, inseguridad y nulas prestaciones sociales. El subcontratista, a su vez, contribuye como contrapeso a la capacidad de resistencia obrera ante los cambios introducidos por la empresa; aporta también condiciones de flexibilidad en la disposición de recursos, servicios y fuerza de trabajo.

Con este mecanismo se trasladan determinadas funciones o actividades de un proceso productivo integrado a otras unidades económicas (personas físicas o jurídicas) real o ficticiamente ajenas a la empresa que realiza el proceso de producción, lo cual es una forma de delegar tareas específicas asociadas con una empresa particular distinta. Se reducen costos de producción, de dirección, vigilancia y supervisión, de seguridad laboral (accidentes y equipo), de disposición, mantenimiento y almacenamiento de insumos y equipos, así como gastos de circulación que tienen que ver con la contabilidad en nóminas, materiales de oficina, personal 
y su respectivo equipo, trasladándolos a esas empresas [Martínez, 1998: 307-308].

La práctica de la subcontratación se realiza de manera más intensa en la industria manufacturera, en las ramas donde se ha observado que es una práctica más común son: las industrias metálicas básicas, la industria química, la industria de las bebidas y del tabaco, la industria del plástico, y la industria de minerales no metálicos [Ruiz, 2009: 18].

La producción flexible modificó el papel del Estado en la economía, por lo que el desarrollo industrial descartó la ISI porque era ineficiente e incapaz de convertirse en exportadora de sus mercancías, además del atraso tecnológico, los subsidios, la corrupción, el déficit público, el grado de endeudamiento externo y, en general, la excesiva participación del Estado en la actividad económica. Las políticas públicas se encaminaron a un proceso de reestructuración, modernización y saneamiento financiero de las empresas improductivas y al apoyo a las empresas que fueran capaces de incorporarse a la globalización. Para ello se destinaron cuantiosos recursos públicos al saneamiento de esas empresas y al pago de deudas acumuladas, a la modernización y la absorción de los costos para la adquisición de las nuevas tecnologías. Se hicieron a un lado los esquemas empresariales rígidos y se adoptaron formas flexibles de organización del trabajo con la incorporación de técnicas mucho más funcionales a las necesidades competitivas del capital.

\section{LAS POLÍTICAS PÚBLICAS PARA LA}

\section{COMPETITIVIDAD INDUSTRIAL EN MÉXICO}

Es hasta la década de los ochenta cuando se estableció plenamente la política liberal en México con los programas definidos por el FMI y el BM en el sentido de limitar lo más posible la intervención directa del Estado en la economía y obligar a los gobiernos a centrar su atención en políticas que beneficiaran el desarrollo 
empresarial. ${ }^{13} \mathrm{El}$ paquete de "cambio estructural" buscaba la total liberalización comercial y financiera con el exterior, así como la orientación fundamental de los gobiernos a garantizar el orden público, reducir su intervención en la vida económica y confiar en la regulación del mercado por medio de la libre competencia.

El gobierno del presidente Miguel de la Madrid (1982-1988), anunció cambios importantes en el papel del Estado, presionado por la crisis de la deuda y los compromisos signados con la banca internacional, aunque en ese momento participaba en forma directa o indirecta en 1,155 empresas que operaban en 63 de las 73 ramas de la actividad económica. La importancia del Estado en la producción representaba $22.8 \%$ del PIB, además de emplear a más de un millón de personas, casi un tercio de los 3700000 trabajadores ocupados en el sector público al inicio del proceso [González, 2008: 95-132]. El sector paraestatal se conformaba por 724 empresas con inversión mayoritaria y en 75 minoritaria; 103 estaban descentralizadas y 223 eran fideicomisos [Gasca, 1989: 152]. Al finalizar el gobierno de Miguel de la Madrid, en 1988, solo quedaron 618 empresas en manos del Estado. Es decir, en el lapso de seis años se desincorporaron 537 empresas paraestatales, además de que otras 204 se encontraban en proceso de liquidación, extinción, fusión, transferencia o venta. Muchas paraestatales fueron cerradas por su inviabilidad económica o se aplicaron programas de reducción de personal, aseguramiento de las ventas, ampliación y modernización de los procesos de producción y comercialización, capacitación de la mano de obra y formas de trabajo más "flexibles" en las empresas [Gutiérrez, 1995: 190].

Los efectos sociales de este proceso se reflejaron en el nivel de desempleo generado por la privatización (ya sea por despido, jubilación o liquidación), que ascendieron, según datos oficiales, a más de 250000 trabajadores [Aspe, 1993: 183]. Las modificaciones

${ }^{13}$ En suma, se trata de incorporar las economías nacionales y regionales al proceso de desarrollo global mediante la liberalización externa y eliminar -en el interior- tal exceso de estatización, poder corporativo y regulación de la economía, para que se manifieste libremente el poder del mercado [Zermeño, 2002: 22]. 
salariales estarían determinadas por el incremento de la productividad de la mano de obra [Banco de México, 1994: 24], con ello se reforzaron los mecanismos para establecer los programas de flexibilidad de la fuerza de trabajo. Todo este proceso se aplicó por medio de "un plan de choque" denominado Programa Inmediato de Reordenación Económica que buscaba implantar el libre comercio y la apertura total de la economía.

El objetivo era tener un Estado minimalista ligado a políticas fiscales y monetarias restrictivas para lograr las metas macroeconómicas y las principales propuestas de la industrialización orientada a las exportaciones (IOE), en la cual el sector privado es concebido como el motor del desarrollo y de la futura industrialización en la que predominen las relaciones laborales flexibles [Balassa, 1988: 17-44; Bhagwati, 1991: 17; Dussel, 1997a: 36 y 137].

El intenso proceso de ajuste y liberación comercial implicó una serie de reformas a la Constitución; destacan las modificaciones a los artículos 25, 27 y 28 concernientes a la definición de la propiedad nacional y el control de los monopolios.

Los esfuerzos de las políticas públicas estuvieron dirigidos a recortar el gasto público, la privatización de las empresas paraestatales, ajustes en el tipo de cambio, y reorientación del esquema generalizado de subsidios para promover actividades manufactureras orientadas hacia la exportación, además de garantizar una fuerza de trabajo barata, la cual se constituye en un elemento esencial para la estrategia neoliberal que provocaría la modificación de los procesos productivos, la organización del trabajo y las relaciones laborales. Sin embargo, los nuevos procesos requerían una fuerza de trabajo más calificada y con nuevas habilidades que permitieran las multifunciones, la capacitación permanente, los horarios flexibles, la movilidad por calificación, los grupos de trabajo y la nueva responsabilidad frente a la empresa. El uso de la computadora, las técnicas flexibles de organización de la producción, el control de calidad, así como la acción sindical y las relaciones laborales modificaron el funcionamiento productivo [CEPAL, 1993: 19]. 
En 1989 se dio un reforzamiento de la política liberal mediante el Consenso de Washington, cuando Estados Unidos consideró que había poca disposición de los países de América Latina para emprender las reformas necesarias para superar la crisis de la deuda externa. En este documento se introdujo la visión de Bretton Woods, de los altos funcionarios del gobierno, del Congreso, de las agencias económicas oficiales, del Consejo de la Reserva Federal de Estados Unidos y de los grupos de expertos que produjeron importantes negociaciones comerciales posteriores a la firma del documento para apuntalar un papel minimalista del Estado. ${ }^{14}$

El proceso de privatización se extendió a las empresas estratégicas cuando se declaró que ya no eran prioritarias para el desarrollo económico, en la medida en que sus productos estaban disponibles en el mercado internacional, a precios competitivos y podían ser privatizadas. En estas condiciones la política neoliberal alcanzó expresiones máximas en el gobierno de Carlos Salinas de Gortari (1988-1994), cuando estableció una “estrategia de la liberalización” con el FMI, el BM, y el Departamento del Tesoro de Estados Unidos para privatizar las empresas públicas estratégicas que se encontraban en manos del Estado, como la siderurgia, la minería, el transporte aéreo y urbano, las telecomunicaciones, la banca, la petroquímica, el petróleo y la energía eléctrica, las carreteras, los puertos, los sistemas agrícolas y la silvicultura [Álvarez, 1994: 20-21]. Entre las industrias privatizadas estuvieron las principales líneas aéreas nacionales (Mexicana de Aviación y Aeroméxico), una de las minas de cobre más grandes del mundo (Compañía Minera de Cananea), la compañía telefónica nacional (Teléfonos de México) y la totalidad de los bancos comerciales. También se hicieron importantes esfuerzos para

${ }^{14}$ Nos referimos a la posterior negociación del TLCAN entre México, Estados Unidos y Canadá, hasta compromisos suscritos en diciembre de 1994, para crear una zona continental de libre comercio, sin dejar de lado que en el plano multilateral concluyeron las negociaciones de la Ronda de Uruguay del Acuerdo General sobre Aranceles Aduaneros y Comercio (GATT, por sus siglas en inglés), nació la OMC y posteriormente se inició una nueva ronda, la Ronda de Doha [Reyes, 2003: 178]. 
desmantelar algunas áreas de los sectores eléctrico y petrolero. Si al inicio de esta administración el gobierno tenía 661 empresas, después del proceso privatizador quedaron solo 258; se habían vendido o dejado en proceso de licitación 403 entidades, aunque algunas de gran importancia todavía conservaban su estatus [González, 2008: 95-132].

La firma del Tratado de Libre Comercio de América del Norte (TLCAN) vino a reforzar los objetivos básicos antes señalados: a) servir de candado a fin de garantizar la permanencia y continuidad de las reformas descritas anteriormente, y b) favorecer las exportaciones mexicanas en el marco de un mayor flujo de inversiones estadounidenses hacia México [Rivera, 2000: 177178]. Se estableció una reducción progresiva de las barreras aduanales tarifarias y no tarifarias durante un periodo de 15 años, la liberalización de los intercambios de servicios y la supresión de los obstáculos a las inversiones en la zona. Los efectos fueron relevantes en los sectores sensibles, por ejemplo, en la industria siderúrgica. Asimismo, es posible ver una progresiva subordinación a los organismos financieros internacionales, con importantes consecuencias políticas tanto por la venta de las empresas públicas como por el manejo del presupuesto nacional en el que la prioridad sería garantizar el pago del servicio de la deuda. Es un instrumento importante para desvanecer la soberanía y "reorientar" la función y existencia misma del Estado nacional; significa un ajuste del aparato normativo para dar seguridad jurídica a los inversionistas y reafirmar las políticas del FMI y el BM, así como hacer efectivos los contratos de traspaso, control o propiedad involucrados en las políticas privatizadoras [Huerta, 1995; Rivera, 2000; Saxe-Fernández, 2002]. Con esas medidas los organismos financieros internacionales pudieron incidir de manera más clara en la estructura de los programas económicos específicos y asumir funciones de evaluación, supervisión, control y vigilancia mucho más amplias [González, 1996: 105-123].

No es extraño entonces el agrado que las grandes empresas trasnacionales capitalistas manifestaron cuando se permitió el libre movimiento de bienes, servicios y capitales, aunque no sucedió 
lo mismo con la fuerza de trabajo. Se derribaron las barreras que impedían la circulación de mercancías en el mercado mundial, al tiempo que se impusieron nuevas formas de protección de sus propios mercados internos.

$\mathrm{El}$ acuerdo comercial dio enormes ventajas a las grandes empresas trasnacionales para su expansión en el mercado global pues les ofreció garantías de seguridad y no discriminación a sus inversiones en México y Canadá, además de crear derechos superiores para los grandes corporativos privados que, en muchos casos, violaban la propia Constitución. ${ }^{15}$ En este aspecto Stiglitz señala que:

El libre comercio no ha funcionado en parte porque no lo hemos intentado: los acuerdos comerciales del pasado no han sido ni libres ni justos. Han sido asimétricos, pues abrían los mercados de los países en vías de desarrollo a mercancías procedentes de los países industriales avanzados sin que se diera una plena reciprocidad. Se mantuvieron multitud de barreras comerciales sutiles, pero eficaces. Esta globalización asimétrica puso a los países en vías de desarrollo en una situación de desventaja. Los ha dejado en una situación peor que la que tendrían en el caso de que estuvieran en un régimen de verdadero comercio libre y justo [Stiglitz, 2006: 94].

Se modificaron las formas de inversión y cada nación debería tratar a los inversionistas foráneos y a sus capitales en forma no menos favorable que a los nacionales.

Más importante aún, los nuevos requisitos de desempeño, como los niveles de exportación, contenido nacional mínimo, balanza comercial y transferencia de tecnología, se eliminarían en el curso de los siguientes diez a quince años, por lo que la disparidad competitiva sería más evidente" [Dussel, 1997a: 162].

De acuerdo con Stiglitz, este tratado comercial creaba lo que en aquel momento era el área de libre comercio más

${ }^{15}$ Stiglitz señala que con esa acción también se cerró la llamada Ronda de Uruguay de negociaciones comerciales internacionales, que crearon la Organización Mundial de Comercio, un organismo regulador del comercio internacional [Stiglitz, 2004: 55]. 
extensa del mundo, con 376 millones de personas y un PIB de casi 9 billones.

Este pacto abría el país más rico del mundo, Estados Unidos, a México. Ambos países cuentan con una historia compartida, aunque no siempre agradable. La inmigración mexicana a Estados Unidos ha sido muy abundante; amplias zonas de este país son de habla hispana; y Estados Unidos precisa de la mano de obra mexicana en sectores como la agricultura, la industria manufacturera y los servicios no cualificados. Unos 10 millones de mexicanos -la décima parte de la población de Méxicoviven, legal o ilegalmente, en Estados Unidos. Aunque los mexicanos vienen a Estados Unidos a trabajar, muchos se quedan, se casan con ciudadanos estadounidenses, crían a sus hijos y ahora incluso dominan comunidades en estados como California, Texas y Arizona [Stiglitz, 2006: 93].

En el capítulo correspondiente a la industria automotriz se desarrollará con mayores elementos la manera en que este sector se benefició de la apertura económica, por ejemplo, en

... la naturaleza de la integración regional auspiciada por el TLCAN. El tratado permitió eliminar una gran cantidad de barreras legales y arancelarias que establecían límites a los esquemas de producción compartida y al comercio intrafirma; así, la lógica de la integración ha estado regida principalmente por la disolución de las barreras al flujo de capitales y mercancías requerido por la operación de las empresas trasnacionales. Esto les ha permitido desplegar estrategias de organización que abarcan al conjunto de la región del TLCAN como plataforma productiva, aprovechando al máximo las ventajas de México en cuanto a su cercanía geográfica, bajos salarios y alta calidad de la mano de obra [Contreras et al., 2006: 260].

Los acuerdos para privatizar los sectores estratégicos continuaron en el gobierno de Ernesto Zedillo (1994-2000), por lo que entre 1996 y 1997 concluyeron cinco procesos de desincorporación de entidades paraestatales: se liquidaron tres puertos (Cabo San Lucas, Dos Bocas y Frontera), el Fondo Ganadero 
y la empresa Tetraetilo de México. Al mismo tiempo, se integraron 15 nuevas entidades como parte de la estrategia de venta para las empresas ferrocarrileras, petroquímicas, satélites, prensa (El Nacional, El Nacional de Guanajuato, etc.) e instalaciones de almacenamiento agropecuario. De esta forma, el número de entidades en manos del Estado pasó de 239 en 1996 a 229 en 1997, de las cuales 185 eran vigentes y 44 estaban en proceso de desincorporación [Zedillo, 1997: 69]. El último año, antes de las elecciones presidenciales de 2000, concluyó con 13 procesos de desincorporación de entidades paraestatales; siete mediante liquidación y seis por venta de la participación accionaria que poseía el gobierno federal o alguna entidad paraestatal. Se crearon seis nuevas entidades con múltiples subdivisiones, de tal manera que el universo de paraestatales pasó de 232 en 1998 a 261 en 1999. De estas últimas, 203 se encontraban vigentes y 57 en proceso de desincorporación, conformadas por 74 organismos descentralizados, 107 de participación estatal mayoritaria y 22 fideicomisos públicos. Entre las 57 entidades en vías de desincorporarse, sobresalen las administraciones portuarias integrales; los servicios portuarios, aeroportuarios y satelital, así como las instalaciones de almacenamiento agropecuario [Zedillo, 1999: 132-134]. Algunos de esos procesos no habían concluido porque la iniciativa privada había mostrado poco interés en ellos.

La mayoría de las áreas privatizadas permanecieron como monopolios y oligopolios que resquebrajaban toda competitividad y aplastaban a los pequeños y medianos industriales y empresas que eran importantes generadores de empleo. La eficiencia empresarial que se difundió, cuando se decidió que el Estado debería separarse de la actividad directa en la economía para liberar recursos que se destinarían a la atención del desarrollo social y la ampliación de la infraestructura productiva, no tuvo los efectos esperados; al contrario, a pesar de que se asignaron elevados recursos públicos para sanear las empresas y venderlas, una vez en manos privadas estas se declararon insolventes para que el gobierno las rescatara con financiamiento público, de modo que los costos nuevamente fueron trasladados a los contribuyentes. 


\section{LA PRODUCCIÓN INDUSTRIAL EN EL SIGLO XXI}

La producción industrial en el mercado mundial plantea la integración más estrecha entre los países y los pueblos del mundo, producida por la enorme reducción de los costes de transporte y comunicación, y la posibilidad de la especialización aunque ello implicara “... el desmantelamiento de las barreras artificiales a los flujos de bienes, servicios, capitales, conocimiento y (en menor grado) personas a través de las fronteras" [Stiglitz, 2002: 34]. En este sentido la comercialización globalizada revive en mayor escala lo que a principios del siglo Xx se llamó imperialismo y significa la hegemonía del capital financiero internacional sobre el capital industrial nacional [Saxe-Fernández, 2002: 68). Se trata de la expansión capitalista en la cual se hace mucho más evidente el predominio de las grandes empresas trasnacionales, así como la necesidad de la ampliación de la producción y el control de las materias primas, el trabajo y los mercados de consumo, en un mundo donde el control militar y la definición política conduce a conflictos internacionales cada vez más peligrosos.

La producción supone el surgimiento de una nueva revolución tecnológica con la creación de nuevas industrias, pero también su capacidad para modernizar todas las industrias viejas y elevar su productividad de modo significativo. El progreso técnico aumenta la productividad del trabajo -considerado en términos generales-, economiza trabajo y eleva la composición técnica y orgánica del capital en el conjunto del sistema. Asimismo, aumenta la productividad mediante la división del trabajo, el empleo de herramientas especializadas e incluso mediante la introducción de alguna máquina para asegurar un incremento cada vez más importante de la productividad del trabajo, de manera que abarata el valor de las mercancías y, a la vez, permite aumentar el tiempo de plustrabajo. Constituye, por lo tanto, un medio poderoso de producir plusvalía relativa [Vence, 1995: 27, 87 y 90].

La modernización productiva requiere mano de obra cada vez más calificada y actualizada que sepa manejar las nuevas 
tecnologías, en particular las tecnologías de la información y la comunicación (TIC), ${ }^{16}$ que por su propia esencia han permitido hacer más eficiente el trabajo inherente a la creatividad, la investigación, el desarrollo y la aplicación tecnológica al tiempo en que han pulverizado la distancia geográfica y la velocidad de respuesta en todos los ámbitos de la vida. Las computadoras por sí solas lograron un profundo y prácticamente virtual impacto universal en todas las áreas de trabajo, desde la agricultura hasta el diseño de ingeniería. Hay pocos, si no es que ningún trabajo que no esté siendo afectado por algún tipo de desarrollo tecnológico reciente. El segundo aspecto de la situación actual es su carácter global; en el pasado, los países eran mucho más aislados e independientes en la tasa y crecimiento de la transformación tecnológica. Los principales sectores en la innovación tecnológica son la biotecnología, la nanotecnología, los nuevos materiales y la bioelectrónica.

Todos estos cambios producen una inevitable resistencia que usualmente se manifiesta como enfrentamiento entre los jóvenes tecnológicamente aptos y los veteranos, antes competentes y ahora perdidos en el nuevo paradigma [Pérez, 2009: 26]. La producción industrial en la globalización económica muestra una división internacional del trabajo, desde la fabricación de una computadora, un automóvil o un televisor, etc., en la cual participan diversas naciones con las partes o componentes que se remiten al país productor o ensamblador y la entrega de los bienes generados. Esta situación plantea nuevas formas de organización del trabajo que impactan en la productividad y calidad de la producción, que a su vez requiere la transformación ideológica de los llamados actores sociales y las instituciones [Pérez, 2004: 47, 73 ]. Se acelera la circulación de mercancías, la competencia y la

${ }^{16}$ Expresión que hace referencia a una gama de servicios, aplicaciones y tecnologías, que utilizan diversos tipos de equipos y de programas informáticos y que con frecuencia se transmiten por medio de las redes de telecomunicaciones. Las TIC incluyen servicios tales como: telefonía, telefonía móvil y fax, correo electrónico, transferencia de archivos e internet [Manpower, 2008: 59]. 
innovación, además de la consolidación de nuevos formatos de relación laboral como es el teletrabajo. ${ }^{17}$

\section{CONCLusiones}

La participación del Estado en la economía durante el siglo XX y hasta nuestros días puede clasificarse en dos grandes periodos. El primero se caracteriza por el predominio del patrón de acumulación basado en un modelo de industrialización sustitutiva de importaciones, con un Estado intervencionista por medio de una amplia y creciente participación directa en la economía, sobre todo a partir de la segunda guerra mundial del siglo Xx. Su acción se despliega en el fomento de la demanda agregada con el fortalecimiento del mercado interno, los estímulos a la inversión privada y la generación de empleos.

El segundo periodo está definido por el patrón de acumulación neoliberal, teniendo como fundamento ideológico la libertad del mercado y el alejamiento del Estado de todas las áreas económicas en las que el capital privado tuviera interés en participar. Las políticas públicas estuvieron centradas en el saneamiento fiscal, la liberalización del comercio exterior, la desregulación financiera, el fomento de la inversión extranjera, el impulso al sector privado, la venta de las empresas estatales y la desregulación de las actividades económicas internas, entre otros, que permitieran fortalecer la expansión capitalista, particularmente para las empresas trasnacionales en la búsqueda de mayores tasas de ganancia con el aumento de la plusvalía absoluta y relativa.

La producción industrial se ve desarticulada por la apertura del mercado interno a favor de las grandes empresas trasnacionales. Las empresas para subsistir necesitan aumentar su competitividad y transformar su base productiva como un poderoso y visible conjunto de novedosas tecnologías, productos e industrias

${ }^{17}$ Es una forma flexible en la que una organización permite a un empleado desempeñar la actividad profesional sin su presencia física en la empresa durante el horario laboral, englobando una amplia gama de actividades a realizarse en tiempo completo o parcial [Manpower, 2008: 59]. 
nuevas y dinámicas, capaces de sacudir los cimientos de la economía y de impulsar una oleada de desarrollo de largo plazo.

La organización del trabajo se transformó por un esquema de organización empresarial más funcional a la apertura, mediante sistemas como el toyotismo, con la incorporación de técnicas mucho más adecuadas a las necesidades competitivas: el trabajo en equipo, los círculos de calidad, así como la organización departamental para aumentar la productividad y la calidad de los productos y propiciar un control mayor de los trabajadores. El desempleo se torna en un elemento que propicia una movilidad mayor del capital y le facilita la aplicación de los mecanismos para incrementar la productividad e intensidad del trabajo como forma de atenuar la caída de la tasa de ganancia.

Las nuevas tecnologías demandan proporcionalmente menor cantidad de fuerza de trabajo, con mayores grados de calificación y con la flexibilidad necesaria para enfrentar la competencia internacional. Las políticas públicas aplicadas en México se engarzan de manera muy eficiente con el capitalismo mundial; se adaptaron a las necesidades de expansión, producción y distribución de mercancías, con las reformas y adecuaciones del marco jurídico para encaminar el proceso de acumulación hacia la liberalización de los mercados, la innovación tecnológica, la calificación laboral y la flexibilidad necesarias para la valorización del capital. El Estado se alejó de la función productiva y se concentró en la estabilidad social con la aplicación de programas asistencialistas para cubrir la enorme deuda social que esa misma política propició para más de la mitad de la población que se encuentra en pobreza y en pobreza extrema.

\section{REFERENCIAS}

Aguilar M., A. [1983], Estado, capitalismo y clase en el poder en México, México, Nuestro Tiempo, 243 pp.

Álvarez B., A. [1994], "Las privatizaciones en México, 1988-1994: economía política de la fabricación de millonarios", ponencia presentada en el Seminario Le Mexique en 1994: Bilan du 
Sexennat du president Carlos Salinas (1988-1994), Université Lavar, Québec, Canadá, del 2 al 4 de noviembre, 46 pp.

Aspe A., P. [1993], El camino mexicano de la transformación económica, México, FCE, 215 pp.

Ayala E., J. [2001], Estado y desarrollo. La formación de la economía mixta mexicana en el siglo XX, México, FE-UNAM, 500 pp.

Balassa, B. [1988], Los países de industrialización reciente en la economía mundial, México, FCE, 565 pp.

Banco de México varios años, "Informe anual”, <http://www. banxico.org.mx/gpublicaciones/Informe>.

Banco Mundial [1997], Informe sobre el desarrollo mundial. El Estado en un mundo en transformación, Estados Unidos de América, Oxford University Press para el Banco Mundial, 292 pp. Bhagwati, J. [1991], El proteccionismo, Madrid, España, Alianza, 150 pp.

Calva, J. L. [1995], El modelo neoliberal mexicano. Costos, vulnerabilidad, alternativas, México, Juan Pablos Editor, 193 pp. Carrión, J. y Aguilar M., A. [1977], La burguesía, la oligarquía y el Estado, México, Nuestro Tiempo, 4a. ed., 231 pp.

CEPAL [1993], Organización industrial, competitividad internacional y política pública en la década de los años noventa, Organización de las Naciones Unidas, Comisión Económica para América Latina y el Caribe, 31 de diciembre, LC/R 1329, 26 pp.

Contreras, O. F.; L. R. Schnierle y V. Solís G. [2006], "Reestructuración y trabajo en la industria automotriz", Enrique de la Garza y Carlos Salas (coords.), La situación del trabajo en México, México, UAM-I/Solidarity Center/Instituto de Estudios del Trabajo/Plaza y Valdés, pp. 255-275.

Coriat, B. [2000], El taller y el cronómetro (ensayo sobre el taylorismo, el fordismo y la producción en masa), México, Siglo XXI, $12^{\mathrm{a}}$ ed., $204 \mathrm{pp}$.

De la Garza T., E. [2006], Reestructuración productiva, empresas y trabajadores en México, México, FCE/UAm, 294 pp.

Dussel P., E. [1997a], La economía de la polarización. Teoría y evolución del cambio estructural de las manufacturas mexicanas (1988-1996), México, unAm/Jus, 326 pp. 
[1997b], "En el nombre de la libertad. El sistema teórico del neoliberalismo", en Economía Informa, México, FE-UNAM, (255): 20-25, marzo.

[2004], Efectos de la apertura comercial en el empleo y el mercado laboral de México y sus diferencias con Argentina y Brasil (1990-2003), México, unAm/Unidad de Análisis e Investigación sobre el Empleo, Departamento de Estrategias de Empleo, OIT, 76 pp.

Michael Piore y Clemente Ruiz Durán [1997], Pensar globalmente y actuar regionalmente: hacia un nuevo paradigma industrial para el siglo XXI, México, UNAM/JUs, 527 pp.

Fajnzylber, F. [1983], La industrialización trunca de América Latina, México, Nueva Imagen, 416 pp.

Friedman, M., y R. Friedman [1980], Libertad de elegir, Barcelona, España, Grijalbo, 436 pp.

Gasca Z., J. [1989], "Fuentes para el estudio de las empresas paraestatales de México y su privatización 1983-1988”, en Comercio Exterior, México, Bancomext, 39 (2): 151-175, febrero. González C., G. [1996], "La crisis actual y el Estado neoliberal”, México: pasado, presente y futuro, t. I, México, IIEc-UnAm/ Siglo XXI, pp. 105-123.

[2008], El Estado y la globalización en la industria siderúrgica mexicana, IIEc-UNAM/Juan Pablos, 373 pp.

[2007], Mito y realidad de la globalización neoliberal, México, UAm/Miguel Ángel Porrúa, 334 pp.

Guillen, H. [1997], La contrarrevolución neoliberal en México, México, Era, 257 pp.

Gutiérrez A., A. [1995], "Reflexiones sobre la reestructuración del capital y del trabajo en México", en Problemas del Desarrollo, México, IIEc-UNAM (101): 173-204, abril-junio.

Hernández C., A. [2010], "Los cambios del Estado y el derecho en el contexto de la globalización económica”, José Alfonso Bouzas Ortiz (coord.), Perspectivas del trabajo en México, México, IIEc-UnAm, pp. 17-67.

Hirschman, A. O. [1973], La estrategia del desarrollo económico, México, FCE, 210 pp. 
[1996], "La economía política de la industrialización a través de la sustitución de importaciones en América Latina”, en El Trimestre Económico, México, FCE, LXIII-2 (250): 489-524, abril-junio.

Holzmann, R., Richard Hinz y Worldbank Team [2002], Soporte del ingreso en la vejez en el siglo XXI: una perspectiva internacional de los sistemas de pensiones y de sus reformas, Washington, D.C., Banco Mundial.

Huerta G., A. [1995], "La crisis del neoliberalismo mexicano", Problemas del Desarrollo, México, IIEc-UnAm (101): 7-28, abril-junio.

Lipietz, A. [1979], El capital y su espacio, México, Siglo XXI, 203 pp.

Manpower [2008], La integración al mercado laboral del talento latinoamericano, México, Manpower Inc. (NYSE: MAN), 70 pp., $<$ http://www.manpower.com.mx>, 5 de enero de 2012.

Martínez A., J. [1998], "Flexibilidad y productividad laboral en la siderúrgica Lázaro Cárdenas-Las Truchas (Sicartsa)”, Francisco Zapata, ¿Flexibles y productivos? Estudios sobre flexibilidad laboral en México, México, Colmex, pp. 265-318.

Palley, T. I. [2005], "Del keynesianismo al neoliberalismo: paradigmas cambiantes en economía”, en Economía UNAM, México, FE-UNAM, (4): 138-148, enero-abril.

Pérez P., C. [2004], Revoluciones tecnológicas y capital financiero. La dinámica de las grandes burbujas financieras y las épocas de bonanza, México, Siglo XXI, 269 pp.

[2009], "Innovación y crecimiento. Comprender la dinámica y el cambio de las oportunidades para América Latina”, Adriana Martínez Martínez et al., Innovación y competitividad en la sociedad del conocimiento, México, Consejo de Ciencia y Tecnología del Estado de Guanajuato/Plaza y Valdés, pp. 21-42.

Poulantzas, N. et al. [1977], El marxismo y la crisis del Estado, Puebla, Instituto de Ciencias-UAP, 168 pp.

Rey R., B. [1984], La ofensiva empresarial contra la intervención del Estado, México, Siglo XXI, IIEc-UnAm, 157 pp. 
Reyes, G. E., y Ma. C. Rojas [2003], ALCA y OMC: América Latina frente al proteccionismo. El libre comercio en los tiempos del ántrax, México, UnAM, 208 pp.

Rivera R., M. A. [2000], México en la economía global. Tecnología, espacio e instituciones, México, UNAM, 212 pp.

Ruiz D., C. [2009], "México: Las dimensiones de la flexiguridad laboral”, Serie Macroeconomía del Desarrollo, Santiago de Chile, Naciones Unidas, CEPAL (83): 63, abril.

Saxe-Fernández, J. [2002], La compra-venta de México. Una interpretación bistórica y estratégica de las relaciones MéxicoEstados Unidos, México, Plaza \& Janés, 598 pp.

Sennett, R. [2001], La corrosión del carácter. Las consecuencias personales del trabajo en el nuevo capitalismo, México, Anagrama, $5^{a}$ ed., 188 pp.

Stiglitz, J. E. [2002], El malestar en la globalización, España, Taurus, 314 pp.

[2004], Los felices 90. La semilla de la destrucción, España, Taurus, 415 pp.

[2006], Cómo bacer que funcione la globalización, México, Taurus, 433 pp.

[2010], Caída Libre. El libre mercado y el bundimiento de la economía mundial, México, Santillana Ediciones Generales, 423 pp.

Sunkel, O. [1993], "El marco histórico de la reforma económica contemporánea”, Pensamiento Iberoamericano I (22-23): 15-51.

Sweezy, P. [1969], Teoría del desarrollo capitalista, México, FCE, pp. 265-359.

Valenzuela F., J. C. [1990], ¿Qué es un patrón de acumulación?, México, FE-UnAM, 189 pp.

Vence, X. [1995], Economía de la innovación y del cambio tecnológico: una revisión crítica, España, Siglo XXI, 470 pp.

Villarreal, R. P. [1988], Industrialización, deuda y desequilibrio externo en México. Un enfoque neoestructuralista (1929-1988), México, FCE, 616 pp.

Vincent, J.-M. [1977], "El Estado en crisis”, El marxismo y la crisis del Estado, Puebla, México, Instituto de Ciencias-UAP, pp. 103-116. 
Vizgunova, I. [1980], La situación de la clase obrera en México, México, Ediciones de Cultura Popular, 202 pp.

Zedillo P.-L., E., Informe de Gobierno: 1995, 1996, 1997, 1998, 1999.

Zermeño, F. [2002], "México: Progreso técnico y retroceso social. ¿Hay una alternativa?”, en Memoria, México, Siglo XXI, (159): 18-23, mayo. 


\title{
Capítulo 2 \\ EL EsTADO, LA EMPRESA TRASNACIONAL AUTOMOTRIZ Y LOS TRABAJADORES
}

\author{
Angelina Gutiérrez Arriola*
}

\section{INTRODUCCIÓN}

La reestructuración sistemática de la empresa trasnacional automotriz (ETA), ${ }^{1}$ en su búsqueda por atenuar la caída de la tasa de ganancia y acelerar su ciclo de reproducción del capital, viene implicando cambios profundos en sus procesos de organización de la producción y del trabajo en el ámbito mundial, proceso en el cual el gigantesco y acelerado desarrollo tecnológico ha sido parte integral. Su reorganización en red, basada en la relocalización de sus plantas de ensamble final y la delegación de fases de su proceso productivo en empresas proveedoras de diverso

* Académica del IIEc-UnAm y participante en el proyecto de investigación PAPIIT IN305610. Correo electrónico: <anguarr@unam.mx>.

${ }^{1} \mathrm{La}$ empresa trasnacional automotriz constituye una empresa paradigmática cuya influencia en las formas de organización en la producción y el trabajo, en las últimas fases del capitalismo, la han convertido en un modelo a seguir, además de tratarse de un sector cuya relación con las más diversas ramas y sectores económicos (petróleo, acero, aluminio, vidrio, textil, plástico, electro/electrónica, informática, comercio y servicios diversos) la convierten en un factor dinámico de crecimiento. 
origen y tamaño, ha dado paso a la formación de cadenas y subcadenas de valor de carácter global, regional y local. Parto de la hipótesis de que esta situación viene a reconfigurar el mapa productivo internacional con implicaciones profundas en la fuerza de trabajo y, a su vez, ha conllevado cambios radicales en las formas de comercialización y consumo de la sociedad en su conjunto. Asimismo, en este proceso de reestructuración, el papel del Estado en sus diferentes modalidades ha sido fundamental para facilitar las condiciones de expansión mundial del capital bajo las nuevas formas de acumulación.

\section{PERIODO DE TRANSICIÓN}

Entre las décadas de los setenta y noventa del siglo pasado y después de un periodo de crecimiento con estabilidad, el capitalismo entró en un proceso de transición caracterizado por crisis recurrentes que expresaban las dificultades de un sistema de acumulación de capital, basado en la oferta y definido por su rigidez, para dar paso a otro, basado en la demanda y definido por la flexibilidad, en su búsqueda por eliminar los obstáculos a su expansión ante la caída tendencial de la tasa de ganancia.

En ambos casos los principios básicos de la organización del proceso de producción y trabajo -como son la cadena de ensamble, la producción en serie y en masa, la estandarización de procesos y productos y el control de tiempos y movimientos- permanecen, pero son adaptados a las condiciones propias de cada fase.

a) En el fordismo, en la cadena de ensamble se utilizaban tecnologías electromecánicas de la época; existía concentración de diversas fases del proceso en una misma empresa, donde la división técnica del trabajo era vertical y rígida sustentada en el puesto fijo; se producía para el mercado interno y la productividad se medía individualmente.

b) En la fase flexible, con la revolución tecnológica, la cadena de ensamble se vuelve global; se utilizan tecnologías de la 
información, comunicación, robotización, nuevos materiales, etc., que facilitan la globalización de la producción y una nueva división técnica del trabajo con base en la flexibilidad, tanto por la delegación de diversas fases del proceso en proveedores, como por la polivalencia, trabajo en equipo, elasticidad salarial y numérica; se produce principalmente para el mercado externo y la productividad se mide de manera global.

En ambos casos el papel del Estado es fundamental para dar cauce legal a la contradicción capital/trabajo, aplicando políticas de acuerdo a cada fase y estructura económica, política y social de los países. De ese modo, iría cambiando su papel como regulador del desarrollo -el llamado "Estado benefactor"-, para concentrarse cada vez más como garante del crecimiento -o el llamado "Estado mercado"-, adaptado a una nueva relación con el mercado que viene imponiendo nuevas reglas económicas, mediante un sistema institucional de mediación político-económico-social, transmisor de una nueva ideología necesaria para la acumulación, como una forma de dar respuesta a la necesidad de expansión del capital. ${ }^{2}$

Sobre el comportamiento de los Estados nacionales influirían, cada vez en mayor medida, el llamado "Grupo de los 8",3 apoyado en instituciones y organismos internacionales como el Fondo Monetario Internacional (FMI), el Banco Mundial (BM) y la Organización de las Naciones Unidas (ONU), así como por el cada vez más importante capital financiero internacional que se convertiría en uno de los principales instrumentos de concentración y centralización del capital.

Estos cambios en el papel del Estado se observan en el siguiente cuadro.

\footnotetext{
${ }^{2}$ Esto no significa que el Estado se retire de la actividad económica, sino más bien de la productiva.

3 Se denomina "Grupo de los 8" a un grupo de países industrializados cuyo peso político, económico y militar es relevante en la definición de estrategias del capitalismo; lo conforman Estados Unidos, Canadá, Alemania, Francia, Inglaterra, Italia, Japón y Rusia.
} 


\section{El papel del Estado}

\begin{tabular}{|c|c|}
\hline Estado benefactor, keynesiano & Estado del beneficio; Estado mercado \\
\hline $\begin{array}{l}\text { Regulador del desarrollo: } \\
\text { - Impulso a la inversión pública en sec- } \\
\text { tores estratégicos para el desarrollo } \\
\text { (energía, telecomunicaciones, ferroca- } \\
\text { rriles, puertos, aeropuertos etc.), obras } \\
\text { de infraestructura (carreteras, presas), } \\
\text { así como servicios diversos (agua, dre- } \\
\text { naje, etc.), y banca de desarrollo, todo } \\
\text { con base en recursos propios. }\end{array}$ & $\begin{array}{l}\text { Garante del crecimiento: } \\
\text { - Impulso a la inversión mixta y a la } \\
\text { privatización de sectores estratégicos } \\
\text { (energía, telecomunicaciones, ferroca- } \\
\text { rriles, puertos, aeropuertos, etc.) y obras } \\
\text { de infraestructura (carreteras, presas), } \\
\text { todo con base en el endeudamiento } \\
\text { público. }\end{array}$ \\
\hline $\begin{array}{l}\text { - Regulación de la inversión pública y } \\
\text { privada, nacional y extranjera. }\end{array}$ & $\begin{array}{l}\text { - Desregulación de la inversión y aper- } \\
\text { tura creciente a la inversión extranjera. }\end{array}$ \\
\hline $\begin{array}{l}\text { Regulación de la banca nacional por } \\
\text { medio de un banco central, aplicando } \\
\text { políticas fiscales y monetarias orienta- } \\
\text { das al desarrollo. }\end{array}$ & $\begin{array}{l}\text { - Desregulación financiera; políticas } \\
\text { fiscales y monetarias que, orientadas } \\
\text { a controlar la inflación, las tasas de in- } \\
\text { terés y los tipos de cambio, buscan el } \\
\text { equilibrio macroeconómico. }\end{array}$ \\
\hline $\begin{array}{l}\text { Orientación al mercado interno: } \\
\text { - Políticas proteccionistas. } \\
\text { - Intentos de integración regional co- } \\
\text { mercial: ALDI, ALALC, UE, etcétera. }{ }^{4}\end{array}$ & $\begin{array}{l}\text { Orientación al mercado externo: } \\
\text { - Políticas de apertura. } \\
\text { - Integración regional productiva y co- } \\
\text { mercial mediante tratados de libre } \\
\text { comercio: TLCAN, UE, etcétera. }\end{array}$ \\
\hline $\begin{array}{l}\text { Regulación capital/trabajo: } \\
\text { - Contrato colectivo. } \\
\text { - Estabilidad en el empleo. } \\
\text { - Duración de la jornada de trabajo. } \\
\text { - Salario según el puesto. } \\
\text { - Prestaciones sociales (seguridad social, } \\
\text { pensiones y jubilación). }\end{array}$ & $\begin{array}{l}\text { Desregulación capital/trabajo: } \\
\text { - Outsourcing o subcontratación. } \\
\text { - Inestabilidad en el empleo. } \\
\text { - Flexibilidad en la jornada. } \\
\text { - Salario por productividad. } \\
\text { - Reducción de prestaciones sociales. }\end{array}$ \\
\hline $\begin{array}{l}\text { Incremento en el gasto público social: } \\
\text { educación, salud y vivienda. }\end{array}$ & $\begin{array}{l}\text { Ajuste del gasto público social y tendencia } \\
\text { la privatización en educación, salud y } \\
\text { vivienda. }\end{array}$ \\
\hline
\end{tabular}

Fuente: Elaboración propia.

${ }^{4}$ Asociación Latinoamericana de Integración (ALDI), Asociación Latinoamericana de Libre Comercio (ALALC), Unión Europea (UE, Acuerdo Franco-Alemán del Carbón y el Acero a finales de la década de los cuarenta).

5 Tratado de Libre Comercio de América del Norte (TLCAN), Unión Europea (UE integración económica, política y social de 27 países europeos, 15 de ellos en la llamada Zona Euro). 
La transición de un sistema a otro ocurre entre las décadas de los setenta y ochenta en un contexto caracterizado por una serie de acontecimientos que fueron creando las condiciones para eliminar rigideces y facilitar una mayor libertad al capital en su proceso de internacionalización; entre otros la sustitución del Acuerdo de Bretton Woods por un régimen monetario flexible, la crisis del petróleo en 1973, la creación del Acuerdo General sobre Aranceles aduaneros y Comercio (GATT) y más tarde la Organización Mundial de Comercio (OMC), que establecieron las normas básicas para abrir las fronteras necesarias para la internacionalización de la producción, comercio, banca y otros servicios, impulsando, para ello, políticas orientadas a reducir al mínimo toda regulación por parte del Estado nacional, el cual aplicaría políticas de ajuste estructural -como el Consenso de Washington-, impuestas por organismos como el FMI y el Banco Mundial.

En este cambiante marco internacional de apertura y desregulación, las grandes empresas de la industria automotriz -en especial las estadounidenses- llevarían a cabo un proceso de reestructuración, en un contexto de acelerado desarrollo tecnológico, para pasar de la gran empresa fordista, vertical y rígida y producción en función de la oferta, a una nueva empresa más flexible que, para producir en función de la demanda, requiere eliminar rigideces y obstáculos con el objetivo de recuperar su tasa de ganancia.

En el caso de las grandes empresas estadounidenses que, sobre todo a partir de la segunda posguerra, se habían expandido con éxito bajo el concepto de organización fordista, que las había convertido en el modelo a seguir -no solo para el resto de las empresas, sino también para los trabajadores a escala mundial-, en los setenta enfrentaron el problema de la caída de su tasa de ganancia, dada su propia estructura que las volvía cada vez más ineficientes. Organizadas en grandes plantas que concentraban numerosas fases del proceso productivo, su división técnica del trabajo se basaba en el puesto fijo, lo que requería un gran número de trabajadores. ${ }^{6}$ Esta forma de organización

${ }^{6}$ Cada empresa encerraba en su interior una extensa cadena que comprendía no solo las plantas ensambladoras, sino también el manejo de sus materias primas, así como la 
productiva facilitó la organización social de los trabajadores por medio de la cual fueron conquistando -no sin grandes luchasmejores condiciones de vida y trabajo. A esto hay que agregar que, conforme fueron creciendo estas empresas -por medio de fusiones y adquisiciones, nuevos mercados y productos-, se fueron volviendo más complejas, burocráticas y verticales en su funcionamiento, ya que existía duplicidad de puestos, tiempos muertos, grandes y costosos inventarios, reprocesos y desperdicios, los cuales a largo plazo se convirtieron en verdaderos obstáculos y rigideces que estorbaban los cambios que el desarrollo tecnológico y las nuevas formas de organización de la producción les exigían para incrementar su tasa de ganancia frente a una competencia cada vez más aguda.

El proceso se intensificó al enfrentar la competencia en su propio territorio con la llegada de las automotrices japonesas, que se caracterizaban por su eficiencia y productividad, basadas en los nuevos métodos y técnicas de organización de la producción y el trabajo que ofrecía el naciente toyotismo, como son el justo a tiempo (JIT), el cliente proveedor (kanban), la mejora continua (kaisen), la tendencia a cero inventarios, la importancia de la calidad, el mantenimiento preventivo (poka-joke), la flexibilidad y polivalencia en el trabajo, la integración de equipos y el empleo del número justo de trabajadores, lo que representaba la respuesta a cómo enfrentar sus propias rigideces [Ohno, 1991].

Así, en especial General Motors y Ford Motor, teniendo como base los principios básicos del fordismo -como son: la cadena de montaje, la producción en serie y en masa (para obtener economías de escala), la estandarización de procesos y productos, control de tiempos y movimientos, diferenciación de modelos mediante la innovación del producto (generalmente cosmética)llevaron a cabo un complejo proceso de reestructuración en sus

operación de acerías, laminadoras, flotas de transporte y distribuidoras propias. Esta situación creó una de las condiciones para el surgimiento del sujeto social trabajador (sindicato) que se fue estructurando en función de esta división como una forma de dar respuesta a las condiciones específicas de explotación. 
formas de organización de la producción y del trabajo adoptando los métodos y técnicas japonesas que conllevaban una nueva organización técnica del trabajo con base en la flexibilidad, como una forma de ser más competitivas al eliminar obstáculos y acelerar el ciclo de reproducción de capital. De esta manera se dio un complejo proceso de reestructuración en el que, en una misma empresa, coexistían viejas plantas fordistas en proceso de modernización con nuevas plantas en las que la tecnología y los métodos de organización toyotistas eran predominantes. ${ }^{7}$

Por otra parte, como una forma de bajar costos, se aprovechó la apertura de fronteras y las políticas de ajuste y desregulación por parte del Estado en esta fase de transición para continuar su expansión. Se dio un gran peso a la relocalización de su producción hacia regiones y países con menor tradición industrial (green fields), que les ofrecían mejores alternativas de rentabilidad. Además, comenzaron a instalar plantas maquiladoras especializadas en la elaboración de insumos de bajo valor agregado, caracterizadas por utilizar intensivamente fuerza de trabajo -como es el caso de la maquila tradicional de exportación en determinados países como México- ${ }^{8}$ y delegaron algunas fases del proceso en ciertos proveedores locales que ofrecían los mejores precios.

\section{CONSOLIDACIÓN DE LA FASE FLEXIBLE}

Desde la década de los noventa se acelera la reestructuración del capital a escala global al darse paso a una fase basada en la flexibilidad, apoyada en un rápido desarrollo tecnológico y cambios organizativos en la producción, distribución, comercialización y

${ }^{7} \mathrm{La}$ reestructuración de la empresa conlleva nuevas formas en la contradicción capital/trabajo, para lo cual la estructura sindical ha presentado, la mayoría de las veces, limitaciones para dar respuesta a esta nueva expresión de la contradicción [Angelina Gutiérrez, tesis de doctorado en proceso].

${ }^{8}$ La segmentación de la producción manufacturera automotriz estadounidense tuvo sus inicios a mediados de la década de los sesenta, con la instalación de plantas maquiladoras en México, caracterizadas por utilizar fuerza de trabajo intensiva, con poca calificación y de bajo costo y que abastecían de insumos intermedios de poco valor agregado a las tres grandes automotrices, lo que aumentó su competitividad. 
servicios; esto configuró una nueva división internacional del trabajo, dentro de la cual el capital financiero -convertido en el eje del financiamiento y de la renta a escala mundial- adquirió una gran hegemonía con base en una desregulación desmedida, lo que le permitió a las empresas diversas formas para incrementar sus ganancias por medio de la especulación (mercado de acciones, divisas, derivados, etcétera).

En esta fase, el nuevo papel del Estado es fundamental para proporcionar los incentivos y facilidades que ofrece el país receptor para atraer el capital: entorno fiscal y legal, barreras arancelarias, cuotas de importación, niveles salariales y capacitación de la fuerza de trabajo, insumos, obras de infraestructura, servicios en general, ambiente laboral y cultural, aspecto político y económico e incluso medioambiente. ${ }^{9}$ En especial contribuye a la conformación de mercados regionales -internos y externos-, al suscribir un sinnúmero de tratados de libre comercio que favorecen la integración regional -productiva y comercial-, como el TLCAN, la Región Asia/Pacífico, la UE, etcétera.

En estas condiciones, las ETA continuaron la reestructuración sistemática de su producción y trabajo en el ámbito mundial, que se manifestó en lo que se denomina lean production (empresa ajustada o reducida en tamaño) para convertirse en la gran empresa global o empresa red basada en la flexibilidad en todos los sentidos: productiva, laboral y financiera.

Parte fundamental de la estrategia de la ETA es la búsqueda de una mayor competitividad, a partir de la concentración en su centro corporativo -ubicado en países desarrollados-, desde ahí controla, planifica, coordina y aplica su estrategia a escala internacional, la cual se caracteriza por convertir la cadena de ensamble en una gran red global conformada por múltiples cadenas y subcadenas de producción y servicios -locales y regionales-, a cuyo frente encontramos las plantas ensambladoras -filiales y subsidiarias-; en torno a estas giran un sinnúmero de plantas provee-

${ }^{9}$ Batres Soto, Roberto y García Calderón [2006]. Además, hay que agregar que se tiende a que el financiamiento público se base en un creciente endeudamiento. 
doras especializadas de primero, segundo y tercer nivel -sean o no de su propiedad-, en las cuales delega diversas fases del proceso productivo, cuya vinculación con la empresa automotriz está sujeta a una relación contractual: el outsourcing. ${ }^{10}$

Toda esta estructura se rige por la estandarización de procesos de producción, productos, servicios y puestos de trabajo, lo cual conlleva la homologación del trabajo -sea en países desarrollados como subdesarrollados-, factores que a su vez facilitan la relocalización de plantas y fases de producción hacia diversos países y regiones que les garantizan mayor rentabilidad.

Esta estructura de organización permite a la empresa que, en el interior de sus cadenas y subcadenas de producción, se lleven a cabo operaciones y transacciones de comercio internacional sin tener que recurrir realmente a los mecanismos tradicionales del mercado. Se trata de una relación empresa/proveedor que se expresa en un incesante intercambio de insumos, bienes intermedios y servicios estandarizados de menor o mayor valor agregado -que se encuentran en diferentes etapas del proceso de producción-; y que, a su vez, proceden de diferentes proveedores especializados en diversos sectores y ramas económicas, ubicados en diversos países y regiones, y que contribuyen a la realización del bien final, sobre los cuales la gran empresa automotriz impone sus condiciones e internaliza sus costos de transacción.

$\mathrm{Al}$ interiorizar sus relaciones de compraventa de bienes y servicios a lo largo de la cadena de producción entre sus filiales, subsidiarias y proveedoras -sean o no de su propiedad-, pero que forman parte del mismo proceso productivo, la ETA favorece sus propios intereses, ya que al encontrarse al margen de la fijación de precios internacionales, la matriz decide los precios de transferencia a los que se deben vender o comprar los insumos y, por lo tanto, darles el valor más adecuado para sus propios fines. Para ello toma en consideración las diversas medidas fiscales, salarios, tipos de cambio, etc., de los diferentes países eligiendo los

${ }^{10}$ Outsourcing: delegación de fases del proceso productivo en empresas especializadas sujetas a controles rigurosos mediante contratos. 
más adecuados para sus intereses, lo cual es básico para que el comercio interfirma e intrafirma funcione de manera eficiente a lo largo de la cadena internacional de producción. ${ }^{11}$ Esto da lugar a exportaciones e importaciones entre múltiples países, donde una parte importante del déficit o superávit comercial concierne a este tipo de relaciones. Así elimina rigideces y obstáculos que implican las barreras espaciales y geográficas y aprovecha para lograr la maximización de sus ganancias. ${ }^{12}$

Las empresas proveedoras -tanto de países desarrollados como subdesarrollados- se caracterizan por su diversa conformación respecto a capital, tamaño y origen; en su conjunto, forman parte del mismo proceso productivo de la gran empresa y operan mediante una compleja red de relaciones contractuales sustentadas en el outsourcing o subcontratación, para llevar a cabo diferentes fases de este proceso en las que, con mayor eficiencia y a menor costo, se va agregando valor. ${ }^{13}$ Es así como, por medio de las cadenas, se van integrando una amplia gama de

${ }^{11}$ Es difícil medir el comercio intrafirma de las empresas trasnacionales dentro del comercio internacional; por lo general pasa desapercibido por los propios gobiernos a los que les causa un impacto negativo dentro del aspecto de las obligaciones fiscales. Una mayor idea sobre la importancia que esto tiene en el comercio internacional nos la da Isaac Minian [2012].

${ }^{12}$ Si bien la teoría clásica del comercio internacional basada en el modelo de las ventajas comparativas explica el comercio entre países con diferentes dotaciones de factores (comercio interindustrial), hoy ya no es la más adecuada para interpretar el comercio de manufacturas, que tiende a ser predominantemente intraindustrial y cuyas ventajas competitivas, producto de la interdependencia y la complejidad en el comportamiento estratégico de las empresas trasnacionales, adquieren una importancia fundamental.

${ }^{13}$ Actualmente, la heterogeneidad en la composición del capital que caracteriza a las empresas proveedoras y el hecho de que estas operen bajo el concepto de outsourcing, ha creado una confusión con el concepto de maquiladora de exportación que, en su fase inicial, consideraba solo aquellas plantas caracterizadas por emplear fuerza de trabajo intensiva, utilizando baja tecnología para elaborar insumos y autopartes más o menos simples. Hoy, con la globalización, las plantas maquiladoras se han transformado al emplear fuerza de trabajo más capacitada, utilizar tecnología más compleja, aplicar los nuevos métodos y técnicas en la producción y el trabajo para la elaboración de insumos y componentes también más complejos y que son orientados a la exportación de manera directa o indirecta (al ser integrados al producto final). A lo anterior hay que agregar que, en el caso de México, la industria automotriz opera bajo el régimen fiscal de maquila de exportación que le proporciona el Estado como una forma de disminuir costos. 
materias primas, insumos, componentes y bienes intermedios estandarizados y producidos en serie y en masa o por nicho de mercado, necesarios para ser utilizados por la ensambladora en la producción del bien final bajo una misma plataforma de producción. A ello hay que agregar los diversos servicios, como son la logística, distribución, comercialización y servicios posventa para su realización en el mercado, de acuerdo a las condiciones y requisitos que exige la gran empresa dentro de su estrategia global. ${ }^{14}$

Dentro de la estrategia de reestructuración productiva global de la gran empresa está la reducción al máximo de los costos de producción en espacios, tiempos, inventarios, fuerza de trabajo, comunicaciones y transporte. Para ello, a lo largo de toda la cadena, se utilizan cada vez más las nuevas tecnologías de la información y la comunicación (TIC), la robotización y la electrónica, las nuevas técnicas de organización en la producción y el trabajo -principalmente el sistema JIT y el kanban-, así como los modernos sistemas de transporte que le permiten responder a la demanda en el lugar y momento preciso. De esta forma a lo largo de la cadena fluyen, en tiempo real, conocimiento, información, órdenes, insumos, productos y capital de arriba a abajo y de abajo hacia arriba, sin importar distancias o fronteras, como una manera de aumentar la eficiencia y responder a la demanda, acelerando con ello el ciclo de rotación del capital. ${ }^{15}$

En la década de los noventa, la introducción del sistema modular en la estrategia de la empresa automotriz ${ }^{16}$ permite ahorrar

${ }^{14}$ Un automóvil moderno contiene decenas de miles de partes cuyo diseño y fabricación requieren centenares de sistemas y subsistemas que involucran conocimientos cada vez mayores dada su complejidad tecnológica.

${ }^{15}$ En términos generales se trata de una relación cliente/proveedor que facilita la introducción sistemática de innovaciones en procesos y productos al conjunto de las plantas que conforman la cadena internacional de producción, lo que permite acortar el ciclo de vida del producto.

${ }^{16}$ El sistema modular se aplicó por primera vez en la década de los noventa, en las plantas alemanas de Volkswagen (vw) y Mercedes Benz ubicadas en Resende, Brasil; Basblar, Checoslovaquia; Basel, Alemania del Este; Vence, Estados Unidos, y Hambach, Francia y se basa en cambios en la arquitectura de producción de vehículos, al pasar del ensamble de partes al de subsistemas o módulos como son: paneles de instrumentos, asientos e interiores, cajas de cambio, sistema eléctrico, sistema de frenado, etc. Posteriormente este sistema se generalizaría a toda la industria automotriz. 
tiempo en el ensamble de sistemas y subsistemas modulares, así como disminuir el número de proveedores, convirtiendo a los proveedores globales de primer nivel en fundamentales, debido a que estos son los que integran los insumos y componentes que proveedores de menor nivel suministran para la producción de módulos que deben llegar justo a tiempo y con la calidad y en la cantidad necesaria a la ensambladora, lo que los convierte en una especie de filtro.

Esta nueva estructura de organización de la producción y el trabajo ha dado lugar a un nuevo tipo de industrialización regional especializada en determinadas fases de producción o modelos del producto, en la que intervienen tanto países desarrollados como subdesarrollados que, de acuerdo a la estrategia de la empresa, cumplen con las condiciones y requisitos - "factores localizantes"- necesarios para desarrollar determinadas fases del proceso productivo [Batres-Soto y García-Calderón, 2006: 4952] en forma competitiva. Cabe citar los casos de la región de América ${ }^{17}$ en la que Estados Unidos es el productor central; la Unión Europea, con Alemania como eje, o los países asiáticos donde Japón y China marcan la pauta, aunque Corea tiene un crecimiento importante $;{ }^{18}$ ellos desarrollan un intenso comercio interregional e intrarregional. De esta manera se reconfigura el mapa productivo automotriz mundial, en la búsqueda por abatir costos, consolidarse en los mercados e incrementar sus ganancias, como se puede observar en la gráfica 1 :

${ }^{17}$ Por región de América se incluyen Estados Unidos, Canadá, México, Brasil y Argentina.

${ }^{18}$ En el caso de la región asiática tenemos que, a raíz de la apreciación del yen japonés en 1982, las empresas japonesas, afectadas por el incremento en sus costos laborales y con la necesidad de seguir exportando a países desarrollados como Estados Unidos, llevarían a cabo una política orientada a la integración en Asia oriental, donde el fraccionamiento productivo de las firmas manufactureras japonesas iniciarían un proceso de transferencia de partes y componentes con empresas de Corea del Sur, Taiwán, Singapur y Hong Kong, a las que delegarían sobre todo las fases caracterizadas por trabajo intensivo. A ello se agrega, en la década de los noventa, la apertura al exterior de China y su creciente participación en la conformación de la integración productiva de la región en la que, en pocos años, se convertiría junto a Japón en el motor que impulsaría la especialización industrial de los países de la región, especialmente en la industria electrónica y automotriz. 


\section{Gráfica 1. Produccción regional automotriz (miles de unidades)}

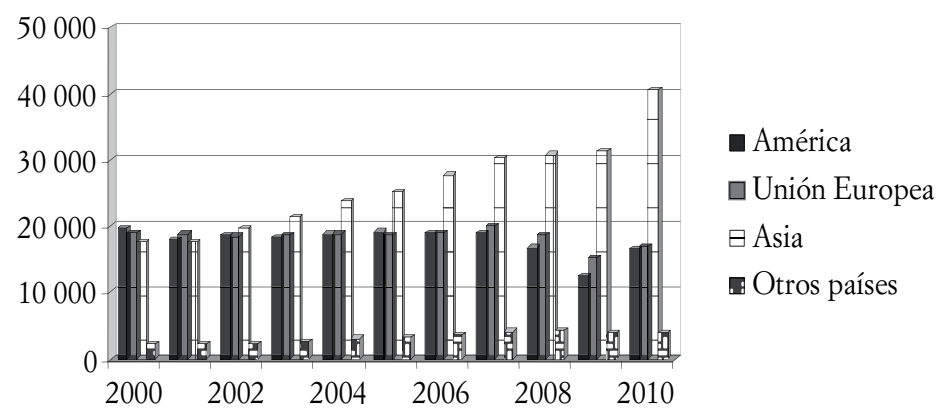

Fuente: Elaboración propia con base en Organisation Internationale des Constructeurs d'Automobiles (OICA), varios años.

La reconfiguración del mapa productivo mundial conlleva la especialización de un pequeño número de países en este tipo de industria, en los cuales se van concentrando la mayoría de las grandes empresas automotrices que llegan atraídas tanto por los diversos beneficios que estos países ofrecen, como por la competencia que entre estas se desarrolla. Dentro del total de la producción mundial en 2010, los 14 países plataforma ${ }^{19}$ más importantes fueron, por orden de importancia: China (23.3\%), Japón (12.2\%, USA (9.8\%), Alemania (7.5\%), Corea del Sur (5.5\%), Brasil (4.6\%), India (4.4\%), España (3.2\%), México (2.9\%), Francia $(2.8 \%)$, Canadá $(2.5 \%)$, Tailandia (2.1\%), Reino Unido $(1.8 \%)$ y Turquía $(1.4 \%)$, cuya producción en conjunto representó $84 \%$ del total.

La reestructuración de las grandes empresas automotrices provocó la reestructuración del mapa productivo local y regional. Por ejemplo, en el caso de México las plantas ensambladoras llegan a instalarse atraídas no solo por la cercanía al mercado

${ }_{19}$ Por países plataforma entendemos los principales países productores, lugares en donde se están concentrando las principales empresas automotrices. 
estadounidense y aun por el tamaño del mercado interno, sino por el conjunto de facilidades que el país ofrece, en especial su fuerza de trabajo. En este proceso adquiere gran importancia el nuevo papel del Estado como coordinador, facilitador, impulsor de la inversión privada y garante del crecimiento en sus tres niveles de gobierno -federal, estatal o local-, por medio de políticas de infraestructura (ferrocarriles, carreteras, puertos, aeropuertos, telecomunicaciones, etc.), sistemas fiscales y de seguridad social, que incluyen salud, vivienda y educación, orientada esta última a la formación y capacitación de la fuerza de trabajo especializada (ingenieros, técnicos, diseñadores, investigadores, consultores y tecnólogos) que ha demostrado ser altamente competitiva en las destrezas y procesos involucrados en la línea de producción. Factores que coadyuvan a la conformación de complejos o clústers industriales, ${ }^{20}$ como lo observamos en localidades que se han convertido en polos de desarrollo: Ramos Arizpe y El Derramadero, en Coahuila; Toluca y Cuautitlán en el Estado de México; Puebla, Puebla; Chihuahua, Chihuahua; Hermosillo en Sonora; Aguascalientes, Aguascalientes; Cuernavaca en Morelos; Silao en Guanajuato; San Francisco de los Reyes en San Luis Potosí; Querétaro, Querétaro; El Salto en Jalisco; Ciudad Sahagún en Hidalgo; y Monterrey en Nuevo León.

\section{LA NUEVA DIVISIÓN TÉCNICA DEL TRABAJO}

El complejo proceso de reestructuración y descentralización productiva de la empresa automotriz a escala global tiene un gran impacto sobre la organización del proceso de trabajo al crear una nueva división técnica basada en la flexibilidad y la polivalencia, requisitos indispensables para que la empresa funcione con mayor eficiencia, lo que conlleva nuevas formas de la contradicción capital/trabajo.

${ }^{20}$ Para el capital nacional lo anterior ha representado una nueva opción para integrarse a cadenas productivas de carácter internacional. 
La distribución de la producciónde la ETA a escala mundial por medio de plantas de ensamble y proveedoras especializadas integradas a sus cadenas de producción y servicios conlleva el empleo de un gran número de trabajadores que directa o indirectamente forman parte de su mismo proceso productivo, pero que están sujetos a las más diversas formas de explotación, dependiendo de la fase del proceso y del tipo de planta en que se ubiquen. Las plantas proveedoras laboran para la ETA, y su vínculo con ella depende de la subrogación u outsourcing, si bien su relación contractual se rige de acuerdo con los términos de la proveedora.

La internacionalización de cadenas y subcadenas de valor es una condición para que el mercado de trabajo adquiera un carácter global, paso fundamental para la generalización de los nuevos métodos y técnicas de gestión del trabajo a escala mundial, con una fuerte tendencia a la estandarización de puestos y de tareas.

Esta nueva organización de la producción y del trabajo ha llevado al surgimiento de un nuevo tipo de trabajador sujeto a los nuevos métodos y técnicas de organización de la producción y el trabajo, con base en la flexibilidad, la polivalencia y el trabajo en equipo. La integración a las cadenas y subcadenas de producción, donde los procesos se encuentran estandarizados, conduce a la homologación mundial del trabajo, uniformando a los trabajadores automotrices, con independencia de si se ubican en países centrales o subdesarrollados.

La facilidad con que la ETA se reestructura (cierra, abre, moderniza, o deslocaliza plantas filiales y subsidiarias, así como puestos, fases o procesos de producción hacia otros países y regiones que le ofrecen las mejores expectativas de rentabilidad) se centra en la capacidad que tiene para asignar globalmente fases que conllevan tareas y actividades estandarizadas, lo que supone la movilidad global del trabajo, ya se trate de la relocalización de un puesto, una función, un departamento, una fase del proceso o una planta completa, lo que le permite que, en el ámbito mundial, la fuerza de trabajo, capacitada o de menor calificación y que reúna los requisitos para garantizar el funcionamiento eficiente de la cadena de producción, tienda a su homologación y, 
por lo mismo, la gran empresa pueda emplear fuerza de trabajo en diferentes países bajo los mismos criterios.

Hay que resaltar que cada reestructuración implica racionalización del proceso de producción y trabajo conforme a la flexibilidad, tanto salarial como numérica de los trabajadores que pasan por el pago de bonos por productividad e introducción de diferentes esquemas salariales, ${ }^{21}$ o el despido o contratación bajo nuevas condiciones de trabajo, ${ }^{22}$ dependiendo de si se trata de plantas de ensamble final o de proveedoras o subcontratistas, así como del país o región donde se encuentren; ello implica mayor competencia entre los trabajadores de las diversas regiones y países.

Lo anterior crea las condiciones para que se profundice la competencia intertrabajadores a escala mundial, regional o local y que la ETA defina una estrategia global, con una fuerte tendencia a la baja en salarios y prestaciones de su fuerza de trabajo. ${ }^{23}$ No se trata de desplazar personas sino de exportar trabajo, no trabajadores.

En ello han influido factores como el avance en los sistemas educativos de nivel medio y superior, en un cierto número de países en desarrollo que han contribuido a la formación de este nuevo trabajador capacitado, para dar respuesta a las exigencias de la nueva división técnica impuesta por los actuales sistemas de producción y trabajo. Así, se ha ampliado un mercado de fuerza de trabajo calificada y semicalificada que compite en cuanto a preparación, con los trabajadores de los países centrales. Lo anterior ha representado para la empresa automotriz un factor más para la relocalización de sus plantas hacia estos países, que pasan de fases intensivas en la utilización de fuerza de trabajo de

${ }^{21}$ Como son los casos de contratación a prueba o de primer empleo, pago por tiempo efectivo de trabajo (pago por hora), trabajo a distancia y la temporalidad en el empleo.

${ }^{22}$ En especial aquellas regiones que no cuentan con tradición industrial, los llamados green fields, tanto en países desarrollados, como subdesarrollados.

${ }^{23}$ Por ejemplo, durante la crisis automotriz de 2009, la General Motors obligó a los gobiernos y trabajadores de Inglaterra, Alemania, Suecia y España donde están instaladas sus plantas de la Opel, a competir y a aceptar el despido y la disminución en sus condiciones de vida y trabajo bajo la amenaza de cerrar o trasladar la producción o procesos de estas plantas a otros países. 
baja calificación, a otras más complejas en que es cada vez más importante el trabajo con mayor calificación.

En el caso de la industria automotriz, la maquila adquiriría nuevas características, sujeta a una organización técnica del trabajo más compleja. ${ }^{24}$ Puede afirmarse que el sistema de delegar ciertas fases del proceso productivo en un gran número de proveedores y subcontratistas, en los que prevalece la heterogeneidad, ha convertido al mundo en una gran maquila basada en la subrogación de procesos de producción y trabajo. Ello exacerba aún más la competencia entre los trabajadores en el mundo, teniendo como consecuencia una mayor fragmentación de la organización sujeto social trabajador, ya se trate de aquellos ubicados en plantas de ensamble final o de aquellos otros subcontratados mediante el outsourcing en empresas proveedoras, según la región o país donde se ubican. Lo anterior se agudiza por la existencia de un enorme ejército industrial de reserva que crece exponencialmente en el mundo. ${ }^{25}$

En la reorganización productiva y laboral de la ETA, se privilegia cada vez más el conocimiento, forma de capital intangible que se ha vuelto fundamental en la integración de los equipos de trabajo, definición de puestos y categorías, así como en la dis-

${ }^{24}$ A fin de bajar costos se comenzó por la delegación de servicios como comedores, limpieza y mantenimiento. Posteriormente, dentro de la división espacial y evolutiva del trabajo, las tareas más estandarizadas y menos cualificadas como la producción de arneses y asientos fue transferida a las plantas maquiladoras instaladas en la frontera con México y en el Sudeste Asiático cuya producción se orientaba al exterior. Con el tiempo las plantas maquiladoras adquirieron nuevo estatus, integradas a subcadenas de valor como plantas maquiladoras suministradoras de autopartes para proveedoras especializadas de mayor nivel, cuya producción está sujeta a las condiciones que imponen las plantas de ensamblado final en el ensamblado de módulos completos ubicados en el interior o exterior del país. Por ello, es necesario una nueva definición del concepto de maquila.

${ }^{25} \mathrm{~A}$ fin de generar un crecimiento sostenible y mantener la cohesión social, el mundo enfrenta los desafíos urgentes de crear 600 millones de empleos productivos, así como de proporcionar trabajo decente para los aproximadamente 900 millones de trabajadores que viven con sus familias por debajo de la línea de la pobreza de dos dólares al día. El escenario base de la Organización Internacional del Trabajo (Оіт) prevé que el número de desempleados en 2012 sea de 200 millones, de los cuales 27 millones se achacan directamente a la crisis a partir de 2007: Según esta misma fuente, 74.8 millones de jóvenes estaban desempleados en 2011 [OIT, 2012]. 
tribución de tareas que hay que efectuar en cada nivel; proceso

de gran complejidad en la medida que se requiere la gestión de la fuerza de trabajo en el ámbito global.

El objetivo de la ETA por la gestión global del trabajo es lograr la mayor uniformidad del mismo, homologando criterios de organización en producción y trabajo en sus diferentes plantas filiales, subsidiarias y proveedoras, y adaptándolos a los respectivos entornos locales. Así, se potencia un proceso de hibridación adaptando la identidad y cultura global corporativa a la idiosincrasia cultural local o regional, como una forma de transferir experiencias y conocimientos. ${ }^{26}$

Parte fundamental de la gestión del trabajo se centra en la búsqueda de personal adecuado para integrarlo a su red de producción y servicios -internacional, regional o local. En un primer nivel se trata de personal altamente calificado -particularmente los llamados talentos-, para ser ubicado en las áreas de investigación y desarrollo o en los campos de dirección, planeación o administración en general. ${ }^{27}$

En un segundo nivel se encuentra el personal técnico, local o extranjero, ubicado en las diferentes fases de la producción, como son los ingenieros y trabajadores calificados y polivalentes que gozan de cierta estabilidad, sujetos a una capacitación sistemática, indispensable para el buen funcionamiento de las líneas de producción y servicios. ${ }^{28}$ Se ubican, sobre todo, en las plantas de

${ }^{26}$ Coordinar hábitos organizacionales de los participantes con diferentes culturas corporativas puede ser una tarea difícil, dado que en cada país hay reglas no escritas o códigos de conducta informales que resultan en restricciones de los accesos a una red.

${ }^{27}$ Estos trabajadores son fundamentales para llevar a cabo el proceso de hibridación, tienen un amplio conocimiento tanto de la estrategia global de la empresa como de la situación local imperante, lo que les permite tomar decisiones. Por medio de internet, están en comunicación permanente con la matriz. Un ejemplo es el ingeniero Ernesto M. Hernández, actual director de GM de México, mexicano formado en el Instituto Politécnico Nacional y en el Instituto Tecnológico Autónomo de México (ITAM), y que cuenta con una larga trayectoria en la empresa.

${ }^{28}$ En el caso de los servicios se ha dado un fenómeno de especialización de trabajadores técnicos en ciertos países y ramas específicas, como es el caso de la India, donde se han desarrollado sistemas de software vinculados al funcionamiento eficiente 
ensamble final y en proveedoras globales de primer nivel, que operan con tecnología de punta y donde el trabajo intelectual tiene tendencia a predominar. En ello ha influido el avance en la formación educativa de nivel medio y superior tanto en países desarrollados como subdesarrollados, ${ }^{29}$ lo que ha conducido a una cierta universalización y homologación de habilidades que permite una mayor externalización de la formación de muchos trabajadores. ${ }^{30}$

En un tercer nivel se encuentra el mayor número de trabajadores que son funcionales al proceso, caracterizados por una menor calificación y ubicados en fases más intensivas de explotación de la fuerza de trabajo, ya se trate de trabajadores que directamente laboran para la ETA o de trabajadores subrogados mediante el outsourcing en plantas proveedoras de diverso nivel, donde los bajos costos laborales constituyen uno de los principales factores que determinan la relocalización de este tipo de plantas. Este escalón de la cadena de producción se caracteriza por la temporalidad en el empleo, menores salarios y mínima seguridad social.

Dentro de la estrategia global de gestión del trabajo está también la contratación, mediante el outsourcing, de un número cada vez mayor de trabajadores del sector servicio, ubicados en las más diversas áreas, como son finanzas, logística, marketing, comercialización y servicios diversos, cuyo trabajo es fundamental

de la ETA.

${ }^{29}$ El valor en el mercado de una buena educación toma fuerza en la década de los ochenta cuando las ETA, a escala global, empiezan a demandar más y más habilidades técnicas a sus trabajadores, fuese cual fuese el tipo de trabajo que desempeñasen. De esta manera se produce un desplazamiento en la estructura de la demanda laboral a trabajadores con niveles educativos medio y superior que diversos países subdesarrollados ofrecen con salarios menores. En cualquier caso, a partir de 1987 los salarios de los trabajadores de los países desarrollados, ajustados a la inflación, empezaron a disminuir, unidos al declive de los sindicatos de estos países.

${ }^{30}$ Por ejemplo, en el caso de México, el impulso a universidades y escuelas tecnológicas de nivel medio y superior, no solo en el Distrito Federal, sino en entidades como Guanajuato, Coahuila, Sonora, Puebla, Nuevo León, Estado de México, Querétaro y Aguascalientes, donde se han establecido plantas de ensamblado final con sus respectivas proveedoras. 
para el funcionamiento eficiente de la cadena de producción. Estos trabajadores también están sujetos a las mismas exigencias de organización del trabajo que impone la gran empresa al formar parte de la misma cadena de producción y servicios; sus circunstancias de vida y trabajo son desiguales, dependiendo de sus condiciones de subcontratación y de la fase o sector en que se ubican.

\section{CONCLUSIONES}

Vivimos una fase de reestructuración del capital con base en la flexibilidad y caracterizado por: 1) acelerado avance tecnológico; 2) utilización de nuevas técnicas y formas de organización de la producción y del trabajo; 3 ) fragmentación y subrogación de fases del proceso productivo a partir del outsourcing; 4) integración en red de cadenas y subcadenas internacionales de producción; 5) relocalización del proceso de producción con la consecuente modificación del mapa productivo; 6) incremento en el comercio internacional y regional, particularmente interfirma e intrafirma, y 7) nueva división técnica del trabajo y un nuevo tipo de trabajador. Todo eso conlleva un nuevo papel del Estado.

Al caracterizarse el prototipo de organización de la ETA, imbuida en una red de redes que integra filiales y proveedores a escala mundial, se reconoce la estratificación de una fuerza de trabajo sujeta a la productividad. En general los trabajadores formales de las plantas ensambladoras tienen mayor estabilidad en el empleo, mejores prestaciones y gozan de una capacitación interna sistemática tanto formal como informal, pero con disposición a reducir su número. ${ }^{31}$ Los trabajadores ubicados en proveedoras tienden a ser un gran número que se ve sometido al outsourcing y la subrogación, tiempo parcial, contratos temporales, salarios

${ }^{31}$ Algunos trabajadores tienen incluso la posibilidad de acceder a oportunidades de promoción, aunque en una era de redes de producción flexible, un movimiento ascendente a menudo significa un cambio de una empresa a otra. 
bajos, beneficios extrasalariales casi nulos. Por consiguiente, se acelera la polarización de los salarios y su precarización ampliando la desigualdad social; así la estructura de la ETA va imponiendo un mayor control al conjunto de jerarquías y segmentos del mercado laboral de esta industria, tanto en su núcleo como al conjunto de su red en el mundo.

En el fondo, mediante esta reestructuración la gran empresa intenta contrarrestar la tendencia decreciente de la tasa de ganancia, globalizando la producción y socializando pérdidas y ganancias a lo largo de la cadena. Esto se refleja en que, por un lado, el número de trabajadores contratados directamente por la empresa disminuye, en tanto crece el número de trabajadores subcontratados por medio de proveedoras especializadas que se caracterizan por su heterogeneidad en la composición orgánica del capital y que son empresas independientes en lo formal, pero que al estar directamente integradas a la cadena internacional de producción forman parte del mismo sistema productivo. ${ }^{32}$

Todo lo anterior hace que, a escala mundial, el cálculo sobre el número de trabajadores que dependen de la industria automotriz englobe a millones de estos, los cuales, de una u otra forma, agregan o contribuyen a la realización del valor mediante formas de explotación de lo más diverso. De allí que la productividad no pueda ya medirse solo dividiendo el número de vehículos producidos por la ensambladora final entre el número de trabajadores que directamente laboran en ella en un determinado país; se trata de un automotor cuyos componentes y partes varían según el grado de complejidad, producto del esfuerzo que realizan trabajadores de diferentes países y regiones -desarrollados y subdesarrollados-, sujetos a diferentes condiciones de vida y trabajo, y esos componentes llegan a la línea de montaje bajo el sis-

32 De acuerdo a cálculos del Instituto Nacional de Estadística y Geografía (INEGI), el total de trabajadores en cada empresa ensambladora debe multiplicarse por tres o cuatro para estimar el número de trabajadores de las plantas proveedoras de autopartes. Consideramos que a esta cantidad se le debe agregar otro contingente de trabajadores ubicados en diversos sectores de servicios, así como de ramas económicas ligadas a esta industria y que directa o indirectamente contribuyen a su realización. 
tema $\mathrm{JIT}^{33}$. Se trata de una producción multipaíses en la que es necesario tomar en cuenta los miles de trabajadores que, directa o indirectamente, laboran en una multitud de empresas proveedoras especializadas en las más diversas áreas de producción y servicios y que forman parte del mismo sistema productivo global, lo que hace que el tiempo socialmente necesario para producir un vehículo sea cada vez menor.

\section{REFERENCIAS}

Antunes, R. [2003], ¿Adiós al trabajo?, Buenos Aires, Herramienta, $184 \mathrm{pp}$.

[2005], Los sentidos del trabajo, Buenos Aires, Herramienta, $248 \mathrm{pp}$.

Arza, V. [2011], "El Mercosur como plataforma de exportación para la industria automotriz", en Revista de la CEPAL, 103: 139164, abril.

Batres S., R. y L. García-Calderón [2006], Competitividad y desarrollo internacional. Cómo lograrlo en México, México, Mc Graw Hill, 329 pp.

Bennett, H. [1997], La empresa que viene, España, Paidós, 337 pp. Bonache, J. [2010], "El valor estratégico de la movilidad global de puestos, personas y conocimientos en las multinacionales", en Universia Business Review, tercer trimestre, pp. 14-29.

__ y L. Stirpe [2011], "La planificación de los recursos humanos en las multinacionales", en ICE. La nueva geografía de la internacionalización, 859, 73-82, marzo-abril.

Coriat, B. [1992], Pensar al revés, trabajo y organización en la empresa japonesa, México, Siglo XXI, 163 pp.

Durán L., J. E., y V. Ventura-Dias [2003], Comercio intrafirma: concepto, alcance y magnitud, Santiago de Chile, CEPAL, Serie

33 Se calcula que en México 40\% de los componentes de un vehículo provienen del exterior. 
Comercio Internacional, 44, diciembre, 81 pp.

Gutiérrez A., A. [2006], La empresa trasnacional en la reestructuración del capital, la producción y el trabajo, México, IIEc y FE-UNAM/Casa Juan Pablos, 290 pp.

$[\mathrm{s} / \mathrm{f}]$, "La empresa trasnacional automotriz en la reestructuración productiva y laboral de México", proyecto de tesis en proceso.

[2011], "La reestructuración de la empresa trasnacional y sus implicaciones en los cambios estructurales de la producción y el trabajo", Seminario Internacional de Teoría del Desarrollo: Crisis estructural y alternativas de desarrollo en México, IIEc-UnAm, en prensa.

Harvey, D. [2004], La condición de posmodernidad. Investigación sobre los orígenes del cambio cultural, Buenos Aires, Amorrortu Editores, $401 \mathrm{pp}$.

Juárez, H. [2011], "La crisis de la industria del automóvil y el fin de una época”, Isabel Rueda Peiro, La industria automotriz en época de crisis. Efectos económicos, financieros y sociales, IIEc y FCA-UNAM, pp. 67-121.

Minian, I. [2012], "Empresas trasnacionales y segmentación internacional de la producción”, Isaac Minian y Elisa Dávalos (coords.), Redes globales y regionales de producción, México, IIEc y Cisan-UnAM, pp. 53-92.

Ohno, T. [1991], "El sistema de producción Toyota. Más allá de la producción a gran escala", UNCTAD, World Investment Report 2011, Barcelona, Ediciones Gestión 2000, 180 pp.

Organización Internacional del Trabajo [2012], Tendencias mundiales del empleo 2012. El desafío de la recuperación del empleo, Suiza, Oficina Internacional del Trabajo, Departamento de Comunicación y de la Información Pública, <http://www. ilo.org>. 


\section{Capítulo 3 \\ LA PARTICIPACIÓN DEL ESTADO \\ EN EL DESARROLLO Y LA COMPETITIVIDAD \\ DE LA INDUSTRIA AUTOMOTRIZ EN MÉXICO}

Luz María Jiménez Ramírez*"

\section{INTRODUCCIÓN}

El presente capítulo analiza los elementos que contribuyeron a fortalecer el desarrollo de la industria automotriz en México. Se observan las políticas públicas que el gobierno mexicano aplicó para el desarrollo de esta industria en el tránsito de los dos patrones de acumulación: la industrialización sustitutiva de importaciones (ISI) y la industrialización orientada a las exportaciones (IOE). Aquí se profundiza en el estudio de los diversos decretos y apoyos al consumo de automóviles hasta el Tratado de Libre Comercio de América del Norte (TLCAN), que explican el proceso de desarrollo de la industria automotriz y su importancia para la industria manufacturera en México.

Parto de la hipótesis de que la industria automotriz en territorio nacional ha respondido esencialmente a las necesidades de las grandes empresas extranjeras; sin embargo, la derrama que

* Participante del proyecto de investigación PAPIIT IN305610. Correo electrónico: $<$ jluzmaria@gmail.com>. 
ha permitido su instalación en algunas regiones del país ha traído consigo la creación de empleo y la entrada de divisas, convirtiéndose en el sector exportador por antonomasia, aunque, por otro lado, no ha creado los suficientes apalancamientos tecnológicos como para desarrollar una industria nacional que genere el crecimiento y empleo que necesita la economía nacional. Se deben crear las oportunidades para que se dé un desarrollo tecnológico nacional en la industria, particularmente en el sector de autopartes, por lo que el apoyo gubernamental por medio de inversiones, debe ir encaminado hacia esos rumbos.

\section{IMPORTANCIA DEL TEMA}

El sector automotriz en México ha sido históricamente uno de los más dinámicos dentro de la industria manufacturera y no lo ha dejado de ser hasta la actualidad; por ejemplo, en el año 2003, el valor de la producción era de 410242312 (miles de pesos) y representaba $5.7 \%$ del producto interno bruto (PIB) y $30.5 \%$ del total de la industria manufacturera; ocupaba a 495476 trabajadores. En 2008, la producción ya era de 690039493 (miles de pesos) representando $5.8 \%$ del PIB y $14.15 \%$ de la producción bruta total de la industria manufacturera, con un personal ocupado total de 457517 trabajadores, representando $9.8 \%$ del personal ocupado de la industria manufacturera [INEGI, 2012]. Si bien se nota un estancamiento en el personal ocupado para este periodo, la industria automotriz no deja de tener un efecto de arrastre hacia otros sectores económicos, por lo que el nivel de empleo global que genera se encuentra en alrededor de un millón de empleos [Presidencia de la República, 2006].

\section{EL ESTADO MEXICANO Y LA \\ INDUSTRIA AUTOMOTRIZ}

La participación del Estado en el fortalecimiento de la producción, distribución y consumo de automóviles ha sido un factor 
esencial para entender la evolución de producción industrial desde principios del siglo xx hasta nuestros días. Las políticas públicas para el fomento de la industria automotriz han sido fundamentales en el establecimiento de las condiciones generales de la producción y la regulación de las contradicciones del mercado y de los trabajadores, para su buen funcionamiento.

En la primera fase de la acumulación capitalista fue muy clara su participación por medio del proteccionismo, fomento a la empresa privada y participación directa para crear las mejores condiciones para el proceso de industrialización, como generador de demanda por la vía de la masa salarial con la creación de empleos directos e indirectos en la construcción de infraestructura, y como el creador de las empresas estratégicas que el capital privado requería. Le otorgó al capital extranjero las condiciones necesarias para el buen funcionamiento de la fuerza de trabajo, en un entorno de estabilidad social, con una política pública que propició altas tasas de crecimiento económico y grandes márgenes de ganancia al sector automotriz. ${ }^{1}$

En la fase neoliberal de globalización económica, el Estado estableció una política pública encaminada a fortalecer los mecanismos del mercado, como forma más eficiente de funcionamiento para el capital. Se transformó el modelo de industrialización sustitutivo de importaciones por otro que favorece las exportaciones en un mercado globalizado. Los teóricos de este modelo señalan que lo mejor para el sistema capitalista es la organización de la actividad económica mediante empresas privadas que operen en un mercado libre y que, al descentralizar el poder económico, el sistema de mercado compensará cualquier concentración de poder político. El Estado mexicano considera a la industria automotriz como un sector estratégico, por lo que ha procurado mantenerla libre de restricciones.

No podríamos entender la complejidad del sector automotriz sin incluir el análisis de la participación del Estado en él, pues según Dombois, citado por Carrillo y García [1987: 305]:

${ }^{1}$ El desarrollo de estos aspectos se encuentra en el primer capítulo de este libro. 
... los grados de integración nacional que adoptan las empresas extranjeras de la rama automovilística y las políticas de producción para el mercado externo están definidas por obligaciones que marca el gobierno mexicano, a las cuales las empresas se sujetan con tal de conservar el control del mercado interno y de seguir incrementando las ventajas económicas.

La industria automotriz se ha desarrollado de diferentes maneras en el tiempo y alrededor del mundo. Sin embargo, hay elementos y condiciones generales que deben existir para que funcione exitosamente, y ese es el caso de la organización del trabajo y el establecimiento de las nuevas técnicas en la fábrica para la producción, como el taylorismo-fordismo ${ }^{2}$ o el toyotismo, ${ }^{3}$ que son elementos indispensables en la producción de automóviles y que funcionaron durante toda la etapa del Estado intervencionista y ahora neoliberal con buenos resultados para la acumulación durante un largo periodo.

Como he mencionado el desarrollo de la industria automotriz en México se ha visto impulsado por dos modelos económicos: la industrialización por sustitución de importaciones (ISI) y la industrialización orientada a las exportaciones (IOE). Cabe mencionar que estos modelos también fueron aplicados en toda la región de América Latina, y que son comunes a los países sub-

${ }^{2}$ Es la producción de vehículos basada en los tiempos y movimientos, división social y técnica del trabajo, la cadena de montaje, la estandarización e intercambiabilidad de las piezas, y producción en masa. A esto habría que añadir las aportaciones de Alfred Pritchard Sloan, Jr., el cual agregó al sistema de Taylor y Ford la invención de un sistema de gestión de una empresa multidimensional, en el que se concentraba y analizaba toda la información concerniente a la empresa. Esto permitía tener el control de los diversos productos que creaba la empresa, además de desarrollar esquemas de financiamiento para la obtención de un automóvil por parte de los consumidores [Neffa, 1999].

${ }^{3}$ Esta forma de organización del trabajo considera, entre otras aportaciones más concernientes a la ingeniería, la alta calificación de los trabajadores como generadora de mayores ganancias; supervisión sistemática de los errores de producción; just in time, solo fabrica lo que se requería fabricar mediante el sistema kanban, que se refiere a un sistema de tarjetas en el que se especifica la cantidad de productos que debe suministrar un proceso dado para el siguiente proceso, esto en función de la demanda; kaizen o mejora continua; y trabajo en equipo [Womack, Jones y Roos, 1993]. 
desarrollados incluyendo el sur de Asia. Es importante explicar ambos modelos para entender su impacto en el desarrollo de la industria automotriz en México.

\section{EL DESARROLLO INDUSTRIAL}

Y EL SECTOR AUTOMOTRIZ

La producción industrial con el modelo de acumulación intervencionista estuvo sustentada en la ISI, mediante un programa estatal de impulso a las industrias claves, particularmente de bienes finales de consumo directo e incluso intermedio y una proyección para la producción de bienes de capital. Se buscaba mejorar la eficiencia productiva y diversificar las exportaciones, a la vez que se desarrollaba el mercado interno para fortalecer la producción nacional. La política proteccionista para la industria automotriz fue esencial para el desarrollo del mercado interno, pues se abandonaron las prácticas del laissez faire para emprender acciones de protección dirigidas por el Estado como un actor fundamental para el proceso de acumulación, aunque con diversos matices específicos para la industria automotriz. Era necesario un alto grado de desarrollo de infraestructura, así como de otras áreas del sector industrial para establecer una industria automotriz nacional y que se pudieran realizar las etapas de su proceso de producción. Es así como el Estado mexicano tuvo que recurrir al capital extranjero para tener una industria nacional del automóvil.

\section{La INDUSTRIA AUTOMOTRIZ EN MÉXICO}

La industria automotriz mexicana comienza operaciones en 1925, con la instalación de la primera planta armadora de automóviles, Ford; anteriormente se importaban automóviles terminados y juegos completos de partes y piezas de automóviles para ser montadas posteriormente. Este sistema recibía el nombre de completely knocked down (CKD). La producción de autopartes no 
existía, y la mano de obra ocupada en la industria solo realizaba el armado de los conjuntos mecánicos y de las carrocerías. Diez años después, en 1935, se instaló la General Motors en la Ciudad de México; en 1938 llega Automex, que más tarde se convertiría en Chrysler. El mercado automotriz estuvo dominado por las empresas estadounidenses durante más de 35 años, aunque esta situación cambió a principios de los sesenta, cuando la empresa alemana Volkswagen, la francesa Renault y la japonesa Nissan llegaron a México para competirles, de tal manera que en la década de los sesenta la composición del mercado de automóviles ya era la siguiente: “... 71\% era de los europeos, el $27.8 \%$ de los norteamericanos y el 1.2\% para los japoneses" [Carrillo y García, 1987: 307]. Desde sus inicios la industria se ha concentrado regionalmente en el centro y el norte de la República, principalmente en Monterrey, Puebla, Cuernavaca, Saltillo, Distrito Federal y Estado de México.

En la segunda fase del modelo de sustitución de importaciones, la industria automotriz estaba integrada por tres grandes sectores: terminal, auxiliar y distributivo. El sector terminal se encargaba de la fabricación y ensamble de vehículos para el mercado interno y el externo con la producción de automóviles, camiones, tractocamiones y autobuses integrales. "El sector terminal ocupa en 1975 a 40939 personas que perciben un salario anual de 3620 millones de pesos; el valor de la producción es de 26533 millones, y las ventas sumaron 19550 millones en 1974" (Aguilar, 1982): 28). El sector auxiliar (que actualmente llamamos de autopartes) abastecía al sector terminal, a las exportaciones y al consumidor en general; estaba integrado por 560 empresas, de las cuales 280 producían exclusivamente autopartes y otro tipo de productos para distintas ramas; empleaba a 70000 personas; el valor de la producción era de 12500 millones y las ventas fueron de 18000 millones de pesos, y de estas empresas solo 37 eran las más fuertes en tecnología y administración. El sector distributivo era un grupo de empresas que comercializaban los productos automotrices, y en 1975 constaba de 1049 centros distribuidores dispersos por toda la República mexicana, entre 
los que se encuentran: Chrysler, Ford, General Motors, Internacional Harvester, Nissan Mexicana, Vehículos Automotores Mexicanos, Volkswagen y Diesel Nacional (Dina Renault) [Aguilar, 1982: 28].

\section{EL PROTECCIONISMO ECONÓMICO Y LA INDUSTRIA AUTOMOTRIZ}

El Estado se convirtió en el gran promotor del crecimiento económico por medio de la protección de la naciente industria y del mercado interno, con la implementación de altas y crecientes tarifas arancelarias, derechos de importación, tipos de cambio múltiples, subsidios e incentivos para promover las importaciones de bienes intermedios y de capital. Además, se siguieron políticas de comercialización y financiamiento que, entre otros aspectos, fueron utilizados para inducir y orientar la expansión del sector público que demandaba la industrialización por sustitución de importaciones [Fajnzylber, 1983: 19]. El modelo de la IsI fue una estrategia de desarrollo económico y de industrialización del país que comenzó en la década de los cuarenta y concluyó en los ochenta.

Este modelo se desarrolló en tres etapas:

La primera de estas se identifica con la sustitución de importaciones de bienes de consumo, y en términos generales abarca el periodo de mediados de los años cuarenta hasta finales de la década de los cincuenta. La segunda etapa, de creciente sustitución de bienes de capital e intermedios, que comprende hasta fines de los sesenta, y la tercera etapa abarca desde 1970 hasta el presente [Trejo, 1987: 17].

La injerencia del Estado en el desarrollo de la industria automotriz dentro del modelo de sustitución de importaciones se vio reflejada en la expedición de diversos reglamentos, con restricciones a la importación de vehículos y montaje, así como con cuotas de ensamble establecidas para reducir modelos y marcas, que de ser 75 al inicio de la IsI pasaron a ser 24 a mediados de 
ella. En 1947 los productores deciden organizarse y crean la Asociación Mexicana de la Industria Automotriz, que se encarga de negociar con el Estado las demandas de los empresarios. En esta asociación solo se encuentran incorporadas las empresas terminales, y se definen con el gobierno distintos reglamentos como un intento de lograr la integración nacional de la industria y de tener un mayor control desde la producción hasta el número de trabajadores; sin embargo, el impacto de esa reglamentación no reduce de manera significativa el número de productos importados por las empresas establecidas, por lo que manifestaban su inconformidad debido al alto déficit en la balanza comercial.

En 1962 se promulgó el Decreto de Apoyo a la Industria Automotriz, siendo dentro de la ISI el más representativo de los esfuerzos que el gobierno emprendió para desarrollar y fortalecer una industria automotriz nacional. En septiembre de 1962 se prohíbe la importación de motores para automóviles y camiones, así como de conjuntos mecánicos armados para su uso o ensamble [DOF, 1962].

Con este decreto se logró modificar drásticamente la dinámica que venía presentando la industria. En realidad el decreto buscaba reducir las importaciones de vehículos totalmente armados, así como una mayor integración de la industria. Se pretendía desarrollar “... una producción nacional que va desde insumos intermedios y motores hasta la fabricación de vehículos terminados" [Carrillo y García, 1987: 309]. El decreto establecía que $60 \%$ de los componentes de los vehículos debían ser de origen nacional, por lo que produjo un fuerte impacto en la importación de motores, las baterías y los neumáticos.

El auge de la industria se debió en gran medida a las políticas establecidas por el gobierno, llamadas del desarrollo estabilizador que significaron elevados niveles de crecimiento combinados con una estabilidad de los precios:

... durante veinte años entre 1935 y 1953 , el producto interno bruto por persona, en términos reales, creció en promedio a una tasa anual de más de $3 \%$. Pero ese crecimiento económico estuvo acompañado, 
en algunos años, por presiones inflacionarias. En cambio, de 1954 a 1970, el crecimiento promedio anual del producto interno bruto por persona, que fue de $3.4 \%$, se logró con estabilidad de los precios internos. De ahí su nombre: desarrollo estabilizador" [Tello, 2010: 67].

Una consecuencia para el mercado interno fue que expandió el nivel de ventas en 1960, que era de 32152 unidades; ya para 1975 pasó a 231108 unidades. También aumentó la producción de autos, camiones y autobuses, de 49807 a 360678 unidades en el mismo periodo, de modo que el crecimiento fue de $7.24 \%$ anual. El empleo también se vio beneficiado, pues pasó de 7072 trabajadores en 1960 a 41635 en 1975, un incremento de $5.8 \%$ anual; $32 \%$ del empleo estaba concentrado en algunas decenas de empresas pequeñas y medianas de la industria de autopartes, y más de $60 \%$ en la industria terminal. Para el año 1975 alrededor de $80 \%$ de los materiales de montaje eran de origen nacional [Carrillo y García, 1987: 309]. Estas condiciones de expansión del sector automotriz propician la exportación de autopartes; para el año de 1975, de la producción que se destinaba al mercado externo, 66\% era de partes y piezas, y comenzaba ya la exportación de motores. Estos requerimientos posicionaron a la industria automotriz en el segundo lugar del mercado de exportaciones, después de las exportaciones petroleras.

La reglamentación impulsada por el Estado consolidó y promovió el sector de autopartes; se fortalecieron las relaciones de fuerza entre el grupo de los capitalistas, conformado por los monopolistas extranjeros, capital estatal y capital nacional privado (se dio la incorporación de capitales nacionales privados); se consolidó el desarrollo monopolista de la rama en el sector terminal; se redujo drásticamente el número de empresas que controlaban el mercado interno, y de las 19 existentes solo quedaron siete al frente de la industria; se eliminaron empresas importadoras; se crearon nuevas plantas; se favoreció una integración vertical; se amplió la base productiva de la industria, y disminuyó el número de tipos, marcas y modelos. 
Con el decreto del 20 de junio de 1977 para el Fomento de la Industria Automotriz [DOF, 1977], se incrementaron los niveles de exportación y tomó importancia la industria maquiladora en el norte del país. Con este cambio se modifica sustancialmente la estructura de la industria, de la siguiente manera: industria terminal (producción para el mercado interno); industria de las grandes empresas de autopartes y de vehículos para la exportación; industria de autopartes que abastece a las dos anteriores, y la industria maquiladora de autopartes para la exportación.

Los objetivos más importantes del decreto automotriz de 1977 fueron:

- Reestructuración de la industria.

- Aumentar a $60 \%$ la integración nacional hasta llegar a 75 por ciento.

- Subsidiar las exportaciones del sector.

- Exoneración de los derechos de importación.

- Del monto de los impuestos a pagar, deducir el monto por capacitación de los trabajadores.

- Lograr el equilibrio de la balanza de pagos.

Estos cambios permitieron al sector crecer a una tasa de $7.9 \%$, y para 1981 se elevó a $21.7 \%$. En 1977 se produjeron 280 813 unidades y en 1981 eran ya 596 518; el personal ocupado pasó de 37830 a 66 700. Para incentivar aún más la orientación hacia las exportaciones del sector, el gobierno mexicano expide en 1983 el decreto para la Racionalización de la Industria Automotriz [DOF, 1983], con el que se busca reducir el número de modelos en la industria, se inhibe la producción de motores de ocho cilindros, y a la fabricación de nuevos modelos para la exportación se les quitó la obligación de un porcentaje de integración nacional, siempre y cuando el nivel de exportación fuera de 50 por ciento.

La introducción de las maquiladoras pone a la industria automotriz mexicana ante una nueva forma de producción muy particular, ya que cumple con una función muy específica hacia 
dentro de la producción internacional de automóviles. La industria sufrió una transformación radical a partir del comienzo de la producción para intensificar las exportaciones; se feminiza el sector y se adoptan las prácticas del sistema de producción japonés just in time.

Existía una serie de obligaciones que las empresas debían cumplir: Volkswagen, Dina y Nissan debían producir autos pequeños, y las empresas estadounidenses, modelos grandes; tenían que fijar precios máximos a los vehículos; también estaban obligadas a usar componentes nacionales, significaba costos altos y menor calidad, pero el mercado interno les pertenecía completamente, así que las ventajas de acatar las obligaciones eran mayores que los detrimentos en la producción; en comparación con Estados Unidos, la tasa de ganancia era mayor en México; por ejemplo, para Ford el costo de cada motor, con el transporte incluido, en el año de 1980, era de 1233 dólares en Japón, 1325 en Estados Unidos y 821 en México, esto arrojaba una tasa de ganancia de 0 , 1 y $29 \%$, respectivamente [Carrillo y García, 1987: 315].

\section{INSTITUCIONES REGULADORAS}

DE LA INDUSTRIA AUTOMOTRIZ

Entre los organismos estatales para supervisar las actividades de la industria estaba la Comisión Intersecretarial de la Industria Automotriz, que integraba a tres representantes de la Secretaría de Comercio, tres representantes de la Secretaría de Hacienda, un presidente (el subsecretario de industria de la Secretaría de Comercio), y un secretario, que era el director general de Estudios Hacendarios y Asuntos Internacionales de Hacienda.

Dentro de la Secretaría de Patrimonio y Fomento Industrial, estaba la Subdirección de la Industria Automotriz y del Transporte, que fungía como presidencia de la comisión fundada, y tenía carácter técnico y consultivo del Ejecutivo federal, sobre todo en lo relacionado con la industria y el comercio automovilístico. Las empresas de producción auxiliar (autopartes) se integraron en 
tres grupos por su gran diferencia: Asociación Nacional de Fabricantes de Productos Automotrices, Sección de Fabricantes de Autopartes de la Cámara Nacional de la Industria de la Transformación y la Asociación Mexicana de Productores de Partes Automotrices [Aguilar, 1982].

Posteriormente, el Estado amplió los organismos públicos para llevar a cabo la política industrial para este sector, entre los que se encontraban: la Subdirección de la Industria Automotriz de la Secretaría del Patrimonio Nacional y Fomento Industrial, para cuidar que se respetaran los acuerdos en política industrial y comercialización interior y exterior; la Dirección y Subdirección General de Estudios Hacendarios y Asuntos Internacionales de la Secretaría de Hacienda y Crédito Público, encargada de observar los acuerdos en importaciones, exportaciones y política fiscal; la Secretaría de Relaciones Exteriores, que vigilaba a los tenedores de las acciones de cada empresa (registrando la posesión de la empresa ya sea por nacionales o extranjeros), y la Comisión Intersecretarial de la Industria Automotriz, en la que actuaban la Secretaría de Comercio y la Secretaría de Hacienda, y que funcionaba como órgano de consulta para los principales actores de la industria, como productores, distribuidores y exportadores. Actualmente el organismo federal que se encarga de las regulaciones al sector es la Secretaría de Economía [Aguilar, 1982].

\section{CRISIS DE LA ISI EN LA INDUSTRIA AUTOMOTRIZ}

Durante el modelo de sustitución de importaciones se lograron grandes cambios en la industria en general. Se alcanzó un crecimiento sostenido y una estabilidad política y social precisa. Sin embargo, no se pudieron sentar las bases que propiciaran una industria fuerte y consolidada que no dependiera del exterior en la generación de bienes de capital y de desarrollo tecnológico. El endeudamiento público y privado había llegado a su límite y se había profundizado por los subsidios a un número reducido de actores económicos públicos y privados en ciertos sectores 
productivos, por lo que se privilegiaba la acumulación; sin embargo, llegó el momento del colapso en la década de los ochenta y se hizo insostenible ya la continuación de la IsI: "Es cierto que no se lograron objetivos de eficiencia, equidad, empleo o equilibrio regional. Ello se debe a que nunca se plantearon sino de manera muy general y nunca se llegó a especificar la relación entre el crecimiento industrial y dichas metas" [Trejo, 1987: 37].

La sustitución de importaciones en bienes de consumo final había llegado al tope, por lo que el paso siguiente era la sustitución de bienes de capital y duraderos, etapa de desarrollo que la industria no podía llevar a cabo, pues no tenía la suficiente madurez y tampoco capacidad para generar los recursos que se requerían para invertir en bienes de capital. Según Huberto Juárez, el balance final del impacto de la ISI en la industria automotriz es que no proporcionó los elementos necesarios para crear una industria verdaderamente nacional:

De manera que en esta primera gran fase de la industria del automóvil en México, los resultados fueron totalmente magros para efectos de los propósitos sociales vinculados con el desarrollo de cadenas productivas nacionales de producción para exportación y consolidación de una industria mexicana especializada [Juárez, Lara y Bueno, 2005: 120].

Las consecuencias inmediatas de la crisis de la ISI, a principios de la década de los ochenta, es que la producción de automóviles disminuyó en más de 20\% y 10\% de los trabajadores perdió su empleo.

\section{LA APERTURA ECONÓMICA}

La transformación del modelo intervencionista por la corriente neoliberal planteó el retiro del Estado en lo referente a la inversión productiva y la disminución de los gastos destinados a los aspectos sociales, así como una política de estabilización entre salarios y productividad, conocida como flexibilidad del trabajo. 
Esta política pretendía la disminución de los costos laborales y el aumento de la productividad, por lo cual se lanzó una ofensiva de gran envergadura del capital contra el trabajo, para contrarrestar la caída de los beneficios mediante la modificación de los procesos productivos, la organización del trabajo y profundos cambios en las relaciones laborales. Se establece la flexibilidad laboral, el desmantelamiento de la seguridad social y de los sistemas de bienestar, la racionalización de los procesos de trabajo y la utilización de políticas de abatimiento de costos, como el recorte de personal, la subcontratación o la precarización del trabajo.

La política industrial se enfrenta a un crecimiento limitado y los grupos económicos internacionales más poderosos intensificaron sus presiones para que se liberara el mercado interno, a pesar de que la política de industrialización estuvo centrada en la liberalización del mercado interno y se derribaron las barreras que impedían la circulación de mercancías a escala mundial, al tiempo que los países desarrollados aplicaron nuevas formas de protección de sus propios mercados internos. De igual modo, esos grupos económicos impusieron una reducción de la acción del Estado al mínimo y se establecieron políticas fiscales y monetarias restrictivas, con una industrialización orientada hacia las exportaciones, por lo que se promovieron la apertura económica, la disminución de la participación directa del Estado en la economía (la privatización de las empresas públicas), el estímulo a la inversión privada y la regulación de la fuerza de trabajo.

En el ámbito mundial también estaban aconteciendo cambios importantes como consecuencia de la crisis internacional por la caída de los precios del petróleo: la recuperación de las economías de Europa, que después de la segunda guerra mundial habían quedado devastadas; el nacimiento de Japón como gran productor de manufacturas, que modificó la forma de organización del trabajo del taylorista/fordista al de la producción ajustada; el cambio en la correlación de fuerzas entre viejas potencias y potencias ascendentes; la constitución de grandes bloques económicos supranacionales por medio de tratados comerciales, para ampliar los espacios económicos, lo cual se corresponde con 
la incursión de México al Acuerdo General sobre Aranceles Aduaneros y Comercio (GATT), que después derivaría en el Organización Mundial de Comercio (OMC); el desarrollo de las telecomunicaciones que acelera el ritmo de rotación de capital; el encarecimiento del crédito, y la flexibilización de los mercados de trabajo. Se intensifica la internacionalización comercial y financiera, por lo que los países subdesarrollados se ven impelidos a subordinarse a la lógica de las exportaciones y abrir los mercados internos. Para el caso de México el Tratado de Libre Comercio de América del Norte (TLCAN), firmado en 1994, implicó una serie de cambios en la dinámica de la economía mexicana con un fuerte impacto en la industria automotriz, como lo veremos más adelante.

\section{LA INDUSTRIALIZACIÓN ORIENTADA}

\section{A LAS EXPORTACIONES EN LA INDUSTRIA AUTOMOTRIZ EN MÉXICO}

Como mencioné anteriormente, desde los años setenta el gobierno mexicano ya venía incentivando la producción automotriz hacia el mercado de exportación. Sin embargo, esta acción respondía más a la dinámica que presentaban las empresas extranjeras:

La fuerte protección estatal hacia el sector, tendiente a impulsar una industria automotriz integrada sobre bases nacionales, dio paso a una gradual liberalización acorde con un proceso de reestructuración en función del mercado mundial y, de manera destacada, del mercado estadounidense [Bayón, 1997: 29].

Los resultados son apremiantes para el sector: se da un excedente de divisas; la producción para la exportación es mayor en comparación con la producción para el mercado interno; ambos mercados se tornan sensibles a las transformaciones de la economía internacional; dentro de la industria se da un crecimiento heterogéneo por categoría, actividad, producto y región, así como en el nivel de tecnología y en la mano de obra. Se plantea la "reestructuración productiva internacionalmente racionalizada, 
estandarizada y automatizada con reubicaciones en nuevos centros fabriles" [Carrillo y García, 1987: 323]. Esto conduce a una nueva dinámica para el fortalecimiento de las empresas extranjeras que van transformando constantemente sus estrategias de producción en función de los cambios que traerá consigo la globalización de los mercados.

El giro hacia el crecimiento de las exportaciones le dio a la industria del automóvil ventajas que no tenía con el anterior modelo, a saber: se presentan economías de escala; reducción de las distancias geográficas que otorgan disminución de costos y rapidez en los tiempos de circulación del capital; la región norte del país presenta particularmente características óptimas para la exportación; mano de obra calificada; ventajas arancelarias para las maquiladoras, y menor sindicalización tanto en México como en Estados Unidos, debido a la desarticulación de las plantas industriales para ser establecidas en el norte de México. Es importante señalar que los cambios en la industria automotriz son determinados por las necesidades de producción de las empresas extranjeras, y en menor medida por los requerimientos que el Estado pudiera exigir en beneficio de una industria nacional.

Ahora bien, como ya había mencionado, estos cambios dentro de las empresas respondían a las transformaciones que se estaban dando en un nuevo contexto internacional, que se encaminaban hacia un mayor intercambio comercial de las economías nacionales con el exterior, en el que uno de los factores para ser competitivos y rentables incluía los bajos costos de producción, situación que favorecía a los países subdesarrollados como México,

El tránsito hacia la segunda fase ... o de las partes del nuevo decreto de Apoyo en 1983, tampoco dependía de la capacidad de gestión del Estado mexicano para generar acuerdos con las filiales de las empresas trasnacionales del país más bien, la explicación proviene de las estrategias que las multinacionales establecen para salir de la crisis en sus grandes mercados y áreas de producción. Nos referimos a la gran crisis de la industria automotriz internacional de los años 1979-1982 ... [Juárez, Lara y Bueno, 2005: 121]. 
Sumado a esto, se presenta una disminución de la producción para el mercado interno, así como una heterogeneidad en todos los ámbitos de la industria; la región norte del país se convierte en el espacio por excelencia para el desarrollo de la industria automotriz, sobre todo en el segmento de autopartes para la exportación.

El efecto positivo de esta reestructuración de las empresas automotrices en la economía mexicana fue que la balanza comercial tuviera un superávit. Como efecto negativo, el alejamiento del Estado de su actividad directa mostró que no existía un interés por desarrollar una industria nacional, un ejemplo de lo anterior fue que el gobierno vendió las acciones de la empresa Renault y Vehículos Automotores Mexicanos (VAM) a inversionistas franceses, acabando así con la única posibilidad de un desarrollo nacional de la industria terminal en manos del Estado.

En 1989, con el Consenso de Washington en puerta, surge el Decreto para el Fomento y Modernización de la Industria Automotriz, que en el Artículo $1^{\circ}$ dice: "El Decreto tiene por objeto fomentar el desarrollo de la industria automotriz para consolidar los avances logrados, ampliando su participación en la economía internacional" [DOF, 1989], aunque el objetivo más claro era lograr una mayor integración nacional descartando el modelo ISI para que las empresas ensambladoras incorporaran porcentajes mínimos $(36 \%)$ como valor agregado nacional a sus productos. El Artículo $3^{\circ}$ señala que: "Las empresas de la industria terminal seleccionarán los tipos de vehículos que producirán en el país considerando las características y ventajas de sus plantas y procurando el uso eficiente de la capacidad instalada y de sus recursos disponibles" [DOF: Secofi, 1989]. Con estos acuerdos se permitió también la importación de vehículos por las propias empresas, para satisfacer la demanda en el mercado nacional. En un principio se les impuso una cuota por cada peso o unidad monetaria de importación de vehículos nuevos, que fue disminuyendo conforme pasaran los años. "Se afirma que este decreto ha sido exitoso al convertir a la industria automotriz asentada en México en competitiva, exportadora, de alta calidad y no dependiente exclusivamente del mercado nacional, al complementar la oferta 
nacional con vehículos automotores ligeros importados" [Rueda y Álvarez, 2011: 177].

Es importante señalar que en esos momentos tales propuestas no eran del todo posibles porque el sector de autopartes nacional (que era el sector con el que se pretendía generar los niveles de integración) carecía de los elementos indispensables para cubrir las necesidades de la industria terminal (como veremos más adelante), por lo que se terminó importando estos productos. Sin embargo, se incentivó la participación de la inversión extranjera directa en este sector, como lo menciona el Artículo 6o:

Las empresas de la industria de autopartes deberán ajustarse a las disposiciones de la Ley para Promover la Inversión Mexicana y Regular la Inversión Extranjera y de su Reglamento. En la integración del capital social reservado a mexicanos podrán concurrir personas morales en las que participe, a su vez, mayoritariamente el capital mexicano [DOF, 1989].

Se observa la facilidad que el gobierno mexicano otorga a las empresas extranjeras para operar con sus propias reglas.

En 1990 se emite otro decreto [DOF, 1990] que reforma y adiciona el decreto de 1989, de modo que se incentiva la importación de vehículos nuevos para las empresas terminales que se encuentren ubicadas en la franja fronteriza del país, así como en las zonas libres de Baja California, Baja California Sur y parcialmente de Sonora. Esto también se aplica a empresas distribuidoras ubicadas en la región fronteriza del norte, dejando ver la importancia de la región norte del país para las empresas, por su cercanía con el mercado de Estados Unidos. "Esta situación hizo que más del $15 \%$ de los vehículos que se vendieran en México entre 1991 y 1992 fueran importados, cifra que alcanzó un nivel del 20\% en 1993" [Vicencio, 2007: 225]. Tal decreto establece diversos Programas de Importación Temporal para producir artículos de Exportación (Pitex). El objetivo del decreto era dotar a la industria de insumos, como las materias primas, partes, componentes, materiales auxiliares, envases, material de empaque, combustibles y lubricantes que se utilicen en el proceso de producción de 
las mercancías de exportación, libres de impuestos de importación $\mathrm{y}$ al valor agregado, permitiendo así el incremento y fortalecimiento de la actividad exportadora, la cual es uno de los motores de la economía nacional [ProMéxico, recurso electrónico].

Como requisitos para hacerse acreedores a este beneficio, debían exportar al menos $10 \%$ de las ventas totales anuales o 500000 dólares estadounidenses, aquellos interesados en importar materias primas, partes, componentes, materiales auxiliares, envases, material de empaque, combustibles y lubricantes que se utilicen en el proceso de producción de las mercancías de exportación, así como contenedores y cajas de tráiler. Asimismo, debían exportar menos de $30 \%$ de las ventas totales anuales, los interesados en importar herramienta, equipos y accesorios de investigación, de seguridad industrial y productos necesarios para la higiene, asepsia y para la prevención y control de la contaminación ambiental de la planta productiva; manuales de trabajo y planos industriales; equipo de telecomunicación y cómputo; maquinaria, aparatos, instrumentos y refacciones para el proceso productivo; equipo de laboratorio, de medición y de prueba de sus productos, y los requeridos para el control de calidad, para capacitación de su personal, así como equipo para el desarrollo administrativo de la empresa, este último cuando se trate de instalación de nuevas plantas industriales. Tales requerimientos solo los podían cumplir las empresas trasnacionales, por lo que el mayor beneficio se concentraba en ellas.

Los decretos anteriores marcaron la antesala para los argumentos que se plantearían en la negociación del Tratado de Libre Comercio de América del Norte, en el que se buscaría garantizar la competitividad de la industria automotriz terminal y el impulso al desarrollo del mercado interno de automóviles.

\section{El Tratado de Libre Comercio de América DEL NoRTE EN LA INDUSTRIA AUTOMOTRIZ}

El Tratado de Libre Comercio de América del Norte (TLCAN) se firmó entre los tres países de la región: Canadá, Estados Unidos y 
México. Este Tratado tiene un apartado especial sobre la industria automotriz, en el Anexo 300A. Los principales elementos que aquí interesa rescatar al respecto de la industria automotriz son:

- Se reducen a la mitad los montos arancelarios por importaciones.

- El monto de importación de automóviles y camiones ligeros se redujo de 20 a 10\%, para ser eliminado por completo a partir del 2004.

- Del sector de autopartes $16 \%$ se reduce también a la mitad de manera inmediata, y en los próximos 10 años se desgravarían totalmente el pago de aranceles.

- El factor de compensación de la balanza comercial se redujo de 1.75 a 0.8 acelerando el ritmo de las importaciones.

- El porcentaje de contenido nacional se fue reduciendo paulatinamente, quedando de la siguiente manera: 34 a $36 \%$ en $1993,29 \%$ en 1998 y $0 \%$ para el 2004.

Un aspecto sobresaliente del TLCAN se refiere a las reglas de origen (RO), ya que implicaron la eliminación de una serie de barreras para la entrada a la región de empresas que proceden de otras áreas del mundo. Esto permitió garantizar los mercados a los socios del acuerdo comercial y tener un trato preferencial ante la oscilación de los mercados y la competencia de los asiáticos, por considerar a las empresas estadounidenses débiles en la competencia. Las RO se aplican en dos categorías: "1) para automóviles de pasajeros, camiones ligeros, motores y transmisiones se espera un valor originario de insumos y/o transformación regional del $62.5 \%$ y 2) para el resto de los vehículos y las autopartes del 60\%” [Buzo de la Peña, 1997: 228].

\section{EFECTOS DEL TLCAN EN LA INDUSTRIA AUTOMOTRIZ}

Los resultados que se registraron en el nivel de exportaciones automotrices en el periodo que va de la puesta en marcha en 1994, cuando se exportaron 10796.5 millones de dólares, ya se habían 
duplicado para 1997, cuando se registraron 20778.3 millones de dólares, y para el año 2002 la cifra ya era de 31721.7 millones de dólares. Cabe destacar que estos incrementos se dan incluso con una desaceleración de la demanda estadounidense [Juárez, Lara y Bueno, 2005: 128]. En tanto tuvo una reducción de la producción para el mercado interno en favor de las exportaciones.

La producción total de automóviles en México mostró un comportamiento ascendente a partir de la firma del tratado, como se puede observar en el cuadro 1 .

\section{Cuadro 1. Producción total de automóviles en México, 1994-2011}

\begin{tabular}{c|c|c|c}
\hline Año & Mercado nacional & Mercado de exportación & Total \\
\hline 1994 & 352974 & 503588 & 856562 \\
\hline 1995 & 102573 & 596739 & 699312 \\
\hline 1996 & 163651 & 634031 & 797682 \\
\hline 1997 & 262986 & 593097 & 856083 \\
\hline 1998 & 355332 & 597577 & 952909 \\
\hline 1999 & 316104 & 677668 & 993772 \\
\hline 2000 & 347878 & 931211 & 1671440 \\
\hline 2001 & 352658 & 856336 & 2349108 \\
\hline 2002 & 374719 & 765073 & 1139792 \\
\hline 2003 & 297174 & 616135 & 913309 \\
\hline 2004 & 323693 & 579620 & 903313 \\
\hline 2005 & 320209 & 732614 & 1052823 \\
\hline 2006 & 310874 & 1060019 & 1370893 \\
\hline 2007 & 288833 & 1127832 & 1416665 \\
\hline 2008 & 284877 & 1103036 & 1103036 \\
\hline 2009 & 199307 & 810607 & 1009914 \\
\hline 2010 & 282697 & 1182272 & 1464969 \\
\hline 2011 & 321662 & 1367504 & 1689166 \\
\hline
\end{tabular}

Fuente: Elaboración propia con base en el volumen de la producción por marca y empresa, registrado por INEGI (varios años). 
En 1994, se producían en México 856562 automóviles, con la entrada en vigor del TLCAN, la producción se incrementó a 1671440 unidades para finales del siglo xx. En 2001 se alcanzó una cifra récord de 2349108 unidades, aunque con la crisis económica de 2002 la producción cayó en más de un millón de unidades. La tendencia descendente se mantuvo de 2003 a 2004 y se recuperó levemente entre 2005 con una producción de 1052823 y en 2007 con una producción de 1416 665, sin embargo, no supera la producción del primer año de esta década. A consecuencia de la profunda crisis de 2008 hubo una nueva caída de más de 300000 unidades, ya que la producción fue de 1103 036. Esta tendencia se mantuvo hasta 2009, cuando se registró una caída superior a las 93000 unidades. Finalmente, entre 2010 y 2011 se observó una recuperación de más de 670000 unidades. Hasta la fecha no se ha alcanzado la cifra de 2001 (véase cuadro 1).

\section{NuEVOS DECRETOS DESPUÉS DEL TLCAN}

A pesar de todas las facilidades que significó el TLCAN para la industria, en 2003 se emitió un nuevo decreto promulgado por el presidente en turno Vicente Fox, con el fin de incrementar la competitividad de la industria automotriz terminal y dar un mayor impulso al desarrollo del mercado interno de automóviles, fortaleciendo el TLCAN: se dio un mayor impulso a las inversiones en el sector; se incrementó la inversión extranjera directa (IED); los costos de producción disminuyeron vía la reducción de los aranceles; se autorizó el registró de nuevas empresas en el sector terminal que estuvieron dispuestas a invertir 100 millones de dólares y fabricar 50000 vehículos anuales como mínimo; se otorgó la tasa cero en aranceles para la importación de vehículos con un volumen de $10 \%$ de producción respecto del año anterior; y por último, la autorización para importar mayores cantidades de vehículos a razón de incrementar sus niveles de producción en el país, desarrollar programas de capacitación, así como el 
fortalecimiento de proveedores locales de primero y segundo nivel a los que se les transfiriera su tecnología.

Indudablemente que estos ajustes al TLCAN dieron resultados importantes para la producción, ya que en el 2006 la industria automotriz reportó un volumen de producción de 1370893 unidades, de las cuales 1060019 unidades fueron para exportación y 310874 unidades para el mercado nacional. En 2008 la industria entró en crisis internacional; la sobreproducción de automóviles y la incapacidad de los mercados internacionales para absorber la oferta mostraron una realidad difícil de corregir. General Motors se declaró en bancarrota, por lo que el gobierno del presidente de Estados Unidos, Barack Obama, planteó un plan de rescate para las empresas automotrices en 2009, con un monto de 17.4 miles de millones de dólares a cambio de una reestructuración profunda de la producción de automóviles hacia una orientación más amable con el medioambiente y que radica en la producción de autos híbridos [La Jornada, 2009]. El problema del calentamiento global es un elemento del nuevo milenio, y la búsqueda de energías más eficientes se vuelve un objetivo a seguir por los gobiernos nacionales, de ahí que la inversión pública decretada por el presidente de Estados Unidos para General Motors estuviera dada como una condición para la subsistencia y el mejoramiento del medioambiente.

\section{LOS DECRETOS DE 2009 Y 2011 Y LOS ACUERDOS COMPLEMENTARIOS}

En 2009, el presidente Felipe Calderón emitió un decreto señalando que se permitiría la importación de vehículos usados a razón de haber sido fabricados o ensamblados en alguno de los países integrantes del TLCAN, sin un arancel de $10 \%$, sin permiso previo de importación y sin presentar certificado de origen. Esto se aplicaría también para la importación de vehículos en la franja fronteriza y para la importación de vehículos pesados, todos con una antigüedad de entre 5 y 10 años. Por último, en 
2011 se derogó el decreto de 2009, para permitir la importación de autos usados con 8 y 9 años de antigüedad, pagando $10 \%$ de arancel y $16 \%$ de impuesto al valor agregado (IVA).

Otro ejemplo de ayuda por parte del Estado a las empresas trasnacionales se puede ver con los Acuerdos de Complementariedad Económica entre México, Argentina y Brasil. Estos convenios tienen sus orígenes en la conformación de la Asociación Latinoamericana de Integración (Aladi) con sede en Uruguay, y de la que emana el Tratado de Montevideo de 1980. Asimismo, para incentivar las inversiones de los países miembros (Argentina, Brasil, Paraguay y Uruguay) se celebró, el 5 de julio de 2002, el Acuerdo de Complementación Económica número 54, con la finalidad de eliminar gravámenes y demás obstáculos que limitaban el comercio mutuo, además de regular jurídicamente las inversiones recíprocas.

El acuerdo automotriz signado entre México y Brasil (ACE 55) consideraba la exportación e importación de 1450 millones de dólares en 2012, 1560 millones en 2013 y 1640 millones de dólares en 2014, libres de aranceles entre ambas naciones. Sin embargo, Brasil y Argentina, en marzo de 2012 decidieron no suscribir más este Acuerdo, debido a que:

La medida proteccionista busca frenar las importaciones de automóviles mexicanos más competitivos que los ensamblados en Brasil, uno de los mercados más dinámicos del mundo donde la apreciación de la moneda local, el real, ha restado fortaleza a la industria brasileña [El Economista, 2012].

Lo que busca Brasil es aumentar su nivel de producción nacional para satisfacer la demanda de su mercado interno, evitando que se beneficiasen otros países, en este caso México, con la venta de vehículos importados. Sin embargo, las realmente afectadas son las subsidiarias, apostadas en territorio mexicano, de las grandes armadoras trasnacionales, y también es un golpe para la derrama económica nacional que se hubiera podido generar con ese nivel de producción. "El límite que impuso Brasil a las 
importaciones de autos desde México sacudió los planes de las grandes ensambladoras y se vieron obligadas a sacar la calculadora para redistribuir sus envíos y cumplir con sus metas de producción de este año" [El Economista, 2012].

A pesar de este panorama, en México se presentó un alto crecimiento de la inversión en la industria automotriz como resultado de la recuperación industrial a escala global y las condiciones óptimas de inversión en el país: mano de obra calificada y competitiva en el ámbito internacional, a bajo costo, y demás incentivos ya expuestos en este trabajo. Es de esperarse que esta inversión crezca y que haya un aumento de nuevas marcas y empresas dispuestas a asentarse en el mercado mexicano. Por ejemplo, la empresa Tata Motors procedente de India pretendía invertir 100 millones de dólares en una nueva planta, y busca asociarse con alguna compañía mexicana para construir una red de proveedores. Esta empresa fabricará en territorio mexicano sus modelos Tata Vista, Tata Indica, Tata Manza, Tata Aria y el Nano, vehículo que al momento de su introducción al mercado fue considerado el más barato con un costo de 1800 dólares. Esta estrategia económica puso en alerta al resto de las empresas automotrices en América Latina.

\section{Apoyos gubernamentales AL CONSUMO DE AUTOMÓVILES}

Como parte de los apoyos al consumo de autos nuevos, la Asociación Mexicana de la Industria Automotriz (AMIA), que integra a los ensambladores en México, negoció con el gobierno federal un programa de chatarrización o "efectivo por carcachas", que pretende retirar del parque vehicular a los automóviles con más de 10 años de antigüedad y otorgar a cambio facilidades para la obtención de modelos nuevos.

Otra forma de fomentar el consumo interno de automóviles se da mediante la continuación del programa "Hoy no Circula". Este programa comenzó a aplicarse desde 1989 en el Distrito 
Federal, en la temporada invernal, como una medida para abatir los altos índices de contaminación registrados durante ese periodo del año, y que consistía en dejar de usar el automóvil un día a la semana; sin embargo, el programa se volvió permanente en el año de 1990 y se mantiene vigente hasta nuestros días, por lo que el consumo de un automóvil más, en sustitución del automóvil que "descansa", se volvió una necesidad de las familias mexicanas. Ha sufrido varias modificaciones, pero este programa significó sacar de la circulación a una parte importante del parque vehicular $(20 \%)$ una vez a la semana, y también un día del fin de semana, una vez al mes, con la posibilidad de que esto pasara a dos días a la semana dependiendo de los niveles de contaminación en la Ciudad de México.

El programa de restricción del gobierno generó empleos mediante la instauración de centros vehiculares de verificación para mantener en circulación a los modelos con más de ocho años de antigüedad, lo que propició la adquisición de "licencias" de servicio de verificación, la generación de un número importante de empleos y la apertura de un negocio con altas utilidades.

\section{EL SECTOR DE AUTOPARTES}

Un sector complementario fundamental de la industria automotriz es la producción de autopartes, ya que es el segundo sector exportador más importante de la industria manufacturera; en 2008 existían 1236 productores, el personal ocupado era de 441179 personas y la producción bruta total era de 340562845 (miles de pesos) [INEGI, 2012]. Su relevancia radica en que abastece con equipo original a la industria terminal nacional y extranjera, así como al mercado de reposición o refacciones.

Existen tres niveles de proveedores en el sector de autopartes: Tier 1 , integrado en su mayoría por empresas trasnacionales y que tienen una relación de largo plazo con las ensambladoras; Tier 2 y Tier 3 , que en su mayoría son empresas mexicanas y que proveen a la primera. Los principales insumos que suministran 
al sector terminal se clasifican en cuatro rubros: 1) fundición, forja, estampados, maquinados y soldadura (27\%); 2) lingotes y barras de aluminio y acero $(20 \%) ; 3)$ insumos indirectos, como aceites industriales, gases, electricidad (14\%), y 4) hules, plásticos, fibras y vidrio (12\%) [Mortimore y Barron, 2005: 31].

Las empresas ensambladoras buscan tener una relación más cercana con sus proveedores, por lo que los requisitos para formar parte de su red son altamente rigurosos. Pretenden medir constantemente el desempeño de los proveedores, el servicio y el producto usando sistemas de calidad, como ISO-9000 y QS-9000 (normas internacionales que certifican la calidad de los procesos). Las oportunidades para satisfacer la demanda de las armadoras son amplias: del lado de la fundición, forja, estampados, maquinados y soldadura, 35\% y en hules, plásticos y fibras, 23\% [Mortimore y Barron, 2005: 31]. En este contexto las empresas mexicanas no han logrado ser parte de los encadenamientos productivos de las ensambladoras, pues no cuentan con las tecnologías mínimas requeridas, volumen de ventas, calificación de los trabajadores, ni grado de especialización mínima. Tampoco disponen de los suficientes apoyos para lograrlo, y si le sumamos que la empresas extranjeras buscan ubicarse en el territorio nacional aprovechando los beneficios del TLC, la competencia se vuelve desigual y se cae en un círculo vicioso imposible de superar.

Por lo anterior, el gobierno mexicano debe incentivar el desarrollo tecnológico de este sector, así como concentrar los elementos que lo vuelvan competitivo como la calificación de la mano de obra. Según Mortimore y Barron [2005: 33], se requiere tener una visión global de la industria que empate con la estrategia nacional de desarrollo, también se debe atraer empresas prioritarias y es necesario integrar las empresas nacionales a la base de proveedores ya establecida en el país para profundizar la cadena productiva [Mortimore y Barron, 2005: 33].

Es importante señalar que el apoyo gubernamental debe ir en el sentido de lo que estipulan las reglas de origen del TLCAN, 
pues si bien es cierto que Estados Unidos ha protegido su mercado nacional, México debería hacer lo mismo teniendo como instrumento de negociación un sector de autopartes altamente desarrollado y competitivo que significaría una ventaja para la industria nacional y un beneficio mayor para las empresas armadoras extranjeras.

\section{CONCLUSIONES}

El desarrollo de la industria automotriz en México surge como parte del proceso de acumulación de capital que el Estado nacional buscaba consolidar en el sector industrial, sin embargo, la industria automotriz fue y sigue siendo extranjera, por lo que no existe un verdadero desarrollo nacional del sector.

Si bien es cierto que hubo algunos esfuerzos de empresas mexicanas para producir automóviles, estos no fructificaron ni maduraron lo suficiente como para sobrevivir a la competencia extranjera antes y después de la apertura.

El Estado mexicano beneficia a los capitales extranjeros en detrimento de los capitales nacionales, convirtiendo a la industria nacional en inexistente.

Por otro lado, el sector de autopartes pudo ser el generador de un desarrollo hacia dentro, pero el gobierno nunca intervino en su mejoramiento, se desentendió por completo de las potencialidades que hubiera podido lograr.

Es por esto que considero que este sector debería ser sujeto de nuevas políticas públicas, tanto en materia de competitividad como de desarrollo tecnológico, ya que existe un número considerable de empresas de autopartes de segundo nivel (que proveen a las empresas que están en línea directa con la ensambladora trasnacional), susceptibles de aparecer y desaparecer fácilmente del mercado, pero que tienen el conocimiento necesario de la industria como para desarrollarse ampliamente, por lo tanto, es importante identificarlas y apoyarlas. También es trascendente mencionar que la calificación de la mano de obra 
es muy importante para este sector, por lo que un elemento más de política pública debe dirigirse en ese sentido.

\section{REFERENCIAS}

Aguilar G., J. [1982], La política sindical en México: industria del automóvil, México, Colección Problemas de México, Era, $195 \mathrm{pp}$.

Bayón, Ma. C. [1997], El sindicalismo automotriz mexicano frente a un nuevo escenario: una perspectiva desde los liderazgos, México, Flacso/Juan Pablos Editor, 207 pp.

Boltvinik, J., y E. Hernández L. [1986], "Origen de la crisis industrial, el agotamiento del modelo de sustitución de importaciones, un análisis preliminar", < http://www.oocities.org/ $\mathrm{mx} /$ gunnm_dream/modelo_sustitucion_y_evolucion_economica.html>, 4 de marzo de 2013.

Buzo de la Peña, R. M. [1997], La integración de México al mercado de América del Norte, México, UAm-Azcapotzalco, 463 pp.

Carrillo, V., J. y P. García [1987], "Etapas industriales y conflictos laborales: la industria automotriz en México", en Revista Estudios Sociológicos, México, Centro de Estudios Sociológicos, El Colegio de México, 14: 303-340.

Diario Oficial de la Federación [1962], "Secretaría de Comercio y Fomento Industrial, Decreto que prohíbe la importación de motores para automóviles y camiones, así como de conjuntos mecánicos armados para su uso o ensamble, a partir del 1o. de septiembre de 1962", publicado el 25 de agosto, $<$ http://www.ropsa.com.mx/Default.aspx>, 5 de marzo de 2013.

[1977], "Secretaría de Patrimonio y Fomento Industrial, Decreto para el fomento de la industria automotriz, publicado el 20 de junio, $<$ http://www.ropsa.com.mx/Default.aspx $>$, 12 de marzo de 2014.

[1989], "Secretaría de Comercio y Fomento Industrial, Decreto para el fomento y modernización de la industria 
automotriz, <http://200.66.72.180/dof/pdf/1989/12/ t19891211.pdf>, 7 de marzo de 2013.

[1990], "Secretaría de Comercio y Fomento Industrial, Decreto por el que se reforma y adiciona el relativo al Fomento y Modernización de la Industria Automotriz", publicado el 11 de diciembre de 1989, <http://200.66.72.180/dof/pdf/ 1990/06/t19900608.pdf>, 10 de marzo de 2013.

Dirección General de Gestión Ambiental del Aire, Dirección y Modelación de Emisiones, Dirección de Instrumentación de Políticas-Gobierno del Distrito Federal/Secretaría del Medio Ambiente [2004], "Elementos para la propuesta de actualización del programa 'Hoy No Circula' de la Zona Metropolitana del Valle de México", <http://www.sma.df.gob.mx/sma/ download/archivos/elementos_actualizacion_phnc_dime. pdf $>, 3$ de diciembre de 2012.

El Economista [2012], "Acuerdo con Brasil sacude planes de armadoras en México”, edición en línea, 28 de marzo de 2012, $<$ http://eleconomista.com.mx/industrias/2012/03/28/acuerdo-automotriz-brasil-sacude-planes-armadoras-mexico $>, 3$ de diciembre.

Fajnzylber, F. [1983], La industrialización trunca de América Latina, México, Nueva Imagen, 416 pp.

Garrido, C. [2002], "Industrialización y grandes empresas en el desarrollo estabilizador, 1958-1970”, en Análisis Económico, revista de la división de Ciencias Sociales y Humanidades, México, UAM-A, 17(35):233-267, < http://www.analisiseconomico.com.mx/pdf/3511.pdf>, 4 de marzo de 2013.

González Ch., G. [2008], El Estado y la globalización en la industria siderúrgica mexicana, México, IIEc-UnAm/Casa Juan Pablos, 376 pp.

Instituto Nacional de Estadística y Geografía, INEGI [2013], "La industria automotriz en México", varios años, <http://www. inegi.org.mx/sistemas/productos/default.aspx $>, 10$ de marzo. Juárez N., H.; A. Lara R. y C. Bueno (coords.) [2005], El auto global, desarrollo, competencia y cooperación en la industria del automóvil, Puebla, Pue., Benemérita Universidad Autónoma 
de Puebla/Conacyt/Uam-Xochimilco/Universidad Iberoamericana, $602 \mathrm{pp}$.

La Jornada [2009], "Obama nacionaliza GM en forma temporal; Chrysler se vende a Fiat", nota periodística, <http://www. jornada.unam.mx/2009/06/02/economia/023n1eco>, 10 de marzo de 2013.

Mortimore, M., y F. Barron [2005], "Informe sobre la industria automotriz mexicana", Serie Desarrollo Productivo 162, Santiago de Chile, CEPAL/ONU, 53 pp.

Neffa, J. C. [1999], Los paradigmas productivos taylorista y fordista y su crisis: una contribución a su estudio desde la teoría de la regulación, Argentina, Asociación Trabajo y Sociedad, 224 pp.

Presidencia de la República [2006], "La industria automotriz se ha convertido en uno de los sectores más dinámicos del proceso industrial de México", Rubén Aguilar, Vocero de Presidencia, <http://foc.presidencia.gob.mx/actividades/? contenido $=23855>, 10$ de marzo de 2013.

ProMéxico [2013], "Cómo exportar, servicios y apoyos para el exportador”, <http://www.promexico.gob.mx/work/models/ promexico/Interactivos/Capacitacion_virtual/Formacion_integral_para_exportar/curso3/3-04f.htm>, 11 de marzo.

Rivera R., M. A. [1992], El nuevo capitalismo mexicano, México, Era, 223 pp.

Rueda P., I., y M.L. Álvarez M. [2011], “Capítulo V. El impacto de las políticas económicas y sociales de México y China en la industria automotriz", La industria automotriz en época de crisis. Efectos económicos, financieros y sociales, México, FCA, IIEC-UNAM, $325 \mathrm{pp}$.

Siqueiros, J. L. [2007], "Régimen de solución de controversias en el Acuerdo de Complementación Económica celebrado entre México y Brasil", en Boletín Mexicano de Derecho Comparado, nueva serie, año XL, (118): 243-250, enero-abril.

Tello, C. [2010], "Notas sobre el desarrollo estabilizador", en Economía Informa, México, FE-UNAM (364): 67, julio-septiembre.

Trejo, R., S. [1987] El futuro de la política industrial en México, México, El Colegio de México, 195 pp. 
Vicencio, M., A. [2007], "La industria automotriz en México. Antecedentes, situación actual y perspectivas", en Contaduría y Administración, México, Facultad de Contaduría y Administración, UNAM, (221): 211-248, enero-abril.

Womack, P. J., T. D. Jones y D. Roos [1993], La máquina que cambió el mundo, Madrid/México, MIT/McGraw Hill, 292 pp. 


\section{Capítulo 4 \\ LA INDUSTRIA MANUFACTURERA Y SU LOCALIZACIÓN: EL CASO DE LA CIUDAD DE MÉxiCo ENTRE 1993 y 2008}

Roberto Ramírez Hernández*

\section{INTRODUCCIÓN}

La Ciudad de México, como todas las grandes ciudades en el mundo, no es simplemente un espacio urbano que se expande y concentra población paulatinamente. En realidad, el crecimiento y la expansión de las ciudades mantiene hechos importantes de naturaleza económica que no deberían soslayarse. El desorden de las ciudades y los costos urbanos inherentes a este son producto no solamente de la ausencia de planes de desarrollo urbano, sino del desconocimiento de cómo se comporta la actividad económica en el territorio. La actividad económica en general tiene lógicas diferentes en términos de localización. Las demandas de suelo dependerán del tipo de actividad, por lo que los requerimientos de suelo condicionan la ubicación. Asimismo,

* Académico del IIEc-UnAm y participante en el proyecto de investigación PAPIIT IN305610. Correo electrónico: <robrami@unam.mx>. 
la orientación al mercado interno o a la exportación, la dotación de recursos naturales del territorio, el nivel de desarrollo tecnológico y de capital humano también son determinantes en este proceso.

Lo anterior es relevante además para el caso de la industria, cuya comprensión cabal pasa por el entendimiento de los principios de localización y por su relación directa con las ciudades. Industria y ciudad coexisten debido a una clara interdependencia: la industria requiere mano de obra de las ciudades y la ciudad necesita abastecerse de productos transformados a partir de la actividad industrial.

En recientes fechas, para el caso de la Ciudad de México, han existido planteamientos en el sentido de que, ante el incuestionable proceso de tercerización que vive la ciudad, ${ }^{1}$ esta debe ir desapareciendo toda su industria para ser únicamente una ciudad de servicios en virtud de su jerarquía y tamaño.

Lo anterior refleja el desconocimiento de los procesos de localización industrial en las grandes ciudades y la función económica que realizan los centros de actividad mencionados; de allí que los procesos de planeación urbana no tomen en cuenta dichos procesos, causando importantes costos urbanos.

${ }^{1}$ Por tercerización se entiende el proceso económico mediante el cual se sustituyen paulatinamente las actividades económicas de naturaleza primaria y secundaria por actividades de servicios (actividades terciarias). La manera en que se expresa lo anterior en una ciudad es claramente identificable a escala territorial, los sitios o predios urbanos dedicados en otros tiempos a actividades agropecuarias, minería o industria, se transforman en áreas de servicios de toda índole: áreas comerciales, financieras, profesionales, oficinas administrativas y corporativas, así como áreas de nueva residencia para la población urbana.

En el caso de la Ciudad de México se ha identificado y documentado claramente este fenómeno. Por ejemplo en la zona norte de la ciudad y a partir de los años cuarenta del siglo Xx, se localizaba la mayor cantidad de áreas industriales en las zonas de Gustavo A. Madero, Azcapotzalco, Naucalpan y Tlalnepantla, por mencionar algunas de las más importantes. Si bien actualmente aún estos sitios muestran grandes concentraciones de industria, es claro que existe una fuerte tendencia al desplazamiento de la industria hacia sitios aún más hacia el norte, tales como Cuautitlán Izcalli, Tepotzotlán y Tultitlán. 


\section{Antecedentes Históricos: LA CiUdAD \\ DE MÉXICO Y SU CRECIMIENTO INDUSTRIAL \\ HACIA LA MITAD DEL SIGLO XX}

La actividad industrial incidió particularmente en la Ciudad de México hacia los años cuarenta y cincuenta del siglo xx, cuando aún se experimentaban fuertes tasas de migración interna, es decir, desde múltiples lugares en la República mexicana hacia la ciudad, con lo que el crecimiento urbano constante representó un importante factor en el crecimiento capitalino, impulsado en muy buena medida por factores exógenos como la segunda guerra mundial y otros internos como las políticas centralistas en favor de la capital. Este crecimiento planteó fuertes necesidades de empleo que el desarrollo industrial debía satisfacer. Por ello, el impulso económico al principal mercado interno del país fue sostenido. La construcción de nuevas fábricas sobre territorio no urbanizado fue típica de este periodo.

En este sentido, la Ciudad de México tuvo un dinamismo envidiable en el periodo en comparación con el crecimiento económico del país. La capital presentó una tasa de incremento del PIB de $7 \%$ anual, mientras que el país en conjunto creció en promedio $6.2 \%$ anual, teniendo lugar la mayor velocidad de crecimiento del PIB en el sector secundario, pues la ciudad creció 7.8\% anual y el país lo hizo 7.2\% anual [Sánchez, 2011: 4-28].

Este dinamismo económico en la Ciudad de México entre 1940 y 1970 tuvo como principal consecuencia una nueva estructura económico-territorial para la capital, dando lugar no solamente a una expansión urbana explosiva sino también a nuevos patrones de ocupación territorial en su actividad productiva. De allí que el patrón monocéntrico típico en ciudades pequeñas y específicamente en la Ciudad de México pasó a una etapa de clara transición hacia un patrón policéntrico, en el que se generaron nuevos procesos de aglomeración económica en algunos sitios de la ciudad.

Pese a las características centralistas de la actividad económica de la Ciudad de México de los años cuarenta, la actividad 
industrial comenzaba ya a mostrar señales de descentralización, por lo que la cada vez más importante actividad económica industrial de la ciudad contribuyó también a la expansión urbana hacia el municipio de Tlalnepantla en el Estado de México y después a Naucalpan; además, dicha actividad en la Ciudad de México absorbió parte de Gustavo A. Madero, Azcapotzalco, Álvaro Obregón y la actual delegación Miguel Hidalgo. Hacia 1940 estaban registrados 3018 establecimientos industriales de transformación, la mayoría localizados al norte de la ciudad [Espinosa, 2007].

Entre 1941 y 1950, se realizó por primera vez un esfuerzo por contar con una normatividad en relación a la industria en todo el Distrito Federal, de esta manera, en el Diario Oficial del 4 de febrero de 1941 se publicó el Reglamento de Zonificación Industrial, en el que fueron establecidas 11 zonas industriales, ubicadas en su gran mayoría al norte y al poniente, así como a las afueras de la Ciudad de México de la época² [DOF, 1941].

2 En las zonas I y IX se permitía la industria en general, con excepción de las que producían olores persistentes, emanaciones gaseosas y líquidos nocivos. La zona I se ubicaba en las colonias Santa María Insurgentes, Atlampa, San Simón y Tolnáhuac, en la parte norte dentro de la Ciudad de México, o sea en el cuartel V. La zona IX se ubicó en el oriente de la terminal de carga de Pantaco, en la delegación Azcapotzalco.

En las zonas II y VI se autorizó la industria de transformación de productos animales. La zona II se ubicó en las actuales colonias Felipe Ángeles y Nicolás Bravo; la VI en las colonias de Observatorio y Bellavista, en la delegación Álvaro Obregón.

La zona III se ubicaba en la parte oriente de la Ciudad de México, que correspondía al cuartel III, y aquí se permitía la industria que requería predios con una gran superficie y servicios de ferrocarril.

En la delegación Miguel Hidalgo, actualmente la colonia Granada y parte de las colonias Ampliación Popo, Ahuehuetes y Anáhuac, se localizaba la zona industrial IV, en la que se admitían establecimientos industriales que no produjeran olores molestos, rugidos sensibles fuera de los propios locales, emanaciones gaseosas ni desechos líquidos nocivos.

La zona V localizada en la delegación Álvaro Obregón, que comprendía las colonias Abraham González, Carola, 8 de Agosto y Lomas de Becerra se destinó a industrias afines o similares a las del cemento, cal, yeso, etcétera.

En la zona VII, ubicada en la delegación Gustavo A. Madero, que comprende las actuales colonias de Guadalupe Tepeyac y 7 de Noviembre, autorizaron talleres mecánicos, plantas de montaje de automóviles, laboratorios, etcétera.

En la zona VIII se permitieron establecimientos que producían emanaciones gaseosas y desechos líquidos nocivos; hoy se encuentran en ese lugar las colonias Granjas 
Con tales esfuerzos por ordenar la naciente actividad económica capitalina, entre los años cuarenta y cincuenta la industria de la ciudad comenzó un paulatino proceso de crecimiento principalmente en la periferia norte, surgiendo la zona industrial de Vallejo (en el límite entre las delegaciones Azcapotzalco y Gustavo A. Madero), cuyo principal eje de transporte lo fue la calzada Vallejo. Asimismo, crecieron las zonas industriales de Naucalpan, Tlalnepantla y Xalostoc en los municipios de Naucalpan y Tlalnepantla, conurbados con las delegaciones mencionadas, al norte de la Ciudad de México. Azcapotzalco en particular fue dotada con suficiente infraestructura para considerarla una zona industrial de gran importancia para la ciudad. La terminal de Pantaco fue el principal nodo de carga al enlazar otros puntos de la nueva industria capitalina como las zonas industriales de Vallejo, Tlalnepantla, Naucalpan y la zona norponiente de la ciudad (actual delegación Miguel Hidalgo) colindante con el sur de Azcapotzalco por medio de vías ferroviarias [Espinosa, 2007].

Cabe decir que otras zonas de la ciudad también tuvieron un crecimiento industrial notable, tales como las colonias Lomas de Becerra, 8 de Agosto y Carola al poniente de la ciudad, en la delegación Álvaro Obregón. La principal actividad fue la explotación de minas de arena y fabricación de cemento, cal, yeso, etc. En colonias como Anáhuac, Granada y Ahuehuetes en la actual delegación Miguel Hidalgo se desarrollaron actividades como ensamblado de automóviles, fabricación de bebidas, piezas y artículos de oficina. Algunas de estas actividades son aún llevadas a cabo. Adicionalmente surgieron actividades industriales que se establecieron de manera definitiva, como la refinación de petróleo en Azcapotzalco (Refinería 18 de Marzo), el ensamble de automóviles en Gustavo A. Madero (Planta de Ford Motors),

Modernas, Ampliación San Juan de Aragón, Santa Coleta, D.M. Nacional y Héroes de Chapultepec.

La zona X se forma por fajas de 100 metros de ancho, adyacentes a las barrancas y ríos en la parte oeste de la ciudad; allí se permitió la explotación de tabique.

La zona XI se conformó por las áreas en las que se llevaba a cabo la explotación de minas de arena en las colonias Tacubaya y Mixcoac. 
elaboración de cerveza (Cervecería Modelo) en Miguel Hidalgo [Conapo, 1998].

Como resultado de la gran expansión económica de la ciudad a partir de este periodo, ocurrieron procesos de urbanización adyacentes a las zonas industriales, de allí que estos lugares ofrecieran a la población trabajadora opciones de vivienda. Tales procesos de urbanización desencadenaron un incremento de costos en el suelo urbano como resultado del cambio en la rentabilidad del suelo y del nuevo grado de centralidad en estos sitios, teniendo que relocalizarse en las nuevas periferias de la ciudad en expansión. Sin embargo, la continua expansión de la Ciudad de México ubicó mucha de la naciente industria en los municipios mexiquenses vecinos al Distrito Federal, particularmente aquellos al norte de la ciudad. De este modo, pequeños conglomerados industriales comenzaron a "fusionarse" con la nueva expansión, esto es: se convirtieron en un mismo conglomerado desde el punto de vista geográfico. La industria en la actual delegación Miguel Hidalgo se conectó con la industria en Azcapotzalco, "fusionándose" ambas con la naciente industria localizada en la delegación Naucalpan y convirtiendo toda la zona en un gran conglomerado industrial. Así, se dieron procesos de "unión" de otros conglomerados industriales de Azcapotzalco con los de Gustavo A. Madero (como la zona de Industrial Vallejo, localizada entre vías como Río Consulado, Vallejo y Cuitláhuac)y con la zona industrial de Tlalnepantla, esta última fue ocupada principalmente por industria de armado de automóviles (Chrysler y General Motors) o de fabricación de llantas (Euskadi) [Conapo, 1998].

Otras áreas hacia el poniente de la ciudad aprovecharon las ventajas naturales de la zona, como el caso de las minas de arena y tepetate en las Lomas de Santa Fe y Becerra. De allí que industria como la de fabricación de cemento (Cementos Tolteca) u otras derivadas se instalaran en San Pedro de los Pinos o en otros sitios de la delegación Álvaro Obregón.

La expansión urbana e industrial hacia el oriente, en cambio, fue mucho más pausada y se concretó a localizarse a lo largo de la vía principal (calzada Ignacio Zaragoza). Al sur se acomodaron 
algunos desarrollos industriales modestos, debido a las limitaciones naturales del Distrito Federal dadas por las reservas territoriales de delegaciones como Tlalpan o Milpa Alta. De esta manera, las actividades industriales en la Ciudad de México encontraron mejores condiciones para su asentamiento en la zona poniente y principalmente en la norte. Independientemente de las ventajas mencionadas en términos de disponibilidad territorial, la orientación al mercado estadounidense representó un factor que reforzó la idea de un norte capitalino de carácter industrial, el cual se consolidó en los años posteriores.

\section{ESTRUCTURAS POLICÉNTRICAS Y SU IDENTIFICACIÓN: EL CASO DE LA ZMCM}

Como pudo verse, la Ciudad de México manifestó históricamente un fiel comportamiento al patrón monocéntrico hasta la década de los años cuarenta del siglo xx, cuando el Centro Histórico aglomeraba casi toda la actividad económica.

Pese a la existencia de actividad industrial en la periferia urbana de la época, ubicada en las zonas centrales de la ciudad y en las delegaciones Gustavo A. Madero, Azcapotzalco y Álvaro Obregón, se presentaron incrementos en dicha actividad en otros centros, localizados en la actual Miguel Hidalgo, Naucalpan y Tlalnepantla, mismos que consolidaron la relocalización industrial y con ello la creciente tendencia al cambio hacia patrones policéntricos.

De acuerdo con Muñiz García y Glindo [2003], McMillen [2001], Giuliano [1991] y McDonald [1987], conforme una ciudad crece, existe la acentuada tendencia a la formación de centros de actividad económica (también llamados subcentros de actividad económica). Estos centros resultan ser áreas dentro de una ciudad que se caracterizan por su alta concentración económica y que por ello dan lugar a usos de suelo específico, lo que puede provocar serios problemas urbanos dadas las necesidades particulares, muy distintas a las de otras zonas de la ciudad. 
Una ciudad que tiene un único centro económico, generalmente ciudades pequeñas o medianas, estructura su actividad económica alrededor de este centro y es conocida como ciudad monocéntrica o con un patrón monocéntrico. Cuando la ciudad es de un tamaño significativamente mayor (una gran metrópoli, por ejemplo) es típica la presencia de más de un centro económico, con lo que el patrón imperante en este tipo de ciudad es polinuclear o policéntrico [McMillen, 2001]. De allí que un espacio urbano pasa de una lógica monocéntrica a una polinuclear o policéntrica. Estos nodos, núcleos o subcentros son entonces los responsables de ejercer toda la influencia en la formación y evolución de las ciudades.

Identificar subcentros en los espacios urbanos no es tarea sencilla, es necesario por lo menos conocer los antecedentes y las funciones económicas de esta.

El análisis espacial exploratorio de datos (ESDA) que se usará en el presente trabajo es reconocido como uno de los mejores métodos en la actualidad por un amplio grupo de investigadores, incluyendo a J. F. McDonald, uno de los precursores y más importantes expertos en el tema.

El presente trabajo de identificación de la estructura policéntrica en la Zona Metropolitana de la Ciudad de México (ZMCM) está basado en el ESDA, que sin duda es una de las técnicas más modernas y sofisticadas en la actualidad. Ha reportado buenos resultados. Sus dos principales ventajas son que, por un lado, no requiere puntos de corte como lo hacen las demás técnicas. La otra ventaja es que analiza cuantitativamente la interacción existente entre unidades espaciales (cosa que no hacen las demás técnicas). Dicho de otra manera: mide el efecto que tienen las vecindades de otras unidades, a partir del índice de Moran, que calcula el nivel de correlación espacial existente mediante una matriz de vecindades o contigüidades que previamente debe definirse y que se denomina matriz espacial de pesos [Baumont y Led Gallo, 1999].

Entonces se define el análisis espacial de datos como "el conjunto de técnicas orientadas a la descripción en términos de 
verificar patrones de asociación espacial de datos, estableciendo los niveles de autocorrelación espacial, autocorrelación espacial local y heterogeneidad espacial" [Baumont y Le Gallo, 1999]. Una vez que se emplea esta matriz, es posible establecer el nivel de significancia estadística relativa a la asociación espacial entre unidades.

El cálculo del índice de Moran $\mathrm{I}_{i}$, cada día más usado debido a su eficacia, se expresa a continuación:

$$
{ }_{i}=\frac{\left(x_{i}-\mu\right)}{m_{0}} \sum_{j} w_{i j}\left(x_{j}-\mu\right)
$$

Donde:

$m_{\mathrm{o}}=\sum_{i}\left(x_{i}-\mu\right)^{2} / n$

Donde $W_{i j}$ es la matriz de pesos definida de los sitios $i$ y $j ; x_{j}$ es la observación en la unidad espacial $j$ y $\mu$ es el promedio de todas las observaciones.

Este índice mide la correlación espacial y su significancia, especificando el tipo de interacción que tienen dos unidades espaciales contiguas, con lo que es posible determinar las áreas de mayor actividad económica y, por consiguiente, las zonas de la ciudad, en este caso área geoestadística básica (AGEB), que se especializan en actividades de industria.

\section{Datos empleados en la identificación}

De acuerdo a la definición de ZMCM más ampliamente aceptada, ${ }^{3}$ se usaron los datos de los censos económicos del INEGI de 1994 y

${ }^{3}$ La Zona Metropolitana de la Ciudad de México, o simplemente Ciudad de México, de acuerdo a la definición oficial más reciente de Conapo, INEGI y Sedesol del año 2005, consiste en las 16 delegaciones del Distrito Federal, 40 municipios del Estado de México y un municipio del estado de Hidalgo. 
de 2004, es decir, datos de 1993 y 2003 respectivamente, por área geoestadística básica (AGEB), ${ }^{4}$ de los 40 municipios del Estado de México, uno de Hidalgo y las 16 delegaciones del Distrito Federal (57 en total), todos considerados metropolitanos (previamente separados en industria, comercio y servicios).

Con 5187 observaciones en total, se obtuvo una base de datos con las variables correspondientes a superficie (en hectáreas y en acres), población ocupada (empleo), unidades económicas, valor agregado censal bruto, ingresos totales, activos fijos netos y formación bruta de capital fijo.

Se calculó la densidad económica por medio de la variable de población ocupada (empleo) por AGEB.

El software empleado para determinar los índices locales de Moran por AGEB y su nivel de significancia fue el GeoDa 0.9.5-i. Se empleó la rutina LISA univariada para determinar estos índices. El resto de cálculos se elaboró en Excel de Windows. El nivel de significancia escogido para la identificación, es de 1 por ciento.

Con todo lo anterior, se procedió a determinar qué áreas de la ciudad son altamente especializadas en industria y, de este modo, identificar las zonas industriales de la Ciudad de México y su crecimiento (o cambio) en el periodo especificado.

\section{Identificación de subcentros de empleo en industria para 1993 y 2003}

En el cuadro 1 se presentan los subcentros identificados, para la industria de la ZMCM, de acuerdo con los datos del censo económico de 1994:

Se encontraron 18 subcentros de actividad industrial que al ser

${ }^{4}$ Un AGEB o área geoestadística básica es una delimitación territorial definida por el INEGI de una desagregación mayor a un municipio o una delegación política. Su principal propósito es su uso como unidad territorial mínima donde se efectúa el levantamiento de la información que el INEGI realiza en los diferentes censos, conteos y encuestas. Generalmente, la suma de un determinado número de AGEB conforma un municipio o una delegación política. 


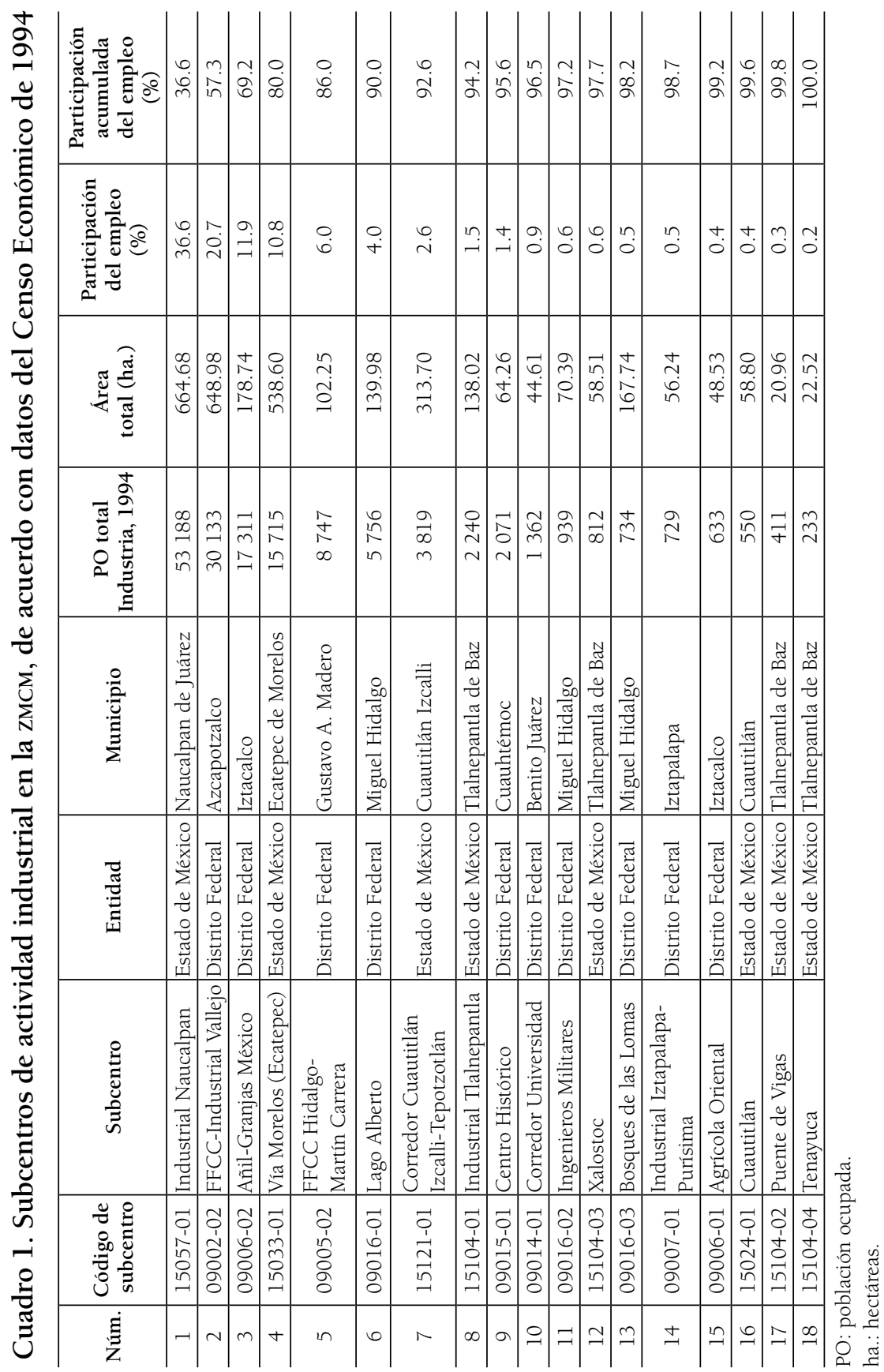


ordenados de acuerdo a su participación en número de empleos podemos ver los más importantes. Los primeros cuatro subcentros (Industrial Naucalpan, Industrial Vallejo, Granjas México y el Corredor Vía Morelos en Ecatepec) registraban 80\% del empleo industrial en la Ciudad de México.

Es claro que eran siete los subcentros industriales los que ocupaban alrededor de $80 \%$ del suelo para ese destino, y puede verse que algunos subcentros ocupan mucho suelo pero no absorben mucho empleo, como sería el caso del Corredor Cuautitlán IzcalliTepotzotlán, con una ocupación de casi 10\% del suelo industrial total, aunque apenas participa con $2.6 \%$ del empleo industrial.

Diez años después, la industria sufrió pequeños cambios (se detalla la información en el cuadro 2). En este caso, los subcentros aumentaron a 22, pero se tienen los mismos subcentros identificados de empleo industrial en la ZMCM usando datos del censo económico 2004, en cuyo caso son cinco los subcentros que abarcan $80 \%$ del empleo industrial, los mismos cuatro de hace 10 años más el corredor Cuautitlán Izcalli-Tepotzotlán.

Dos hechos a destacar. Primero, los dos principales subcentros industriales en 1993, según datos del Censo Económico 1994 (Industrial Naucalpan e Industrial Vallejo), pierden presencia 10 años después, ya que, aunque siguen siendo muy importantes, el nivel de empleo industrial que presentan en 2003 (datos del censo económico 2004) disminuye drásticamente (Naucalpan registraba $36.6 \%$ del empleo y 10 años después cayó a $28.7 \%$, e Industrial Vallejo posó de $20.7 \%$ a $14.8 \%$ ). El corredor Cuautitlán Izcalli-Tepotzotlán, en cambio, siendo séptimo lugar en 1993 subió a cuarto lugar 10 años después, pasando de una participación de 2.6 a 9.4\% del empleo industrial. Esto indica que la industria sufrió un desplazamiento desde las zonas tradicionalmente industriales como Miguel Hidalgo, Azcapotzalco y Gustavo A. Madero hacia zonas consideradas periferia en la actualidad, como Cuautitlán, Cuautitlán Izcalli o Tepotzotlán.

Otro dato importante: de acuerdo con el censo de 1994, los subcentros que captaban 80\% del empleo, registraban 116347 empleos industriales. Para el censo de 2004, los subcentros que 


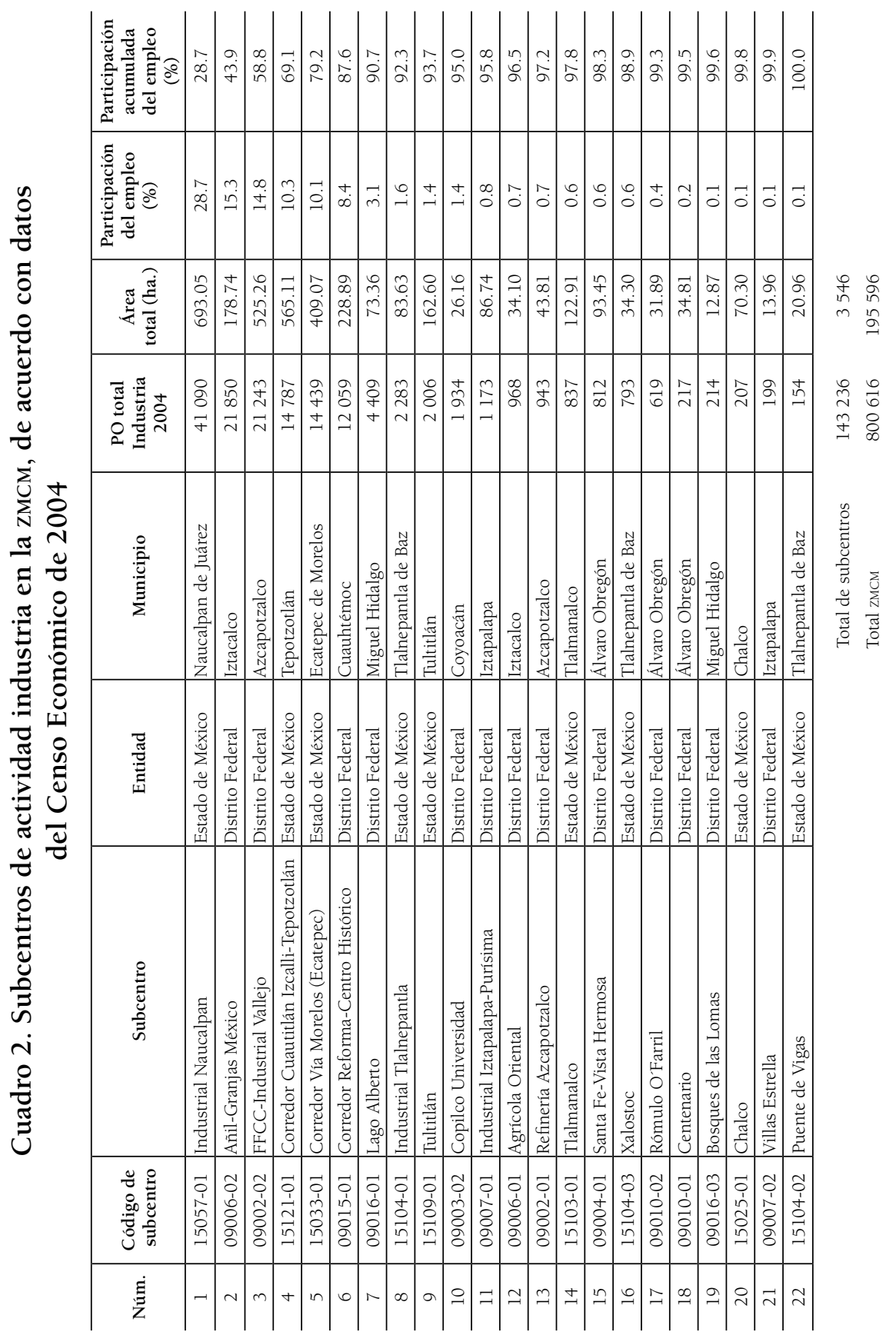


ocupaban el mismo 80\% del empleo generaban 113409 empleos industriales, lo que señala el desplazamiento y pérdida de la actividad industrial metropolitana. En los mapas 1a y b puede apreciarse la localización de los subcentros de empleo industrial referidos.

\section{La localización de la industria entre 1993 y 2003}

La industria en la ciudad tiende a ubicarse lejos del distrito central Central Business District (CBD). ${ }^{5}$ Primero se ubicó en nodos relativamente cercanos al CBD, en Azcapotzalco y Gustavo A. Madero y posteriormente Naucalpan al norte de la ciudad, cuando estos lugares eran periferia de la pequeña Ciudad de México de los años cuarenta.

Al darse la gran expansión de la ciudad, en los lugares tradicionales de actividad industrial se dio un incremento de costos en el suelo urbano como resultado del cambio en la rentabilidad del suelo y del nuevo grado de centralidad en estos sitios, teniendo que relocalizarse a las nuevas periferias de la ciudad. Por este motivo, la industria en la ZMCM se ha relocalizado en municipios como Cuautitlán Izcalli y Tepotzotlán formando un corredor alrededor de la autopista México-Querétaro. Lo mismo se puede decir de subcentros como el de Vía Morelos en Ecatepec. Generalmente, los subcentros en la periferia de una ciudad se localizan alrededor de las principales vías de acceso a la ciudad formando corredores, lo cual se debe a que en estos sitios se tienen los mayores niveles de accesibilidad a las zonas centrales de las ciudades [Ramírez, 2009].

Es claro que, aunque los antiguos subcentros como Industrial Vallejo o Industrial Naucalpan siguen teniendo un peso importante en la industria metropolitana, su tendencia es ya al decrecimiento y por lo tanto, al cambio en el uso de suelo. Para

${ }^{5}$ El CBD es considerado el centro económico más importante o el único (dependiendo de si se habla de una estructura de un solo centro o monocéntrica o bien de una estructura de varios centros o policéntrica). Su estudio y referencia en el análisis de todas las ciudades es clave para entender la actividad económica dentro de los espacios urbanos. 







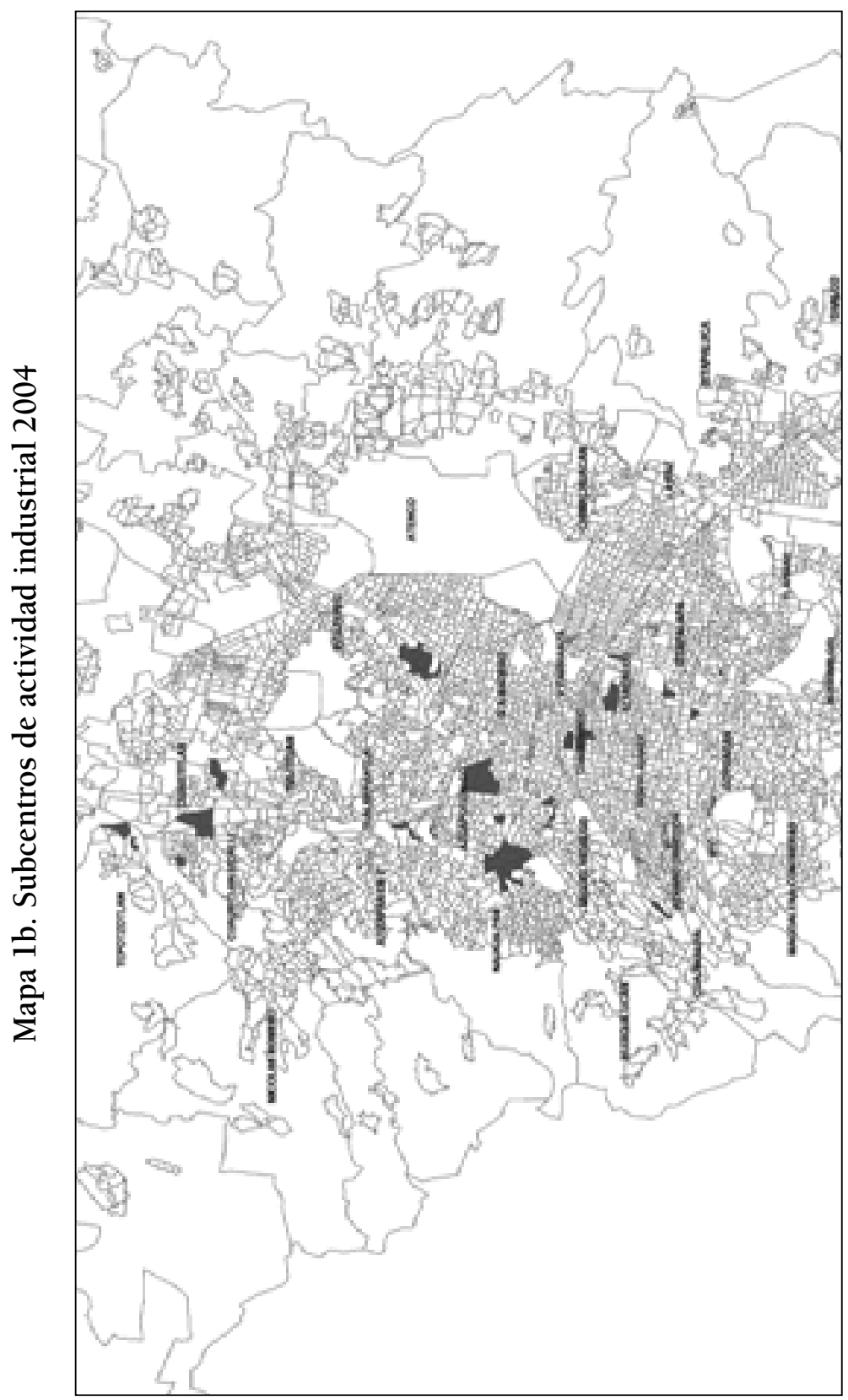


los próximos años, como se ha observado entre 1993 y 2003 , muy posiblemente el suelo de uso industrial cambiará al uso habitacional o de alguna actividad terciaria como el comercio o los servicios.

Lo mismo sucederá con otros como Añil o Martín Carrera e Industrial Tlalnepantla, que han comenzado a mostrar señales de agotamiento. La especialización en la industria de la metrópoli es eminentemente manufacturera, pues la industria pesada no tiene presencia en la ZMCM de acuerdo con los datos de los censos económicos del Instituto Nacional de Estadística y Geografía.

De este modo, las señales de tercerización en la Ciudad de México dan clara evidencia del cambio económico en la ciudad y su expresión espacial, lo cual tiene importantes implicaciones en materia de planeación urbana y planeación económica. Algunas autoridades locales han planteado la posibilidad de no recuperar los espacios que la industria va dejando, sino apuntalar la vocación en materia de servicios de la ciudad, sin meditar en las graves pérdidas que esto traería al tejido productivo de una ciudad como la de México y su inherente impacto en los empleos y en la competitividad urbana.

\section{EVOLUCIÓN DE LA ESTRUCTURA POLICÉNTRICA}

\section{industrial DE LA CiUdAD DE MÉXICO EN 2008}

Es claro que la estructura territorial de la actividad industrial de la Zona Metropolitana de la Ciudad de México está cambiando constantemente. Entre 1993 y 2003 se identificó plenamente que los centros industriales tradicionales y de mayor importancia en la ciudad, experimentaron lentamente un decrecimiento en términos de población ocupada, tal es el caso de zonas industriales en la ciudad como Industrial Vallejo (Gustavo A. Madero y Azcapotzalco), Naucalpan o Vía Morelos en Ecatepec de Morelos.

Por otra parte, nuevos centros industriales como los ubicados en Cuautitlán Izcalli, Tepotzotlán o Tultitlán están ganando participación, con lo que la evidencia empírica demuestra que 
los centros industriales localizados más cercanamente al centro de la ciudad están disminuyendo su importancia, misma que están ganando los nuevos centros localizados en la periferia de la ciudad.

De acuerdo con los datos revisados para 2008, en el último censo económico mexicano (censos económicos 2009) disponible, la industria en la Ciudad de México ha seguido menguando la importancia que tuvo hasta los años ochenta del siglo xx al perder alrededor de 3\% del empleo respecto del año 2003. Esto significa que la población ocupada en la industria de la Ciudad de México es, en número, similar a la que se tenía en 1988, en contraste con otros tipos de empleo, como del comercio y servicios, que se han multiplicado por tres y por seis respectivamente, en relación con su número total en 1988.

Esta pérdida ha tenido una expresión muy clara al reafirmar el proceso de tercerización económica experimentado en la ciudad lo cual está provocando que grandes extensiones de suelo urbano originalmente industrial se hayan despoblado para ser ocupadas por actividades de servicios, comercio o habitacional. Cabe decir, por ejemplo, que centros típicamente industriales como la zona industrial de Lago Alberto (en la actual delegación Miguel Hidalgo) han sido prácticamente sustituidos por nuevos centros y plazas comerciales dirigidas a los estratos económicos más elevados. Asimismo, es posible corroborar el vaciamiento industrial en zonas como Naucalpan o Industrial Vallejo, cuyos predios antes industriales se encuentran hoy vacíos o se han convertido en bodegas de artículos para comercialización, o en unidades habitacionales de interés social o interés medio.

De allí que se concluya que el proceso de sustitución de industria en la Ciudad de México continúa su marcha sin que hasta el momento las autoridades muestren proyectos o por lo menos intenciones de detener el detrimento de la actividad industrial.

\section{ESPECIALIZACIÓN EN LOS CENTROS}

INDUSTRIALES DE LA ZMCM

Las zonas industriales de la ciudad cumplen, como función 
principal, suministrar alimentos procesados, textiles, productos derivados de la madera, metal, plástico y productos químicos, entre otros; esto es, se abastece de productos procesados para la Ciudad de México, el principal mercado del país. De este modo, las zonas como Naucalpan, Tlalnepantla, Industrial Vallejo en Azcapotzalco, Cuautitlán Izcalli, Tepotzotlán, así como Xalostoc y Ecatepec en el norte, y las zonas como Añil, Parque Industrial Iztapalapa o Lomas Estrella en el oriente se especializan en las actividades mencionadas para el suministro a la ciudad, según pudo verificarse en la identificación de los subcentros industriales y su evolución.

¿Qué clase de actividades industriales específicas se realizan en los centros industriales identificados en la ciudad? Se dispuso de información de industria por AGEB con los censos económicos. La poca disponibilidad de información limita el análisis. No obstante, se calcularon los índices de especialización con la mayor desagregación disponible, es decir, a dos dígitos (sectores).

En el cuadro 3 se puede observar la especialización de los centros y subcentros manufactureros en la ZMCM, de acuerdo con el censo económico de 2004 (con una clasificación basada en una clave) conforme a lo cual: 1 significa especialización en alimentos, bebidas o textiles; 2, especialización en madera, papel, industria química o plástica; 3 , especialización en industria metálica, maquinaria, equipo o transporte, y 4, que el centro es de alta diversificación, es decir, no domina especialidad alguna.

Debido a que la poca precisión de los datos disponibles no permite efectuar un cálculo de coeficientes de especialización que distinga suficientemente los centros o subcentros industriales, es decir, que la mayoría resultan diversificados, es importante entonces conocer, dentro de esta diversificación, qué sector manufacturero es el de mayor peso. Por ello, se estableció un criterio para diferenciar si en el centro existe una especialización significativamente mayor que otras.

Se tienen tres sectores (de acuerdo a la clasificación de actividad económica SCIAN) de manufactura: alimentos y bebidas con textiles; artículos de madera y papel con productos químicos y de plástico, 





y finalmente productos metálicos junto con maquinaria y equipo.

De los tres sectores o grupos mencionados se calculó el coeficiente de especialización. Como es de esperarse, en la mayoría de los centros existe especialización en los tres grupos, lo que indica que estos centros son diversificados, sin embargo, en casi todos ellos sobresale alguno por un coeficiente significativamente mayor.

Por ejemplo, en el centro con clave ICD15057-01 (localizado en la zona industrial de Naucalpan) se observa que no existen distancias significativamente mayores entre los coeficientes de los tres sectores de actividad principales $(2.60,3.25$ y 2.80) por lo que puede asumirse alta diversificación en dicho centro. Sin embargo, en el subcentro ICD15104-01 (localizado en la zona industrial de Tlalnepantla), el coeficiente en el sector de productos metálicos, maquinaria y equipo (3.21) es significativamente mayor que los otros dos citados (1.60 y 2.68).

Los resultados del análisis de especialización pueden verse en el cuadro 3 y en el mapa 2. De este modo, es posible ubicar la actividad industrial de la ZMCM y la localización por especialización industrial. Puede verse que, por ejemplo, la zona industrial de Naucalpan, quizá por ser la de mayor importancia para la Ciudad de México, no se especializa en algo particular, sino que contiene todo tipo de manufactura en proporciones similares. Caso distinto es el de otras zonas industriales, como la de Vallejo (subcentro ICD09002-01), en la que predomina la manufactura de productos metálicos, fabricación de maquinaria y equipo, lo mismo que se identificó en la zona industrial de Tlalnepantla (subcentro ICD15104-01).

Asimismo, la zona industrial de Añil se especializa en el procesamiento de alimentos, bebidas y producción de artículos textiles; contempla las zonas de Añil y de Agrícola Oriental, ambas asentadas en la delegación Iztacalco.

Finalmente, en algunas zonas de la delegación Iztapalapa (Lomas Estrella y Granjas Esmeralda) se localiza industria de madera, papel, químicos y plásticos. En el caso de la delegación Xochimilco predomina industria química (específicamente in- 


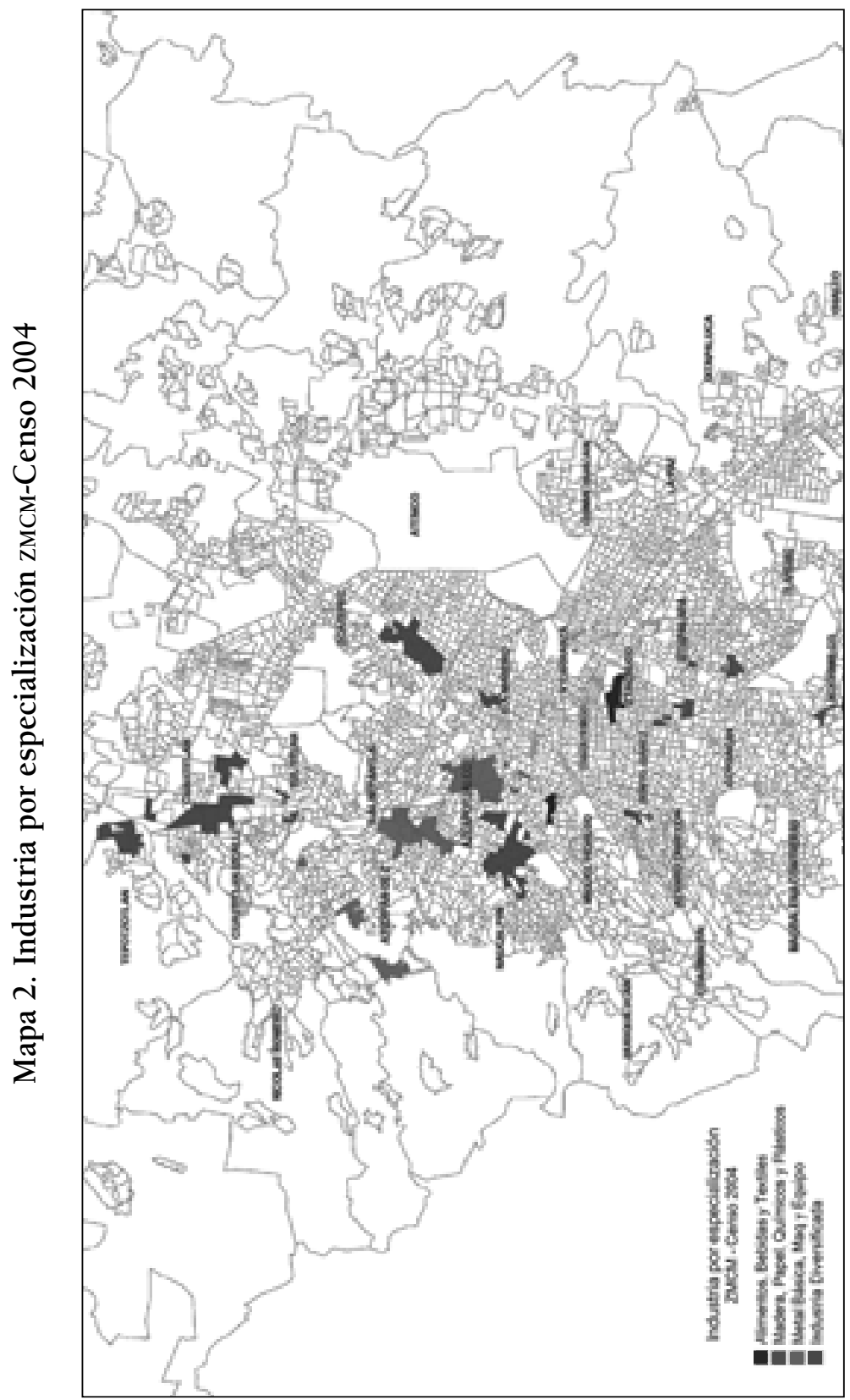


dustria de perfumería y laboratorios farmacéuticos).

\section{CONCLUSIONES}

Es patente a lo largo de este trabajo que los procesos de relocalización de la industria de la Ciudad de México son muy importantes para el periodo de 1993 a 2008. Los motivos para que se dieran estos desplazamientos, si bien en parte son explicados por costos urbanos (dadas las necesidades extensivas de suelo de la mediana y gran industria), también tienen que ver con los procesos de tercerización de una economía grande como la de la Ciudad de México. Ante la ausencia de políticas públicas para las ciudades o bien ante la mala aplicación de la política urbana, los procesos de tercerización se hacen muy evidentes y provocan pérdida del tejido productivo que la industria aporta, con consecuencias tales como pérdida de competitividad y de empleos.

Por otra parte, los constantes desplazamientos de la industria detonan nuevas necesidades en servicios urbanos (agua potable, nuevas vialidades, infraestructura urbana, etc.). Si asumimos que se dan fuera de todo proceso de planeación urbana es evidente que tendrán como consecuencia altos costos para los gobiernos locales, como es el caso del Distrito Federal y el Estado de México. De allí la necesidad de conocer bien estos procesos.

\section{REFERENCIAS}

Aguilar, G., y C. Alvarado [2004], "La reestructuración del espacio urbano de la ciudad de México. ¿Hacia la metrópoli multinodal?", Procesos metropolitanos y grandes ciudades, México, unAM, Miguel Ángel Porrúa/Cámara de Diputados, 35 pp.

Asuad, N. E. [2007], "Un ensayo teórico y metodológico sobre el proceso de concentración económica espacial y su evidencia empírica en la región económica megalopolitana de 1970 a 2000 y sus antecedentes" [inédito], tesis doctoral, México, 
UNAM, 370 pp.

L. Quintana y R. Ramírez [2007], "Desarrollo y políticas regionales en México: retos y perspectivas 2006-2020”, José Luis Calva Téllez (coord,), Políticas de desarrollo regional, 13, México, unAm/Miguel Ángel Porrúa/Cámara de Diputados, pp. 231-264.

, L. Quintana y R. Ramírez [2007], "Desarrollo y políticas urbanas en México: Retos y perspectivas 2006-2020”, José Luis Calva Téllez (coord.), Políticas de Desarrollo Regional, 13, México, unAm/Miguel Ángel Porrúa/Cámara de Diputado, pp. 353-383.

Baumont, C., y J. Le Gallo [1999], "Spatial analysis of employment and population density: the case of the agglomeration of Dijon, France”, real 03-T-6 [documento de trabajo], Regional Economics Applications Laboratory (real)], Chicago, Il, 42 pp. Conapo [1998], "Escenarios demográficos y urbanos de la Zona Metropolitana de la Ciudad de México, 1990-2010”, síntesis, documento de trabajo editado por Conapo, México, 120 pp.

Diario Oficial de la Federación [1941], Reglamento de Zonificación Industrial, publicado el 4 de febrero, tomo CXXIV, núm. 29, pp. 2-4.

Espinosa L., E. [2007], Ciudad de México, compendio cronológico de su desarrollo urbano 1521-2000, México D.F., Instituto Politécnico Nacional, 2a. ed., 325 pp.

García, M. A. e I. Muñiz [2005], "Descentralización del empleo: ¿compactación policéntrica o dispersión? El caso de la región metropolitana de Barcelona 1986-1996”, documento de trabajo del departamento de Economía Aplicada, Barcelona, España, Universidad Autónoma de Barcelona, 30 pp.

[2010], "El impacto espacial de las economías de aglomeración y su efecto sobre la estructura urbana. El caso de la industria en Barcelona 1986-1996", en Economía Aplicada, Facultad de Ciencias Económicas, Universidad de Zaragoza 68 (52): 91-119.

Giuliano, G., y K. Small [1991], "Subcenters at the Los Angeles Region", documento de trabajo del UCTC núm. 39 (The Uni- 
versity of California Transportation Center), Regional Science and Urban Economics (North-Holland), Elsevier Science Publishers B.V., (21): 163-182.

Giuliano, G., y C. Redfearn [2005], "Not all sprawl: evolution of employment concentrations in Los Angeles, 1980-2000", documento para publicación en Urban Studies, 57 pp.

Lombardo de Ruiz, S. [2000], "Evolución de México Tenochtitlan”, La Ciudad de México en el fin del segundo milenio, México, Colegio de México/Gobierno del Distrito Federal, $25 \mathrm{pp}$.

McDonald, J. F. [1987], “The identification of urban employment subcenters", en Journal of Urban Economics, (21): 242-258.

[2001], "Polycentric urban structure: The case of Milwaukee", en Economic Perspectives, mayo (segundo cuatrimestre), The Federal Reserve Bank of Chicago, 25: 15-27.

McMillen, D. P. [2003], "Employment subcenters and home price appreciation rates in Metropolitan Chicago", documento preparado para la obra Advances in Econometrics, Spatial and Spatiotemporal Econometric Methods, Chicago, Estados Unidos, James LeSage, University of Illinois, 18: 29.

Moran, P. A. P. [1948], “The interpretation of statistical maps”, en Journal of the Royal Statistical Society, B-10, UK, pp. 243-251.

Muñiz, I., Ma. García, y A. Galindo [2003], “¿Es Barcelona una ciudad policéntrica?", documento de trabajo del departamento de Economía Aplicada, Barcelona, España, Universidad Autónoma de Barcelona, 29 pp.

[2005], "Descentralización, integración y policentrismo en Barcelona”, documento de trabajo del departamento de Economía Aplicada, Barcelona, España, Universidad Autónoma de Barcelona, 30 pp.

Pan, Q., y Ma. L. [s.f.], "Employment subcenter identification: a gis-based method", documento de trabajo, Texas Southern University, Estados Unidos, 14 pp.

Ramírez, R. [2009], "La dispersión económica de la zona central de la Ciudad de México a su área metropolitana y sus efectos 
en la estructura económica del suelo urbano de la ZMCM: aplicación de un modelo matemático para el periodo de 1994 a 2004" [inédito], tesis de maestría, México, UnAm, 146 pp.

Sánchez A., A. [2004], Panorama histórico de la Ciudad de México, México, IIEc-UnAm, $116 \mathrm{pp}$.

Sánchez A., A. (coord.) [2011], "La evolución de la Ciudad de México", Consejo de Evaluación del Gobierno del Distrito Federal, documento de trabajo disponible en internet: $<$ http://www.evalua.df.gob.mx/files/transparencia/2011/ evpobcdm.pdf>, 5 de enero de 2013. 


\section{Capítulo 5 \\ COMPETITIVIDAD DE LAS PEQUEÑAS Y MEDIANAS EMPRESAS EN EL SECTOR MANUFACTURERO}

Evelia Rojas Alarcón*

\section{INTRODUCCIÓN}

Este trabajo es resultado de la participación en el proyecto de investigación denominado "El desarrollo tecnológico y la competitividad en la industria manufacturera", con el interés por desarrollar la temática sobre la competitividad de las pequeñas y medianas empresas (pymes) manufactureras, para destacar su importancia en la economía mexicana al ser el único sector capaz de generar riqueza y aumentar la productividad por medio de encadenamientos múltiples (hacia delante y hacia atrás) con el resto de la economía. Desde luego que el estudio de las pymes manufactureras está fundamentado en estadísticas que destacan su fortaleza en la economía nacional desde la perspectiva del mercado interno. En los estudios analizados en el seminario se observó la conveniencia de destacar la importancia de la participación de

* Académica del Instituto Politécnico Nacional (IPN) y participante en el proyecto de investigación PAPIIT IN305610. Correo electrónico: <eve720819@hotmail.com>. 
las pymes manufactureras en la economía nacional, como una alternativa que permitiera promover por medio de ellas el crecimiento económico sostenido, que le ha hecho falta a la economía nacional, desde hace más de tres décadas.

La hipótesis de este trabajo de investigación considera que, a pesar de que fueron desprotegidas en el nuevo modelo de desarrollo, las pymes manufactureras en México muestran tener posibilidades de convertirse nuevamente en factor de crecimiento económico, que atraigan el capital y generen empleo apoyadas por una política de financiamiento productivo.

Si bien este trabajo aborda algunos aspectos esenciales, no tiene alcances más amplios que convendría intentar en otro momento; se presenta un análisis en el que se detallan los obstáculos que enfrentan las pymes manufactureras con el fin de que, en otras líneas de investigación, se realice una propuesta más completa.

Se toman en cuenta tres aspectos para abordar la problemática de las pymes. Primeramente, se hace una breve descripción de los hechos que anteceden al origen y formación de las pymes; se pretende establecer las condiciones bajo las cuales surgieron y se han mantenido estos actores que apoyan al crecimiento y el desarrollo nacional, rescatando el fortalecimiento industrial derivado del modelo de industrialización sustitutivo de importaciones (ISI), a partir de la importancia que ese modelo de desarrollo ejerció sobre las pymes en el contexto de la economía nacional, así como sus efectos resultantes del crecimiento anual promedio superior al 6\% del PIB, lo que permitió impulsar a diversos sectores, tales como el de la educación superior, el financiero, la urbanización, la creación de infraestructura y el apoyo fiscal que impactaron de manera muy significativa en el desarrollo de las pequeñas y medianas empresas. El segundo aspecto del análisis se refiere a las circunstancias de la producción actual para definir las nuevas condiciones competitivas en el mercado mundial y el comportamiento de las empresas para la exportación. En tercer término, se plantea un análisis empírico por medio de entrevistas realizadas a pequeños y medianos empresarios para construir 
una narrativa directa de los dueños dirigentes (DD), que permita, desde la perspectiva metodológica, corroborar su conducta frente a los problemas de la iniciación, el crecimiento y el desarrollo de la empresa estudiada. Se evalúa la forma en que los empresarios hacen frente a las condiciones actuales de la competencia, pues, entre los casos expuestos, dos de ellos son de empresas exitosas que han logrado superar las condiciones que exige el mercado globalizado a partir de mantener cierta vinculación con instituciones educativas, así como su actitud frente a las necesidades de innovación para aumentar su capacidad competitiva.

En este capítulo se resalta la importancia de la participación de las pequeñas y medianas empresas manufactureras en la economía nacional, pero además la urgencia de establecer políticas públicas que generen el apoyo hacia las pymes de manera similar a las que se aplican a nuestros socios comerciales para que no desaparezcan.

\section{ANTECEDENTES DE LAS PYMES}

La participación de la industria manufacturera en la economía ha sido muy importante desde los años cuarenta, pues ha contribuido al crecimiento económico del país. El desarrollo industrial estuvo sustentado en la aplicación de la política de la ISI ${ }^{1}$ con una participación creciente del Estado como principal promotor de la inversión y articulador del crecimiento económico de las empresas, al proteger la naciente industria y el mercado interno por medio de altas y crecientes tarifas arancelarias, derechos de importación, tipos de cambios múltiples, subsidios e incentivos para promover las importaciones de bienes intermedios y de capital. El Estado atendió la demanda de créditos blandos, garantías a la propiedad, asistencia técnica, barreras arancelarias o facilidades para la importación y exportación de bienes y servicios,

${ }^{1}$ Un desarrollo más amplio de esta problemática se encuentra en el primer capítulo de este libro. 
lo que permitió que el sector privado también se desarrollara al cobijo de la inversión pública, principalmente por la inversión en infraestructura (electricidad, petróleo, ferrocarriles y otras comunicaciones básicas). Aplicó políticas comerciales de fomento (tasa de cambio, aranceles y control cuantitativo) como instrumentos de protección a la industria, entre ellos: los aranceles a la importación, los subsidios a las exportaciones, las licencias de importación (principal instrumento de protección y regulación de las compras en los mercados internacionales), los programas de fabricación y la política fiscal [Villarreal, 1998: 76].

El desarrollo industrial en la primera fase de la ISI impulsó la producción de bienes de consumo no durable (como ropa, calzado y enseres domésticos), y a sus insumos (como textiles, cueros y madera) para la producción nacional, es decir, el reemplazo de productos no duraderos por bienes producidos internamente, lo que permitió la ampliación significativa de las pequeñas y medianas empresas, con encadenamientos hacia adelante y hacia atrás que favorecieron un desarrollo más equilibrado de diversos sectores, que además aprovecharon estas circunstancias para incrementar las exportaciones de las manufacturas con una competitividad aceptable, a pesar de que la prioridad fuera el desarrollo del mercado interno. Se fortaleció el sector industrial, además de sectores como el de la educación y el financiero [Moreno-Brid, 2009: 103; Ros, 2008]. El periodo de auge duró más de tres décadas, durante las cuales permitió la consolidación de la economía mexicana y constituyó uno de los periodos de crecimiento más importantes de la misma. Haciendo un balance general, el modelo isi para México fue positivo, considerando que se tuvo un crecimiento promedio anual de $6.5 \%$ en el periodo 1940-1970 [Olivera, 2008: 63].

Con base en lo anterior, se puede decir que de 1940 a 1970 la industrialización estuvo apoyada en estrategias tales como canalización selectiva del crédito, la inversión pública en infraestructura, los subsidios y otros estímulos fiscales, lo que favoreció avanzar y fortalecer el mercado interno en ese momento. Además, entre 1968 y 1974 hubo un gran auge en la economía, fincado sobre todo 
alrededor de la producción de bienes de consumo durables, con los automóviles y accesorios eléctricos como principales artículos [Robinson, 1952: 99].

Un factor esencial que contribuyó al fortalecimiento industrial fue la participación del Estado en el financiamiento -que determinó en buena medida las características de la política monetaria aplicada por el Estado-, además de que no se utilizó la política impositiva como fuente de financiamiento autónomo; al mismo tiempo, esto originó que la participación de los impuestos en el ingreso nacional disminuyera de $9.5 \%$ en 1939 a $7.4 \%$ en 1958 , provocando que el gobierno se financiara en forma considerable mediante la emisión primaria de dinero y que por lo tanto la oferta monetaria creciera a $19 \%$ en promedio anual durante el mismo periodo [Villarreal, 2005: 35].

Con base en estos aspectos, cabe destacar que la política pública utilizó tres instrumentos para fortalecer la inversión en el sector industrial: el encaje legal, el encajonamiento de créditos y el impulso de los bancos de desarrollo. El primero tuvo que ver con una alianza de clases entre la fracción que controló el Estado y el capital financiero. Mientras que el segundo y el tercero permitieron que se tuviera una fuerte injerencia en el financiamiento a la inversión mediante la canalización de recursos públicos y privados por el mecanismo del encaje legal y de las políticas selectivas de créditos a sectores considerados "prioritarios". Por el lado de los bancos privados, se aplicaron redescuentos, reglamentación para la cobertura de los valores emitidos por instituciones de crédito, topes de crecimiento en la captación en ciertos instrumentos y convenios que permitieron canalizar recursos hacia la producción mediante fideicomisos especiales. Todos estos instrumentos fueron coordinados por el Banco de México.

A pesar de que hubo una clara conexión corporativa y de propiedad entre el sector financiero y las empresas, no se desarrolló una relación robusta entre el financiamiento, la inversión y la producción, de manera que las políticas monetarias diseñadas para direccionar el crédito a sectores "prioritarios" fueran un elemento central en el crecimiento de la producción, ni se acompañaran 
de un marco jurídico que estableciera de manera clara las reglas, normas y periodos de financiamiento [Levy, 2001: 165].

En estas condiciones, al estar la política de canalización de recursos sustentada en los coeficientes de liquidez denominados encaje legal, tomaron la forma de depósitos que el Banco Central usó como recursos para regular las reservas internacionales, financiar al gobierno y dar crédito a los intermediarios financieros, principalmente a los fideicomisos de fomento, como lo plantea Sánchez-Lugo, citado por Mántey [2010: 184]. Esto propició desequilibrios en la economía mexicana a finales de los años setenta, aunado a una apertura comercial rápida, amplia e indiscriminada, así como a reformas institucionales tendientes a estimular la inversión extranjera y un libre movimiento de capitales, dando paso a un cambio estructural denominado comúnmente neoliberalismo. ${ }^{2}$ Este cambio afectó al sector manufacturero, no solo en su participación en el PIB, sino también en la generación de empleo, crecimiento del sector y en la creación de tecnología.

En el capítulo 1 se mencionan los problemas que presentó la ISI en cuanto a la incapacidad creciente de convertirse en exportadora de sus mercancías, además del atraso tecnológico, los subsidios, la corrupción, el déficit público, el grado de endeudamiento externo y, en general, la excesiva participación del Estado en la actividad económica, que obligaron a cambiar de estrategia de desarrollo y encaminarse hacia un proceso de reestructuración, modernización y saneamiento industrial para que las empresas fueran capaces de incorporarse a la globalización.

La economía de libre mercado planteó que la política de industrialización debería estar concentrada en la liberalización del mercado interno, y en el establecimiento de garantías de seguridad y no discriminación a las inversiones en México, además de crear derechos superiores para los grandes corporativos privados al derribar las barreras que impedían la circulación mundial de

${ }^{2}$ El modelo neoliberal se caracteriza por el alejamiento del Estado en la actividad económica directa y deja al mercado la solución de los problemas de acumulación; su acción está encaminada a establecer los mecanismos de regulación que permitan el flujo financiero, las privatizaciones y la apertura comercial. 
mercancías, al tiempo que los países desarrollados impusieron nuevas formas de protección de sus propios mercados internos. Aunado a lo anterior, como se menciona en el capítulo 1, a las grandes trasnacionales se les permitió la libre circulación de productos lo que no sucedió con muchos productos nacionales que requerían autorización para su venta, mediante diversos pretextos que impidieron en los hechos el cumplimiento de los acuerdos signados por los países involucrados.

Los resultados de la política de apertura económica en el sector industrial se manifestaron en la quiebra de un gran número de empresas, particularmente micro, pequeñas y medianas, con el consecuente incremento del desempleo. Asimismo, las nuevas relaciones en el mercado internacional profundizaron la dependencia y subordinación de nuestro país al exterior, pues se enfrenta a una competencia por completo inequitativa, con un sector industrial sumamente fragmentado y graves problemas de atraso tecnológico, crecimiento constante del desempleo y bajos niveles de crecimiento económico.

Como ya se mencionó, las condiciones en que se aplicó el modelo IsI favorecieron el fortalecimiento de la producción industrial para el mercado interno, al sustentarse en una estrategia económica basada en la amplia participación del Estado en la actividad económica, considerando que el sector privado nacional carecía en ese momento de la capacidad necesaria para detonar el crecimiento económico. Así, el estímulo a una clase empresarial posibilitó que la economía, por medio de una estructura proteccionista y de impulso a la industrialización, creciera de manera sostenida [Villarreal, 2005: 32]. El Estado, durante estas tres décadas, generó la infraestructura necesaria mediante una política fiscal que se encaminó hacia el estímulo del ahorro y la inversión productiva, exenciones tributarias a los ingresos de capital y subsidios a los sectores productivos para elevar las utilidades, mejora del transporte, las comunicaciones, la energía, el agua, etc., y a la par la educación, la salud y el bienestar general de la población [Flores, 2010: 79]. La intervención directa del Estado, mediante el suministro de infraestructura básica, se complementó con la 
política comercial aplicada durante ese periodo, la cual consistió en el uso de aranceles, y el otorgamiento de subsidios y restricciones a las importaciones [Ros, 2008: 540]. También fue importante la estructura crediticia que se creó para las empresas públicas y privadas por medio de créditos de mediano plazo con una participación de $64 \%$ del total por parte de la banca privada, y seguido por las instituciones nacionales de crédito (banca de desarrollo) con una participación de 37\% [Levy, 2001: 43].

\section{SiTUACIÓN ACTUAL DE LAS PYMES}

En la República mexicana existen 5144056 empresas formalmente establecidas, de las cuales las mipymes representan $99.8 \%$ del total y generan $78.5 \%$ del empleo nacional y $52 \%$ del producto interno bruto (PIB), además de ser proveedoras de bienes intermedios para las grandes empresas, y en algunos casos, formar encadenamientos productivos significativos [Álvarez, 2012: 15].

De acuerdo con un estudio realizado por el Sistema Económico Latinoamericano y del Caribe (Sela) a escala global, las pymes también tienen suma importancia, pues constituyen más de $90 \%$ de las empresas en la mayoría de los países del mundo, independientemente de la clasificación que se haga de estas en cada país. ${ }^{3}$ En la Unión Europea y en Estados Unidos, por ejemplo, representan $95 \%$ de las unidades económicas y proveen más de $75 \%$ de los puestos de trabajo. En América Latina, estudios empíricos estiman que estas contribuyen entre 35 y $40 \%$ a la generación de empleo en la región, 33\% del PIB y 25\% de la inversión [Sela, 2009: 4]. Pese a estas cualidades, las pymes también se caracterizan por tener una alta tasa de mortalidad, debido a problemas de permanencia en el mercado por diferentes circunstancias. En países como México, 24\% de las nuevas empresas han cerrado dos años después, y $53 \%$ antes de los cuatro

${ }^{3}$ Por ejemplo, una mediana empresa, en México, puede ser considerada pequeña en un país de Europa. 
años [Benavente, 2005: 4], debido entre otras circunstancias a que tienen bajas ventas, con lo que se entorpece la cobertura de algunos pagos, tales como impuestos, nómina y seguro social, entre otros. Un problema adicional, que es motivo de preocupación, es el alto porcentaje de empresas que operan en la economía subterránea, con lo cual se dificulta la operación gubernamental para la aplicación de políticas públicas y desde luego, la recaudación de impuestos.

A partir de la aplicación del modelo neoliberal, el Estado dejó de ser promotor, y en su lugar adoptó el papel de complemento de la actividad económica generada por el sector privado, caracterizándose por la desregulación del sistema financiero, así como por el uso de instrumentos de política basados en la libre operación de los mercados y de una completa apertura comercial, mismos que se han visto reflejados en el crecimiento del PIB, ya que a partir de su implementación este ha oscilado entre 2.0 y 3.0 por ciento.

Aunado a lo anterior, la evolución económica que ha presentado la economía mexicana durante el modelo neoliberal, analizada a partir del comportamiento de la inversión y el ahorro, ha sido inestable, marcada por la recurrencia de ciclos económicos de corto plazo [Garrido y Padilla, 2007: 95]. En términos generales, esto ha representado un entorno extremadamente desfavorable para la actividad empresarial, y en particular para el sector manufacturero, al presentar en tres periodos casi consecutivos una disminución en la producción neta: 1995, 2001-2002 y 2009; con una ligera recuperación para las dos últimas décadas. Por otra parte, la participación de la industria manufacturera en la producción nacional no ha variado sustancialmente, de modo que su aporte al PIB, por ejemplo, no llega a $20 \%$ y crece a un ritmo ligeramente mayor que el del resto de la economía, pues la tasa de crecimiento promedio del PIB total a partir de 1994 apenas llegó a 2.6\%, mientras que para este sector ha sido de $2.8 \%$, esto debido a que el sector comprende nueve divisiones: alimentos, bebidas y tabaco; textiles, vestido y cuero; madera; papel, imprentas y editoriales; química, derivados del petróleo, caucho y plástico; 
minerales no metálicos; metálicas básicas; maquinaria y equipo, y otras manufacturas (véase el cuadro 1) [Alemán, 2012: 55].

\section{Cuadro 1. Participación por división de la industria manufacturera en el PIB, 1995-2010}

\begin{tabular}{l|r|r|r|r}
\hline \multicolumn{1}{c|}{ Industria manufacturera } & \multicolumn{1}{c|}{1995} & \multicolumn{1}{c|}{2000} & \multicolumn{1}{c}{2005} & \multicolumn{1}{c}{2010} \\
\hline Alimentos, bebidas y tabaco & 30.41 & 25.16 & 28.10 & 28.71 \\
\hline Textiles, vestido y cuero & 7.98 & 7.67 & 5.90 & 5.13 \\
\hline Madera & 1.75 & 1.60 & 1.18 & 1.11 \\
\hline Papel, imprentas y editoriales & 3.16 & 2.98 & 2.99 & 3.27 \\
\hline Química, derivados del petróleo, & 17.72 & 15.25 & 15.78 & 14.70 \\
caucho y plástico & 6.57 & 5.99 & 6.68 & 6.29 \\
\hline Minerales no metálicos & 8.49 & 8.84 & 9.39 & 8.58 \\
\hline Metálicas básicas & 21.89 & 30.63 & 27.94 & 29.96 \\
\hline Maquinaria y equipo & 2.02 & 1.87 & 2.02 & 2.26 \\
\hline Otras manufacturas
\end{tabular}

Fuente: Alemán [2012: 56].

De acuerdo con el índice del volumen físico de la producción manufacturera, las ramas que más destacaron durante el periodo 2004-2011 fueron las de alimentos, bebidas y tabaco y la de productos metálicos, maquinaria y equipo, por lo que se definen como las más importantes del sector, como se observa en el cuadro 2.

La gráfica 1 muestra la tendencia de la producción de la industria manufacturera en el periodo 1993-2011, con la finalidad de observar los tres periodos que se mencionaron en la producción neta: 1995, 2001-2002 y 2009. Así, se registra una ligera recuperación para las dos últimas décadas, en 1994-1995 hay una caída de la producción debido a la crisis de 1994 y a partir de 1996 hay un crecimiento sostenido hasta 2001-2002, que es el segundo periodo de disminución en la producción total del sector manufacturero y el último que se da en 2009 por la crisis financiera de Estados Unidos ocurrida en 2008. 


\section{Cuadro 2. Índice de volumen físico de la producción manufacturera, 2004-2011}

\begin{tabular}{l|r|r|r|r|r|r|r|r}
\hline \multicolumn{1}{c|}{ Concepto } & 2004 & 2005 & 2006 & 2007 & 2008 & 2009 & 2010 & 2011 \\
\hline Alimentos, bebidas y tabaco & 210.6 & 220.9 & 230 & 236.6 & 241.3 & 240.6 & 242.4 & 250.3 \\
\hline Textiles, vestido y cuero & 103.7 & 98.0 & 99.0 & 95.9 & 89.2 & 80.5 & 88.4 & 83.7 \\
\hline Madera & 99.8 & 98.7 & 100.1 & 104.2 & 96.3 & 92.1 & 98.0 & 104.2 \\
\hline Papel, imprentas y editoriales & 104.8 & 108.3 & 112.8 & 116.2 & 119.1 & 118.5 & 124.1 & 123.1 \\
\hline $\begin{array}{l}\text { Química, derivados del } \\
\text { petróleo, caucho y plástico }\end{array}$ & 103.3 & 106.1 & 110.3 & 112.6 & 105.8 & 104.7 & 105.4 & 106.0 \\
\hline $\begin{array}{l}\text { Minerales no metálicos } \\
\text { Metálicas básicas }\end{array}$ & 104.8 & 111.4 & 119.1 & 121.9 & 117.3 & 107.4 & 111.1 & 115 \\
\hline $\begin{array}{l}\text { Productos metálicos, } \\
\text { maquinaria y equipo }\end{array}$ & 218.4 & 235.3 & 250.9 & 249.5 & 250.5 & 209.9 & 254.5 & 283.4 \\
\hline Otras manufacturas & 105.4 & 110.3 & 121.9 & 126.0 & 128.1 & 127.2 & 130.5 & 134.4 \\
\hline
\end{tabular}

Fuente: Elaboración propia con base en los datos del Anuario Económico y Financiero, 2012.

\section{Gráfica 1. Producción total de la industria manufacturera, 1993-2011 (millones de pesos)}

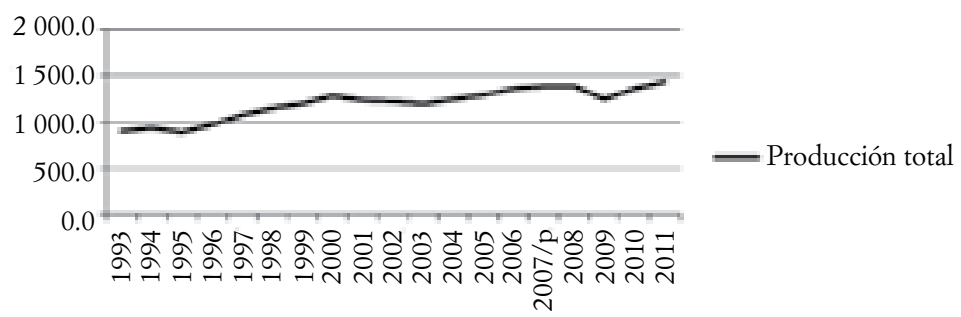

Fuente: Anuario Económico y Financiero, 2012

* p/Preliminar desde la fecha que se indica

Es claro que el sector manufacturero adquiere gran importancia en la creación de empleo y crecimiento económico, pues, a pesar de que ha disminuido su participación, es el sector que más aporta en el desarrollo económico. Los países de mayor crecimiento son aquellos que presentan una mayor expansión de 
su sector manufacturero, pues los rendimientos del sector suelen ser crecientes dado que requiere un nivel mayor de empleo, lo que posibilita que la mano de obra de los sectores menos productivos se beneficie con la creación de empleos indirectos en la industria [Kaldor, 1966: 77].

El sector manufacturero junto con el agroindustrial son los únicos capaces de generar riqueza y aumentar la productividad de un país mediante los encadenamientos múltiples (hacia delante y hacia atrás) con el resto de la economía. Si la industria manufacturera no crece, las posibilidades de ampliar la producción al resto de los sectores se reduce. Pero como se observó en el análisis anterior, al pasar el Estado de promotor y generador de crecimiento económico a complemento de la actividad económica del sector privado, las condiciones para el sector manufacturero se modificaron y están actualmente centradas en políticas de apoyo solamente por medio de programas que pretenden impulsar la producción nacional [Secretaría de Economía, 2011].

Las condiciones de crecimiento de las pymes manufactureras han cambiado debido a que su permanencia se torna más difícil en el mercado, al tener una competencia más intensa con productos importados de precios mucho más bajos, que en gran medida son favorecidos por el Estado mediante subsidios o disminución de aranceles a importaciones, lo que dificulta sostener costos por parte de las pymes nacionales. Además, las pymes requieren también mejorar la calidad y competitividad de sus productos y para ello necesitan inversión en su producción. Las pymes deben acudir a una institución financiera para hacerse de recursos e invertirlos; sin embargo, para algunas empresas el crédito se torna inaccesible, al no cumplir con todos los requisitos que pide el prestamista.

$\mathrm{Al}$ ser un complemento de la actividad económica en el modelo neoliberal, el Estado ha creado programas que proporcionan cierta ayuda a las pymes que carecen de acceso a la banca múltiple. Los programas son muy diversos y de fin específico, de manera que solo serán beneficiadas aquellas empresas que tengan las características que pide el programa.

Entre los programas existentes para el financiamiento de las 
empresas podemos mencionar:

1. Programa de Crédito Productivo. Impulsado por Nacional Financiera, S. A. Está dirigido a micros y pequeñas empresas afiliadas a programas de cadenas productivas de la industria, comercio y servicios, así como a personas físicas con actividad empresarial, proveedoras de empresas de primer orden. Es importante señalar que para obtener el financiamiento requieren un año de antigüedad como proveedor, una situación financiera sana, aval del principal socio accionista para personas morales, comprometer en factoraje las cuentas por cobrar con el intermediario financiero que otorga el crédito y aprobación del financiamiento de acuerdo con las políticas de las instituciones que evalúen. El monto máximo del crédito es 3.5 millones de pesos a una tasa de interés según el intermediario financiero de $\mathrm{TIIE}^{4}+12$ con una comisión por apertura de hasta $2 \%$ y un pago mensual de capital más intereses.

2. Programa de Fondos Sectoriales. Impulsado por el Consejo Nacional de Ciencia y Tecnología (Conacyt). Se trata de fideicomisos que las dependencias y las entidades de la Administración Pública Federal, conjuntamente con el Conacyt, constituyen para destinar recursos a la investigación y desarrollo tecnológico en el ámbito sectorial, así como a las universidades e instituciones de educación superior públicas y particulares, centros, laboratorios, empresas públicas y privadas y demás personas morales que se encuentran inscritas en el Registro Nacional de Instituciones y Empresas Científicas y Tecnológicas que puedan brindar soluciones a las problemáticas de estos sectores. El monto que se les asigna es de acuerdo con la razón social y la línea de investigación.

3. Programa Fondo Sectorial para la Investigación, el Desa-

${ }^{4} \mathrm{La}$ tasa de interés interbancaria de equilibrio (TIIE) es una tasa representativa de las operaciones de crédito entre bancos, y se calcula diariamente (para plazos de 28, 91 y 182 días) por el Banco de México. Es un mecanismo diseñado para reflejar las condiciones del mercado de dinero en moneda nacional. 
rrollo y la Innovación Tecnológica Forestal. Impulsado por el Consejo Nacional Forestal (Conafor) y el Conacyt. Va dirigido a aquellos proyectos que tengan viabilidad científica y tecnológica de laboratorio o con aprobación en su caso de los comités de ética o bioseguridad de las instituciones, con la finalidad de fomentar la investigación forestal y la transferencia de tecnología, privilegiando actividades que aporten valor agregado a las materias primas forestales, al desarrollo humano forestal sustentable o a la mejora de procesos productivos.

Estos programas son algunos ejemplos de financiamiento destinado a la investigación y desarrollo por parte del Estado, en los que los montos asignados al sector manufacturero han ido a la baja, pues a medida que se restringe la disponibilidad de los recursos para las actividades productivas, se reducen también las oportunidades por parte de las empresas de generar mayor productividad, innovación y empleo, por mencionar algunas, y por tanto se anula la posibilidad de una recuperación del crecimiento económico. En este sentido, cabe mencionar lo que argumentó Thiel [2001: 6] "el crecimiento económico depende de la acumulación proveniente de la inversión en el proceso de producción y el progreso técnico". Desde tal perspectiva, con el limitado financiamiento que el Estado ha destinado para el desarrollo de las pequeñas y medianas empresas, es posible corroborar lo anterior.

La importancia de la tecnología radica, de acuerdo con Carlota Pérez [2009: 21], en la innovación, según la cual el crecimiento de las empresas o los países -y en particular la posibilidad de dar un salto al desarrollo- está basado en sacar ventaja de la innovación tecnológica. Pero no basta con identificar una oportunidad tecnológica y de mercado, hace falta también una organización adecuada para aprovecharla, tanto de lo que se va a hacer, como del modo de hacerlo; son igual de importantes, dado que si la organización no es la adecuada, incluso con una buena 
oportunidad de financiamiento y de mercado, es imposible avanzar.

Los grandes cambios en innovación tecnológica en el transcurso de la historia han permitido el crecimiento económico y el desarrollo de la sociedad. Generalmente, los países desarrollados son los que invierten más de $2 \%$ del PIB en gastos de investigación y desarrollo experimental, mientras que países como México le destinan un porcentaje muy pequeño $(0.38 \%)$ [Olivera, 2008: 70]. Esto se debe principalmente a que se atiende como primera instancia a los factores que causan la inflación estructural, hecho que contribuye de manera directa al rezago en la innovación tecnológica, característico de los países desindustrializados; por ello, es imprescindible que se aplique una política monetaria antiinflacionaria, integrada a un programa de industrialización de largo plazo y que se apoye con los recursos financieros internos necesarios [Mántey, 2010: 182].

Dentro del sector manufacturero, solo $10 \%$ de los establecimientos presentan alta tecnología en ramas como: carnes, bebidas, hilados, tejidos, y fibras blandas, manufactura de celulosa y sus derivados e industria del coque [De la Garza, 2006: 89], lo que indica el grado de atraso del sector manufacturero, que a pesar de ello es uno de los que más aporta en el producto interno bruto. Particularmente porque existen sectores más relevantes, tales como: alimentos, bebidas y tabaco, maquinaria y equipo, ambos con una participación de casi 30\% del total de toda la industria manufacturera, como se observa en el cuadro 1.

\section{ANÁLISIS DE LAS PYMES MANUFACTURERAS}

La literatura existente sobre el análisis de las micros, pequeñas y medianas empresas deja claro que los investigadores han enfrentado el problema de utilizar más de una acepción para el término pyme o mipyme. Existe coincidencia sobre la importancia que tienen estos actores de la producción en la generación de la 
riqueza nacional. Entre los criterios más utilizados para clasificarlas están: por personal ocupado, así como el de sector económico al que pertenecen [Pavón, 2010]. De acuerdo con Pavón [2010], las diversas instituciones gubernamentales en México y en el ámbito internacional que utilizan los términos pyme, así como mipyme:

consideran como pyme a la micro, pequeña y mediana empresa, como lo hacen el Banco de México (Banxico), el Instituto Mexicano del Seguro Social (IMSS), la Unión Europea (UE) y la Organización para la Cooperación y el Desarrollo Económico (OCDE), y no excluyendo a la microempresa como lo hacen el Instituto Nacional de Estadística y Geografía (INEGI) o la Asociación de Bancos de México (ABM) que cuentan con el término mipymes [sic]. En el caso de estas instituciones, aun cuando se excluye a las microempresas de las pymes, el desglose de cifras permite integrarlas en el estudio. Sea cual fuere la definición utilizada, se considera para su clasificación, tanto el criterio de personal ocupado como el de sector económico [Pavón, 2010].

Desde luego que el estudio de estos agentes económicos es importante, porque constituyen la fortaleza de la economía nacional desde la perspectiva del mercado interno, ya que ocupan a alrededor de $70 \%$ de la población económicamente activa, en particular del personal ocupado en la industria manufacturera y generan más de 50\% del producto interno bruto. Según la misma fuente, citando a la Secretaría de Economía, estas empresas contribuyeron con $64 \%$ del empleo [SE, 2008]. Estas cifras representan la situación específica del momento en que se recopiló la información; pero por sus características de tamaño y encadenamiento con otras empresas, presentan una gran variabilidad, a causa, entre otras razones del periodo de vida útil real de las mismas, el cual es muy corto, además de su alto y volátil componente informal, como lo señala la OCDE [2007].

Las pymes han sido señaladas en diversos estudios como empresas que no crecen, de baja productividad y que cierran en corto tiempo, también se ha indicado su falta de adopción de 
tecnologías modernas y su alto contenido de informalidad, aunque muestran, por lo general, un menor componente importado en sus insumos y bienes de capital, y se adaptan con mayor facilidad a los distintos escenarios macroeconómicos, dada su estructura y funcionalidad [Pavón, 2010]. Si bien es una forma de apreciar a las pymes, al mismo tiempo se destacan otros aspectos favorables, como su capacidad para emplear mayor cantidad de trabajadores, es decir, que son más intensivas en trabajo, por lo que facilitan una mejor distribución del ingreso.

En el siguiente apartado se muestra un panorama de la estructura de este sector en la economía mexicana, en los años recientes. Estos datos representan la situación en la fecha que se indica, pero seguramente habrán cambiado dado que el sector de las pymes se transforman constantemente, tanto en su estructura como en su valor específico respecto de la economía en su totalidad.

Las unidades económicas han pasado de 3.5 millones de empresas en 1998 a poco menos de 5.2 millones en 2008, en tanto que el personal ocupado aumentó de 17.1 millones de personas en el primer año a 27.7 millones en el segundo; se incorpora tanto el sector manufacturero como el comercio y los servicios, lo que demuestra la importancia de las pymes en la economía en su conjunto (véase el cuadro 3 ).

En lo que corresponde al número de establecimientos por tamaño de la empresa, las microempresas representan más de $95 \%$ y, aunque este valor ha disminuido, su importancia sigue siendo predominante por el número de establecimientos. Por su parte, la pequeña y mediana empresa registran un porcentaje mucho menor, pero su peso relativo se ha incrementado significativamente al pasar de 1.9 a $4.1 \%$ y siguen representando los sectores de mayor ocupación por ser altamente intensivas en trabajo con respecto a las empresas grandes, que a su vez en términos relativos se elevaron de 0.2 a $0.3 \%$ en el mismo periodo aunque por su fortaleza en el empleo tienen un porcentaje absoluto mayor que las mipymes (véase el cuadro 4). 

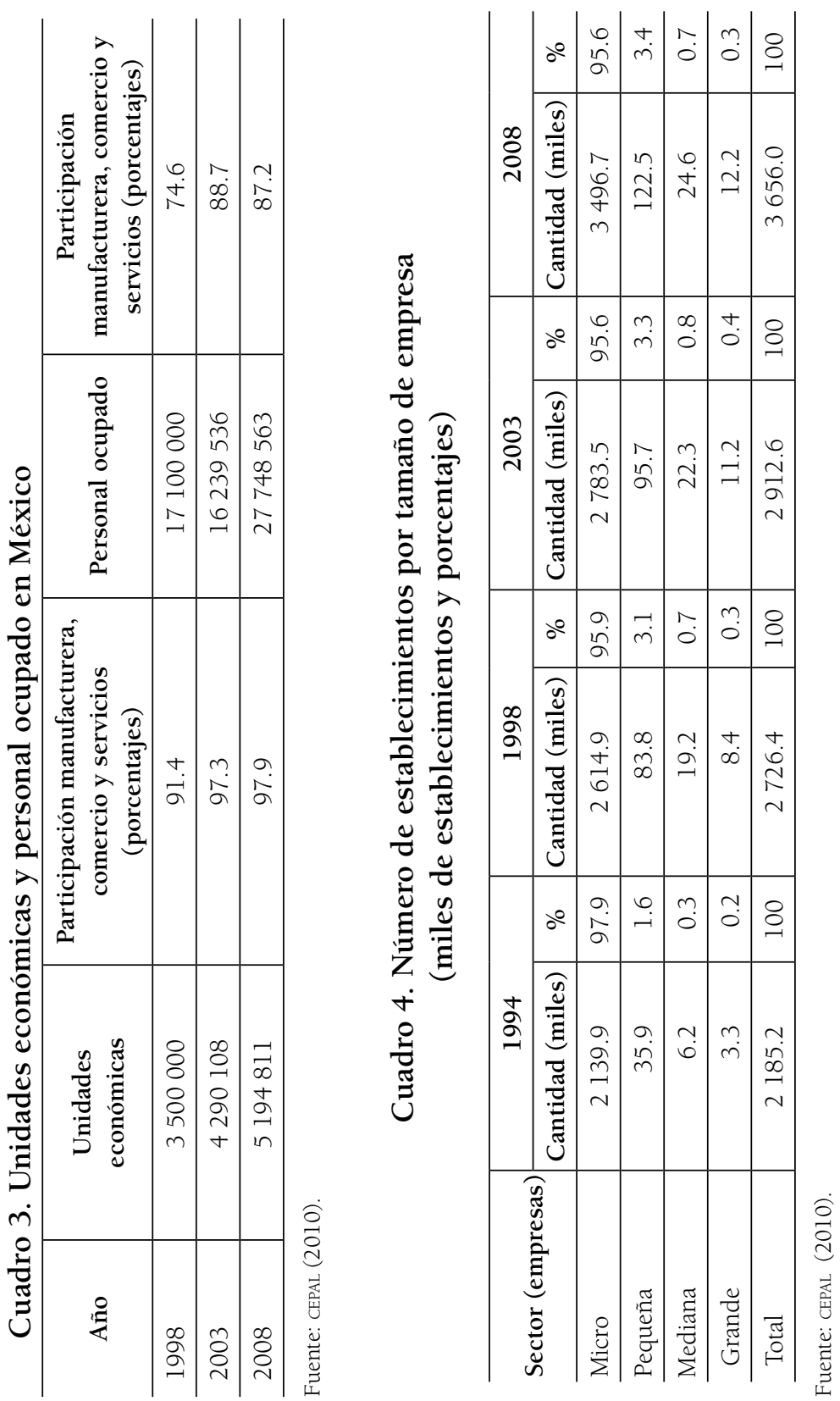


\section{Cuadro 5. Personal ocupado por tamaño de empresa (miles de personas y porcentajes)}

\begin{tabular}{l|c|c|c|c|c|c|c|c}
\hline \multirow{2}{*}{ Sector } & \multicolumn{2}{|c|}{1994} & \multicolumn{2}{c|}{1998} & \multicolumn{2}{c|}{2003} & \multicolumn{2}{c}{2008} \\
\cline { 2 - 10 } & $\begin{array}{c}\text { Cantidad } \\
\text { (miles) }\end{array}$ & $\%$ & $\begin{array}{c}\text { Cantidad } \\
\text { (miles) }\end{array}$ & $\%$ & $\begin{array}{c}\text { Cantidad } \\
\text { (miles) }\end{array}$ & $\%$ & $\begin{array}{c}\text { Cantidad } \\
\text { (miles) }\end{array}$ & $\%$ \\
\hline Micro & 4633.4 & 49.4 & 5180.3 & 42.1 & 6032.1 & 42.7 & 8236.1 & 46.6 \\
\hline Pequeña & 1349.9 & 14.4 & 1657.1 & 13.1 & 1870.2 & 13.2 & 2172.4 & 12.3 \\
\hline Mediana & 1570.2 & 16.7 & 1545.9 & 11.7 & 1679.5 & 11.9 & 1808.3 & 10.2 \\
\hline Grande & 1831.8 & 19.5 & 3554.4 & 33.1 & 4554.2 & 32.2 & 5446.8 & 30.8 \\
\hline Total & 9385.5 & 100 & 11937.8 & 100 & 14136.0 & 100 & 17663.6 & 100 \\
\hline
\end{tabular}

Fuente: CEPAL (2010.

La situación del personal ocupado por tamaño de empresa indica lo que antes había señalado en relación a la composición del capital que es intensivo en trabajo, ya que en el 2008, las microempresas ocupan $46.6 \%$ de la fuerza de trabajo, las pequeñas $12.3 \%$, y las medianas, $10.2 \%$, aunque las grandes, a pesar de representar solo $0.3 \%$ de las empresas, emplean a $30.8 \%$ del personal ocupado en la industria manufacturera. Estos datos demuestran el grado de asimetría entre la concentración del capital y la ubicación de los trabajadores en los diversos sectores económicos por tamaño de empresa (véanse los cuadros 4 y 5 ).

\section{MANUFACTURAS}

La industria manufacturera se caracteriza por generar el mayor valor agregado por unidad económica, además de ser el sector que absorbió a 23.8\% del empleo en 2008 (véase el cuadro 6). A pesar de que se ha observado un estancamiento de la producción industrial en cuanto a su peso en el PIB y el personal ocupado, sigue siendo un elemento clave para entender la generación de riqueza y explicar la crisis financiera por los escasos niveles de crecimiento. Esto justifica su estudio pues es el motor de la economía, como ya se dijo, y genera valor agregado y empleo. Como se observa en el cuadro 6, el sector manufacturero, el principal en México, concentró $11.7 \%$ de las unidades económicas, $22.3 \%$ 
del personal ocupado y $31 \%$ de las remuneraciones. Las pymes manufactureras fueron las responsables de la mayor parte de la caída en la importancia de este tamaño de empresas como proveedoras de empleo, ya que si bien en 1994 contribuían con 76.7\% del empleo del sector, en el 2008 esta participación cayó hasta $15.8 \%$ (véase el cuadro 5).

\section{Cuadro 6. Manufacturas: personal ocupado por tamaño de empresa (miles de personas y porcentajes)}

\begin{tabular}{l|c|c|c|c|r|r|r|r}
\hline \multirow{2}{*}{$\begin{array}{c}\text { Sector } \\
\text { (miles) }\end{array}$} & \multicolumn{2}{|c|}{1994} & \multicolumn{2}{c|}{1998} & \multicolumn{2}{c|}{2003} & \multicolumn{2}{c}{2008} \\
\cline { 2 - 9 } & $\begin{array}{c}\text { Cantidad } \\
\text { miles) }\end{array}$ & $\%$ & $\begin{array}{c}\text { Cantidad } \\
\text { (miles) }\end{array}$ & $\%$ & $\begin{array}{c}\text { Cantidad } \\
\text { (miles) }\end{array}$ & $\%$ & $\begin{array}{c}\text { Cantidad } \\
\text { (miles) }\end{array}$ & $\%$ \\
\hline Micro & 815 & 25 & 773.3 & 18.3 & 762.1 & 18.1 & 1075.9 & 23.8 \\
\hline Pequeña & 583.4 & 17.9 & 499.5 & 11.8 & 431.8 & 10.3 & 460.2 & 6.7 \\
\hline Mediana & 939.5 & 28.8 & 916.7 & 21.7 & 810.1 & 19.3 & 765.9 & 9.1 \\
\hline Grande & 925.8 & 28.4 & 2042.9 & 48.3 & 2194.6 & 52.3 & 2220.8 & 60.4 \\
\hline Total & 3263.8 & 100 & 4232.3 & 100 & 4198.6 & 100 & 4522.8 & 100 \\
\hline
\end{tabular}

Fuente: Tomado de CEPAL (2010).

No obstante, la participación de las empresas grandes en el total de establecimientos se ha mantenido, como se observa en el cuadro 7 , lo que implica la existencia de importantes ganancias de productividad en esta dimensión de empresas.

\section{Cuadro 7. Manufacturas: número de establecimientos por tamaño de empresas (miles de establecimientos y porcentajes)}

\begin{tabular}{l|c|c|c|c|c|c|c|c}
\hline \multirow{2}{*}{$\begin{array}{c}\text { Sector } \\
\text { (empresas }\end{array}$} & \multicolumn{2}{|c|}{1994} & \multicolumn{2}{c|}{1998} & \multicolumn{2}{c|}{2003} & \multicolumn{2}{c}{2008} \\
\cline { 2 - 10 } & $\begin{array}{c}\text { Cantidad } \\
\text { (miles) }\end{array}$ & $\%$ & $\begin{array}{c}\text { Cantidad } \\
\text { (miles) }\end{array}$ & $\%$ & $\begin{array}{c}\text { Cantidad } \\
\text { (miles) }\end{array}$ & $\%$ & $\begin{array}{c}\text { Cantidad } \\
\text { (miles) }\end{array}$ & $\%$ \\
\hline Micro & 248.1 & 93.3 & 310.1 & 90.1 & 298.7 & 90.9 & 403.5 & 92.7 \\
\hline Pequeñas & 12.5 & 4.7 & 22.7 & 6.6 & 19.8 & 6.0 & 22.1 & 5.0 \\
\hline Mediana & 3.1 & 1.2 & 8.2 & 2.4 & 7.2 & 2.2 & 6.8 & 1.6 \\
\hline Grande & 2.3 & 0.9 & 3.0 & 0.9 & 3.1 & 0.9 & 3.0 & 0.7 \\
\hline Total & 266 & 100 & 344.1 & 100 & 328.7 & 100 & 435.4 & 100 \\
\hline
\end{tabular}

Fuente: Tomado de CEPAL (2010). 
En un análisis simple, se registra el cambio estructural del sector empresarial en México al inicio del milenio, dado que en una década, 1998 a 2008, las microempresas aumentaron en $30 \%$ al pasar de 310.1 a 403.5 (miles de establecimientos), mientras que el resto disminuyeron o cuando más se mantuvieron en términos del número de unidades. Las pequeñas decayeron en $2.6 \%$, las medianas disminuyeron también en $17 \%$, y las grandes empresas se mantuvieron sin cambios en ese lapso. La CEPAL dice:

... las empresas destinaron su inversión a dos áreas: maquinaria, equipo e instalaciones y comercial. En particular, casi $40 \%$ de las empresas que invirtieron en maquinaria y equipo en manufacturas lo hicieron para expandir su planta productiva, mientras que $30 \%$ planeaba reducir costos. Asimismo, 20\% de las empresas invirtió para automatizar su proceso productivo [Pavón, 2010].

Lo anterior deja entrever que mientras las grandes empresas reestructuraron tecnológicamente sus procesos, quizás incorporando la producción robotizada, las pequeñas aumentaron en número para abastecer solo al mercado interno involucrando procesos de informalidad.

Frente a este panorama, más la situación de la economía internacional, se presenta la urgente necesidad de fortalecer a las pequeñas empresas en sus procesos tecnológicos y sus esquemas de innovación, sobre todo porque las grandes empresas han entrado en estancamiento, al menos en el sentido de crecimiento en el número de ellas, lo cual significa que la economía nacional no tiene poder de atracción para los capitales nuevos, aunque posiblemente existe un aumento en la concentración y poder de los capitales ya establecidos, es decir, el oligopolio. Junto a esta situación, un camino eventual será la profundización en el terreno de la mercadotecnia y de la cadena de suministros. 


\section{EsTUDiO DE CASOS}

Tomando como base la información sobre la importancia de las pymes del sector productivo en la economía mexicana y su presencia en la generación de empleo y en el producto nacional, sobre todo como proveedoras de bienes intermedios para las grandes empresas, generando en algunos casos encadenamientos productivos significativos y proveedoras del mercado interno, se aprovechó la investigación sobre la gestión tecnológica en las pymes que se realizó en el taller sobre "El desarrollo tecnológico y la competitividad en la industria manufacturera" del proyecto PAPIIT IN305610 de la UNAM, para validar esas fortalezas y verificar si estas empresas son poderosas por sí mismas o si reciben algunos apoyos del Estado para fomentar su crecimiento económico. Esto se logró mediante entrevistas a empresarios durante varias reuniones, en las que los mismos narraron al seminario su historia como empresarios y la evolución de la empresa frente a los retos del mercado, y los requerimientos de financiamiento, al igual que su actitud frente a las demandas del cambiante mercado cada vez más globalizado.

El método de entrevista implicó identificar a empresarios exitosos que han mantenido algún vínculo con la UNAM. Durante dos horas narraron su historia desde la creación de la empresa y su actitud frente a las necesidades de efectuar acciones de innovación para aumentar su capacidad competitiva, y respondieron a preguntas de los investigadores miembros del seminario de investigación mencionado. En los tres casos se trata de empresas familiares, aunque la primera ha mantenido el mismo perfil, sin grandes cambios, lo que les ha permitido seguir en el mercado, ajustando los procesos para diversificar el producto final que es vendido a otras empresas especializadas que adquieren sus productos.

Las entrevistas de los tres empresarios de pequeñas y medianas industrias se presentan en seguida mediante un esquema de análisis de casos. El primero de ellos es un empresario que heredó 
la empresa de su padre, quien la creó hace 58 años, en el giro de la industria metalmecánica, de modo que se trata de una pequeña empresa, de carácter familiar. Según la respuesta del dueño dirigente de la empresa, solo ha reaccionado a los cambios del mercado, ajustando su volumen de producción y realizando los cambios de maquinaria y equipo con base en las peticiones de sus clientes, pero no hace estudios de mercado ni análisis tecnológicos para hacer crecer a la empresa.

El segundo caso se trata de un empresario con nivel de estudios profesionales que se jubiló de la empresa petrolera estatal de México, con el pago de su liquidación más la participación profesional de sus hijos, integró una consultora que ofrece servicios de construcción y mantenimiento a las plataformas marinas de la paraestatal.

El tercer caso es el de un empresario también con estudios profesionales en la ingeniería química y que desde joven tuvo la suerte de reconocer una ventana de oportunidades para invertir en la fabricación de material impermeabilizante para la industria de la construcción. Su empresa creció con una fuerte vinculación con el sector educativo donde ha podido contratar a estudiantes que después gozaron de becas para estudios de posgrado en beneficio de la empresa. Esta situación fue favorecida por el carácter docente del empresario y actualmente se ha convertido en una empresa mediana con muchas oportunidades de mercado. Su formación profesional le ha permitido levantar un área de investigación y desarrollo que representa su carácter proactivo en el manejo de su industria y que lo ha llevado a registrar diversas patentes y un número mayor de secretos industriales. Una de sus frases más representativas es: "Si no es vendible, no lo produzcas".

Las entrevistas muestran la importancia que tienen para el éxito de las empresas la búsqueda de oportunidades en el mercado y la capacitación profesional de los dueños dirigentes. Esto es un elemento fundamental en el desarrollo de las empresas, en particular de las pequeñas y medianas, que aquí se estudian. 


\section{Primer caso}

El primer caso se refiere a una pequeña empresa familiar que fabrica resortes para colchones, ganchos metálicos y diversos artículos que adquieren otras pequeñas empresas para la elaboración de productos finales como son tambores para cama, mochilas y asientos para automóviles, su evolución depende de que los productores finales logren introducir al mercado nuevas diferenciaciones del producto.

La empresa fue iniciada hace 58 años con el mismo estilo de trabajo, con excepción de aquella maquinaria que tuvo que adquirir para diseñar los nuevos artículos que los productores finales introducirían al mercado. Por lo anterior, esta empresa debe ubicarse en la tipología de empresas de esquema reactivo, ya que en varias ocasiones, aunque no en todas, se ha visto obligada a adaptarse a los requerimientos del mercado final. ${ }^{5}$

El empresario ha alcanzado los cambios necesarios consiguiendo recursos de manera personal y en general se siente acosado por las obligaciones fiscales. Su familia le ayuda, pero él es el dueño/dirigente (DD), ${ }^{6}$ que en su mayoría toma las decisiones relacionadas con sus empleados; sus hijos realizan las operaciones financieras, visitan a los clientes y proveedores. Su sobrevivencia está vinculada a la penetración del mercado que logren sus clientes en el mercado final.

La empresa alcanzó un tamaño de 65 empleados desde hace muchos años y no ha cambiado su estructura y su estilo de producción. Cuando requiere reparación de equipos o compra de maquinaria especializada, recurre a los técnicos que trabajan en la empresa y que han permanecido ligados a ella durante años por lo que no tiene que buscar apoyo tecnológico en el mercado especializado. Por otra parte, cuando ha tenido problemas de

${ }^{5}$ Las empresas reaccionan de distinta forma ante cambios en el mercado final, y pueden encontrarse empresas reactivas, proactivas y pasivas.

${ }^{6}$ Para el estudio de las mipymes, al personaje que tiene a su cargo la empresa y decide todo lo que pase en ella y no mantiene un equipo de trabajo especializado se le llama dueño/dirigente (DD). 
financiamiento, resuelve sus compromisos por la vía de proveedores. Actualmente, esta empresa ha logrado un encadenamiento con la industria automotriz, en la cual tiene la posibilidad de crecimiento al surtir resortes de calidad para los asientos de los automóviles.

En este caso, se trata de una empresa pequeña que no se ha involucrado buscando oportunidades novedosas en el mercado, que no utiliza financiamiento y que no realiza innovación.

\section{Segundo caso}

Este segundo caso se trata de una empresa ligada al sector de la petroquímica. Fue fundada hace 35 años por su DD quien trabajó en la paraestatal Pemex desde que egresó de las aulas del Instituto Politécnico Nacional (IPN). Al jubilarse de la paraestatal, este empresario mediano utilizó sus recursos, más otros, en la formación de esta empresa.

La parte destacable del proceso es que al momento de su jubilación el empresario decidió formar un grupo de trabajo para atender los requerimientos que la paraestatal dejó de realizar por cuenta propia. El entusiasmo de este empresario lo llevó a promover la preparación profesional de sus hijos en áreas especializadas para que ayudaran a su empresa donde actualmente laboran, uno en el área de producción, otro en el área de finanzas y otro en el de informática, de esa manera pasaron de ser un equipo de trabajo de menos de 10 personas, incluidos sus hijos, a la plantilla actual de 250 personas.

Por el carácter de la empresa, prácticamente cada nuevo contrato implica la aplicación de las técnicas de innovación, ya que debe adaptar la tecnología disponible a las necesidades de la paraestatal.

Durante su desarrollo, la empresa ha adoptado la estrategia de formación de especialistas enviándolos a estudiar a diversas partes del mundo donde se impartan los cursos necesarios para atender 
las necesidades de sus clientes, principalmente la paraestatal petrolera con la cual tiene celebrados la mayor parte de sus contratos. Además, ha hecho múltiples alianzas con empresas extranjeras para intercambiar tecnologías, y promueve sus ofertas internacionalmente.

Actualmente es una mediana empresa dinámica que intenta convertirse en una empresa más grande por lo que requiere contacto con las universidades para consolidar sus cuadros profesionales.

\section{Tercer caso}

El tercer caso es una empresa dedicada a la producción e innovación de productos para la impermeabilización de techos, paredes y demás construcciones que requieran evitar la filtración de agua.

El empresario tuvo una formación en ingeniería química e inició su negocio en la azotea de su casa, probando y experimentando el producto que lo llevaría a contar con 20 naves industriales en toda la República mexicana.

Lo interesante de esta empresa es que tiene un departamento dedicado exclusivamente a la investigación y desarrollo, en el que emplea a más de $7 \%$ del total de su personal que son hasta el momento 300 empleados. Esto la ha llevado a ser totalmente una empresa proactiva basada en la búsqueda de nuevas áreas, como inyectar los túneles del metro para evitar la filtración de agua y por consiguiente la posible inundación.

La prioridad de este empresario es avanzar poco a poco, de manera que ya se encuentra exportando hacia el resto de América Latina, sin embargo, no ha querido abarcar más mercado debido a que, por costumbre, dirige personalmente toda la empresa. Él considera que el crecimiento de una empresa recae principalmente en su habilidad para reinvertir las ganancias generadas al inicio del proceso industrial y no hacer uso de ellas sino hasta alcanzar un poco más de lo que se ha invertido y reinvertido. 


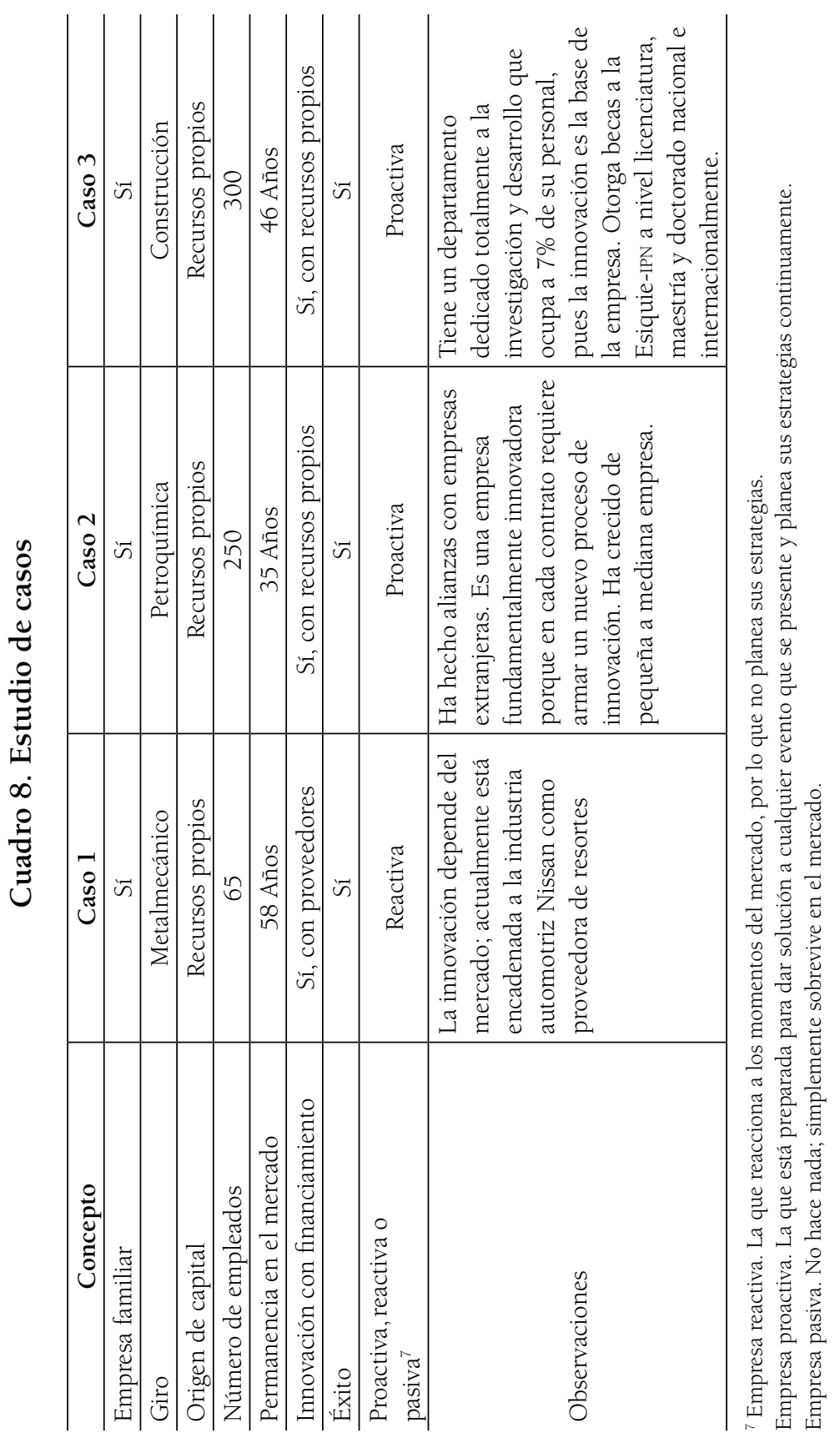


Este empresario tiene una idea clara sobre el papel de la innovación en su proceso de producción. Se encuentra en búsqueda, de oportunidades en el mercado, señala que el camino del éxito empresarial se encuentra en estar pendientes permanentemente de las "ventanas de oportunidad" y destaca que ha registrado algunas patentes, pero tiene un área de investigación y desarrollo para dar respuesta a las necesidades del mercado, fabricando diversos productos que deben ser probados en la práctica antes de decidir su producción masiva. Comenta que esto es muy costoso, dado que debe preparar en niveles altos a sus investigadores y enviarlos a cursos de especialización en el extranjero, lo cual representa un conflicto adicional ya que al regreso estos empleados especializados desean ganar más; también enfrenta la piratería de otras industrias que buscan investigadores con esos niveles de capacitación y en ocasiones aceptan pagar lo que piden.

No obstante lo anterior, parte de ese éxito ha sido capacitar continuamente a su personal, además de otorgar becas a estudiantes que se encuentran en séptimo y octavo semestre de la carrera en ingeniería química, lo que a su vez le permite incorporarlos a su plantilla laboral.

\section{CONCLUSIONES}

Al realizar el presente capítulo se observó que hay dificultad para clasificar a las empresas en términos generales, es decir, se les ha dado un tratamiento homogéneo para atender sus necesidades y problemáticas, de tal forma que si algunas, como es el caso de las microempresas, no cumplen con las especificaciones o requisitos para considerarlas empresas medianas, por ejemplo, las deja fuera de recibir un financiamiento o ser parte de un programa sectorial como los mencionados.

$\mathrm{La}$ industria manufacturera es el sector que genera la mayor parte de la riqueza en la economía, por lo que es posible hacerla crecer aún más, pero para ello se requiere que esas pequeñas y medianas empresas tengan encadenamientos productivos. De los 
tres casos que aquí se presentaron, dos de ellos son casos de éxito sin financiamiento público o privado, que han logrado avanzar en el mercado debido a las estrategias utilizadas de acuerdo con sus necesidades de tamaño y de mercado. Se considera que las pymes del sector manufacturero en conjunto aportan la mayor parte del empleo y del PIB que el resto de la economía. Si fuera posible acrecentar estos encadenamientos se llegaría a aquellos establecimientos en los que se está perdiendo la posibilidad de permanecer en el mercado. En conclusión, hay que reactivar la economía por medio de las pymes, promover los procesos de innovación de producto y vincularlas con los centros de investigación y universidades para fortalecer su capacidad productiva.

La competitividad de las pequeñas y medianas empresas es posible mediante la aplicación de una política industrial que les permita aumentar su nivel de producción, generar innovación y mejorar la calidad de sus productos en el mercado, de manera que sea factible el aumento de la demanda efectiva. En este aspecto, el papel del Estado es fundamental como auspiciador, gerente y regulador de este proceso.

\section{REFERENCIAS}

Alemán, Z. E. [2012], Crédito de la banca comercial y crecimiento de la industria manufacturera en México 1995-2011, México, UNAM, pp. 55-62.

Álvarez, A. S. [2012], "Emprende tu camino hacia el éxito: cómo hacer para que tu empresa no muera", tesis de maestría, México, Facultad de Ciencias Políticas y Sociales-UnAm, pp. 14-18. Benavente, J. [2005], "La dinámica industrial y la financiación de las pyme”, en Trimestre Económico, México, 72 (86): 3-35. CEPAL [2010], Serie Financiamiento del Desarrollo, núm. 226, Santiago de Chile, agosto.

De la Garza T., E. [2006], Reestructuración productiva, empresas y trabajadores en México, México, FCE, pp. 80-90. 
Flores S., J. [2010], Cambio estructural e integración regional de la economía mexicana. Un estudio de desintegración regional, México, UAM-Xochimilco, pp. 63-87.

Garrido, C., y Ricardo Padilla [2007], Evolución estratégica de la manufactura y nueva organización económica nacional. Problemas y desafíos para el desarrollo manufacturero en México, México, FCE, pp. 90-103.

Kaldor, N. [1966], Causes of slow rate of economic growth in the U.K., Cambridge, University Press, p. 77.

Levy O., N. [2001], Cambios institucionales del sector financiero y su efecto sobre el fondeo de la inversión, México, DGAPA-UNAM, pp. $27-42$.

Mántey de Anguiano, G. [2010], "Una propuesta de ajuste estructural con crecimiento", O. Cruz, Crisis y cambio estructural. Una nueva agenda de política. Por una salida social, México, UAM-Xochimilco, pp. 175-186.

[2010], "Instituciones financieras para el desarrollo económico comparación del periodo de sustitución de importaciones y el secundario exportador”, Guadalupe Mántey de Anguiano, Cincuenta años de políticas financieras para el desarrollo de México (1958-2008), México, Plaza y Valdés, pp. 149-178.

Moreno-Brid, J. C. [2009], Desarrollo y crecimiento en la economía mexicana: Una perspectiva histórica, Estados Unidos, Oxford, pp. 103-117.

Olivera, G. [2008], Importancia económica y distribución territorial de la micro y pequeña industria en México en un panorama mundial, nacional, urbano, y de política, México, UNAM, pp. 60-70.

Organización para la Cooperación y Desarrollo Económico [2007], SEM'S in Mexico: Issues and Policies, París, OECD Publishing.

Pavón, L. [2010], Financiamiento a las microempresas y las pymes en México (2000-2009), Sección de Estudios del Desarrollo, Santiago de Chile, CEPAL, serie Financiamiento del Desarrollo número 226, pp. 9-19. 
Pérez P., C. [2009], "Innovación y crecimiento. Comprender la dinámica y el cambio de las oportunidades para América Latina”, Adriana Martínez, Pedro L. López, Alejandro García y Salvador Estrada (coords.), Innovación y competitividad en la sociedad del conocimiento, México, Plaza y Valdés, pp. 21-42.

Robinson, J. [1952], The generalization of the general theory, the rate of interest, and other essays, Londres, Macmillan, pp. 90-105.

Ros, J. [2008] "La desaceleración del crecimiento económico en México desde 1982”, en El Trimestre Económico, México, FCE, 75 (3): 537-560.

Secretaría de Economía [2008], Comisión Intersecretarial de Política Industrial (CIPI), <www.cipi.gob.mx>.

Sistema Económico Latinoamericano y del Caribe (SELA) [2009], "Políticas e instrumentos para enfrentar el impacto de la crisis económica internacional sobre las pequeñas y medianas empresas (pymes) de América Latina y el Caribe", Caracas, Venezuela, Secretaría Permanente del SELA, pp. 6-9.

Thiel, M. [2001], "Finance and economic growth, a review of theory and the available evidence", Economic and Financial Affairs, England, UK, European Communities, pp. 14-16.

Villarreal, R. [1998], Industrialización, deuda y desequilibrio externo en México. Un enfoque neoestructuralista (1929-1988), México, FCE, 616 pp.

[2005], Industrialización, competitividad y desequilibrio externo en México, México, FCE, pp. 30-39. 


\section{Capítulo 6 \\ POLÍTICAS PÚBLICAS PARA LA COMPETITIVIDAD DEL SECTOR TEXTIL EN MÉXICO EN UN ENTORNO DE LIBRE COMERCIO}

Irma Portos Pérez**

\section{INTRODUCCIÓN}

El estudio del sector textil-confección en México y las políticas orientadas a su desempeño sigue siendo un tema de gran importancia en la actualidad, por diversas razones entre las que destacan: el papel que ha tenido este sector en la creación de empleos con diferente grado de calificación, así como sus posibilidades para elevar las exportaciones de bienes con mayor valor agregado, a partir de las oportunidades que brindan los tratados de libre comercio que México ha firmado, principalmente el Tratado de Libre Comercio de América del Norte (TLCAN), y la necesaria consideración de su propio mercado interno. ${ }^{1}$

* Académica del IIEc-UnAm y participante en el proyecto de investigación PAPIIT IN305610. Correo electrónico: <portpri@unam.mx>.

${ }^{1}$ Hasta ahora destaca, sin duda, el TLCAN en la inserción de la producción textil mexicana, sobre todo de prendas de vestir y algunos insumos textiles que siguen siendo competitivos frente al exterior, como la mezclilla de algodón. 
Los resultados del TLCAN en materia textil durante los primeros años de vigencia arrojaron cifras alentadoras en cuanto al incremento de las exportaciones de bienes finales (pantalones, camisas, entre los productos más destacados), y los empleos que fueron generados bajo el esquema del ensamble. Sin embargo, al incrementarse la competitividad de los países asiáticos, sobre todo de China, que tiene costos salariales menores que México, el lugar que este tenía como primer exportador de prendas al mercado estadounidense sería desbancado por la presencia de la producción china en Estados Unidos.

Se calcula que, de 2001 a 2011, las exportaciones de textiles y confecciones a Estados Unidos se redujeron de 9829 millones de dólares, a 5821 millones de dólares; una disminución acumulada de casi 4000 millones de dólares en 10 años [Secretaría de Economía, 2012]. El gobierno mexicano ha llevado a instancias internacionales la defensa de los productos textiles del país, amparado en las regulaciones de comercio internacional escritas en la Organización Mundial de Comercio (OMC), situación que sería resuelta, según la propia SE, en el 2012; de no ser así, se acudiría al establecimiento de un panel que resolviera la controversia.

Existe consenso entre los especialistas en el análisis industrial acerca de que este sector no debe seguir siendo considerado solamente industria maquiladora de exportación, sin atender de manera urgente la reindustrialización de los segmentos de la cadena que producen insumos necesarios para la elaboración de prendas de vestir con destino a la exportación. Por tanto, se debe retomar la propuesta de fomento para impulsar la producción integral de bienes con mayor valor agregado, que se nutre de los diseñadores y productores locales ubicados en algunos estados de la República mexicana, los cuales han sido reconocidos recientemente por los organismos gubernamentales, abriendo pautas de colaboración y vínculo entre los sectores productivo, gubernamental y educativo del país. ${ }^{2}$

${ }^{2}$ El papel que ha venido adquiriendo el gobierno de algunos estados de la República mexicana tradicionalmente productores de textiles, como el de Puebla, en la creación 
En tal sentido, algunas firmas locales de textiles y confección han decidido incorporarse a las nuevas tendencias mundiales en textiles, elaborando prendas con certificación internacional en materia del cuidado del medioambiente y reciclando, en otros casos, productos de desecho.

\section{EVOLUCIÓN RECIENTE DEL SECTOR TEXTIL}

\section{Y SUS PERSPECTIVAS}

El sector textil mexicano actualmente genera alrededor de 400000 empleos directos y 1200000 empleos indirectos, que representan $14.6 \%$ del empleo manufacturero y $2.2 \%$ nacional [INEGI, 2012]. Por el impacto social en esta materia, se le ha considerado uno de los sectores prioritarios. Aunque el impacto en el producto interno bruto (PIB) sectorial se ha venido reduciendo, pues la mayoría de los insumos que se utiliza en la elaboración de prendas de vestir se importa, hacia el 2010 se registró un desempeño ligeramente positivo al pasar de $0.9 \%$ del PIB nacional en 2009 a $1.2 \%$ en 2010 y su aportación al PIB manufacturero se elevó de $5.1 \%$ en 2009 a $18.8 \%$ en 2010 , lo cual dio aliento al sector para coincidir en la necesidad de acciones de apoyo por parte del gobierno.

Según datos del gremio empresarial, la planta fabril en 2012 incluía 8531 empresas, dando empleo a 291104 trabajadores; hacia el primer trimestre de 2012, el monto de la producción de prendas de vestir alcanzaría 8236 millones de pesos (mdp). Marcos Cherem, presidente de la Cámara Nacional de la Industria del Vestido (Canaive). Tan solo el sector textil agrupado en la Cámara Nacional de la Industria Textil (Canaintex), ha declarado que genera empleos formales para más de 100000 trabajadores, de los cuales 25\% se ubican en el Estado de México, $17 \%$ en Puebla, 9\% en Hidalgo y 5\% en Tlaxcala.

de políticas que involucran a los productores, las escuelas de diseño y la infraestructura local en los llamados corredores industriales, se puede considerar como un esfuerzo importante por impulsar al sector textil en el nuevo contexto internacional. 


\section{Cuadro 1. Estructura productiva del sector textil-confección, 2009-2012 \\ (precios constantes)}

\begin{tabular}{l|c|c}
\hline & 2009 & 2010 \\
\hline Valor bruto agregado total (textil y vestido) & 76067 & 86520 \\
\hline Fabricación de insumos textiles y de vestir & 13642 & 16496 \\
\hline Fabricación de prendas de vestir & 38184 & 44534 \\
\hline
\end{tabular}

Fuente: INEGI.

Nota: No se incluye la fabricación de productos de cuero, piel y materiales diversos.

La desindustrialización y el rompimiento de la cadena fibras, textil y confección, de lo cual ya hemos dado cuenta en otro trabajo [Portos, 2008], sigue siendo un hecho, sin embargo, según datos del INEGI, hacia el 2010 se observaba una recuperación de algunos segmentos de la cadena industrial textil, por lo que se puede adelantar la intención del sector empresarial mexicano de demandar mayores acciones de política industrial a favor de su desempeño.

Uno de los problemas de mayor relevancia en el sector textil es sin duda, el comercio desleal y las prácticas de contrabando en México, que no han podido detenerse, sino agravarse durante los últimos años. Se sabe que debido a nuestra ubicación geográfica limítrofe con la economía más grande del mundo, la frontera representa un punto vulnerable para la regulación del intercambio comercial de México con el mundo. Eso, aunado a la proliferación de la corrupción y los mecanismos irregulares en la revisión aduanal, permean una realidad poco favorable a los productores locales de textiles. De ahí que la política pública hacia el sector siga descansando en acciones de política comercial de carácter defensivo, frente a la competencia desleal que presenta una realidad cotidiana en el espacio económico mexicano. Así, la Secretaría de Economía acudió a la Organización Mundial de Comercio (OMC) en contra de la República Popular de China, por el otorgamiento de subsidios a sus productos textiles y del vestido que violan las reglas establecidas por dicha organización.

El problema de las prácticas desleales de comercio y el amplio ingreso de productos de manera ilegal al país ha inhibido la 
generación de actividad textil y ha propiciado el cierre de plantas que no pueden competir con precios de los productos que provienen en su mayoría de países asiáticos agresivamente competitivos frente a los productores locales. Desde inicios del 2012 los empresarios advertían la difícil situación que enfrentaba el sector: $10 \%$ menos producción, $5 \%$ menos empresas y $5 \%$ menos empleos de los registrados en los primeros meses de 2011 [M. Cherem, Canaive].

El vencimiento de las medidas de transición para prendas de vestir provenientes de China será la nube que ensombrecerá las perspectivas de crecimiento del sector en el mercado local. Se calcula que las importaciones chinas de textiles y ropa crezcan entre 30 y $35 \%$ durante el primer trimestre de 2012 en comparación con 2011.

El problema es que tanto telas como prendas de vestir provenientes del país asiático entran al país a un precio que no cubre ni siquiera el costo de la materia prima. La mezclilla, por ejemplo, ingresa a México con precios de entre 0.4 y 0.8 dólares el metro cuadrado, cantidad que no cubre el precio de la fibra de algodón, según datos de la Cámara Nacional de la Industria Textil [Canaintex; 2012]. Por ello, en un discurso empresarial se afirmaría que:

... Canaintex conjuntamente con la Cámara Nacional de la Industria Nacional de la Industria del Vestido y nuestras partes norteamericanas y brasileñas, estamos trabajando junto con la Secretaría de Economía para evitar mayor daño a la producción nacional de prácticas de subsidios por parte de nuestros principales competidores, y poder activar enérgicamente los mecanismos previstos para ello en la Organización Mundial de Comercio [Discurso del presidente saliente de la Canaintex, Rodolfo Muriel Martínez, 2012].

Argumentos como el siguiente, han proliferado, pues: “... se han encontrado sostenes que entran con un precio de 0.01 centavos de dólar y conjuntos deportivos en 20 centavos de dólar. Precios que no alcanzan ni para comprar la etiqueta, botones y elásticos de una prenda" [Cherem; Canaive; 2012]. 
Sin embargo, también se reconoce que:

En el 2011 nuestras ventas al exterior crecieron 12\%, después de que estas crecieron $40 \%$ el año anterior, además, en los últimos dos años hemos logrado una importante diversificación de mercados, destinando ya el $40 \%$ de las exportaciones a Centroamérica, Colombia y el resto de los países de América Latina. Durante mi presidencia impulsamos la ratificación del Acuerdo de Complementación Económica con Perú y participamos en la negociación del Tratado de Libre Comercio Único entre México y Centroamérica, avanzando así en la integración comercial regional en el Hemisferio Occidental, lo que nos fortalece ante la competencia asiática, en un mercado global que demanda diseño, moda y respuesta rápida [LXXV Asamblea de la Canaintex, 2012].

También se ha admitido que la mejor aliada de la innovación y la prosperidad del sector, desde el campo hasta las plantas petroquímicas y pasarelas, es la legalidad, por lo que las acciones del Servicio de Administración Tributaria (SAT) han sido muy importantes combatir la subvaluación en la importación de textiles.

Desde la perspectiva empresarial, las acciones conjuntas de varias entidades gubernamentales, como la Secretaría de Agricultura, Ganadería, Desarrollo Rural, Pesca y Alimentación (Sagarpa), Apoyo y Servicios a la Comercialización Agropecuaria (Aserca), y Financiera Rural y Fideicomisos Instituidos en Relación con la Agricultura (FIRA), son importantes en la promoción de condiciones de financiamiento apropiadas para la compra de algodón nacional, a partir de la puesta en marcha de la agricultura por contrato en el algodón, por lo que esperan avances en este sexenio.

En relación con las acciones que han sido mencionadas como parte de la política industrial hacia el sector textil, destaca lo siguiente: la innovación traducida en diseños originales y automatización de procesos podría ser la tabla salvadora para que la industria nacional pueda navegar en medio de la inundación de productos chinos que llegarán a México en los próximos meses, sin embargo, pocas son las empresas que han invertido en estos rubros. 
Los datos sobre el apoyo financiero al sector textil indican que este no ha sido el requerido, en su mayoría sigue descansando en los financiamientos otorgados por la banca comercial, y en una muy baja proporción, por la banca pública, prácticamente inexistente en el México neoliberal. Por ejemplo, según datos del INEGI: mientras que la banca comercial incrementó los créditos al sector textil, la banca de desarrollo los disminuyó drásticamente entre 2005 y 2010 . En 2005 se otorgaron 4343 millones de pesos y en 2010, tan solo 717 millones [INEGI, 2010].

Por segmentos productivos, destaca la nula atención a la rama de hilados y tejidos de fibras blandas e hilados y tejidos de fibras duras, que no fueron beneficiados de ningún apoyo por parte de la banca pública en 2010 [INEGI]. Cabe destacar que en 2010, del crédito de la banca de desarrollo al sector, 90\% se destinó a "otras industrias textiles", entre las que se encuentran las industrias que abastecen al sector automotriz.

Por entidad federativa, se puede observar la importancia de algunos estados que han sido beneficiados por el financiamiento público para el desarrollo de proyectos vinculados al sector textil y confección. Destacan: el Distrito Federal, Estado de México, Hidalgo, Guanajuato, Jalisco y Puebla.

En esta perspectiva cabe dar seguimiento a los proyectos y convenios que vienen formalizándose entre las entidades gubernamentales y las propuestas del gobierno actual. Es preciso tomar en cuenta que en sexenios anteriores se avanzó en la creación de algunos parques industriales en algunas entidades de la República mexicana, por ejemplo, La Ciudad de la Confección en el municipio Emiliano Zapata (Parque Industrial Nustart), en el que participaron las empresas Gunfilford Mills, Dupont, Burlingtong, Grupo Alfa-Alpek).

Para este proyecto, los gobiernos federal y estatal apoyaron con 20 millones de dólares para estructura y servicios, además de beneficios y estímulos fiscales.

Otros ejemplos son: el Parque Industrial Sector Textil Puebla, con empresas de Huejotzingo y el apoyo a 1500 empresas del sector textil en Puebla, Tehuacán y San Martín Texmelucan que 
exportaron más de $90 \%$ de su producción a Estados Unidos; el Parque Industrial El Coecillo, Estado de México, en el que participan las empresas Avante Textil, Qualifil y Univisa, y el Parque Industrial de La Laguna Duranguense. Asimismo, el estado de Hidalgo ha sido beneficiado de manera relevante durante los años actuales, a partir del Programa Estatal de Fomento Industrial Hidalgo 2005-2011. De igual modo, la Secretaría de Economía informó que la administración de Felipe Calderón creó estructuras de apoyo emprendedor y estableció una red de 500 incubadoras empresariales.

Los datos que brinda el INEGI sobre el comportamiento del sector revelan la caída del número de establecimientos, la cantidad de empleos y la reducción de la producción. En varios trabajos de esta obra se propone la necesaria revisión de los segmentos que constituyen la cadena textil en México, para poder apreciar con mayor certeza los impactos de la apertura comercial, la competencia desleal y la reestructuración productiva que es un elemento clave para entender a aquellas firmas que han sobrevivido y actuado en un entorno económico muy desfavorable.

\section{CONTINUIDAD Y AVANCES DEL NUEVO GOBIERNO (EL DISCURSO Y LOS HECHOS)}

Uno de los primeros encuentros del presidente Enrique Peña Nieto (2012-2018) lo realizó con empresarios del sector textil y del vestido, ahí se comprometió a combatir la ilegalidad y la informalidad y a impulsar una política industrial de Estado, además de poner en marcha el Centro Nacional de Innovación y Moda para las industrias Textil Hidalgo (encuentro con empresarios del sector en Hidalgo, mayo de 2012). Cabe recordar también el carácter sectorial y de impulso que adquirió la Exhibición Internacional Textil (Exintex), llevada a cabo en el mes de marzo de 2012, en Puebla, después de varios años en los que no se organizaba esta exposición textil de importancia internacional en la que se reúnen empresas de toda la cadena industrial textil, 
incluyendo los productores de maquinaria y equipo, así como diseñadores y pasarelas de modas.

\section{LA POLÍTICA SECTORIAL TEXTIL ACTUAL}

Entre las acciones que, desde mi punto de vista, seguramente serán retomadas en la política sectorial del nuevo gobierno, destacan las relacionadas con la producción de textiles ecológicos y la innovación, aplicadas a la producción de prendas con diseños artesanales que serán claves para el sector en el futuro. En ese sentido, se ha anunciado que en 2013, el gobierno federal destinará 3200 millones de pesos para apoyar de manera directa los procesos de innovación del sector privado, la industria textil debe trabajar para adoptar procesos que incorporen un mayor valor agregado a su producción.

En esta perspectiva, la realización de la Exintex (2012), tradicionalmente realizada en el estado de Puebla y que había dejado de organizarse durante varios años, recibió un importante impulso en 2012, gracias al interés del gobierno federal, el gobierno estatal y las cámaras empresariales de Puebla y Tlaxcala involucradas en la cadena textil.

En esta ocasión, resaltó como objetivo central el impulso a la producción de textiles ecológicos y a los jóvenes diseñadores mexicanos. En ese marco, se firmó el convenio de colaboración para el fortalecimiento e internacionalización del sector artesanal textil, con la idea (ya gestada desde hace varios años) de apuntalar los diseños y la creatividad artesanal en los diseños, colores y recursos naturales, que han estado presentes por siglos en amplios grupos de artesanos que aún perviven en nuestro país y que son demandados por mercados de alto nivel de ingreso.

Ante la desaceleración de algunas economías líderes en Asia, el mercado de exportación abre opciones para que México compita incrementando valor agregado en el diseño, a partir de lo que es propio, de nuestra cultura e identidad plasmada en las artesanías 
textiles, que son una riqueza reconocida en todo el mundo [Juan Quintana M., presidente de la Exintex, marzo, 2012].

El convenio conjuga tres aspectos (la artesanía, la innovación y la conservación de la tradición), “... se trata [...], de que las artesanías sean capaces de adquirir conceptos innovadores conservando su esencia, pero con capacidad de internacionalización [...], empatar la riqueza cultural de las artesanías textiles con los gustos del mercado..." [Instituto de Artesanías e Industrias Populares del Estado de Puebla], además de la colaboración entre los sectores que permita disponer de telas de alta calidad y diseño para generar alta costura. ${ }^{3}$

Se espera que con el convenio sean beneficiados alrededor de 4000 artesanos textiles del estado, que tendrán más elementos para competir en mercados de mayor sofisticación, demandantes de mayor valor agregado y prendas únicas de calidad, cotizadas a mejor precio. Para el logro de las metas planeadas en el convenio, se ha trabajado en la estandarización de esquemas productivos y calidad de productos para obtener un volumen de producción acorde con la demanda [Secotrade, 2012].

El programa del Sistema de Administración Tributaria (SAT), durante el sexenio 2006-2012, favoreció al sector textil-confección, pues consistió en fijar precios de referencia de textiles y prendas, además de vigilar que los productos de importación no se introdujeron al país por debajo de estos precios. El programa

${ }^{3}$ En Puebla, las cuatro regiones del estado, en particular 53 municipios, tienen producción textil artesanal, pero muchos de los insumos adquiridos por los artesanos son de mala calidad, lo cual provoca que sus productos pierdan valor. Con diseños de calidad hechos por empresarios y diseñadores poblanos, se fortalece la economía local. Exintex 2012 desea promover las artesanías elaboradas por diferentes grupos en el estado de Puebla, mediante una reinterpretación de los textiles, aplicándolos a bolsas, zapatos, ropa y jeans. Por ello, se desarrolló un proyecto, creando sinergia entre el Instituto de Artesanías e Industrias Populares del estado de Puebla y diseñadores de renombre en el ámbito textil y de moda.

Se ha seleccionado a nueve diseñadores por parte de la Universidad de Diseño Trozmer, Puebla. Asimismo el Instituto de Artesanías de Puebla eligió a los artesanos que forman parte del proyecto en las regiones de Cuetzalan (tejidos) y Huachinango (lana). Los trabajos se mostrarán durante la Exintex 2012 y estarán disponibles en un catálogo. 
reguló el precio de algunas fracciones de textiles y prendas como playeras, que ingresaban a 10 centavos de dólar y ahora entran a un dólar, por lo que los empresarios del ramo esperan que el programa continúe en el nuevo gobierno.

Otros programas dirigidos al sector textil han sido: el Programa de Apoyo a Empresas (mipymes) del sector; "Mi Taller", capacitación a 2000 costureras, y 150 nuevos talleres dedicados a la confección.

Entre las acciones de la administración del presidente Felipe Calderón Hinojosa, que los empresarios del sector textil avalaron, se destaca la entrega de un millón de dólares a la Secretaría de Economía provenientes de la Agencia para el Desarrollo Internacional del gobierno de Estados Unidos (USAID), destinada al apoyo de los emprendedores e innovadores del país. El acierto deriva del retraso y bajo desempeño en la innovación de la mayoría de empresas del sector, como lo han señalado expertos al declarar que solo $30 \%$ de las empresas han automatizado sus procesos productivos. Y aunque cerca de $80 \%$ de las plantas ya cuenta con departamentos de diseño, muchas veces la inventiva se limita a "tropicalizar" diseños ya hechos en otros países, más que a crear los propios. De ahí la importancia de las promesas de Enrique Peña Nieto en relación a la creación del Instituto del Emprendedor que deberá impulsar acciones conjuntas entre los sectores educativo, productivo y gubernamental.

\section{Conclusiones}

La continuidad de la política de apertura ha sido confirmada por el nuevo gobierno, solamente que contempla el apoyo al sector productivo. Los hechos deberán demostrarlo. Se ha informado que el diseño de una política industrial basada en la apertura y el fortalecimiento del mercado interno y el incremento del contenido nacional de las cadenas de valor deberá ser uno de los ejes del nuevo gobierno.

La inserción internacional a partir del fortalecimiento del frente externo consistirá en profundizar y hacer eficientes los 
tratados de libre comercio que México ha firmado como eje de su política exterior desde los años noventa, destacando el TLCAN y los esquemas de integración global en el marco de las negociaciones del Acuerdo de Asociación Transpacífico (TPP) y en la defensa del sector productivo frente a la competencia desleal.

Lo anunciado hasta el cierre del presente trabajo permite concluir que la estrecha relación entre México y el mercado estadounidense en materia textil seguirá siendo una realidad; se reforzará la incorporación de miles de artesanos que serán sujeto de industrialización en cuanto a su creatividad y diseños, bajo el discurso de las industrias creativas y del desarrollo de mayor valor agregado, ahora apropiados por los nuevos agentes "emprendedores" de México y otros países.

\section{REFERENCIAS}

Cámara Nacional de la Industria Textil [2012], Discurso de Asamblea 2012, <www.canaintex.org.mx> .

Cámara Nacional de la Industria del Vestido [2012], Discurso de Asamblea 2012, <http://www.canaive.org.mx>, 8 de marzo. Cámara Nacional de la Industria de Transformación [2013], $<$ http://www.canacintra.com>.

Exhibición Internacional Textil [2012], Memoria 2012, Puebla, Exintex, marzo.

Grupo Editorial Expansión [2012], Servicio de información económica, <http://www.cnnexpansion.com>, 14 de marzo.

Instituto Nacional de Geografía y Estadística [2010], "La industria textil en México", México, INEGI.

, Estadísticas de comercio exterior, México, INEGI. , Encuesta industrial, varios años, México, INEGI.

Instituto Nacional Textil [2011], Informe 2011, México, Intex. Instituto Tecnológico Autónomo de México [2010], La industria textil en México: diagnóstico, prospectiva y estrategia, México, ITAM, Centro de Estudios de Competitividad, 70 pp.

Peña N., E., Declaraciones a la prensa, 2011-2012. 
Portos P., I. [2008], La industria textil en México y Brasil. Dos vías nacionales de desarrollo industrial, México, IIEc-UnAm, $223 \mathrm{pp}$.

Revista Manufactura [2012], <http://www.manufactura.mx>, 9 de enero.

Secretaría de Competitividad, Trabajo y Desarrollo Económico [2012], Puebla, <http://www.secotrade.puebla.gob.mx>.

Secretaría de Economía [2000], Programa sectorial, sector textil 2000, <http://www.secretariadeeconomia.gob.mx>, 19 de octubre de 2012.

[2012], <http://www.secretariadeeconomia.gob.mx>. 


\section{Capítulo 7 \\ LA MANUFACTURA DE LA CONFECCIÓN \\ EN EL Distrito FeDERAL: EL CASO \\ DE LAS COOPERATIVAS DE PRODUCCIÓN \\ DE UNIFORMES ESCOLARES}

María de Jesús López Amador*

\section{INTRODUCCIÓN}

La industria manufacturera se ha configurado como un objeto de estudio complejo, dada su diversidad y dinámicas a las que se enfrenta en un entorno de alta competitividad global. Esto nos lleva a considerar aspectos claves de su devenir histórico en un contexto concreto como lo es la economía mexicana en la última década.

La manufactura ha significado un sector estratégico para el desarrollo industrial de los países en general, en el caso de la economía mexicana tiene un peso económico importante por su especificidad como actividad económica generadora de empleos

* Académica del IIEc-UnAm, miembro de la Unidad de Investigación de Economía del Trabajo y la Tecnología, y participante en el proyecto de investigación PAPIIT IN305610. Correo electrónico:<mdjesus@unam.mx>. 
directos e indirectos y su concurso en el mercado nacional e internacional.

Su estudio y análisis se ha construido desde distintas vertientes, resaltando sin duda los aspectos de su desarrollo tecnológico y los niveles de competitividad que alcanza ante la diversidad regional, empresarial y de la generación de empleo de calidad que puede impulsar.

En primer lugar se caracteriza por ser un sector con una alta heterogeneidad, en sus distintos subsectores de actividad productiva y comercial, así como por su capacidad exportadora. En segundo lugar, las variables en materia del desarrollo tecnológico que alcanza, el tamaño de sus empresas, la calidad y volumen de empleo directo e indirecto que genera, los mercados internos y externos a los que se dirige su producción, entre otros aspectos, son los que dan cuenta de la situación de heterogeneidad que se acentúa en la industria manufacturera mexicana, cuando se observa su distribución en el territorio y los polos de desarrollo industrial en donde se ubica. A estas características se suman la desigualdad en cuanto al perfil y las condiciones laborales de la fuerza de trabajo que participa en ella, la cual se enfrenta a un modelo de organización del trabajo flexible, con intensidad de las jornadas, que está respondiendo a las nuevas reglas de la competencia de la economía global.

Además, es un sector en el que los empresarios y sus organizaciones tienen una importante fuerza política que se expresa en el papel de las cámaras de las industrias del vestido y la confección, lo mismo sucede con el gremio de los trabajadores y los sindicatos.

Por otra parte, al revisar el comportamiento del sector manufacturero se tiene un panorama de lo que ha significado el cambio tecnológico y los nuevos escenarios de la competitividad en una economía global, lo cual representa una tarea estratégica para los gobiernos y las políticas públicas que implica asumir compromisos políticos de transformación y cambio que a su vez deben involucrar a todos los agentes económicos y actores sociales que participan en el desarrollo tecnológico y crecimiento de la economía nacional. 
Parto de la hipótesis de que al analizar la empresa cooperativa como un modelo de organización del trabajo cuyos socios -en su mayoría mujeres-, no solo tienen opciones de participar en empleos formales, sino un potencial que para innovar en el mundo empresarial altamente heterogéneo y competitivo, es posible esperar que sea la forma de organización de la producción que permita mejorar las condiciones de empleo y de vida de las trabajadoras.

En el contexto de la globalización, las empresas cooperativas se incorporan en condiciones de desigualdad, sin embargo, especialistas como Mogrovejo et al. [2012] resaltan su capacidad para adaptarse con nuevos objetivos a la economía global, la cual enfrenta una severa crisis de empleo. A su vez, según la Organización Internacional del Trabajo [OIT, 2012], es un sector que está demostrando su capacidad de respuesta en el escenario de crisis global y que por lo tanto en el plano local se vincula con las cadenas de producción y comercialización en el mercado interno y las de carácter internacional.

En este contexto, es importante recuperar la experiencia del sector cooperativo en la manufactura de prendas de vestir, las cuales se formaron como producto del Programa de Fomento Cooperativo por parte del Gobierno del Distrito Federal y la Secretaría del Trabajo y Fomento al Empleo, ante el desafío de aminorar los efectos de la crisis del empleo. Es esta entidad federativa la que sin duda concentra el porcentaje más alto del empleo $(12.3 \%)$, según datos de la Cámara Nacional de la Industria del Vestido (CNIV) con base en el INEGI [2009].

¿De qué depende su sobrevivencia y desarrollo en el sector de la manufactura en una zona de alta concentración industrial? $¿$ Cuáles son las estrategias que generan sus integrantes para atender los desafíos de la competitividad? ¿La experiencia, el conocimiento acumulado y el aprendizaje de la fuerza de trabajo femenina son herramientas claves para impulsar la innovación?

La tesis guía de esta investigación es: si bien, la cooperativa se constituye principalmente por trabajo, lo que le permite competir en el mercado es la capacidad de organización de su mano 
de obra, más su potencial de innovación tecnológica, las variables que influyen en la calidad de la producción.

En cuanto a la metodología, la investigación se realizó en dos fases: una documental y otra de investigación de campo con enfoque cualitativo. Se seleccionó al azar una cooperativa dedicada a la actividad de la manufactura que estuviera incorporada al Programa de Fomento Cooperativo del Gobierno del Distrito Federal. Posteriormente se realizaron entrevistas a profundidad con actores claves del programa, así como a los socios y socias de la cooperativa, con el objeto de determinar las formas de organización del trabajo cooperativo y el modelo de producción con el que opera la empresa cooperativa.

En primer lugar, se pretende un acercamiento para conocer cómo está funcionando y qué problemáticas enfrenta en materia de desarrollo tecnológico y organización productiva el sector manufacturero en la industria de la confección de prendas de vestir, como uno de los eslabones importantes de la cadena productiva hilo-textiles-confección-diseño. En segundo lugar, se recuperan los avances y cambios tecnológicos que están dinamizando su acción a escala global, en este apartado se anota la visión de algunos empresarios que han manifestado que el nivel tecnológico de la industria de la confección sigue siendo de bajo perfil.

En tercer lugar, se describe de manera breve el recorrido histórico que han tenido las cooperativas en el Distrito Federal, apuntando las características de la política de fomento cooperativo aplicada en lo local, para impulsar el sector cooperativo en la producción de bienes y servicios y la atención para reducir los problemas del desempleo.

En cuarto lugar, se presenta un estudio de caso relacionado con una empresa cooperativa productora de uniformes escolares y se dentifican las variables que son claves para su competitividad, como la organización del trabajo y de la producción desde la base cooperativa. Este punto se retroalimenta con la visión de las trabajadoras cooperativistas, que señalan los obstáculos a sortear para mantenerse en el mercado local y las carencias que se tienen en materia de políticas para el financiamiento del sector. 
En el análisis de las políticas públicas del Gobierno del Distrito Federal, el propósito final es identificar aspectos claves de política pública para el desarrollo del sector cooperativo manufacturero atendiendo al papel que les toca desempeñar a los actores involucrados y al gobierno local, sobre todo en materia de financiamiento, las reformas y adecuaciones del marco legal para la operación competitiva de las cooperativas y la inversión en tecnología, para el fortalecimiento de la industria manufacturera y considerando prioritaria la seguridad y protección de las condiciones laborales para la fuerza de trabajo.

\section{LA INDUSTRIA DE LA CONFECCIÓN Y EL VESTIDO \\ EN MÉXICO: PROBLEMAS Y RETOS}

PARA LA COMPETITIVIDAD

Dan cuenta de la importancia económica de la industria de la confección y el vestido, un sinnúmero de estudios de caso y regionales, la visión de especialistas, así como algunos diagnósticos de los problemas que enfrenta que se han elaborado en las cámaras de industriales que agrupan al sector. Este contexto nos permitirá identificar aquellas políticas públicas que se han dirigido al sector, así como algunos de los efectos que tienen en el desempeño productivo del mismo.

Empresas, mercados laborales y desarrollo tecnológico se han visto potenciados por la marcha global de la economía en un escenario de alta complejidad, con nuevas reglas de la competencia por los territorios y mercados.

La industria manufacturera, a diferencia de otros sectores, se considera uno de los principales motores de desarrollo industrial en las economías. En el panorama actual, este sector se incorpora a una fuerte competencia por los mercados para exportar y a la velocidad con la que las empresas globales están adoptando nuevos modelos de organización del trabajo y de la producción flexible y la subcontratación.

Uno de los especialistas en el sector, Enrique Dussel [2009], analiza los rasgos de la competitividad de la industria manufactu- 
rera, resaltando el valor de la cadena hilo-textil-confección a partir del Tratado de Libre Comercio de América del Norte (TLCAN) y los retos que se enfrentan ante el crecimiento de potencias como China, India y otros países asiáticos partícipes en esta actividad económica. La competencia global incorpora nuevas reglas entre las regiones y en sus procesos de integración comercial. Eso produce grandes transformaciones en el sector manufacturero de la confección y el vestido, ya que en muchos casos obedecen a estas nuevas reglas que se generan con los actuales encadenamientos mercantiles globales. Estos cambios impulsan a la competitividad, modifican los territorios y agregan a nuevos competidores, en este caso la creciente participación socioeconómica de Asia y particularmente de China [Cárdenas y Dussel, 2007].

Si bien es cierto que este sector de la manufactura adquiere una importancia económica significativa, también es evidente la alta complejidad del contexto en el que opera, en el cual los siguientes fenómenos y procesos están influyendo en las condiciones y cambios que presenta la principal cadena de valor bilo-textil-confección global y en México, según el análisis de Dussel [2009: 5-9]: a) saturación y competencia; b) procesos de paquete completo y crecientes costos para los proveedores; c) moda rápida (fast fashion) y diferenciación del producto; d) creciente importancia y control de la cadena de los detallistas; e) tiempo y precios; f) creciente importancia de la proveeduría local; g) nuevos enfoques y estándares laboral, ético y ecológico, y h) la fuerte competencia y creciente participación de Asia y China, y la crisis en América del Norte (véase figura 1).

$\mathrm{Al}$ agregarse nuevos actores, como China, a la competencia global por los territorios y mercados, principalmente el mercado de los Estados Unidos, sus estrategias aplicadas cuestionan a profundidad el patrón productivo y comercial aplicado en México durante los últimos decenios, ya que podría ofrecer mercancías con menor costo laboral, insumos de mayor calidad y mejor precio, así como tecnologías propias y proveedores endógenos" [Cárdenas y Dussel, 2007: 530]. 


\section{Figura 1. Aspectos conceptuales; globalización y competitividad sistémica}



2. Competitividad sistémica

y endogeneidad territorial
3. La creciente participación socioeconómica de Asia y particularmente de China.

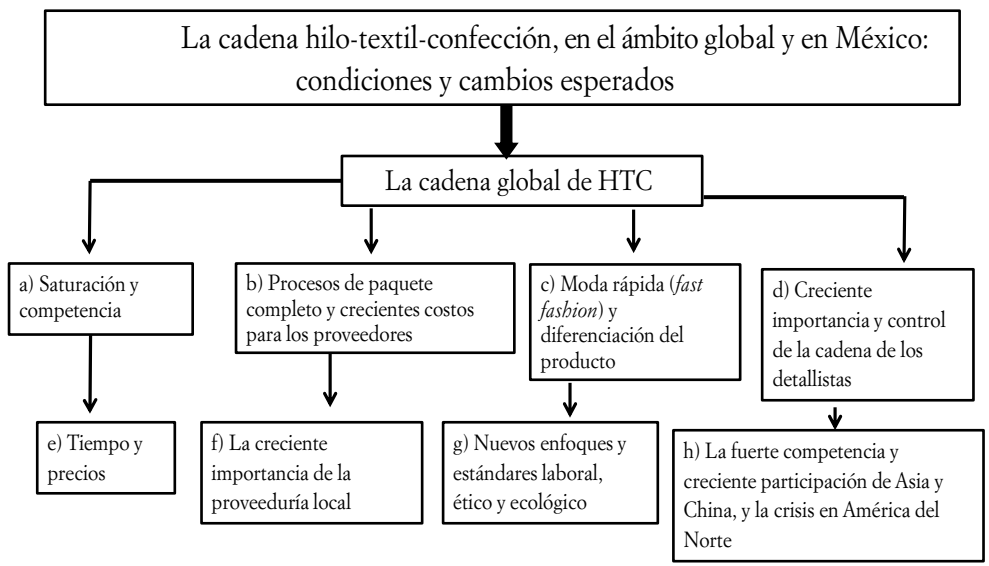

Fuente: Enrique Dussel Peters [2009: 5-9].

De acuerdo con el análisis de la situación por parte de estos autores, en el caso de México, una de las fortalezas de la cadena hilo-textil-confección es su presencia regional, además de generar empleo formal y permanente en el país. En contraste se enfrenta a serios problemas y contradicciones como la especialización y la debilidad en el segmento de la confección y las masivas importaciones en el segmento textil, mostrando su poca capacidad de producir los insumos requeridos para todos los segmentos de la cadena y aumentando la dependencia al importar dichos insumos de Estados Unidos. A su vez, es una cadena con grandes diferencias al igual que otras del sector manufacturero, sobre todo en términos de las propias empresas: tamaño, tecnología, financiamiento, empleo y calidad, requerimientos de capacitación, capacidad de aprendizaje y escalamiento, condiciones comerciales, etcétera [Cárdenas y Dussel, 2007: 531-532]. 
Entre los cambios que se operan en el sector, estos autores señalan comportamientos distintivos de las grandes empresas, que obtienen sus utilidades a partir de las combinaciones de diseño, aprendizaje e investigación, comercialización y servicios financieros, y que en los últimos años han flexibilizado la relación con sus proveedores. Estos a su vez, realizan servicios más personalizados y han incrementado de manera considerable su responsabilidad y costos en ámbitos como el financiamiento, el proceso productivo y la logística, conocido como de paquete completo (o full packaging). Así, los costos en la cadena hilo-confección resultan cruciales para mantener la competitividad, aunque también lo son el tiempo de producción y de reacción ante nuevos productos y la localización de las redes y sus proveedores.

Un ejemplo de empresa de la confección que opera bajo este perfil es Zara (empresa española con el esquema de cooperativas), la cual se caracteriza por su innovación y modelo organizativo que le permite niveles de competencia altos en el plano internacional. Según Martínez [2007: 69], la empresa Zara, bajo la rúbrica del posfordismo o producción flexible, ha sabido introducir prácticas flexibles en diversas esferas de su organización y al mismo tiempo ha conseguido cambiar las reglas del juego del sistema de moda, al incorporar con éxito la última transformación: la "moda rápida" o fast fashion, como se conoce en el sector. Este modelo se basa en la rapidez, y consiste en surtir y resurtir a los clientes con las diferentes prendas novedosas y desarrollar una nueva modalidad de vestir, que une la dimensión de moda con un bajo costo tanto económico como psicológico del consumo.

Actualmente, algunas empresas de confección se encuentran entre las organizaciones mejor adaptadas al nuevo entorno competitivo. Y es que las características particulares de la actividad y su elevada dependencia con respecto al mercado han convertido el nuevo modelo organizativo y de gestión en la piedra angular sobre la que se fundamenta su competitividad y las tecnologías de la información y la comunicación en uno de los principales medios para conseguirlo [Martínez, 2007: 71]. 
Si bien, el costo de la fuerza de trabajo en la confección es una de las variables claves para competir, no es la única, ya que intervienen otras como la calidad, la rapidez de entrega, el acceso a insumos y transporte, la capacidad de diseño y adaptación de nuevas tecnologías; estos desempeñan un papel crucial y en algunos segmentos son de mayor relevancia que el costo de la fuerza de trabajo.

Además, como anotan los especialistas Cárdenas y Dussel [2007: 534], la competencia entre los países asiáticos y latinoamericanos se ha basado en su habilidad de haber generado importantes economías de escala, insumos a costos muy bajos para la cadena, crecientes avances tecnológicos para los principales accesorios y textiles, financiamiento masivo y una larga experiencia en procesos de paquete completo, frente a la cercanía a los mercado y la capacidad de respuesta rápida ante cambios por parte de la demanda y los compradores. Pero, como ya se mencionó antes, las empresas en el ámbito mundial se están caracterizando por otros elementos más, en los cuales la innovación tecnológica aplicada al modelo organizativo es la clave de la competencia.

En el caso del gobierno mexicano, su política de apertura y liberalización comercial ha sido el eje en las últimas décadas para generar competitividad. Según fuentes oficiales, el Tratado de Libre Comercio de América del Norte ha brindado la plataforma a las empresas para la exportación, el mantenimiento de los bajos costos de la fuerza de trabajo barata, así como las políticas, la estabilidad macroeconómica que le dan otro sentido en la ubicación geográfica de los países miembros y diversos apoyos a la exportación.

Así, la apertura comercial es vista por los industriales del ramo como una política favorable funcionando de manera tal, que hoy se expresa en un número importante de tratados comerciales que han dado soporte al intercambio comercial internacional y a la competitividad de la industria, por lo cual se contabilizan en total: 12 tratados de libre comercio con 44 países, 23 acuerdos de promoción y protección de inversiones (APRI) y seis acuerdos de complementación económica (ACE) [CNIV, 2009]. 
En cambio, hay especialistas que señalan que las principales transformaciones que ha tenido este sector como efecto de la apertura comercial y el TLCAN, se observan en el rompimiento de las cadenas productivas y la conversión de la industria del vestido en maquiladora y en el incremento de la dependencia al capital extranjero. Esta apertura también ha modificado la forma de producir por las empresas, concentrando o desincorporando las diferentes operaciones del proceso productivo.

En un estudio de campo se identificó que los principales productos de exportación de estas empresas mexicanas son ropa de mezclilla, uniformes, vestidos de dama y de niña, ropa de bebé, ropa para dama, playeras de tejido de punto, camisas y blusas de vestir, bolsas de coco, guayaberas e hilo de hamaca, entre otros. También se encontraron casos de empresas que se especializan en la maquila de estas prendas [Simón, 2006: 131].

En contraste, se considera la gran dependencia de ciertos segmentos de la cadena de importación de insumos como son telas, hilos, botones, empaques, accesorios y etiquetas. Esto se ilustra con el caso de las cooperativas de producción de uniformes, que son afectadas en sus costos de materia prima, así como en los tiempos de entrega, dadas las demoras para surtir sus principales insumos, lo cual obstaculiza la productividad y con ello la capacidad de respuestas de estas y otras empresas del sector.

Sin duda las políticas gubernamentales para incrementar la competitividad se han traducido en una serie de programas que han buscado resolver problemas muy serios que enfrenta el sector y que no han desaparecido del todo; entre ellos siguen presentándose obstáculos para la exportación, el manejo de las reglas de origen y el tipo de cambio, al igual que la dependencia de las importaciones de los insumos para algunos de los segmentos, así como el financiamiento limitado.

Si bien los mercados de los productos de la industria del vestido son el local y nacional, muy pocas empresas se orientan a exportar su producción, principalmente a Estados Unidos. Los mecanismos de exportación que utilizan los empresarios se basan en: asistencia a ferias o exposiciones, investigación sobre posibles 
clientes en el extranjero, recomendaciones diversas e invitación de los clientes, entre otros [Simón, 2006: 134-135].

Por lo anterior, para volver a reconstruir las cadenas textilvestido se requiere el fortalecimiento de la industria textil en su conjunto, la introducción de nuevas tecnologías, programas de inversión que permitan competir con los productos importados y la creación de nuevas formas de organización de empresas que fortalezcan el mercado interno y den empleo.

Para poder aplicar estos cambios en las empresas, se necesita capital y el financiamiento no solo puede provenir del gobierno, también de proveedores o contratistas, situación que se ha detectado en el caso de algunos empresarios del sector que recurren a estos financiamientos con altas tasas de interés, lo que deja ver la falta de apoyo financiero a esta actividad productiva; el sector demanda, por lo tanto, apoyos financieros con tasas de interés atractivas y plazos razonables. Asimismo, los nulos apoyos del gobierno recibidos por estas empresas para la provisión de maquinaria y equipo dejan sin soporte a cualquier política industrial que se quiera impulsar en el país, ya que mientras estas empresas no puedan renovar su maquinaria y equipo, cada vez les será más difícil incrementar la productividad y por ende su competitividad, la cual se ve obligada a sustentarse en bajos salarios únicamente [Simón, 2006: 141].

La banca de desarrollo solo participó con 3\% de crédito total suministrado a la industria del vestido [CNIV, 2009]. Según Banxico, el financiamiento para la fabricación de prendas de vestir provino de la banca comercial con un monto de 279 millones de dólares, que correspondían a $97 \%$ y de la banca de desarrollo con 8 millones de dólares con $3 \%$. A este respecto los industriales del vestido anotan los siguientes desafíos como los principales [CNIV, 2009]:

- Mayor acceso a crédito y financiamiento.

- Diversificación de mercados.

- Combate a la ilegalidad, el contrabando y el ilícito aduanero. 
- Apoyo para la mejora de la competitividad.

- Atención al reposicionamiento de imagen y marca de los productos en el mercado nacional e internacional.

En cuanto al comportamiento general del sector, tenemos que la fabricación de prendas de vestir se constituyó como el principal pilar de la producción, dentro de la cadena textil-vestido-cuero. El INEGI destaca la importancia de esta cadena con los siguientes datos: las industrias manufactureras generan $95 \%$ de la producción, y la cadena textil-vestido-cuero solo $5 \%$, es decir, de manera específica la producción se distribuyó en este orden en los segmentos del vestido $(2.5 \%)$, textil $(1.3 \%)$ y el segmento de cuero (1.2\%) [INEGI, 2009].

Estas diferencias se agudizan si revisamos cómo se integra el sector manufacturero: en total, 109095 empresas grandes de las cuales solo 10\% corresponde al sector textil-vestido con 11598 empresas, según la CNIV.

La cadena textil-vestido concentró 11\% de empleos en números absolutos correspondientes a 396534 plazas para el año 2009. Según la CNIV, al hacer un balance histórico de dicha cadena, un dato importante es la recuperación de más de 6500 plazas laborales que muestran una tendencia positiva en el nivel de empleo, al mes de octubre de 2009. Se da una concentración en la producción y el empleo en los estados del centro (Aguascalientes, Estado de México, Distrito Federal y Puebla) y en la parte norte (Chihuahua, Coahuila y Baja California), se ha concentrado la industria maquiladora de exportación.

Si bien las diferencias se dan dentro del sector por el tamaño de las empresas que lo conforman y la concentración de su producción, dominando el espectro las micro, pequeñas y medianas empresas, de las cuales algunas pertenecen al rubro de las cooperativas, también vamos a encontrar que las empresas operan y funcionan de diversas formas. Entre ellas se encuentran las que realizan $100 \%$ del proceso de manufactura en sus plantas o talleres; hay algunas más que maquilan para otras empresas bajo el esquema de la subcontratación de manera parcial o bien 
subcontratando hasta $100 \%$ de sus pedidos o solo de forma parcial en algún porcentaje [Simón, 2006: 137].

Entre las operaciones que realizan ciertas empresas mediante la subcontratación o maquila, se tienen las siguientes: mantenimiento de la maquinaria, costura, empaque, mantenimiento de las instalaciones, seguridad y limpieza, el diseño de las prendas, el lavado y el planchado y la comercialización de sus productos. Aun cuando en el 2003 se observó que las empresas han ido incorporando más operaciones, son muy pocas las que realizan el llamado “paquete completo” [Simón, 2006: 137-139].

El trato por parte del gobierno a las empresas en relación con los apoyos, este también es muy diferenciado; sobresalen la capacitación para mejorar la calidad de sus productos, asesoría tecnológica, asesoría administrativa, financiamiento, provisión de maquinaria y equipo, mejora de la calidad de los productos y preservación del medioambiente.

La presencia de competidores como China hace que esta cadena se siga enfrentando a prácticas desleales y competencia de los productos extranjeros que entran e invaden el mercado nacional. En los estudios realizados se detecta que si bien México tiene una de sus fortalezas en la producción de pantalones de mezclilla, corsetería y ropa de dama, no se ha impulsado una política que permita que esta producción manufacturera pueda ser un segmento altamente competitivo, para lo cual se requieren políticas específicas para este sector [Dussel, 2009]. A continuación veremos el desempeño y la polarización al introducir la tecnología y las innovaciones como un componente clave de la competitividad dentro del sector.

\section{DESARROLLO TECNOLÓGICO EN LA INDUSTRIA DEL VESTIDO}

El escenario de innovaciones y cambios tecnológicos aplicados al sector de la industria de la confección sigue siendo bajo en un buen porcentaje de empresas manufactureras mexicanas, las cuales 
continúan trabajando con maquinaria manual y mecánica, eléctrica y electrónica, caracterizadas por su antigüedad, pues el nivel tecnológico de las empresas no es alto ni muy rápido, es decir, se usan máquinas con antigüedad de 10 años o más, manteniendo las características que se requieren actualmente para el proceso productivo [Simón, 2006: 152]. Para la investigadora María Luisa González, en el siglo xx se llevaron a cabo varias modernizaciones que en el tema del desarrollo tecnológico y de la innovación se pueden resumir en dos planos, uno internacional y otro nacional, como se puede observar en los cuadroa $1 \mathrm{a}$ y $1 \mathrm{~b}$.

En el primer plano, este desarrollo tecnológico mundial exigía que las modernizaciones en la industria textil se hicieran aproximadamente cada 10 o 15 años. México retrasaba sus cambios tecnológicos porque se debía comprar en el exterior la maquinaria y el equipo, lo que implicaba endeudarse en dólares y seguir dependiendo tecnológicamente del exterior. Además, se debe tomar en cuenta que la nueva maquinaria es ahorradora de mano de obra y los sindicatos ejercen presión para evitar los despidos. Es un sector que se ha caracterizado por la existencia de numerosas pequeñas y medianas empresas [González, 2006: 91].

Según la especialista González Marín [2006], las medidas de política económica derivadas de la apertura comercial y la integración regional del sector manufacturero poco han contribuido al fortalecimiento tecnológico de esta industria, de la misma manera, las acciones gubernamentales han respondido más a las presiones de un sector de empresarios organizados, que demandan financiamiento, asesoría y mayor flexibilidad en la normatividad en el trabajo para impulsar al sector manufacturero de la confección de prendas de vestir. 







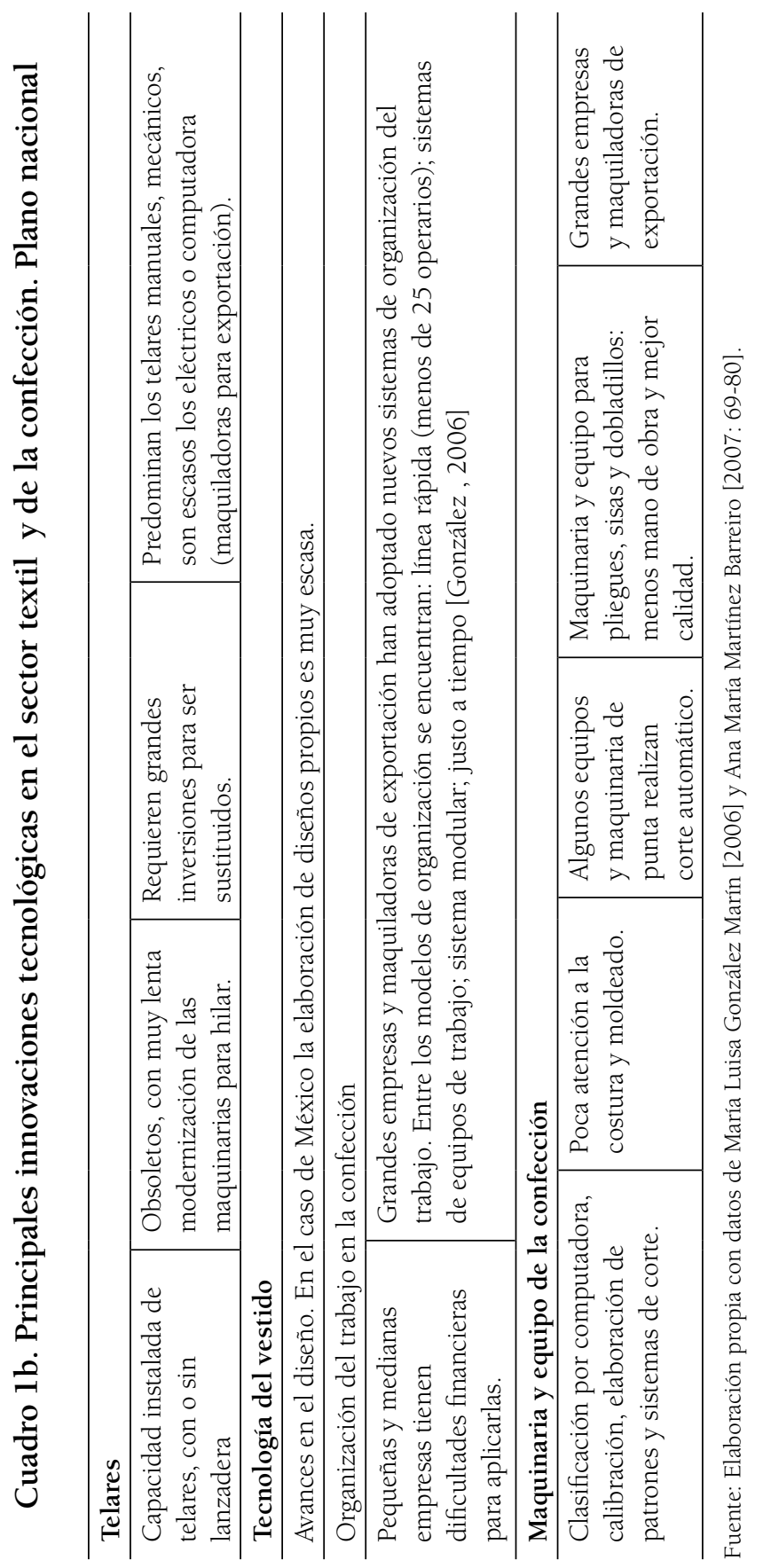


$\mathrm{Al}$ analizar las estrategias de las empresas innovadoras, la especialista Martínez [2007] apunta que, en las últimas décadas, como consecuencia de la globalización económica y la aparición de las tecnologías de la información, el sector textil y de la confección ha experimentado una drástica transformación. Se ha reducido la distancia entre los diferentes agentes que intervienen en el proceso de fabricación y distribución, acortándose el tiempo desde el diseño de una prenda hasta su llegada a la tienda y creando así el concepto de distribución de circuito corto.

Para esta autora, la innovación y el desarrollo tecnológico se pueden ejemplificar en el sector con el caso de la empresa Zara (como se citó al principio), la cual es considerada uno de los gigantes manufactureros en el sector de la confección a escala mundial. Los factores y estrategias de competitividad que resaltan en esta son los siguientes:

- Manufactura de prendas de vestir basada en la maquila y trabajo de pequeños talleres, fundamentalmente más de 300 cooperativas organizadas en red con un desempeño altamente competitivo.

- Moda rápida dirigida para jóvenes.

- Marca propia que se ha distinguido por los diseños y las telas que utiliza.

- Forma de producción que atiende las necesidades del mercado cambiante y su sector de población.

Con este sistema, enteramente basado en la comunicación electrónica, procesado por internet, Zara ha reducido a dos semanas el tiempo necesario para rediseñar una nueva línea de productos, desde su diseño hasta el momento en que se decide ponerlo en su red de tiendas en cualquier parte del mundo, frente a una media de nueve meses del sector [Martínez, 2007: 73].

En México se está poniendo énfasis en competir en un segmento más de la cadena que corresponde al diseño. Para esto los empresarios han impulsado la creación del Centro de Innovación y Moda (Ceinmoda), el cual ha brindado asesoría a las empresas 
en materia de diseño, desarrollo, producción, capacitación y venta de productos para sus afiliados.

En el plano de la innovación tecnológica, en el estudio citado se observa el papel que desempeñan también los contratistas o proveedores en asesoría tecnológica. El gobierno fue señalado por los entrevistados como el principal asesor en el área administrativa. Llama la atención la escasa intervención de las universidades e instituciones educativas en el apoyo a estas empresas, lo cual refleja la falta de un programa de vinculación con este sector productivo, que se agudiza por la poca difusión de los mismos en los casos en que sí se presentan dichos programas [Simón, 2006: 141].

Ahora bien, al explorar el entorno donde opera el sector cooperativo, nos encontramos que no se escapa de conservar un perfil bajo de desarrollo tecnológico y de innovación, lo que sigue presentando fuertes desafíos para este al competir de manera desigual con industrias trasnacionales y de gran desarrollo, con alta productividad y dominio de los mercados regionales y locales.

\section{BREVE PANORAMA SOCIOHISTÓRICO \\ DE LAS COOPERATIVAS EN EL DisTRITO FEDERAL}

Una breve revisión histórica del sector cooperativo en México nos permite recuperar algunos de sus antecedentes ${ }^{1}$ y la coyuntura actual en la que se plantea por algunos especialistas que las

${ }^{1}$ En México, la etapa de gestación del cooperativismo ocurre a fines del siglo XIX por la influencia de inmigrantes extranjeros principalmente europeos, así como con la participación importante del Estado mexicano en un periodo que va de 1940 a 1980; de igual forma, bajo la acción de los gremios y organizaciones de trabajadores que resolvieron ya en épocas más recientes integrar una empresa cooperativa (como los trabajadores de la industria refresquera Cooperativa Pascual). En las primeras experiencias, gremios como los carpinteros, sastres, productores de sombreros, obreros, transportistas, de la industria editorial, así como en el sector de consumo y crédito y vivienda, fueron integrando desde muy diversos orígenes y actividades económicas y sociales el movimiento cooperativo, cuyo potencial permitió en este periodo dar impulso al modelo de sustitución de importaciones y al crecimiento de la economía [Mogrovejo et al., 2012]. 
cooperativas están resurgiendo como una alternativa a la crisis del empleo y por lo tanto se acepta su capacidad de generar empleo en sectores productivos claves para el desarrollo regional y nacional de la economía.

El periodo que más destaca en el desarrollo de empresas cooperativas es el que transcurre desde el sexenio del presidente Lázaro Cárdenas, con la promulgación de las primeras leyes cooperativas, hasta el sexenio de Luis Echeverría. Posteriormente, durante la gestión de Miguel de la Madrid, el Plan Nacional de Desarrollo 1982-1988 contempló el desmantelamiento del sector social al desaparecer la Dirección General de Fomento Cooperativo de la Secretaría del Trabajo y al liquidar el Banco Nacional de Fomento Cooperativo.

A finales de 1998, de acuerdo con los datos de la Universidad Coordinadora de Políticas, Estudios y Estadísticas del Trabajo de la Secretaría del Trabajo y Previsión Social (sTPS), en el Distrito Federal existían 981 cooperativas con un total de 29562 socios, ocupando un lugar relevante en este sector en el plano territorial. Por su tamaño, la mayoría siguen siendo micro y pequeñas empresas [Rojas: 2003: 93].

Actualmente, el movimiento cooperativo no ha logrado recuperar la influencia que aspira a tener en el diseño de las políticas públicas del Estado, sin embargo, desempeña un papel importante en la autogeneración de empleos y recursos para el desarrollo regional en zonas marginadas (CESOP). El movimiento cooperativo en México transita por una fase álgida que en muchas ocasiones deriva en el enfrentamiento de posturas. Por un lado, las recientes reformas a la Ley General de Sociedades Cooperativas y a la Ley de Ahorro y Crédito Popular encaminan al sector hacia la transformación de intermediarios financieros, lo que limita el desarrollo y los objetivos sociales de un número importante de cooperativas, que recientemente participaron en el debate de la Ley de Economía Social manifestando su inconformidad a pesar de que esta fue en cierta medida un logro para ubicar al sector cooperativo como eje de la economía. 
Con el desmantelamiento ${ }^{2}$ de las instituciones que daban cuenta del sector, no hay registros con cifras exactas sobre el número de cooperativas. Sin embargo, se maneja que en México operan en promedio unas 15000 cooperativas en su mayoría de consumo y producción de bienes, y en ellas participan unos cinco millones de personas, según datos del Fondo de Desarrollo Social del Gobierno del Distrito Federal [Godoy, 2011].

En la investigación realizada por Rojas [2003: 20] se detectó que las cooperativas de producción y consumo se distribuyen en las 16 delegaciones políticas del Distrito Federal y solo en cuatro demarcaciones territoriales se concentraban $70 \%$ de las cooperativas. En el estudio se menciona que la inmensa mayoría de las cooperativas no cuenta con ningún tipo de apoyo o subsidio de origen gubernamental o privado, lo cual permite afirmar que actualmente no existen programas específicos de promoción cooperativa a escala federal ni de la entidad para este año. La única excepción a esta regla son dos cooperativas de estibadores, las cuales han recibido crédito: la primera de ellas, de parte del Banco Obrero, la segunda, de la Administración de la Central de Abastos.

Un problema grave de las cooperativas es la falta de capacitación y formación para administrar la empresa, así como para transitar de una producción meramente artesanal y modernizarse. Tienen escasez de mercado y de promoción para la adecuada comercialización de sus productos, y enfrentan la falta de crédito o financiamiento para recapitalizar sus unidades productivas o, incluso, para sostener los gastos de operación de sus empresas.

${ }^{2}$ Con la promulgación de la nueva Ley General de Sociedades Cooperativas [LGSC: 1994], se decretó la desaparición de la Dirección General de Fomento Cooperativo de la STPS, encomendándose la función de control estadístico de las cooperativas existentes en el país a la Secretaría de Desarrollo Social, sin embargo, dicha secretaría solo podía desempeñar eficientemente sus funciones en la medida en que las diferentes Direcciones del Registro de la Propiedad y el Comercio de los estados remitieran, en forma oportuna y de la manera más amplia y fidedigna, "copia de todos los documentos que sean objeto de inscripción y la información que solicite la propia dependencia, para integrar y actualizar la estadística nacional de las sociedades cooperativas" (artículo 17 de la LGSC) [Rojas, 2003: 97]. 
El escaso financiamiento público y privado obstaculiza su formación y funcionamiento, lo que lleva al sector a estar rezagado respecto de otros países latinoamericanos. También anotan la falta de capital para empezar y comprar los insumos [Godoy, 2011].

La Organización Internacional del Trabajo [OIT, 2002] aprobó un nuevo texto para la Recomendación sobre la Promoción de Cooperativas, en el cual se promueve que en los gobiernos locales se mejoren las condiciones para su registro, fortaleciendo su relación con otras organizaciones sociales como sindicatos y empleadores así como una legislación local a favor del movimiento cooperativo. México es uno de los países que ha actualizado su marco jurídico en 2004 con la Ley General de Sociedades Cooperativas y en 2009 , que orientan su acción hacia la economía social y solidaria.

Según el estudio de la OIT, en el caso de México se han identificado decenas de programas federales y al menos una docena de programas estatales que promueven de diversas formas la micro, pequeña y mediana empresa, pero no explícitamente la economía social y el cooperativismo. Se afirma la ausencia ${ }^{3}$ de una estructura institucional y políticas públicas de apoyo a este sector, y en su lugar, más bien se realizan acciones paliativas y desarticuladas. Lo anterior es atribuible a las prioridades del Estado de facilitar la expansión y consolidación de empresas del sector de lucro privado [Rojas, 89-90, citado por la OIT, 2012: 63].

Lo que sí queda claro es un trato diferenciado que desde el gobierno federal se da al movimiento cooperativo por carecer de

\footnotetext{
${ }^{3}$ Si bien es cierto que en los planos internacional y nacional se reconoce su importancia económica, también es verdad que a partir de los ochenta con el desmantelamiento de instituciones importantes y la retirada del Estado para apoyar a este sector no hay un registro sobre el número de cooperativas en el país, por sector de actividad y su distribución estatal, ni sobre su peso en el producto interno bruto mexicano, de modo que se valide su importancia económica y social. A pesar de no contar con datos precisos, sí se ha podido medir que, en 17 de las 32 entidades federativas, 200 instituciones autogestionarias mostraron un importante peso en el desarrollo regional en los últimos años (noticia en línea, www.ipsnoticias.net/nota. Asp?idenws=97763, consultado el 10 de noviembre, 2012).
} 
una política de Estado en la materia, que impulse el desarrollo de las organizaciones que trabajan en el sector social de la economía, estas dependen actualmente de dos programas federales que se ejecutan con estrategias diferentes para la atención de un solo sector, como es el Programa de Coinversión Social de la Secretaría de Desarrollo Social, y el Fondo de Apoyo a Empresas en Solidaridad (Fonaes), de la Secretaría de Economía [Centros de Estudios Sociales y de Opinión Pública, 2006].

En el contexto internacional pareciera abrirse un panorama favorable con los pronunciamientos de organismos internacionales importantes. Por ejemplo, la Organización de las Naciones Unidas (ONU) declaró al 2012 como Año Internacional de las Cooperativas cuyo eslogan era: "Las empresas cooperativas ayudan a construir un mundo mejor". Entre sus principales pronunciamientos y objetivos están: promover el crecimiento fomentando la construcción y crecimiento de cooperativas, establecer políticas adecuadas con el fin de alentar a los gobiernos y organismos reguladores e implementar políticas, leyes y normativas que propicien la constitución y crecimiento de las cooperativas. Este contexto se ha sabido potenciar principalmente desde el gobierno local, como se analizará en el caso de las cooperativas en el Distrito Federal.

\section{LA POLÍTICA DE EMPLEO Y DE FOMENTO COOPERATIVO \\ EN EL DisTRITO FEDERAL: EL CASO DE LAS COOPERATIVAS DE CONFECCIÓN DE UNIFORMES ESCOLARES}

En los últimos años se ha dado un importante debate en cuanto a las reformas constitucionales y las normas secundarias que regulan al sector para librar obstáculos y potenciar las empresas cooperativas. La Ley de Sociedades Cooperativas las define como:

organizaciones basadas en intereses comunes y en los principios de solidaridad, esfuerzo propio y ayuda mutua, con el propósito de satisfacer necesidades individuales y colectivas, a través de la realización de actividades económicas de producción, distribución y consumo de bienes y servicios. 
El impulso del cooperativismo se dio en 2006 por el Gobierno del Distrito Federal. En 2008 se aprobó la Ley de Fomento Cooperativo para el Distrito Federal y se puso en vigor por el GDF y la Secretaría del Trabajo y Fomento al Empleo (STIFE-GDF) el Programa de Fomento Cooperativo; este instrumento programático se ha orientado a impulsar a las cooperativas como una más de las variantes de la economía social.

En 2007, la Secretaría del Trabajo del Gobierno del Distrito Federal elaboró una estrategia de fomento cooperativo que le permitió enlazar varios objetivos económicos y sociales, como parte sustantiva de estas acciones de gobierno se impulsó la creación de empresas cooperativas que pasaran a ser proveedoras de bienes y servicios para el gobierno local. Además, las cooperativas de la ciudad participaron de forma directa en la producción de uniformes escolares, producto base de uno de los programas sociales que se instrumentó mediante la Secretaría de Desarrollo Social del Distrito Federal, para los alumnos de las escuelas públicas de la ciudad. Como lo señalan sus impulsores, el Programa de Fomento Cooperativo se sustenta en el enfoque de la tecnología organizativa, aplicada en el desarrollo de proyectos masivos de producción [Viloria, 2007: 9].

Por lo anterior, se diseñó un programa que se llamó “iQué Buena Puntada!", corrió a cargo de la STyFE y permitió instrumentar la política de fomento al empleo además de atender objetivos sociales y económicos. Con este objetivo se realizó un diagnóstico, que reveló que en el Distrito Federal existían pocas cooperativas, así como micro y pequeñas empresas dedicadas a la costura debidamente formalizadas. Por ello, se convocó públicamente a costureros con experiencia y maquinaria propia, interesados en participar en un proceso de capacitación e integración productiva. Entre los participantes que acudieron a la convocatoria del 2007 se registró un total de 800 personas, de las cuales $75 \%$ eran mujeres que contaban con maquinaria y locales propios (básicamente en sus domicilios, que funcionaban como talleres familiares de entre dos y 10 personas). 
En el estudio diagnóstico que realizó la STyFE se detectó que la mayoría de los talleres familiares no estaban legalmente constituidos y registrados, entre otras razones, porque su producción, obtenida mediante intermediarios, apenas daba para cubrir los propios gastos, generando un empleo precario de menos de un salario mínimo mensual. En su mayoría, los talleres estaban integrados por mano de obra femenina, poco calificada, con bajos niveles de escolaridad, jefas de familia y que no contaban con fuentes de ingreso, también por un porcentaje importante de adultos mayores y un porcentaje pequeño de personas con algún tipo de discapacidad [Informe de la STyFE y de la Coordinación de Fomento Cooperativo, 2011].

El equipo, maquinaria y locales de los pequeños talleres en general eran de tipo casero y semiindustrial, por lo que de manera individual o por taller familiar tenían una capacidad de producción muy limitada (el registro de maquinaria y equipo ascendió a más de 8000 máquinas). Los talleres estaban ubicados en las zonas marginadas de la Ciudad de México, lo que requirió un esfuerzo importante de integración ante la dispersión de los mismos. También se hubo de considerar que ante la falta de tecnología de punta su capacidad estaba en la organización de la fuerza de trabajo [sTyFe, 2011].

Ante este diagnóstico, las estrategias de integración se basaron en la organización de la producción en cooperativas y la especialización técnica sobre el corte y la confección de uniformes. La autonomía y el autogobierno son condiciones básicas del desarrollo cooperativo, por lo que cada cooperativa cuenta ahora con su órgano de dirección, denominado consejo de administración y de vigilancia. Con este proceso de integración, la productividad se elevó en más de $100 \%$, es decir, si un taller de manera "individual" producía cinco prendas, de manera organizada produce en promedio 10 prendas con las mismas horas de trabajo; asimismo, el ingreso por taller se incrementó entre 250 a $350 \%$, un promedio de cinco salarios mínimos en cada etapa de producción.

Según datos de la STyFe, los principales resultados de esta política y programa de fomento cooperativo basado en la organización 
del sector se han traducido en un avance importante en los procesos de integración de las cooperativas, la legalización o estatus formal y la organización del trabajo, y se expresan en mayores índices de productividad, como se observa a continuación en las siguientes cifras que maneja la STyFE:

- En 2008, se elaboraron casi 400000 prendas escolares, participaron 11 cooperativas, con 900 socios pertenecientes a aproximadamente 300 talleres.

- En 2009, las cooperativas se reorganizaron territorialmente, por lo que participaron ocho cooperativas legalmente constituidas con 1100 socios y aproximadamente 300 talleres familiares; se produjeron 108000 uniformes escolares.

- En 2010, seis cooperativas produjeron 123200 prendas escolares.

- En 2011, las cooperativas produjeron 450000 prendas y están llegando a la prenda dos millones, producida desde el 2007.

Al 2011 participaban en el programa “¡Qué Buena Puntada!” 633 socios, mujeres y hombres, organizados en 171 talleres de seis cooperativas constituidas formalmente. Respecto a esto, no hay que perder de vista que durante todo el proceso los grupos de cooperativistas se han reconfigurado tanto en su forma de organización como en su tamaño. Durante la operación del Programa de Fomento Cooperativo, en 24 proyectos para distintas áreas de gobierno local, han participado cooperativas, empresas privadas y fundaciones.

El papel que desempeñan las cooperativas como empresas sociales proveedoras, que abastecen principalmente a las dependencias del Gobierno del Distrito Federal, las ha llevado a diversificar su línea de producción manufacturera, atendiendo no solo la producción de uniformes escolares que responde a un programa temporal, sino a otros sectores sociales, empresas y fundaciones. Los productos comercializados son: uniformes deportivos, uniformes para cocinas populares, gorras, chalecos, 
bolsas de mezclilla, vinílica y de manta, fundas para butacas, playeras, corsetería, cubrebocas, bolsas vinílicas, mandiles promocionales y chamarras.

Durante todo el periodo de implementación del programa se han tenido que proponer ajustes y modificaciones a las leyes y reglamentos que conforman el marco jurídico en la materia (véase figura 2).

Es importante destacar que la Ley de Fomento Cooperativo del Distrito Federal plantea el marco político y el papel de las administraciones locales para que el sector cooperativo se incorpore al sistema de planeación democrática y en los Consejos de Fomento Económico y Social que establecen las leyes locales. Entre las principales acciones gubernamentales se mencionan: considerar a las cooperativas proveedoras de las delegaciones, brindar asesoría jurídica y administrativa a las cooperativas existentes y las nuevas surgidas del programa (constitución y trámites), gestionar apoyo para la creación y desarrollo de proyectos productivos que surjan del programa, apoyar en la gestión de créditos y financiamientos locales, establecer redes de mercado cooperativo en el Distrito Federal, realizar promoción y difusión del sector cooperativo.

Si bien, introducir el tema en la agenda política permite complementar las políticas públicas que fortalecen al sector cooperativo a escalas local, regional y nacional, también es verdad, como se mencionó, que se sigue careciendo de una política de desarrollo económico industrial que se contemple el papel que debe desempeñar dicho sector cooperativo; por lo pronto, su impulso depende de la coyuntura política y económica, como lo ha demostrado la historia.

El resultado final de estas acciones gubernamentales se expresa en el cuadro 2.

En cuanto a la proporción de cooperativas de manufactura que se integraron para atender la demanda de la producción de uniformes escolares para el gobierno local, estas fueron seis; resalta el alto porcentaje de mujeres $(79 \%)$ que participaban en las empresas cooperativas, como se muestra en el cuadro 3. 


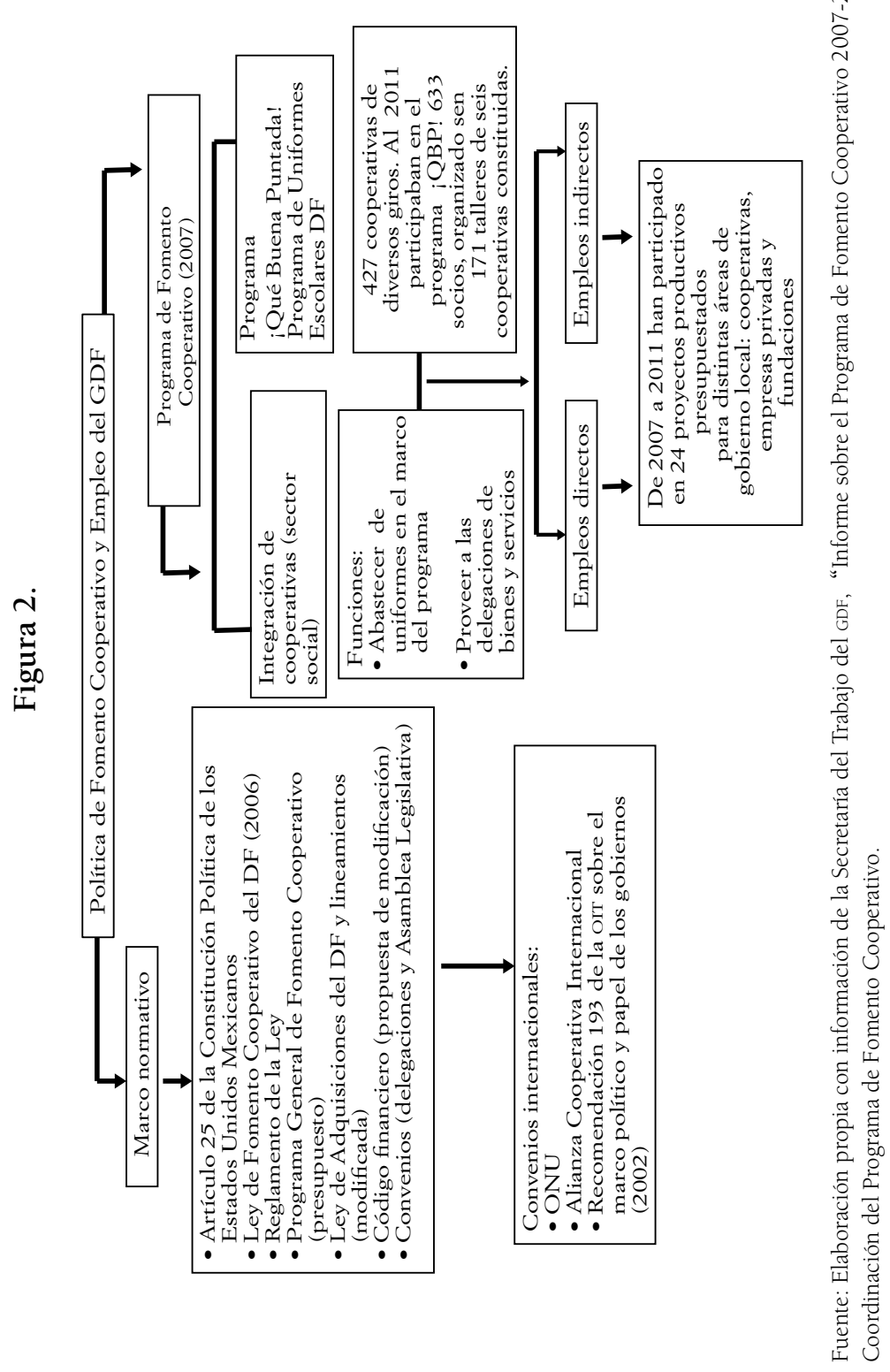




\section{Cuadro 2. Número de cooperativas en el Distrito Federal, 2011}

\begin{tabular}{l|c}
\hline \multicolumn{1}{c|}{ Sector de atención } & Número \\
\hline De servicio & 1261 \\
\hline Agropecuario & 478 \\
\hline Manufacturero & 330 \\
\hline Comercial & 290 \\
\hline Transporte & 89 \\
\hline Transporte y suministro de agua y gas & 8 \\
\hline Minería & 3 \\
\hline
\end{tabular}

Fuente: Secretaría del Trabajo y Fomento al Empleo, 2012b.

\section{Cuadro 3. Cooperativas de manufatura de uniformes escolares, 2007-2010}

\begin{tabular}{l|c|c}
\hline \multicolumn{1}{c|}{ Cooperativas } & $\begin{array}{c}\text { Socios, } \\
\text { mujeres y } \\
\text { hombres }\end{array}$ & $\begin{array}{c}\text { Número de talleres } \\
\text { que las integran }\end{array}$ \\
\hline Cuetzin & 150 & 30 \\
\hline Nic Ithzomas & 100 & 32 \\
\hline Ollintzin. Mujeres en movimiento & 63 & 24 \\
\hline Nuevo Impulso & 67 & 27 \\
\hline Creaciones del Sureste & 181 & 15 \\
\hline Huitzillin & 72 & 171 \\
\hline Total & 633 & . \\
\hline
\end{tabular}

Fuente: Secretaría del Trabajo y Fomento al Empleo, 2012b, "Año Internacional de las Cooperativas".

Por último, sigue siendo un sector vulnerable a los cambios de la economía todavía carece de sistemas de protección y seguridad social para sus participantes. Se enfrenta a las inconsistencias que se dan entre leyes secundarias y a las dinámicas de la administración local que limitan su desempeño autónomo, ya que los apoyos solo se dan a los inscritos al programa. 


\section{LA ORGANIZACIÓN DEL TRABAJO Y SU EFECTO \\ EN LA COMPETITIVIDAD. LAS COOPERATIVAS \\ DE PRODUCCIÓN DE UNIFORMES ESCOLARES}

La cooperativa como organización social para el trabajo, ha demostrado su buen funcionamiento, ya que existen experiencias exitosas en todo el mundo y en México. Para el especialista José Ignacio López el caso no es la cooperativa en sí, sino quiénes la conforman, es decir, el problema fundamental es de índole humana, independiente de otros factores, como pueden ser: apoyos crediticios, financieros o fiscales, deficiencias contables, administrativas y jurídicas, carencia de políticas gubernamentales de fomento a esta organización [López, 2009: 13].

Este autor plantea que la cooperativa como forma de organización socioeconómica es una empresa de carácter social, ya que su finalidad es diferente a la de empresas mercantiles lucrativas. La cooperativa es una de las alternativas para desarrollar una economía social y solidaria, generadora de empleos y equitativa en cuanto a la distribución de la riqueza, ya que no solo se constituye por capital, sino fundamentalmente por trabajo [López, 2009: 13].

Las acciones gubernamentales impulsadas a partir de 2007 por parte del gobierno del Distrito Federal en materia de fomento cooperativo han logrado traducirse, como ya se ha señalado, en la integración de un número importante de cooperativas reactivando el modelo en el contexto actual para generar empleo. En el caso que nos ocupa, se realizó una investigación de campo para determinar las formas de organización del trabajo cooperativo y el modelo de producción con el que operan estas empresas sociales. Así, en entrevistas realizadas con las cooperativistas que participan en el programa “¡Qué Buena Puntada!”, ellas describen y analizan aspectos interesantes de su proceso de conformación como empresa cooperativa, al igual que los problemas y obstáculos que han tenido que salvar en la organización del trabajo y en la producción de la manufactura de uniformes escolares, determinando las variables que influyen para su competitividad en el mercado local, ya no solo como proveedoras de bienes y 
servicios para las dependencias de gobierno, sino también para instituciones privadas y del sector social.

El modelo cooperativo se manifiesta en una forma de organización del trabajo que, a diferencia de la empresa privada, da cuenta de una distribución de cargas de trabajo, tiempos y calidad del producto que tienen que ser atendidos de manera colectiva.

La cooperativa Ollintzin se integró por un porcentaje importante de mujeres $(80 \%)$, cuya especialidad es la costura, ya que muchas de ellas participaban en talleres familiares o del tipo que en su mayoría maquilan para diversas empresas.

Esta particularidad de los grupos de cooperativas, contar con mayor porcentaje de mujeres que de hombres, les da a las costureras un perfil que las va a diferenciar de las trabajadoras en las empresas maquiladoras, aunque ambas se dediquen en muchos de los casos a la maquila mediante la subcontratación de la producción de su taller familiar.

En un principio, por ejemplo, la empresa social cooperativa “Ollintzin. Mujeres en Movimiento" llegó a estar conformada por más de 100 socios, mujeres y hombres, su organización obedeció al modelo que buscó la concentración de esfuerzos de estos talleres familiares en la producción de uniformes escolares al transformarse en proveedoras del gobierno local.

El perfil de los grupos se caracterizó desde sus inicios por ser heterogéneo en sus rangos de edad, pero la mayoría son mujeres de 35 a 60 años, aunque participan algunas jóvenes madres de familia, casadas, con un promedio de tres a cinco hijos, también contó para su integración que dispusieran de sus medios de producción -máquinas de coser manuales y algunas de tipo industrial-, sumada a su fuerza de trabajo y experiencia laboral que en algunos casos fue de 10 a 20 años. Las cooperativistas señalan que, por su rango de edad, para muchas de ellas ya era difícil encontrar trabajo, por otra parte, trabajar de manera individual en sus talleres dificultaba que les asignaran producciones tan importantes como las que se pretendían relacionadas con los uniformes escolares para el Distrito Federal. 
Si bien, uno de los requisitos para integrar una cooperativa era contar con 80 socios, la experiencia ha sido que los grupos han tenido que irse ajustando en su tamaño. En un principio la sumatoria de talleres les dio la posibilidad de conformarse en empresas cooperativas grandes. Posteriormente, por las mismas cargas de trabajo y el desempeño de los miembros de la cooperativa quedaron en un grupo de 75 , número que se manejaba mejor en su organización. En la etapa actual algunos se han desprendido del grupo quedando 53 socias y ocho socios.

Según su experiencia una socia comenta:

Se podría decir que $90 \%$ somos casadas, amas de casa, que no encontramos trabajo. Todas sabemos coser y es una ventaja para integrarse, el requisito es saber coser y usar la máquina industrial. Ya somos mujeres que no encontramos trabajo en los talleres, a los 40 años, ya no, al contrario, esta es nuestra fuerza que en vida sabemos que podemos sacar más trabajo.

\section{La organización del trabajo cooperativo}

El trabajo cooperativo se basó en:

a) La concentración y especialización de ciertas áreas del proceso productivo. Principalmente se buscó concentrar en un área del proceso de corte y diseño de las prendas para los uniformes, lo cual en una primera fase ayudó a manejar de forma homogénea los patrones y el diseño de las prendas bajo ciertos criterios. El papel fundamental del gobierno fue proveer de la materia prima, las cooperativas solo participaban con su fuerza de trabajo. Posteriormente las cooperativistas han señalado las fallas de este modelo, al generarse por parte de la opinión pública críticas importantes en cuanto al tamaño de las tallas y la calidad de la tela.

b) El taller familiar siguió siendo la base de la producción que se distribuyó según sus capacidades en cuanto a máquinas, experiencias y perfil de los integrantes. Como se ha señalado, muchos de estos talleres se tienen que reorganizar en 
relación con sus cargas de trabajo, ya que no han dejado de producir maquila para otras empresas, con un uso intensivo de la fuerza de trabajo. Como toda empresa, al entrar en una licitación hay que responder con la entrega oportuna de la producción y evitar sanciones y multas, por lo que la organización e intensidad del trabajo es básica para generar una respuesta competitiva.

c) El conocimiento tácito que algunos socios conservan de su experiencia cotidiana y laboral adquirida. Este conocimiento se difunde mediante la capacitación entre ellos para resolver problemas relacionados con la producción de manera oportuna; el trabajo en equipo, la distribución de la producción y cargas de trabajo de acuerdo con sus capacidades han hecho que todos se involucren en cada proyecto productivo.

Las cooperativistas reconocen que si bien se brindó capacitación por la Secretaría del Trabajo del Gobierno del Distrito Federal, esta sigue siendo necesaria, ya que al diversificar su línea de producción hay que enfrentar problemas diferentes y generar aprendizajes nuevos en lo individual y en lo colectivo, porque todo proyecto por realizar debe planearse.

$\mathrm{Al}$ respecto, la socia Ana Luisa comenta:

Lograr tener 80 personas reunidas y que estuviéramos de acuerdo en integrarnos, que estuviéramos capacitadas... En la Secretaría pedían cooperativismo, pero más que cooperativismo, como cooperativa dedicada al área de la confección, es tener los conocimientos, en la cuestión de saber dominar las máquinas, saber hacer cualquier tipo de prenda. Estos son básicamente los requisitos para formar parte de una cooperativa.

$\mathrm{Al}$ principio las socias señalaron que, si bien el requisito era saber coser, la Secretaría del Trabajo no brindó capacitación al respecto; posteriormente sí se les dio un curso de costura industrial, pero fue muy rápido, aunque les ayudó a prepararse en otros conocimientos sobre producción industrial. 


\section{Medios de producción: maquinaria y equipo}

Otra socia comenta al respecto de la maquinaria y el equipo que:

Sí. Aquí básicamente están los talleres. La gente que se integra a la cooperativa ya tenía su maquinaria propia. Realmente así, como cooperativa, hasta el día de hoy no tenemos maquinaria como propiedad colectiva. Decir, sí, la cooperativa cuenta con tantas máquinas. No, toda la maquinaria es de los socios, es propiedad de ellos, de cada taller. Fue como se trabajó de inicio este programa que era como ayuda a madres solteras, a personas de 40 años y más que ya no tienen el acceso a los trabajos en el campo laboral, que trabajaran en su casa. Al principio se decía: "con una máquina, una máquina casera, pero eso no funcionó, o sea una máquina casera”, para el tipo de producción que se hace tan grande, no funciona. Entonces ya nuestros talleres han adquirido maquinaria industrial, pero es propiedad de cada socio.

En la entrevista, las socias indicaron que para reemplazar su maquinaria manual por industrial han participado en las convocatorias para proyectos productivos, pero siguen respondiendo de manera individual o por taller para adquirir sus medios de producción. Si bien han conseguido algunos financiamientos para renovar sus equipos, no es la generalidad para todos los socios.

\section{Organización del trabajo y proceso productivo}

Las cooperativistas describen cómo se asigna la producción:

Nosotros asignamos la producción, en base a la capacidad de cada taller. Hacemos reuniones y por decir ahora viene lo de uniformes; nos están tocando 9000 y fracción de uniformes, que sería el doble de prendas. Entonces lo que hacemos es reunir a todos los socios o al menos al representante de cada taller, entonces se comenta la producción de uniformes asignada y se pregunta en base a su capacidad de producción con cuántos se van a comprometer. Así, ellos mismos van dando la producción que pueden sacar en su taller 
según su capacidad. Esta a veces varía, por la cuestión de que algunos talleres tienen producción de otros lados y entonces, si él representante dijo que producía 500, pero le llegó producción de otra parte, lo mejor es elaborar solo 100, pero igual esos 100 se reparten en los otros talleres que tienen poca producción y así más o menos es la asignación de producción, pero siempre mediante consenso. No podría ser equitativamente o por partes iguales, porque algunos talleres son de diferentes tamaños según el número de socio. Así nos encontramos talleres de una o dos personas, otros más grandes de cuatro a cinco, lo que modifica su capacidad de producción, entonces no puede ser de manera equitativa, es según la capacidad de producción de los socios. Así, por ejemplo, en 2007 tuvimos que atender una producción de 700000 uniformes y en el caso de la cooperativa nos tocó producir 124000 uniformes, realizando la transformación por el doble de prendas, bajo el modelo cooperativo todos respondemos apoyándonos entre sí.

Las cooperativistas mencionaron varios problemas para funcionar como empresa cooperativa, entre ellos los de carácter económico. A pesar de ser socios, empezaron con cero capitales, sus únicos recursos eran la maquinaria propia, sus talleres familiares y la fuerza de trabajo.

Si bien para cada proyecto como proveedores del Gobierno del Distrito Federal tienen que cubrir una garantía, esto se logra con el capital que cada socio aporta.

Otro problema ha sido el cambio en la cultura laboral, es decir, los socios se consideraban dueños, era muy difícil controlar y adjudicar responsabilidades en materia de producción, lo que dificultaba administrar grupos tan grandes de miembros de la empresa.

En el tiempo transcurrido se ha podido transitar a una forma de trabajo colaborativo y solidario entre los socios. Se entiende que la producción de uniformes es un compromiso adquirido por la empresa y cada uno de los socios. Este tránsito ha provocado un ajuste constante en el número de socios de la cooperativa, aquellos que han aprendido a trabajar de manera colectiva y los que siguen respondiendo de manera individual esperando 
ganancias rápidas y sin tanto esfuerzo. Por otra parte, el liderazgo y la forma de gestión de los comités directivos de la cooperativa, tienen que ver sin duda con este funcionamiento exitoso. Hasta ahora las mujeres y los hombres, tanto en la industria maquiladora como en las cooperativas, han demostrado su capacidad productiva y el compromiso con proyectos de empresas sociales como es el modelo impulsado.

Su ejemplo les lleva a demostrar que son sujetos de crédito y que una labor empresarial como la manufactura plantea nuevas formas de organización del trabajo cooperativo y de aumentar su capacidad productiva.

Otro problema se refiere a la administración y gestión de la empresa social. Los cooperativistas han tenido que entender que la cooperativa es una empresa y como tal debe funcionar. Se han tenido dificultades para sacar los costos de operación, como agua, luz y compra de insumos, también en materia de distribución de las ganancias y de la repartición del excedente. Con el tiempo han aprendido a administrar mejor la empresa, sus finanzas y los proyectos en los que participan.

En materia de la organización del trabajo y la producción, el tamaño de la empresa los ha llevado a formar comités como los de vigilancia, supervisión y control de calidad, o conciliación y arbitraje para atender los conflictos, entre otros.

¿Cómo se expresa la competitividad de la empresa cooperativa? Para poder cumplir con el volumen de producción que se asigna se requiere que la empresa cooperativa conserve un número importante de personas. Conforme se ha ido reestructurando la cooperativa y ajustando su tamaño, uno de sus pilares ha sido el trabajo especializado y el conocimiento del proceso de producción, que implica conocimiento sobre el proceso de corte, el ahorro de la tela, el número de procesos que integra la confección de una prenda, el pegado de botones, los ojales, el cuello, las mangas, el ensamble de toda la prenda, el planchado, el etiquetado y el empaque, de tal manera que se ha logrado reducir el tiempo de producción en general, como se presenta en la figura 3. 
Los trabajadores de la costura se transforman en conocedores de toda la línea de producción, más que en solo operarias en la industria de la maquila, lo cual le da un valor al trabajo productivo de mayor calidad; si se suma la responsabilidad individual, social y el compromiso de la empresa cooperativa con sus clientes, al cuidar la imagen de proveedores especializados en primer lugar para el gobierno y para sus otros contratistas, esto funciona como uno de sus pilares fuertes para ser productivos.

El grupo de cooperativistas señaló que, buscando siempre el respeto por su autonomía como empresa social, han tenido que sortear obstáculos importantes relacionados con el trato del gobierno, al igual que las experiencias no siempre agradables con el equipo técnico operativo que maneja el programa, pues en algún momento se han sentido invadidos en su materia de trabajo y en los asuntos internos de la cooperativa. A su vez, en la defensa del conocimiento y experiencia que tienen en su materia de trabajo, ya que ellas dependen de las decisiones que se toman en instancias administrativas y por los funcionarios que no toman en cuenta los factores que pueden influir en la entrega de la producción a tiempo y en el rendimiento de los cooperativistas como pueden ser las enfermedades, la descompostura de una máquina, el clima, la dinámica familiar, la falta de accesorios y materia prima en tiempo y forma, entre otros.

El grupo reconoce que el uso intensivo de la fuerza de trabajo es una de las variables que permite salvar la falta de maquinaria de punta, además de la experiencia y el conocimiento del proceso productivo y, por último, el compromiso que tienen los socios con su empresa.

La fuerza de trabajo femenina es en gran medida la de mayor potencial productivo. Tradicionalmente el oficio de costurera se asignaba a las mujeres; las condiciones de la producción actual cambian cuando estas se incorporan a procesos de producción industrial, porque hoy en la maquila se considera de más valor una costurera con conocimientos de todo el proceso de producción y que sabe más que operar una máquina. 


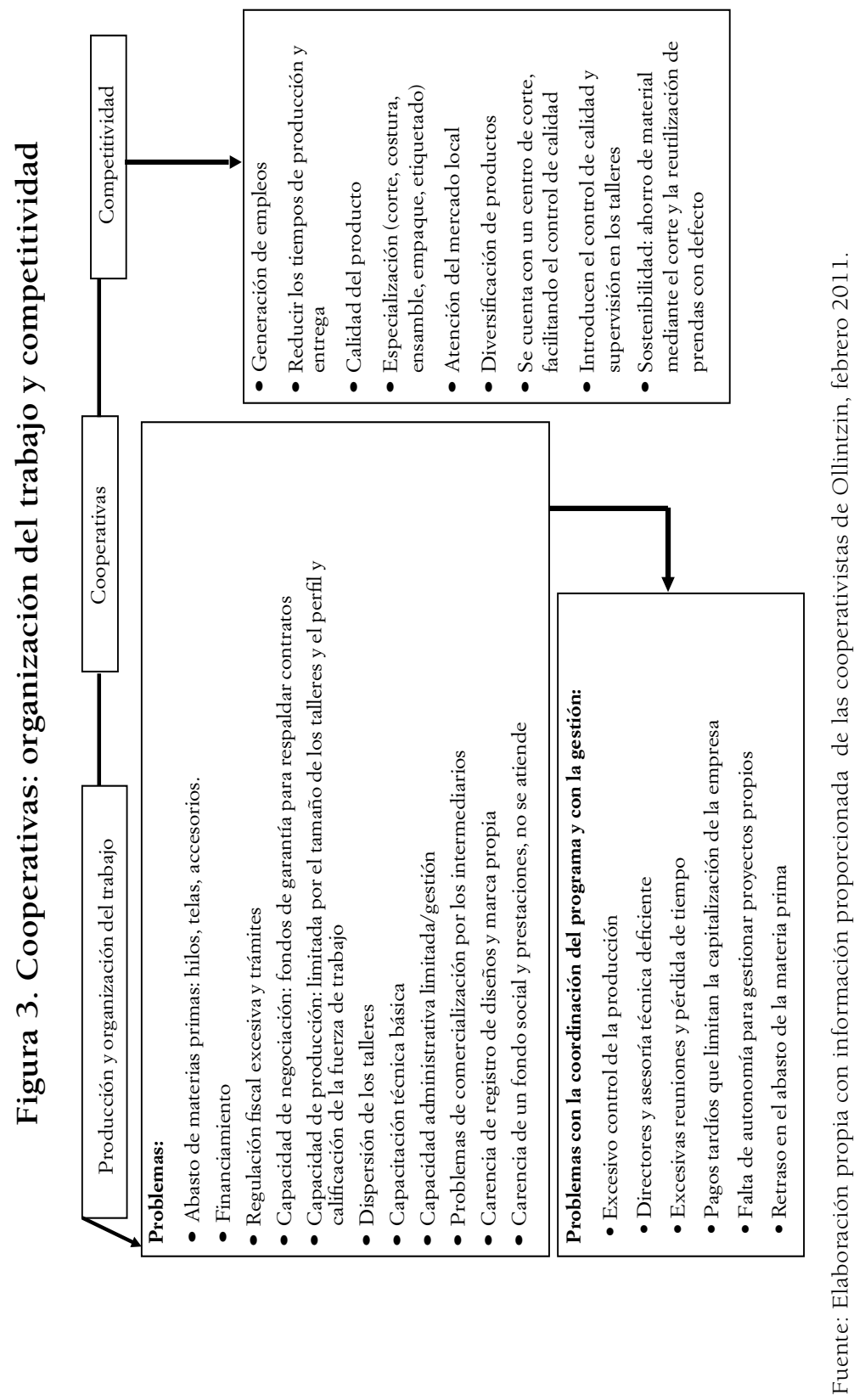


Disponer de un conocimiento integral de todo el proceso de confección de prendas de vestir realza el trabajo de este tipo de empresas, también su capacidad para gestionar y administrar proyectos productivos, en particular la capacidad de innovación en los procesos de producción y en la gestión, en el manejo de expectativas para convertir su empresa cooperativa en una organización con mayor presencia en el mercado local, buscando su autonomía.

El Gobierno del Distrito Federal, con base en el Programa de Fomento Cooperativo, retribuyó en el costo de las prendas, una parte importante del valor de la fuerza de trabajo; las cooperativistas señalan que la remuneración fue buena en los meses que duró la producción de uniformes; posteriormente, esto se ha compensado con la gestión de otros proyectos.

Este apoyo contrasta con el control y supervisión constante por parte del gobierno y las limitaciones a su autonomía para negociar sus propios contratos, por lo que es posible visualizar una política de fomento cooperativo que atienda los rezagos y la competencia desigual entre las empresas del sector social y las trasnacionales, cambie los criterios -asistenciales y marginalescon que se asignan los créditos y, por lo tanto, canalizace mejor los apoyos y recursos para el desarrollo del sector cooperativo local, lo que le permitará incorporarse a una política más coherente del desarrollo industrial y tecnológico, acorde con los retos que seguirá enfrentando la economía mexicana y con ello asegurar una política de empleo más activa. Invertir en el sector y no solo promoverlo requiere políticas más audaces.

\section{CONCLUSIONES}

En México falta una estrategia de desarrollo industrial que siente las bases del cambio para la industria manufacturera y que integre a los sectores privado y social de la producción, considerando a sus principales actores como son: el Estado, los tomadores de decisiones, administradores o gestores de las políticas públicas, los 
empresarios, sus organizaciones, trabajadores y sus sindicatos, los inversionistas y la banca de desarrollo y privada, así como las universidades e instituciones de educación superior formadoras de profesionales y los centros de innovación tecnológica. Este escenario multiactoral es necesario en el terreno de las políticas públicas por impulsar.

La industria manufacturera en México enfrenta fuertes desafíos en un escenario de alta competitividad por los mercados y los niveles diferenciados de desarrollo tecnológico de las empresas en sus distintas actividades económicas. El cambio tecnológico afecta los procesos productivos y las formas de organización del trabajo y modifica las interacciones de tipo comercial que se dan en la economía global. Los países requieren una estrategia de desarrollo industrial y tecnológico que forme capacidades y se adecue a las condiciones de su industria y el tipo de empresas que poseen. En este sentido, la industria manufacturera sigue arrastrando viejos comportamientos y estilos de operar en una economía abierta, lo que dificulta su capacidad de respuesta ante las nuevas formas de acumulación y organización del capital global.

Sin duda, la apertura de los mercados y el estímulo a los procesos de integración comercial, como lo fue el TLCAN, han servido para impulsar la actividad económica de algunos sectores de la manufactura. Pero aun cuando se han generado leyes, normas y programas, siguen siendo insuficientes por su orientación sectorial y aplicación desigual entre los empresarios del sector.

Después del retiro de la inversión pública y de la generación de instituciones impulsoras del desarrollo industrial sectorial, la capacidad de gestión del Estado se ha visto limitada en materia de creación, aplicación y evaluación de políticas públicas para apoyar el desarrollo industrial manufacturero, con ello el sector cooperativo.

Ante esta situación, se siguen enfrentando serios problemas no solo de financiamiento. Las fluctuaciones de tipo cambiario que afectan la compra de insumos para la producción, los pocos apoyos para la exportación, el trato diferenciado para grandes, medianos y pequeños empresarios, la incapacidad del Estado 
para impulsar la inversión productiva y fortalecer a las empresas, así como el lento proceso de innovación tecnológica configuran un panorama que se agudiza con la inestabilidad financiera y los ajustes de los mercados financieros internacionales.

Los especialistas señalan la urgencia de un programa con personal especializado, financiamiento e instrumentos que reconozcan los segmentos y las necesidades específicas de las empresas, en ámbitos como el tecnológico, financiero y de comercio exterior, entre otros [Cárdenas y Dussel, 2007: 549].

En cuanto al sector cooperativo, llama la atención la recuperación del modelo para impulsar empresas sociales que actúen en la economía formal, generadoras de fuentes de trabajo y con posibilidades de competir en las cadenas productivas locales. El desempeño que han mostrado las cooperativas en el segmento de la producción de prendas de vestir y de la confección en general sigue siendo mínimo, estas dependen de los apoyos que las autoridades en curso les quieran brindar, sobre todo por la falta de una política federal y estatal claramente delineada para potenciar a este tipo de empresas sociales. Como se mencionó, el principal motor de desarrollo de las empresas cooperativas son sus trabajadores, como parte de las fuerzas productivas requieren el componente tecnológico que asegure su competitividad. En Europa son estas empresas cooperativas trabajando en red las que están marcando el paso de economías importantes, como se ha señalado en el caso de la empresa Zara.

En respuesta a la tesis de investigación, podemos concluir que el modelo cooperativo, a diferencia de la empresa privada, adopta una forma de organización del trabajo que atiende de manera colectiva a la distribución de las cargas de trabajo, los tiempos y la calidad del producto, por lo tanto, al pago equitativo por su trabajo. Los procesos innovadores se centran en la organización de la producción y el manejo del conocimiento tácito y la "expertis" que se refleja en el desempeño de sus socios. La capacidad de respuesta de la fuerza de trabajo femenina -en su mayoría- en la defensa de un proyecto colectivo les ha permitido competir en el mercado local. 
No obstante la demostración que han hecho de que el trabajo cooperativo es una fuerza impulsora importante, como parte del sector social las cooperativas siguen siendo un sector vulnerable a los cambios de la economía, todavía carecen de sistemas de protección como la seguridad social para sus participantes. Se enfrentan a las inconsistencias que se dan entre leyes secundarias y a las dinámicas de la administración local que limitan su desempeño autónomo, ya que los apoyos solo se dan a los inscritos al programa, dejando al margen a otras sociedades cooperativas.

En consecuencia, siguen presentándose situaciones de inequidad para las mujeres cooperativistas que, como en el caso de estudio, han demostrado su capacidad de respuesta organizativa y su productividad de una manera ejemplar, aunque las políticas públicas continúen desviando su atención de la problemática de género en el espacio de la economía popular solidaria, en la que se requiere superar la visión marginal de las actividades que la definen.

Por último, las críticas también se orientan a señalar que se requieren políticas de empleo activas, que canalicen inversión productiva para generar fuentes de trabajo con empleos mejor remunerados; si bien son necesarias políticas pasivas, estas aún son limitadas y no resuelven el problema de desempleo estructural. Particularmente en el caso de los jóvenes y mujeres, la oferta disponible está muy por debajo de las capacidades de la fuerza de trabajo del Distrito Federal, los procesos de precariedad e informalidad siguen violentando los derechos laborales de manera diferenciada entre hombres y mujeres, por lo tanto, la justicia laboral con equidad sigue faltando.

\section{REFERENCIAS}

Cámara Nacional de la Industria del Vestido [2009], La industria del vestido en México: situación actual y perspectivas 2009-2010, México, CNIV. 
Cárdenas C., L. y E. Dussel P. [2007], "México y China en la cadena hilo-textil-confección en el mercado de Estados Unidos", México, Comercio Exterior, 57(7): 530-545.

Centro de Estudios Sociales y de Opinión Pública [2006], "Antecedentes", en Fomento cooperativo, <http://www.diputados. gob.mx/cesop/Comisiones/2_fomento.htm>, 23 de marzo.

Dussel P., E. [2009], "Políticas e instrumentos, para profundizar la integración regional de la industria del vestido en la zona del TLCAN”, México, CNIV/UnAM-CECHIMEX, pp. 1-32.

Feldman E., S. [2009], "La industria del vestido en México: situación actual y perspectivas 2009-2010”, México, Cámara Nacional de la Industria del Vestido, <http://www.canaiveags.org.mx/Docs/MEXICO.pdf $>$.

Godoy, E. [2011], "Cooperativas, una alternativa para México", México, Agencia IPS, publicado en línea, 16 de marzo.

González M., Ma. L. [2006], "La tecnología en la industria textil y del vestido. Avances en México", Isabel Rueda Peiro y Nadima Simón, El dilema de la industria del vestido en México. Los casos de Aguascalientes y Yucatán, México, Miguel Ángel Porrúa/DGAPA, IIEc-UnAM, pp. 91-125.

INEGI, [2004], "Industria manufacturera", México, 44 pp., <www.inegi.org.mx>, 5 de noviembre de 2011.

[2011], "La industria textil y del vestido en México", Aguascalientes, 204 pp., <www.inegi.org.mx>, 30 de enero de 2012.

Ley de Fomento Cooperativo [2006], Gaceta Oficial del Distrito Federal, <http://www.consejeria.df.gob.mx/uploads/gacetas/ enero06_20_9.pdf>, 20 de enero.

Ley General de Sociedades Cooperativas [1994], Diario Oficial de la Federación, México.

López C., J. I. [2009], La empresa social y su administración: el caso cooperativo, México, Fundación Cultural Pascual, 237 pp. Martínez B., A. Ma. [2007], "Un modelo de empresa innovadora y flexible: el caso Zara", en Investigaciones Políticas y Sociológicas, España, Universidad de Santiago Compostela, 6(001): 69-80. 
Mogrovejo, R.; A. Mora y P. Vanhuynegem (eds.) [2012], El cooperativismo en América Latina, una diversidad de contribuciones al desarrollo sostenible, OIT, <http://www.oitcinterfor.org/ sites/default/files/file_publicacion/El\%20cooperativismo\%20en \%20AL \%20OIT\%20ACI.pdf>, 10 de septiembre. Organización Internacional del Trabajo [2012], "Conferencia Internacional del Trabajo, Nonagésima Reunión, Actas Provisionales", Ginebra, Suiza, <http://www.ilo.org/public/spanish/ standards/relm/ilc/ilc90/pdf/pr-8.pdf>, 3 de enero de 2012.

Programa de Fomento Cooperativo para el Distrito Federal [2009], Gaceta Oficial del Gobierno del Distrito Federal, 10 de julio.

Rojas H., J. J. [2003], Las cooperativas en la Ciudad de México: educación, capacitación y formación, México, Molino de Letras, serie Estudios Cooperativos, (2): 218.

Secretaría del Trabajo y Fomento al Empleo [2011] "Acciones de fomento cooperativo", Informe, STyFE, México, DF.

[2012]. Informe sobre las cooperativas, $<\mathrm{http} / /$ home/ PRENSA/BOLETINES/Cooperativasanporlaprenda2.5mill onesdeuniformesescolaresparaelDF>, 12 enero.

[2012b], "Fomento cooperativo, 2012. Año internacional de las cooperativas", <http://www.styfe.df.gob.mx/index.jsp>, 20 de febrero de 2012.

Simón D., N [2006], "Resultados de dos encuestas realizadas a empresas de la industria de la confección de prendas de vestir localizadas en los estados de Aguascalientes y Yucatán”, Isabel Rueda Peiro y Nadima Simón, El dilema de la industria del vestido en México. Los casos de Aguascalientes y Yucatán, México, Miguel Ángel Porrúa/DGAPA, IIEc-UnAM, pp. 126-173. Viloria G., C. V [2007], "Programa de elaboración de uniformes por cooperativas de la Ciudad de México: la tecnología organizativa, utilizada para desarrollar proyectos masivos de producción", memoria del VII Seminario de Economía del Trabajo y la Tecnología: La flexibilidad laboral y tecnología: situación actual y perspectivas, México, IIEc-UNAM, disco compacto. 


\section{ENTREVISTAS REALIZADAS}

Ingeniera Verónica Viloria Gómora, directora de Promoción al Empleo de la Secretaría de Trabajo y Fomento del Gobierno del Distrito Federal, agosto de 2011.

Comité directivo de la Cooperativa Ollintzin, delegación Iztapalapa, febrero de 2010 y diciembre de 2012. 


\section{Capítulo 8 \\ POLÍTICAS PÚBLICAS PARA LA INNOVACIÓN TECNOLÓGICA EN LA INDUSTRIA MEXICANA DEL LIBRO}

Graciela Reynoso Rivas*

I NTRODUCCIÓN

De acuerdo con la Organización de las Naciones Unidas para la Educación, la Ciencia y la Cultura (Unesco), las industrias culturales son "aquellos sectores de actividad organizada que tienen como objeto principal la producción o la reproducción, la promoción, la difusión y/o la comercialización de bienes, servicios y actividades de contenido cultural, artístico o patrimonial" [Unesco, 2005]. Comprenden la editorial (incluye la del libro y la de publicaciones periódicas), la fonográfica y a la radio, los medios televisivos, la cinematográfica, medios videográficos y la publicitaria, así como la de producción de contenidos vinculados a las tecnologías de la información y comunicación, expresiones cuyo soporte principal es internet.

* Académica del IIE c-unam, participante en el proyecto de investigación PAPIIT IN305610. Correo electrónico: <gracielr@unam.mx>. 
Además de su alto valor simbólico como expresión de los valores y tradiciones de una sociedad, las industrias culturales constituyen una fuente de creación de riqueza, de empleo y de desarrollo económico. Por otro lado, en virtud de que la utilidad de sus productos excede la materialidad de sus insumos y su consumo incide en el desarrollo cultural de la propia sociedad, los procesos de producción y de circulación comercial no pueden ser dejados a la exclusiva lógica del mercado, lo que determina la existencia de regulaciones y políticas públicas para su fomento.

En el caso del libro, la sociedad le ha otorgado un elevado papel simbólico, lo que lo convierte en objeto de debate público y de regulaciones estatales. La industria del libro, además de compartir con las industrias culturales los rasgos anteriormente mencionados, posee algunas características propias. En primer lugar, produce un bien que para ser consumido requiere como condición la existencia de un público alfabetizado.

La cadena productiva del libro está integrada por diferentes etapas en las que intervienen y se relacionan los distintos actores: producción intelectual, producción material y distribución y comercialización.

\section{HISTORIA DE LA INDUSTRIA EDITORIAL}

Considerado el libro uno de los más poderosos instrumentos con los que cuenta la cultura occidental para preservar y difundir el pensamiento humano, su historia es la historia de la humanidad. Sin embargo, la producción industrial de libros es mucho más reciente. Su origen, en su forma actual, lo encontramos en la Edad Media, antes incluso de la introducción de la imprenta en Europa, en los códices y libros manuscritos que se producían de manera artesanal y en muchos casos artística en los scriptoria de los monasterios medievales, verdaderos centros de preservación de las ideas.

La producción de libros manuscritos corresponde al modo de producción feudal, pues se elaboraban mediante una disciplinada 
división del trabajo, a cargo de copistas, miniaturistas, iluminadores, etc. Por supuesto, estos productos no estaban a la venta para un público, que por lo demás tampoco era numeroso si se considera que la mayor parte de la población europea no sabía leer, incluso si pensamos en los miembros de las clases sociales superiores.

El desarrollo de las ciudades a finales de la Edad Media y la aparición de una nueva clase social y de centros de estudio no ligados directamente a los monasterios (las universidades) propiciaron la necesidad de una más rápida reproducción de copias y de una mayor fidelidad en el proceso. La reproducción de libros manuscritos adquirió entonces los rasgos de la manufactura en serie. Se realizaba en talleres mediante una estricta división del trabajo basada en la especialización de los participantes en el proceso. La reproducción de copias empezó a ser regulada y normalizada bajo la supervisión de las autoridades universitarias. Las réplicas autorizadas no se efectuaban a partir de cualquier copia anterior, sino de copias aprobadas llamadas exemplares, las cuales servían de modelo a los copistas. La producción de libros en serie se hacía por encargo o para ofrecer en venta a un público cada vez más numeroso [Fevbre, 2005].

La demanda de un mayor número de copias que respetaran con mayor fidelidad el original (o la copia anterior) crea un ambiente propicio para el desarrollo de la imprenta en Europa, que significó la industrialización y el abaratamiento de la producción de libros, hasta entonces muy costosos por la cantidad de trabajo que involucraba y el elevado valor de las materias primas necesarias. Los historiadores consideran que la imprenta fue una respuesta, al mismo tiempo que un estímulo y una herramienta de conocimiento.

La producción de libros impresos no significó al principio un cambio en su aspecto material, su función social ni en los procesos de creación, normalización y circuito de circulación. Las transformaciones fueron paulatinas y responden a los distintos momentos históricos por los que ha transitado el libro hasta llegar a nuestros días. 
Los impresores del siglo XV no tenían interés en publicar textos de nueva creación. Según Martínez-Val [2005: 84],

... excluyendo la Biblia, que era un éxito editorial seguro a mediados del siglo XV, con un sector de mercado amplio, influyente y perfectamente identificado, los textos de muchas de las obras impresas en las primeras décadas de la imprenta tenían varios siglos de antigüedad, aunque se tratara de diccionarios u obras de temas más o menos enciclopédicos. No se distingue la menor pulsión por incorporar valores nuevos. El primer libro impreso de un autor vivo salió de las prensas en 1467, tenía como título Meditaciones, era de autor español, Juan de Torquemada.

La industrialización de la producción de libros introdujo por primera vez la posibilidad de explotación pecuniaria de las obras. Sin embargo, en las primeras décadas de los libros impresos, los autores consideraban deshonroso obtener ganancias directas de la impresión y comercialización de su obra. Como autor, era aceptado vivir bajo la protección de un mecenas e incluso "vender" dedicatorias o prefacios.

A diferencia de los autores, los impresores-libreros sí exigieron la protección del Estado desde etapas tempranas de la industrialización del libro, la cual se manifestó mediante privilegios de exclusividad por cierto tiempo. De esta manera se protegía la inversión del impresor. Estas primeras normas eran muy imperfectas, por lo que ocasionaron múltiples problemas entre los propios impresores. Por su parte, los autores no contaron con ninguna protección hasta 1710, cuando se proclamó en Inglaterra el Estatuto de la Reina Ana.

En el siglo XIX se inventó la fotografía y se introdujo en los procesos de edición, lo que significó importantes cambios, pues dio origen a lo que después se conoció como fotomecánica, una técnica para imprimir basada en procesos fotosensibles, que elimina la necesidad de utilizar los grabados para imprimir imágenes. Los nuevos procesos renovaron y enriquecieron las posibilidades de impresión de los libros, sin modificar la forma de los mismos. La impresión offset es la más usada en la actualidad. 
Como en el caso de la tipografía indirecta, la tinta pasa de la forma impresa a un rodillo cubierto de caucho -la mantilla-, que es el que la transfiere al soporte.

Sin embargo, esta innovación tecnológica en la producción de libros no sustituyó la tradicional, pues, aunque los procedimientos fotomecánicos facilitaban y abarataban la impresión del libro, los impresores continuaron utilizando los antiguos sistemas de prensa directa en algunos casos hasta finales del siglo xx, según Martínez-Val [2005].

En México, la producción de libros empieza con la llegada desde España de la primera imprenta, a cargo de Juan Pablos de Bresca como representante de Juan Cromberger, impresor alemán radicado en Sevilla. Cromberger había sido autorizado en exclusiva por Carlos V para imprimir y vender libros en Nueva España. En 1539 Juan Pablos firmó con Juan Cromberger un contrato que le permitía trabajar la imprenta, con la condición de que, durante 10 años sus libros llevarían la leyenda "en casa de Juan Cromberger”, por lo que las primeras ediciones no incluían del nombre de Juan Pablos como impresor. Solo pudo hacerlo una vez concluido su acuerdo con Cromberger y obtenido del virrey de Mendoza el privilegio exclusivo para imprimir en la Nueva España.

La demanda de productos editoriales durante la Colonia y en el México independiente prerrevolucionario estuvo limitada por el analfabetismo de la población. El desarrollo de grupos ilustrados en los centros urbanos favoreció la demanda principalmente de publicaciones periódicas con fines informativos y propagandísticos durante el siglo XIX y principios del XX. En este periodo es común la presencia de restricciones oficiales a las publicaciones periodísticas.

Una vez establecida la paz posrevolucionaria en México, la producción editorial adquirió el perfil de industria, pues existía una sociedad que demandaba sus productos culturales. Como parte de la industria florecieron importantes empresas periodísticas y de producción de libros.

Néstor García Canclini destaca la importancia que para el desarrollo de la industria editorial tuvieron la expansión urbana y el avance educativo en la modernización del país durante el siglo XX. 
Menciona que, al comenzar el siglo, uno de cada 10 mexicanos vivía en las 33 ciudades de más de 15000 habitantes que había en el país [García y Piedras, 2008: 13]. Según el INEGI, en 1950 poco menos de $43 \%$ de la población en México vivía en localidades urbanas, en 1990 era de $71 \%$ y para 2010 esta cifra aumentó a casi 78 por ciento.

El crecimiento de la población urbana y el incremento de la escolaridad contribuyeron directamente al auge de la producción editorial a fines de la primera mitad del siglo xx, lo que trajo consigo una fuerte demanda de papel que no podía ser satisfecha por la industria papelera nacional. Así, los empresarios debían hacer frente a condiciones muy desfavorables para la adquisición del insumo dentro y fuera del país. Para garantizar precios oficiales al papel, el gobierno de Lázaro Cárdenas decretó la fundación de la Productora e Importadora de Papel, Sociedad Anónima, PIPSA [Zacarías, 1995].

La existencia de PIPSA durante las décadas cuarenta y cincuenta del siglo pasado significó una dependencia importante de las empresas periodísticas, parte de la industria editorial, con el Estado.

En el ámbito de la producción de libros, durante las décadas de los sesenta y setenta, la industria editorial mexicana se desenvolvió al amparo de la política de sustitución de importaciones, por lo que no se vio en la necesidad de renovar la planta tecnológica de producción, tanto en el aspecto propiamente editorial, como en la industria de las artes gráficas.

García Canclini destaca que las dificultades para sobrevivir de la industria editorial en México se debieron al deterioro interno de la economía, a la competencia de las editoriales españolas en ascenso, a la contracción del mercado lector regional y a las quiebras de centenares de librerías en Argentina, Uruguay, Perú, Venezuela, Colombia y Centroamérica por crisis económicas y devaluaciones [García y Piedras, 2008: 14].

La participación directa o indirecta del Estado es un elemento muy importante en el análisis de la producción editorial periodística mexicana, pues "forma parte integrante del metabolismo funcional de la prensa, ya sea como agencia de noticias, como 
anunciante, como intermediario en la venta o la producción directa de papel, o como estructura corporatista" [Zacarías, 1995: 86].

Posteriormente, la incorporación del país al modelo neoliberal a partir de las década de 1980, ha puesto de manifiesto el atraso tecnológico de la industria editorial, tanto en su rama periodística como de producción de libros, lo mismo que la de las industrias vinculadas, en particular la de las artes gráficas.

Vale la pena mencionar que las innovaciones tecnológicas en la industria editorial mexicana siempre han dependido de los proveedores de maquinaria y equipo, extranjeros en su totalidad, lo que implica la completa dependencia del exterior para el desarollo de nuevas tecnologías editoriales. Hasta la década de los noventa del siglo xx, la mayoría de la maquinaria utilizada en las imprentas mexicanas era adquirida de segunda mano en Estados Unidos. En las décadas subsiguientes la situación ha variado pues importaciones de maquinaria nueva de Alemania, principalmente de prensas Heidelberg y Man-Roland [Corona y Jaso, 2004: 189].

\section{PERFIL DE LA INDUSTRIA EDITORIAL EN MÉXICO ${ }^{1}$}

La industria editorial es un sector vinculado estrechamente a la industria de las artes gráficas, de tal manera que es muy común que se identifiquen una con la otra. Sin embargo, las actividades de ambos sectores difieren considerablemente: el objetivo de la industria editorial es la publicación de obras intelectuales a partir de la selección de textos y otros contenidos para ofrecerlas después de su producción al lector, ya sea en forma impresa o en cualquier otro soporte. La industria de las artes gráficas funge

${ }^{1}$ La mayor parte de los datos de esta sección proviene de dos fuentes: "Estudio estratégico y programa sectorial para elevar la competitividad y el desarrollo sustentable de la industria editorial mexicana", publicado en marzo de 2007 por la Cámara Nacional de la Industria Editorial Mexicana, y patrocinado por la Fundación Mexicana para la Innovación y Transferencia de Tecnología en la Pequeña y Mediana Empresa (Funtec, A.C.), y la Secretaría de Economía por medio del Fondo de Apoyo para la Micro, Pequeña y Mediana Empresa. La segunda investigación es "El sector editorial en México", estudio de mercado publicado en junio de 2010 y realizado por Noelia Carmona Fernández bajo la supervisión de la Oficina Económica y Comercial de la Embajada de España en México. 
como maquiladora de la rama impresa de la industria editorial. Por su parte, esta industria abarca una variedad de productos que no son editoriales: papelería, empaques, anuncios, etc. El desarrollo tecnológico de la industria editorial la aleja de la industria de la impresión al crecer la relevancia de los productos digitales.

La industria editorial se divide en dos ramas: libros y revistas. Aunque hemos mencionado las publicaciones periódicas, este trabajo en particular se refiere al sector libros de la industria.

Según la Cámara Nacional de la Industria Editorial (Caniem), en 2005 existían en México 274 empresas privadas dedicadas a la edición de libros. ${ }^{2}$ De acuerdo con la magnitud de la facturación de sus ventas, la Caniem clasifica las empresas en seis rangos: proyecto inicial, micro, pequeña, mediana, grande y macro.

En 2005, las 274 empresas del sector privado con actividad editorial se distribuían de la manera siguiente: $82.1 \%$ del total estaba integrado por empresas de proyecto inicial, micro y pequeñas; el restante $17.9 \%$ lo constituían empresas medianas, grandes y macro.

Por otra parte, las firmas editoriales se clasifican sobre la base de la división editorial en la que se especializan. En 2005 la edición de libros de interés general concentró al mayor número de empresas (130), seguida por la edición de libros científicos, técnicos y profesionales (74) y la edición de libros de texto (48). La edición de libros religiosos se realizó en 22 empresas, mientras que la Caniem agregó la división de enciclopedias, fascículos y colecciones (8 empresas) a la división de interés general.

Cifras proporcionadas por la Caniem señalan que en 2010 hubo una producción total de 143250 títulos y 138607058 ejemplares vendidos, con un valor de facturación de 8907 millones de pesos.

2 Por su parte, el Directorio Latinoamericano de Editoriales que aparece publicado en el sitio web del Centro Regional para el Fomento del Libro en América Latina y el Caribe (Cerlalc) en 2012, señala que en México hay 241 casas editoras. Con respecto a esta cifra, vale la pena recordar que además de las editoriales comerciales, diversas dependencias gubernamentales, universidades y ONG cuentan con publicaciones periódicas y no periódicas. Existen también los autores-editores, que publican su propia obra. 
El cuadro 1 muestra la producción de libros de acuerdo con su clasificación temática.

\section{Cuadro 1. Producción de ejemplares por clasificación temática}

\begin{tabular}{l|r|r|r|r}
\hline \multirow{2}{*}{ Tema } & \multicolumn{5}{|c}{ Año } \\
\cline { 2 - 5 } & \multicolumn{1}{c|}{2005} & \multicolumn{1}{c}{2006} & \multicolumn{1}{c}{2007} & \multicolumn{1}{c}{2008} \\
\hline $\begin{array}{l}\text { Infantiles y } \\
\text { juveniles }\end{array}$ & 25597392 & 32357186 & 19850644 & 17535963 \\
\hline Literatura & 11975815 & 9077062 & 9855882 & 9728563 \\
\hline Lenguas & 5670687 & 7311402 & 4733058 & 6206178 \\
\hline Religión & 5657327 & 4473699 & 5550241 & 2718393 \\
\hline Filosofía y psicología & 5616577 & 6641361 & 6909874 & 5511147 \\
\hline $\begin{array}{l}\text { Arte, cultura y } \\
\text { deportes }\end{array}$ & 936231 & 655294 & 725177 & 840862 \\
\hline Ciencias puras & 901775 & 1011010 & 1012712 & 1127265 \\
\hline $\begin{array}{l}\text { Tecnología y } \\
\text { ciencias aplicadas }\end{array}$ & 4556670 & 5674153 & 5444687 & 4672958 \\
\hline Ciencias sociales & 2212453 & 2690830 & 3248457 & 4756112 \\
\hline $\begin{array}{l}\text { Educación básica } \\
\text { Sector privado }\end{array}$ & 70077626 & 65074276 & 66636729 & 67943120 \\
\hline $\begin{array}{l}\text { Educación básica } \\
\text { Sector gobierno }\end{array}$ & 182591331 & 170271255 & 148876855 & 161826783 \\
\hline $\begin{array}{l}\text { Total } \\
\text { privado }\end{array}$ & 252668957 & 235345531 & 215513584 & 229769903 \\
\hline Geografía e historia & 1179424 & 603830 & 779814 & 747084 \\
\hline Generalidades & 2353559 & 1571776 & 3067861 & 2607009 \\
\hline Otros & 732173 & 452430 & 1535240 & 981951 \\
\hline Fran total & 13709 & 137594309 & 129350376 & 125376605 \\
\hline
\end{tabular}

Fuente: Caniem (Cámara Nacional de la Industria Editorial Mexicana).

De acuerdo con un estudio realizado en 2010 por la Oficina Económica y Comercial de la Embajada de España en México, el sector editorial tiene un papel menor en la economía mexicana, con una participación de $0.4 \%$ del PIB en 2008 , de $2.1 \%$ dentro de la industria manufacturera y de $0.7 \%$ de las exportaciones 
mexicanas. Aunque esta participación es limitada, ha aumentado considerablemente en la última década. El sector privado de la industria editorial privada de libros en México se encuentra compuesta por 229 editores, de los cuales solamente 12 se consideran macro, es decir, que su facturación anual supera los 200 millones de pesos al año. Estas empresas obtienen 55.3\% de los ingresos totales del sector. Por el contrario $78 \%$ de los editores pertenece al rango de pequeño, micro y proyecto inicial, lo cual evidencia la alta concentración del mercado editorial. En total, el sector privado produce 129.3 millones de libros cuyas ventas dejan ganancias a la industria por 7000 millones de pesos (véase el cuadro 1).

Las cifras de la Caniem indican que desde 1998 los libros de texto constituyen casi $50 \%$ del volumen total de producción de libros, teniendo su participación más alta en 2005 con 51.8 por ciento.

Con respecto al empleo, esta industria da trabajo a 7677 personas, tiene una participación bastante pequeña dentro del empleo formal del país $(.05 \%$ ) y también dentro del empleo de la industria manufacturera (.54\%). Por otro lado, en lo referente al comercio exterior, los últimos datos disponibles muestran que en 2007 se exportaron 15 millones de ejemplares $(68$ millones de dólares), mientras que las importaciones ascendieron a 19 millones (69.6 millones de dólares). Aun así, la industria editorial no tiene déficit todos los años e, incluso, en algunos periodos ha tenido superávits importantes como en el comprendido entre 2004 y 2006.

La Caniem clasifica el empleo de una manera diferente a la utilizada por el INEGI, ya que lo agrupa en dos grandes divisiones: empleados directos y free lance. Así, en 2005 la industria editorial privada ocupó a 12959 personas, de las cuales 9125 eran empleados directos y 3834 correspondían a la modalidad free lance. Entre 1998 y 2005 la ocupación total prácticamente permaneció estática, ya que registró una variación de $1.1 \%$ en promedio anual. Entonces, el empleo directo representó en promedio $72.8 \%$ del total, mientras que las contrataciones free lance a $27.2 \%$ restante en ese periodo. 
De acuerdo con datos de la Organización de las Naciones Unidas para la Alimentación y la Agricultura (FAO), citados por Funtec (2007: 146), en 2003 México produjo 4060 millones de toneladas métricas de papel y consumió 5576 millones, por lo que es mayoritariamente importador de este producto. Para los editores mexicanos la disponibilidad de papel no es un problema relevante, ya que la apertura comercial permite importar papel de cualquier tipo y a precios determinados fundamentalmente en el mercado internacional. Consideran que en México existe buen abasto de papeles estándar, sin embargo, para ciertas especialidades es casi obligada la importación.

La impresión es sin duda uno de los eslabones proveedores del sector editorial más relevantes, ya que realiza la transformación final del producto. En un estudio efectuado por la Cámara Nacional de la Industria de Artes Gráficas [Canagraf, 2012], para un universo de 203 empresas localizadas en el Valle de México, los cinco principales problemas del sector se identificaron como: maquinaria obsoleta, capital insuficiente, personal irresponsable, tamaño físico insuficiente y capacitación.

En entrevistas realizadas por la Caniem a editores de libros y revistas se preguntó acerca de los impresores y el estado de su nivel tecnológico. En general las empresas mencionaron que el nivel tecnológico de impresión en México era adecuado para sus procesos.

Una de las empresas más grandes señaló que los impresores mexicanos eran altamente competitivos, debido a que desde hace cuatro años se depende únicamente de dos impresores, se han dado a la tarea de promover el desarrollo de nuevas empresas, por lo cual hoy cuentan con cinco impresores muy competitivos. Para las empresas más pequeñas el problema no es tanto la impresión, ya que afirmaron que en efecto en el país hay empresas modernas. Sin embargo, plantearon que la dificultad central se encuentra en el servicio, porque los impresores mexicanos en general no realizan el envío de los productos, por lo que la distribución genera costos adicionales a la empresa. 
De acuerdo con la información de la Caniem, la venta de libros en México se lleva a cabo por medio de los siguientes canales: ventas al gobierno, ventas directas a crédito, librerías, expendios propios, tiendas de autoservicio y departamentales, otros eventos, exportaciones, ferias del libro, distribuidores, correo directo, locales cerrados, puestos de periódicos, ventas a escuelas, ventas a bibliotecas y centros de documentación, ventas a empresas privadas, internet y ventas a asociaciones de padres de familia.

El canal de comercialización más importante de México durante 2004 fue el gobierno que compra a las editoriales, sobre todo libros de texto para la educación primaria y secundaria. Hasta 1997, los libros de texto para las escuelas primarias y secundarias oficiales eran producidos y distribuidos gratuitamente por el Estado. En años posteriores se establecieron diferentes programas para que el sector privado participe en los planes editoriales del gobierno; un ejemplo de esto es el Consejo Nacional para la Cultura y las Artes (Conaculta) que coedita $80 \%$ de sus publicaciones con la iniciativa privada. Por otro lado, está la Comisión Nacional de Libros de Texto Gratuitos (Conaliteg) que se encarga de la producción o compra de los libros de texto gratuitos tanto de educación primaria como secundaria hasta su distribución final. Aproximadamente $25 \%$ de los libros de primaria son producidos en los talleres de la institución, mientras que el resto se produce en talleres e imprentas privados, los cuales son escogidos previa licitación.

En segundo lugar se encuentran las librerías, que son los establecimientos mercantiles de libre acceso al público, de cualquier naturaleza jurídica, que se dedican exclusiva o principalmente a la venta de libros. En los últimos años el número de librerías ha disminuido de manera importante, esto como resultado de una tendencia que empezó años atrás. Otro de los canales de comercialización de libros importante son las tiendas de autoservicio y departamentales, que se dedican a la venta de una variedad limitada de títulos, generalmente best sellers. Entre las tiendas más importantes podemos mencionar a Liverpool, Palacio de Hierro y Sanborns. 
Los expendios propios son las librerías o puntos de venta propiedad de las editoriales, donde se comercializan los libros que producen ellas mismas. El canal de las ventas a escuelas incluye a las escuelas privadas, que no están estimadas en la distribución de libros de texto gratuitos por parte del gobierno, por lo que realizan la compra directa de libros a las editoriales. Lo mismo sucede con las ventas a empresas privadas, que compran a las editoriales sin intermediarios. Existen otros canales de venta, como los puestos de periódico, bibliotecas, eventos, ferias del libro, internet y por correo; estos son los de más baja participación en el total de las ventas. Las compras del gobierno, que no pasan por el canal librero y dependen de las políticas y presupuestos oficiales han crecido en los últimos años, muestran una tendencia positiva a partir de 2001, cuando se registró una tasa de crecimiento de $77 \%$ en relación al año previo.

Las ventas de libros por internet tuvieron un gran incremento durante el año 1999, cuando pasaron de 26000 ejemplares a 251000 ejemplares vendidos por este medio. Esto pudo ser provocado por la novedad que era realizar compras por internet, además de que se podían conseguir precios más accesibles en librerías virtuales extranjeras, pero no se mantuvo mucho tiempo, pues en 2001 las ventas cayeron 75.4\% hasta que en 2004 se registró una disminución de $50.5 \%$ respecto del año previo.

\section{PROBLEMAS DE LA INDUSTRIA EDITORIAL}

La Caniem identifica los siguientes problemas para el desarrollo de la industria editorial en México: falta de lectores, tiradas pequeñas (mayor precio), actividad editorial del Estado, piratería y reprografía en libros, y dificultades de acceso a la distribución.

\section{Falta de lectores}

México se caracteriza por tener un nivel promedio bajo y menor que el de países industrializados e incluso que algunos con 
desarrollo similar. La Encuesta Nacional de Lectura 2012 reportó una disminución en torno al hábito de la lectura que se tiene en México. En comparación a la muestra realizada en 2006, cuando se registró que 56\% de los mexicanos leían libros, este estudio arrojó que la cifra actual es de 46.2 por ciento.

Respecto al número de libros que leen los mexicanos por año, la cifra fue de 2.94. De acuerdo al estudio, $43 \%$ de los mexicanos cada vez leen menos; $34 \%$ lee la misma cantidad de libros, y solo $22 \%$ ha aumentado en su lectura.

El documento subrayó que entre las principales razones expresadas por los mexicanos para no leer, o por las cuales no leerían, se encuentran: falta de tiempo, dedicarse a otras actividades recreativas o que no les gusta leer.

Por sectores de edad, la encuesta informó que el grupo de entre 12 y 17 años siguen leyendo igual o más en comparación con el resto de los grupos de edad. Sin embargo, se observó una caída en la frecuencia de lectura a partir de los 18 años, edad a la que la mayoría de los jóvenes terminan sus estudios y es cuando leen menos, incrementándose la disminución de lectura notablemente con el aumento de la edad.

Además, se indicó que las dos terceras partes de la población leen por placer menos de 30 minutos diarios o su equivalente si leen un día a la semana por una o dos horas. La encuesta se levantó del 25 al 28 de agosto del 2012 con un margen de error del 19\%, consistió en 89 preguntas, extraídas de la Encuesta $\mathrm{Na}$ cional de Lectura, hecha por Conaculta en 2006, del Cuestionario de Estudiantes de la Prueba Nacional para la Evaluación de Estudiantes 2009 y otras elaboradas por la Fundación Fomento a la Lectura (FunLectura).

\section{Tirajes pequeños: mayor precio}

La menor demanda de libros tiene como consecuencia la disminución de los tirajes producidos por las editoriales, lo que finalmente redunda en un mayor costo por unidad (ejemplar) que, a su vez, se refleja en un mayor precio para el comprador final. 
Los análisis sobre la relación entre tiraje y precio no consideran el ingreso de las editoriales mexicanas al nuevo modelo de negocios de la impresión por demanda.

\section{Actividad editorial del Estado}

El Estado es el principal competidor de la industria editorial en México, pues de acuerdo con la Caniem, citada por Carmona [2010], más de $60 \%$ de la producción editorial mexicana corresponde al Estado. Por otro lado, el gobierno es el principal distribuidor de libros en México. Las compras del gobierno a las editoriales son sobre todo de libros de texto para la educación primaria y secundaria. En 2002, estas adquisiciones aumentaron considerablemente con el establecimiento del programa Bibliotecas de Aula.

Tanto la producción como las ventas de la industria dependen en gran medida de la participación del gobierno mexicano en la misma. Según Caniem, la actividad pública en la producción editorial siempre supera $50 \%$ y, en su papel de Estado comprador, las ventas de la industria privada al gobierno ocupan el primer lugar de importancia en el sector con algo más de la tercera parte de las ventas totales.

De acuerdo con Carmona ([2010], la participación privada en libros de texto para la enseñanza secundaria en ese año era atendida únicamente por seis empresas, dos de las cuales concentraban alrededor de $40 \%$ del mercado. La misma investigadora señala que la principal dificultad para entrar a ese mercado consiste en que la reglamentación obliga a realizar inversiones muy fuertes y de alto riesgo, pues en principio el editor produce un libro, lo cual puede llevarle uno o dos años, después tiene que someterlo a evaluación para asegurar que cumpla con los objetivos de los planes de estudio vigentes y debe editar un tiraje inicial para enviar un libro de prueba a los centros en los que se seleccionará el libro de texto que se va a utilizar en el curso: si el libro es elegido, se logrará un pedido de gran tiraje, si no, nunca se recuperará la inversión inicial. 


\section{Piratería y reprografía en libros}

La piratería y el fotocopiado ilegal es otro de los problemas al que se enfrenta la industria editorial mexicana. Según el Centro Mexicano de Protección y Fomento de los Derecho de Autor (Cempro) citado por Carmona [2010], en México se piratean alrededor de 10 millones de libros al año, sin embargo, no hay estadísticas confiables y precisas sobre la magnitud de la piratería y la fotocopia de libros. Esta situación dificulta la evaluación precisa de sus efectos en la industria editorial mexicana. Sin embargo, algunas estimaciones de Cempro sobre la magnitud que alcanzan el volumen y el valor de la piratería y reprografía en México indican que dos de cada 10 libros que se encuentran en el mercado mexicano son de origen ilegal y cuatro de cada 10 libros son fotocopiados. Estas cantidades muestran que la industria formal sólo surte al mercado local $40 \%$ de las ventas totales.

El fenómeno de la piratería está creciendo. Antes solo se reproducían copias piratas de libros denominados best sellers. Actualmente, la reproducción ilegal de libros va más allá de tales obras y abarca libros de muy diversa clase. Según la Caniem, la diferencia de precios entre los libros editados de manera legal y los piratas es muy variable. El precio de un ejemplar pirata comprado en un puesto en la calle puede llegar a ser hasta $50 \%$ menor al que se pagaría en una librería formal, incluso con descuento; en promedio, señala Caniem, se puede considerar una diferencia de $20 \%$. Este mercado informal también absorbe sobrantes de tirajes realizados por editores formales. Ya que el papel usado en las ediciones formales y piratas es el mismo, es difícil distinguir el original de la copia. Además, a veces se trata de papel robado.

La fotocopia de libros es una práctica que ha crecido mucho en los últimos años, aunque no existen datos sistemáticos para evaluar sus consecuencias sobre la industria editorial. Anteriormente, esta práctica afectaba principalmente los libros usados por los estudiantes, pero la situación ha cambiado y hoy se fotocopia prácticamente todo tipo de libros, según la Caniem [Funtec, SE y Caniem, 2007]. La Caniem estima que se producen entre 
5000 y 7000 millones de fotocopias al año, de las cuales $70 \%$ corresponden a libros, y usualmente a ciertos capítulos (no el libro completo). De acuerdo con la estimación realizada por la empresa Kinko's (empresa estadounidense de franquicias de fotocopiadoras), citado por Funtec, SE y Caniem [2007], sobre el mercado de las fotocopias en México, se considera que el valor de este mercado alcanza una cifra de 5900 millones de fotocopias al año.

La piratería y el fotocopiado se ven beneficiados por el acelerado cambio tecnológico en los equipos de reproducción, lo cual ha abaratado la calidad y los costos de reproducir o fotocopiar. Aunque la leyes son estrictas para estas prácticas, como resultado de la presión constante de asociaciones de productores como la Caniem o la sociedad de gestión colectiva Cempro, la capacidad institucional continúa siendo débil para hacer cumplir estas leyes.

Dada la elevada magnitud de la piratería y la reprografía, sus consecuencias para la industria editorial formal no son marginales. Son problemas de dimensiones estructurales y que afectan profundamente el funcionamiento de la industria.

\section{Dificultades de acceso a la distribución}

México cuenta, según los datos de la Asociación Nacional de Libreros, con alrededor de 600 librerías en toda la República, una cifra muy baja en comparación con las de España y otros países europeos. Son las grandes superficies las que dominan la distribución del sector en detrimento de las ventas por librerías tradicionales [Carmona, 2010: 5].

De acuerdo con Carmona [2010: 6],

México, a pesar de tener tasas medias de lectura ínfimas, es uno de los once mercados más grandes del mundo. Por su extensión, el idioma común con España y la buena aceptación del producto español, es un mercado con gran potencial y que supone una buena oportunidad para las editoriales españolas que quieran internacionalizarse. 
Uno de los problemas del ingreso al negocio de la distribución editorial es que las editoriales ya establecidas cuentan con acuerdos comerciales difíciles de homologar por empresas entrantes. Así, las pocas empresas distribuidoras existentes tienen un gran control de los canales de venta, por lo cual a nuevos participantes les resultaría muy costoso crear sus propias redes. Además, en el caso de las revistas hay preferencias de distribución debido a que, en algunos casos, pertenecen a algún grupo editorial.

Según la Caniem [Funtec, sE y Caniem, 2007] no hay elementos que permitan evaluar la tendencia de la generación de puntos de venta, aunque existe la impresión de que han aumentado en tiendas departamentales y ha disminuido la importancia de la librería tradicional. De acuerdo con la misma fuente, hay estimaciones que señalan que entre 40 a $43 \%$ de librerías han cerrado en los primeros años del siglo, esto significaría, considerando el número de librerías (alrededor de 606 librerías) en el año del estudio, que a mediados de los años noventa existían en el país cerca de mil librerías y que cada año habría cerrado un promedio de 40 de ellas. El informe señala que, de acuerdo con las declaraciones vertidas en el Boletín Cerlalc 11, Educal afirma que se ha pasado de 700 a 523 librerías y se han ido perdiendo 20 librerías al año.

La política de descuentos típica, de acuerdo con entrevistas a libreros hechas por Funtec, es la siguiente [2007: 246]:

$40 \%$ a libros de catálogo.

20 a $35 \%$ a libros de texto.

$45 \%$ en libros de catálogo para librerías de cadena.

30 a $35 \%$ en libros de texto para cadena.

$50 \%$ para tiendas y tiendas departamentales.

$10 \%$ extra como margen comercial a los distribuidores.

INNOVACIÓN TECNOLÓGICA EN LA INDUSTRIA EDITORIAL

La industria editorial ha sido muy susceptible al desarrollo de nuevas tecnologías, en particular de las denominadas tecnologías 
de la información y la comunicación (TIC). Inciden tanto en el proceso productivo como en la circulación de los productos editoriales.

Las capacidades tecnológicas en la industria editorial consisten tanto en la incorporación de equipos y maquinaria novedosa, como en el desarrollo de nuevos procedimientos de organización del trabajo. Como mencioné antes, la innovación tecnológica está vinculada directamente a los proveedores de equipos.

Desde finales del siglo xx, la utilización de nuevas tecnologías en la industria editorial ha llevado a modificaciones radicales en la concepción tanto en los productos de la industria, libros y revistas, como en los procesos de producción e impresión. Los cambios han incidido en la elaboración del manuscrito -capturado digitalmente desde su origen-, la revisión, corrección de originales, diseño y composición tipográfica. La fase final en la producción de libros, gracias a las nuevas tecnologías, puede seguir varios caminos: impresión tradicional en offset, impresión digital o publicación electrónica online.

En el circuito tradicional del libro, el autor escribía la obra, que era procesada por el editor, se reproducía y, ya con el libro impreso, se buscaban los mejores canales de distribución, muchas veces por intermediarios, hasta que llegaba a su destinatario final: el lector. Cuando se agotaban los ejemplares, se realizaba una nueva tirada. Este circuito ha cambiado notablemente en las últimas dos décadas a partir de la introducción de nuevas tecnologías en el campo de la producción editorial. La incorporación de estas innovaciones implica el desplazamiento de ciertos perfiles profesionales y la necesidad del surgimiento de nuevos productos en un proceso de apropiación tecnológica.

La aplicación de innovaciones tecnológicas ha agilizado y mejorado los procesos editoriales, lo mismo que hizo el offset con la prensa plana y esta a su vez con los libros manuscritos. Lo cierto es que la aparición de una tecnología no sustituye la anterior de manera automática, sobre todo tratándose de un artilugio -el libro impreso- que ha demostrado su utilidad durante más de cinco siglos. 
La instrumentación de estas tecnologías tiene lugar en lo que llamaremos "salida" de las obras y que ya mencionamos antes: los libros electrónicos y la impresión digital.

Se entiende por impresión digital una tecnología que permite imprimir y encuadernar libros en tiros cortos, desde un ejemplar en adelante [Woll, 2004]. Comprende los procesos de edición, impresión y encuadernación. Ha hecho posible la impresión por demanda que, a su vez, puede utilizarse en la edición de ejemplares "preliminares", el mantenimiento de disponibilidad mediante la reimpresión digital de obras previamente impresas en offset y que se encuentran agotadas, la exploración del mercado con vistas a una tirada mayor en offset, o la "personalización" de las ediciones, con contenido variable por persona, grupo de personas, idioma o región.

Para el editor, sobre todo para el editor en pequeño, es una gran ventaja el imprimir solo los ejemplares necesarios sin que se encarezca el costo unitario del libro, lo que le implica un ahorro en términos de disposición inmediata de efectivo, así como la reducción, incluso eliminación, de los costos de almacenaje, pues aunque la impresión digital puede usarse para tiros cortos, la impresión por demanda en su grado máximo se ha denominado "tiraje cero": significa que no hay una impresión previa a la distribución o venta del ejemplar, se imprime como consecuencia de la solicitud del comprador. En el caso de las editoriales universitarias en México, esta opción tecnológica, ya sea en su versión de tiros cortos o el tiraje cero, resulta muy útil.

Después de la imprenta, considerada como la mayor revolución tecnológica, las que se sitúan como lo novedoso son las publicaciones electrónicas. Hoy, estas publicaciones electrónicas o digitales se diversifican en libros, revistas, blogs, páginas web, que utilizan el soporte digital y se distribuyen por internet para ser leídas en computadoras o en otros dispositivos, incluyendo teléfonos inteligentes. La distribución física (CD o DVD) está cayendo en desuso.

En este trabajo nos referiremos a los libros electrónicos o digitales en el sentido de publicaciones formales que requieren 
un proceso de producción editorial. Puede tratarse de una publicación "migrada", es decir, aquella que fue publicada impresa inicialmente y luego subida a la red en una versión digital, o de un libro planeado de origen con este formato y para este medio. Por sus características, uno de los géneros idóneos para este tipo de publicación es el de los textos académicos, técnicos y científicos. No es rara esta circunstancia si consideramos que es este tipo de público el que cuenta con los requisitos técnicos para tener acceso a tales materiales. Un punto a favor según los editores es que la participación en esta modalidad de explotación de las obras permite la reutilización no solo de estas sino también del trabajo editorial ya realizado. Una obra publicada en impreso puede publicarse en un medio electrónico aprovechando la inversión en trabajo editorial que ya se realizó.

Desde los primeros dispositivos y formatos, mucho han avanzado las publicaciones electrónicas. Se han desarrollado nuevos artefactos y programas lectores, ha mejorado la calidad visual de los mismos y se ha universalizado la utilización en múltiples dispositivos. Asimismo, se han desarrollado nuevos formatos, además del documento portátil (pdf). Cada vez son más populares los formatos líquidos, en los que el texto se adapta al tamaño de la pantalla, como el epub, que se ha convertido en un estándar, principalmente en dispositivos de lectura portátiles como tabletas y celulares.

Aunque ya ha pasado el tiempo en que se tenía la certeza de que los libros electrónicos sustituirían en el corto plazo al libro de papel, lo que sí es cierto es que el concepto de libro se ha extendido, al incorporarse los nuevos soportes, formatos y estructuras de información propios del libro electrónico. Algunas ventajas del libro electrónico son las siguientes: ediciones dinámicas y susceptibles de modificarse después de publicadas, para corregirlas o actualizarlas, pueden incluir contenidos multimedia y servicios agregados como búsquedas, enlaces y la posibilidad de retroalimentación con el lector.

Entre sus desventajas encontramos que requieren un dispositivo para ser consultadas, son vulnerables, no se puede asegurar 
su acceso a largo plazo, deben actualizar sus formatos conforme avanza la tecnología y existe resistencia por parte de los lectores acostumbrados a la lectura en papel.

Un rasgo importante de las publicaciones electrónicas es su vinculación con el medio global de internet. Su acceso se dinamiza a partir de la posibilidad de ser ubicados por medio de los buscadores, que permiten su lectura en cualquier momento y desde cualquier lugar del mundo.

Una vez en el mundo virtual, el libro se "desmaterializa", su valor vuelve a centrarse no en el del libro-objeto, papel y tinta encuadernados, sino en los derechos de explotación de la obra. Las nuevas tecnologías vuelven la atención al punto central del valor del libro, representado por los derechos de autor y al poseedor de los mismos. Los actores participantes del circuito del libro luchan en este escenario: autor, editor y lector demuestran tener intereses que no solo pudieran no tener nada en común, sino muchas veces contrarios.

Ha disminuido la resistencia inicial de los autores a publicar sus obras en medios diferentes al tradicional impreso. El cada vez mayor conocimiento de los derechos de autor, las diferencias entre piratería y plagio, así como las posibilidades reales de acceso a su obra en espacios de otra manera inalcanzables, han modificado la actitud de los autores en cuanto a las nuevas tecnologías en la edición de sus libros.

Por el otro lado, ante la desigual calidad de los materiales publicados en línea, la publicación formal de libros electrónicos adquiere especial valor para el investigador, principalmente cuando están respaldados por una editorial universitaria con el correspondiente dictamen académico y cuentan con los beneficios que supone el trabajo editorial profesional, desde la corrección de originales, el diseño y la composición hasta la arquitectura de la información, el uso de estándares de navegación y la incorporación de metadatos que faciliten su ubicación en línea.

Según Sánchez y Díaz [2005], 
...las tendencias que dominan el sector editorial moderno son:

- El desdoblamiento de los libros y las revistas en físicos y electrónicos.

- En el segmento de libros físicos, el reemplazo del método de impresión de información fija por información variable según demanda.

- La gradual desaparición de los almacenes físicos (stocks) y su reemplazo por mecanismos industriales de impresión a demanda (print-on-demand).

- La irrupción del comercio electrónico a nivel global, con la aparición de intermediarios que han revolucionado la cadena de distribución tradicional.

- La ampliación de productos de una marca y la reutilización del contenido.

- La utilización de las redes de telecomunicaciones para realizar una distribución ilimitada y universal a las masas.

- El surgimiento de nuevos conceptos y entidades relacionadas con la aplicación de las tecnologías de la información y comunicación.

- La exigencia de nuevas competencias profesionales en los trabajadores del sector para lograr desempeños exitosos.

\section{Políticas PÚBlicas CULTURALES EN MATERIA EDITORIAL}

Como mencioné antes, el carácter cultural de los productos editoriales les confiere un valor simbólico extra a los materiales y al trabajo invertido en ellos. Su importancia como bien cultural para la sociedad en que surgen, se destaca por el cúmulo de regulaciones que lo enmarcan. Los intereses de los diversos actores involucrados en la industria editorial -autores, editores, distribuidores, lectores- se manifiestan y pugnan por influir en los distintos escenarios de la economía y la política en nuestro país.

En México, las políticas culturales que inciden en la industria del libro comprenden todas las etapas, desde la creación hasta la comercialización, distribución y circulación de los productos editoriales.

Varias instituciones se encargan de ejecutar las políticas culturales del Estado mexicano, a continuación mencionaré las 
principales y la manera en que promueven el desarrollo tecnológico en la industria del libro en México. Son el Consejo Nacional para la Cultura y las Artes y el Fondo Nacional para la Cultura y las Artes (Fonca) quienes ejecutan las políticas públicas de fomento a la creación, producción y divulgación de obras culturales en beneficio de la sociedad mexicana. Entre las tareas que se han desarrollado en los últimos años con respecto a nuestro tema, podemos destacar las siguientes: ${ }^{3}$

- Otorgamiento de becas a escritores, entre otros artistas. En este sentido, el apoyo a la creación no se vincula con la utilización de nuevas tecnologías o al desarrollo de nuevos géneros literarios vinculados a internet.

- Financiamiento directo a proyectos específicos mediante la participación en la coedición de colecciones y títulos cuya amplia difusión se considere de particular importancia sociocultural.

- Formación de profesionales. Durante 2012, el Conaculta organizó diversas actividades de capacitación para editores. Destaca el $4^{\circ}$ Seminario Multidisciplinario: El Derecho de Autor en el Ámbito Editorial, organizado en colaboración con el Instituto Nacional del Derecho de Autor (Indautor), cuyo objetivo fue formar conciencia sobre los procesos legales de creación y producción editorial entre los editores, escritores, correctores de estilo, diseñadores, abogados y todos los involucrados e interesados en la industria editorial. Algunas de las materias que se abordaron durante las sesiones fueron la protección tecnológica en el entorno digital, los modelos de negocios en internet, las licencias en el ámbito digital y el libro electrónico.

Asimismo, desde 2011, el Conaculta ha organizado tres simposios internacionales del libro electrónico anuales, "como espacio de diálogo innovador en América Latina y el mundo, así como un

${ }^{3}$ La información relativa al Conaculta y al Fonca proviene de las convocatorias y programa de trabajo [2012]. 
esfuerzo por conformar una agenda de ideas y acciones en torno al libro electrónico en español" ${ }^{4}$ En estos simposios, además de intercambiar experiencias de proyectos de edición electrónica, se promueve el aprovechamiento de las ventajas del medio digital para los profesionales del libro y se difunde el programa que en la materia propone el Conaculta para los próximos años.

\section{Derechos de autor}

En el aspecto de la producción editorial, es importante la protección a los derechos de autor. Para el editor, se manifiesta como el derecho de explotación exclusiva de un texto, lo que da un rasgo de competencia monopolística al mercado editorial. Este monopolio no implica necesariamente una ventaja sobre los competidores, pues siempre existe un importante riesgo para editores y distribuidores sobre el éxito comercial de un libro. A pesar de que las editoriales se esfuerzan por elegir materiales que garanticen por lo menos la recuperación de la inversión, sobre todo a partir del prestigio del autor, el destino de la mayoría de los libros es incierto, pues su buen desempeño en el mercado editorial depende de factores que no se pueden controlar.

En la Ley Federal del Derecho de Autor (LFDA) el Estado mexicano reconoce en favor de todo creador, el goce de prerrogativas y privilegios exclusivos de carácter personal y patrimonial vinculados con su obra. Los primeros integran el llamado derecho moral y los segundos, el patrimonial. Además de estos, la LFDA otorga los denominados derechos conexos que protegen los derechos de los editores:

Artículo 125. Los editores de libros tendrán el derecho de autorizar o prohibir:

I. La reproducción directa o indirecta, total o parcial de sus libros, así como la explotación de los mismos.

${ }^{4}$ Información tomada de la página web del Segundo Simposio Internacional del Libro Electrónico en Español [2012]. 
II. La importación de copias de sus libros hechas sin su autorización.

III. La primera distribución pública del original y de cada ejemplar de sus libros mediante venta u otra manera.

Artículo 126. Los editores de libros gozarán del derecho de exclusividad sobre las características tipográficas y de diagramación para cada libro, en cuanto contengan de originales.

Artículo 127. La protección a que se refiere este capítulo será de 50 años contados a partir de la primera edición del libro de que se trate.

Con respecto a las nuevas tecnologías, la LFDA, desde 1997 incluye menciones expresas a las nuevas posibilidades de edición:

Artículo 6o. Fijación es la incorporación de letras, números, signos, sonidos, imágenes y demás elementos en que se haya expresado la obra, o de las representaciones digitales de aquellos, que en cualquier forma o soporte material, incluyendo los electrónicos, permita su percepción, reproducción u otra forma de comunicación.

Aunque el origen de la protección a los derechos de autor se remonta a varios siglos, es a mediados del siglo xx que en México se crea una ley específica para regular el derecho de autor. A partir de entonces, esta ley se ha modificado en respuesta a las nuevas condiciones de producción y comercialización de los distintos productos intelectuales que tutela, además de los convenios internacionales que México ha signado. La actual ley de los derechos de autor, promulgada el 24 de diciembre de 1996, entró en vigor el 24 de marzo de 1997. La última modificación a la ley se realizó en 2003.

\section{Precio único}

En 2008 se promulgó en México la primera Ley de Fomento a la Lectura y el Libro (LFLyL) como resultado del impulso de la Cámara Nacional de la Industria Editorial Mexicana. Su principal 
elemento innovador es el establecimiento del precio único para los libros durante los primeros 18 meses de su existencia. El objetivo era frenar el proceso de concentración y desplazar la competencia sobre el terreno del servicio y de la variedad de títulos propuestos. El principal interés del precio fijo del libro es su capacidad para realizar algunos objetivos culturales. El libro es un bien cultural que todos los Estados defienden y cuya difusión debe ser promovida por el Estado.

Entre los objetivos del establecimiento del precio único, Gerlach [2003: 74-76] menciona los siguientes:

- Preserva la existencia de una red densa y variada de librerías. Garantizándoles unos márgenes mínimos, evita una guerra de precios sobre los títulos de rotación rápida que tendría como consecuencia la erosión de los márgenes de los libreros y pondría en peligro el sistema de precuación. Además, la defensa de una red de librerías densa y repartida equitablemente [sic] sobre todo el territorio corresponde a un objetivo importante que es el acondicionamiento regional, iniciado desde hace algunos años en la mayoría de los países europeos. Por razones urbanísticas y sociales, casi todos estos países luchan contra la desertización de las zonas rurales y de los centros de las ciudades, que lleva consigo la concentración de los puntos de venta al por menor en las grandes superficies.

- Limita la subida de los precios y la desaparición de títulos más "difíciles”, es decir, de rotación más lenta y con una menor tirada. Recordemos que este tipo de obras representa el $95 \%$ de los títulos que se editan. El precio fijo asegura así la variedad de la oferta editorial que constituye por definición un objetivo cultural innegable.

... Hoy en día, en un contexto en el que la vida de los productos culturales está amenazada por el "zapping" de los consumidores y por una oferta mediática desmesurada, esta presencia duradera resulta más importante que nunca.

- Asegura la existencia de un cierto número de servicios (consejo, pedido de libros, presentación de novedades) de los que se benefician tanto lectores como editores. 
- Favorece el traspaso internacional de la cultura y del saber. Es importante mencionar este aspecto que es competencia tanto de la política cultural como de la política de educación e investigación. En efecto, este traspaso, que se realiza a menudo a través de libros traducidos, también se beneficia del precio fijo. La edición es una industria de costos fijos, particularmente elevados cuando se añaden a los de fabricación, los costos de traducción.

Una de las principales tareas que establece la LFLyL es la de "crear y mantener permanentemente actualizada una base de datos, con acceso libre al público, que contenga el registro del precio único de los libros”.

Asimismo, en el artículo 8, la ley ordena que "las autoridades responsables... deberán impulsar la creación, edición, producción, difusión, venta y exportación del libro mexicano... asegurando su presencia nacional e internacional". Esto quiere decir que la edición de libros debe apoyarse con estímulos fiscales, en las negociaciones para exportar más libros de fabricación nacional a otros mercados, en la ampliación de la red librera, o con ayudas para traducir obras de autores nacionales a otros idiomas o de otros idiomas al español, etcétera.

En el artículo 4, fracción VIII, la ley aclara que, entre otros, tiene por objeto "estimular la capacitación y formación profesional de los diferentes actores de la cadena del libro y promotores de la lectura". Aunque algunos programas universitarios de licenciatura incluyen asignaturas vinculadas con la actividad editorial y existen posgrados y diplomados especializados, el contenido de la ley refuerza la obligación del Estado de contribuir a la formación de profesionales del libro, desde editores hasta libreros en la que la Secretaría de Educación Pública (SEP) debe desempeñar el papel fundamental mediante la certificación de los conocimientos adquiridos empíricamente, lo que garantizaría la capacidad de enfrentar el desafío que significa la modernización y actualización de las empresas editoriales y libreras mediante la introducción de las nuevas tecnologías de producción y difusión de los contenidos culturales y editoriales. 
Sobre el precio único, el tema en discusión no es realmente el precio del libro, sino el descuento que algunas cadenas libreras otorgaban al público sobre el mismo. Antes, como las cadenas libreras exigían al editor un gran descuento a cambio de comprarles una cantidad importante de ejemplares $50 \%$ sobre el precio de venta), los editores simplemente incorporaban ese descuento como una parte más del costo del libro, con lo cual mantenían su margen de ganancia aunque inflaban el precio final. Ahora, los editores deberían fijar su precio sin tener que agregar este componente del descuento artificial, con lo que teóricamente los precios de los libros deberían bajar. Además, se elimina la desventaja de las pequeñas librerías en su capacidad de otorgar descuentos al comprador final.

\section{Apoyos fiscales a editores}

De acuerdo con la Caniem [Funtec, sE y Caniem, 2007], en México se han ido reduciendo los estímulos fiscales a la industria del libro, incluyendo las disminuciones de impuestos que aplicaba el gobierno. Los apoyos que existían se basaban en el criterio de que la edición de libros era una actividad necesaria para el desarrollo. El artículo 13 de la anterior Ley del Impuesto sobre la Renta permitía la reducción del monto del impuesto al negocio de la edición de libros. Este artículo fue derogado y ese estímulo fiscal se eliminó gradualmente, por lo que los editores de libros pagan el impuesto sobre la renta (ISR) como todos los contribuyentes. Otro estímulo fiscal a la industria de la edición de libros fue el apoyo concedido en 1990 (y que operó hasta 2003) que permitía a los editores incorporarse al régimen simplificado, lo que fomentaba la reinversión de utilidades.

En cuanto al impuesto al valor agregado, desde que se estableció ha dado estímulos al sector editorial. Así, los contribuyentes que editen o vendan libros, periódicos y revistas están exentos de ese impuesto y tienen el derecho de acreditar el impuesto trasladado por adquisiciones de materias primas, productos terminados 
y gastos e inversiones identificadas de modo pleno con esa actividad. Aunque este tipo de estímulos favorece la reducción de los costos, no parece suficiente para impulsar el desarrollo de la cadena productiva y de la industria en su conjunto [Funtec, SE y Caniem, 2007].

Estos estímulos se refieren a la industria editorial tradicional, la que produce libros impresos en papel. No existen en México estímulos específicos para la incorporación de nuevas tecnologías en el sector editorial.

\section{CONCLUSIONES Y PROPUESTAS}

Considerada como parte de la industria del entretenimiento, la principal competencia de la industria editorial son las otras industrias culturales: el cine, la televisión, las redes sociales, internet, etc. Por otro lado, como factor de transmisión de conocimientos y valores para la sociedad, el libro tiene un gran valor simbólico, lo que vuelve fundamental el apoyo del Estado para su creación, producción, promoción y distribución.

El libro es un producto que requiere del Estado para su consumo, pues es necesario un público alfabetizado. La historia muestra cómo la aparición y desarrollo de una clase con acceso a la instrucción propicia el desarrollo de la industria editorial.

La utilización de nuevas tecnologías en la industria editorial mexicana no es generalizada en todas las etapas de producción debido a varios factores. Por un lado, la renovación de tecnología depende de los proveedores de nuevos equipos, lo cual requiere inversiones importantes, los principales cambios tecnológicos en los últimos años se han dado en el trabajo editorial propiamente dicho.

La corrección en pantalla, el diseño y composición tipográfica en computadora mediante programas de diseño que se actualizan constantemente, son procesos que se han impuesto de manera general en la industria. En mayor medida se ha extendido la filmación directa de negativos e incluso de láminas para impresión 
offset. Más lenta ha sido la penetración de la impresión digital contra el offset, la cual depende de las necesidades de tiraje de cada edición. Así, la mayoría de los estudios consultados enfocan la producción editorial en el sentido tradicional de la economía a escala: mayor producción, menores costos y menores precios al consumidor. Sin embargo, la producción por demanda mediante la impresión digital, que implica tirajes mínimos de inicio, abre posibilidades que aún no han sido explotadas de manera general por la industria editorial mexicana.

Con respecto a la producción del libro electrónico, su desarrollo tampoco ha sido generalizado en México, pues la mayor parte de la población no tiene acceso a estas tecnologías, que no solamente se requieren para la producción, sino también para la lectura.

En el mismo sentido, la situación económica del país afecta a la industria editorial, dado que en una sociedad que debe resolver la satisfacción de sus necesidades básicas, el libro es un artículo de lujo. De la misma manera, la competencia con otras industrias culturales que cuentan con mayores recursos de promoción no propicia el acceso a los libros, incluso de aquel sector de la población alfabetizado y con los recursos necesarios para adquirirlos.

La opinión generalizada en este tema por parte de los editores, es que no hay apoyo suficiente por parte del gobierno. Además, este apoyo no se enfoca en impulsar la innovación tecnológica en la industria, aunque hay diversos proyectos de digitalización centrados especialmente en acervos bibliotecológicos. Serían necesarios mayores estímulos fiscales a la industria y en general a toda su cadena productiva.

La opinión de los editores sobre la web - "internet contribuye a que menos gente compre libros"- muestra que ingresar a este medio no es una prioridad de los pequeños editores que consideran que su negocio se concentra en los libros impresos. Para ellos, internet es una competencia, más que un aliado. La capacitación impartida por el Conaculta no ha permeado en el medio editorial que continúa siendo muy tradicional con respecto a las nuevas tecnologías, sobre todo las que no se refieren a libros impresos. 
Para los editores, la relación con el Estado es complicada. Por un lado, se trata de su principal competidor y no está sujeto a la demanda de sus productos, pues las áreas editoriales de las dependencias de gobierno cuentan con presupuestos, aunque limitados, que no dependen del éxito comercial de sus productos. Por otro lado, el gobierno es el principal comprador de libros. En ese sentido, las necesidades de la industria se vinculan primordialmente con los largos plazos de pago y las complicadas formas de selección y adquisición de materiales. Como se mencionó antes, los procesos de concurso de las obras para las bibliotecas de aula requieren de una importante inversión por parte de los editores, lo que resulta prohibitivo para empresas muy pequeñas o para proyectos iniciales.

Con respecto a los libros de texto, en opinión de los editores, sería muy útil si se modificaran los procedimientos de entrega, de manera que se propicie el contacto de los niños y jóvenes con las librerías.

La promulgación de la primera Ley de Fomento a la Lectura y al Libro en México ha sido un avance importante, sin embargo, se requiere mayor promoción cultural a favor del libro. Además, aunque esta ley se promulgó hace ya varios años, no ha tenido los resultados esperados en lo que se refiere al establecimiento del precio único. La laxitud de su aplicación ha convertido prácticamente en letra muerta este ordenamiento.

En cuanto al combate a la piratería y al fotocopiado, la sociedad de gestión colectiva Cempro y la Caniem son los organismos que han tenido mayor participación. Sin embargo, los resultados tampoco son considerados satisfactorios por los editores, a pesar del endurecimiento de las normas al respecto. Por otro lado, las corrientes de pensamiento vinculadas con el acceso abierto de las obras en internet no cuentan con la simpatía de los editores, aunque, experiencias en otros países han demostrado que no solo pueden convivir ambos modelos sino potenciarse uno al otro.

La mayor inversión en capacitación por parte de los empresarios y del Estado es un factor que podría modificar las condiciones de la industria editorial mexicana de manera que se pudieran 
incorporar las nuevas tecnologías en beneficio de los productores de libros y, en última instancia, de la sociedad en su conjunto.

\section{REFERENCIAS}

Canagraf [2012], "Estudio estratégico y programa sectorial para elevar la competitividad y el desarrollo sustentable de la cadena productiva de la industria de artes graficas, <http://www. canagrafgrafico.com/img/estudios/IV-Estrategico_y_Programa_Sectorial_para_Elevar_la_Competitividad.pdf $>, 15$ de octubre.

Caniem y Conaculta [2010], "Principales indicadores del sector editorial privado en México”, <http://www.caniem. org/archivos/estadistica/indicadores \%20booklet \%202010. pdf $>, 12$ de octubre de 2012.

Carmona F., N. [2010], “El sector editorial en México”, Oficina Económica y Comercial de la Embajada de España en México, <http://www.icex.es/icex/cma/contentTypes/common/ records $/$ mostrarDocumento/?doc $=4400060>$, 15 de octubre de 2012.

Corona A., Juan Manuel y Marco A. Jaso [2004], “Interacción y aprendizaje en las pymes: un estudio empírico en la industria de la imprenta y las artes gráficas de México", Stumpo, Giovanni et al. (2004), Pequeñas y medianas empresas y eficiencia productiva, México, Siglo XXI/CEPAL, pp. 183-234.

Febvre, L., y H.-J. Martin [2005], La aparición del libro, México, Fondo de Cultura Económica, 515 pp.

Funtec, SE y Caniem [2007], "Estudio estratégico y programa sectorial para elevar la competitividad y el desarrollo sustentable de la industria editorial mexicana", documento consultado en línea, <http://www.ediciona.com/documents/recursos/estudio_estrategico_sector_editorial_2007.pdf $>, 18$ de octubre de 2012.

García C., N. y E. Piedras F. [2008], Las industrias culturales y el desarrollo de México, 2a. ed., México, Siglo XXI/Flacso, 140 pp. 
Gerlach, M. [2003], Cómo proteger el libro. Desafíos culturales, económicos y políticos del precio fijo, París, Alliance des Éditeurs Indépendants, $108 \mathrm{pp}$.

Ibarra G., A. C. [2002], "El desarrollo de la imprenta", en Raquel Chang-Rodríguez, Historia de la literatura mexicana, México, Siglo XXI/unam, pp. 69-84.

Martínez-Val, J. [2005], Gutenberg y las tecnologías del arte de imprimir, Madrid, Fundación Iberdrola (col. Gigantes), 305 pp.

Sánchez T., N., y Y. Díaz A. [2005], "El sector editorial contemporáneo y las competencias profesionales", Acimed 13(5), <http://bvs.sld.cu/revistas/aci/vol13_5_05/aci08505.htm>, 10 de mayo de 2011.

Unesco [2005], "Convención sobre la protección y la promoción de la diversidad de las expresiones culturales", firmado en París, 20 de octubre de 2005, <http://unesdoc.unesco.org/ images/0014/001429/142919s.pdf $>, 19$ de noviembre de 2012. Woll, T. [2004], Editar para ganar, estrategias de administración editorial, México, Fondo de Cultura Económico (col. Libros sobre Libros), 356 pp.

Zacarías, A. [1995], "El papel del papel de PIPSA", Comunicación y Sociedad, DECS, Universidad de Guadalajara, (25-26): 73-88, septiembre de 1995-abril de 1996. 


\section{Capítulo 9 \\ UNA MIRADA A LA INDUSTRIA DEL MEZCAL DE OAXACA}

María Elena Lopes Pacheco*

\section{INTRODUCCIÓN}

De las ramas de la industria manufacturera del estado de Oaxaca destaca el sector de alimentos y bebidas, y de ellas, la producción de mezcal, que aporta entre 70 y $75 \%$ de la producción nacional, pues las características agroclimáticas han favorecido la producción del agave mezcalero, planta a partir de la cual se produce la bebida [Bautista y Ramírez, 2005: 445; Aguirre, 2012: 4].

Aun cuando la demanda de mezcal ha empezado a ampliarse en escala nacional e internacional, todavía se le considera una bebida de baja calidad, en especial cuando lo comparan con su competidor más cercano: el tequila.

La cadena agroalimentaria maguey-mezcal es importante en México, pues de ella viven muchas familias, aunque no hay datos confiables sobre la superficie que cubre la producción de la materia prima y el número de personas ocupadas en la actividad [Illsley et al., 2009: 16]

* Miembro de la Unidad de Investigación de Economía del Trabajo y la Tecnología y participante en el proyecto PAPIIT IN305610. Correo electrónico: <naele0115@yahoo. com.mx>. 
La estructura productiva de esta industria en el país se caracteriza por el predominio de las unidades de producción tradicional, las micro y pequeñas empresas, situación que es similar en el estado de Oaxaca.

Este trabajo es un acercamiento a la industria del mezcal establecida en el estado de Oaxaca, con la finalidad de iniciar el análisis de la cadena agroalimentaria maguey-mezcal en dicha entidad.

Considero que la producción actual de mezcal tradicional es resultado del conocimiento tácito, desarrollado, conservado y dinamizado, que se ha transmitido de generación en generación. Las formas de producción tradicional han sido aprovechadas para desarrollar empresas de corte industrial por medio de la transferencia de ese saber tradicional, potenciándolo a partir de innovaciones tecnológicas.

Diversos estudios señalan que en 24 o 26 entidades del país se encuentra el agave mezcalero [Colunga, 2012: 1; Calvillo, 2012: 1], sin embargo, solo siete estados (Oaxaca, Guerrero, Hidalgo, Zacatecas, Durango, San Luis Potosí y Tamaulipas), son reconocidos oficialmente como productores de mezcal [Colunga, 2012: 1; Bautista, 2008: 10-11 e Illsley et al., 2009: 20], de los cuales Oaxaca es el principal productor [CNSPMM, 2012: 10].

En México se pueden encontrar más de 10 especies diferentes de agave mezcalero, ${ }^{1}$ denominado comúnmente maguey, que se utilizan para producir destilados [Larson y Neyra, 2004: 6; Illsley, 2004: 2]; son plantas que se adaptan en zonas secas y semisecas, resistentes a la sequía [Illsley et al., 2009: 11], en su

${ }^{1}$ Cuando hablamos del mezcal, necesariamente tenemos que hablar de la diversidad biológica, pues el agave está íntimamente ligado a la biodiversidad. México ocupa el cuarto lugar en escala mundial en diversidad biológica y el estado de Oaxaca concentra $40 \%$ de esta. Un número importante de dichas especies son endémicas y las agaváceas son parte de la diversidad de esta entidad con 58 especies, de las cuales 13 son endémicas, algunas de estas son materia prima para la elaboración del mezcal [Illsley et al., 2009: 4]. 
mayoría silvestres, con excepción del agave tequilana Weber variedad azul [NOM-006-SCFI-2005] de Jalisco y el espadín de Oaxaca, que son cultivados [Illsley, 2004: 2]. Por lo tanto, en centenares de regiones del país se produce mezcal ${ }^{2}$ [Larson y Neyra, 2004: 6].

\section{PRINCIPAL PRODUCTOR DE MEZCAL: OAXACA}

El estado de Oaxaca se caracteriza por su riqueza gastronómica, destacando la producción de mezcal (véanse los cuadros 1 y 2), de las siete entidades que cuentan con la denominación de origen, Oaxaca tiene el mayor número de empresas y fábricas, un alto volumen de producción en comparación con los otros seis estados [CNSPMM, 2012: 10; Bautista y Ramírez, 2005: 445; Aguirre, 2012: 4].

\section{Cuadro 1. Estatus de la industria del mezcal (diciembre de 2010)}

\begin{tabular}{|c|c|c|c|c|c|c|c|}
\hline \multirow{2}{*}{ Entidad } & \multirow{2}{*}{ Empresas } & \multirow{2}{*}{ Fábricas } & \multirow{2}{*}{ Envasadoras } & \multirow{2}{*}{ Bodega } & \multirow{2}{*}{$\begin{array}{c}\text { Marcas } \\
\text { certificadas }\end{array}$} & \multicolumn{2}{|c|}{ Mercado destino } \\
\hline & & & & & & Nacional & Exportación \\
\hline Oaxaca & 46 & 209 & 41 & 30 & 72 & 34 & 50 \\
\hline Zacatecas & 10 & 19 & 19 & 18 & 16 & 14 & 12 \\
\hline Guerrero & 3 & 54 & 4 & 2 & 3 & 3 & 2 \\
\hline Durango & 3 & 8 & 3 & 1 & 5 & 1 & 5 \\
\hline $\begin{array}{l}\text { San Luis } \\
\text { Potosí }\end{array}$ & 2 & 4 & 4 & 1 & 3 & 2 & 3 \\
\hline Tamaulipas & 0 & 2 & 2 & 0 & 0 & 0 & 0 \\
\hline Guanajuato & 1 & 0 & 1 & 0 & 1 & 1 & 1 \\
\hline Total & 65 & 296 & 74 & 52 & 100 & 55 & 73 \\
\hline
\end{tabular}

Fuente: Comercam. Cierre Ejercicio 2010. Tomado de cnspmm [2012].

${ }^{2}$ Algunos autores señalan que la palabra mezcal viene del náhuatl, significa maguey cocido y se elabora a partir de los tallos y bases de las hojas cocidas de dicha planta. 


\section{Cuadro 2. Consumo de agave y producción de mezcal $100 \%$ agave, $2011 *$}

\begin{tabular}{l|r|r|r}
\hline \multicolumn{1}{c|}{ Estado } & $\begin{array}{c}\text { Kilogramo } \\
\text { de agave } \\
\text { consumido }\end{array}$ & $\begin{array}{c}\text { Número } \\
\text { de piñas }\end{array}$ & $\begin{array}{c}\text { Volumen de } \\
\text { producción de mezcal } \\
\text { (litros) }\end{array}$ \\
\hline Oaxaca & 10207186.40 & 237409 & 1387260.70 \\
\hline Zacatecas & 1397465.90 & 38847 & 128932.50 \\
\hline Guerrero & 30193.00 & 650 & 3076.20 \\
\hline Durango & 7480.00 & 250 & 354.40 \\
\hline Guanajuato & 438.30 & 11 & 57.70 \\
\hline Total & 11542763.60 & 277167 & 1519681.60 \\
\hline
\end{tabular}

*Corresponde a 45\% vol. alcohol.

Fuente: Informe del Consejo Directivo del Consejo Mexicano Regulador de la Calidad del Mezcal, A.C. [Comercam, 2012].

Sus características agroclimáticas han favorecido la producción de agaves, conocidos comúnmente como magueyes y la producción del mezcal se encuentra en todo el territorio oaxaqueño, pero las zonas con el mayor inventario magueyero y gran producción de mezcal se ubican en la regiones de los Valles Centrales, en los distritos políticos de Tlacolula, Ejutla, Ocotlán, Zimatlán y en la sierra sur, en los distritos de Yautepec, Miahuatlán y Sola de Vega [Illsley et al., 2009: 23].

La cadena de producción del mezcal abarca cuatro eslabones: magueyeros (agricultores), palenqueros (destiladores), envasadores y comercializadores.

\section{MATERIA PRIMA: AGAVE}

La cadena productiva del mezcal inicia con la materia prima, el agave, que puede ser silvestre o cultivado de manera orgánica o bien utilizando químicos como herbicidas, fertilizantes y otros. En el primer eslabón intervienen los campesinos en el cultivo de maguey, se requiere cierto número de trabajadores para el cuidado del cultivo y cosecha [Jiménez y Pablo, 2011: 4]. 
Algunos productores de mezcal artesanal utilizan maguey silvestre o cultivado de manera orgánica y respetan el tiempo de maduración que necesita el maguey para ser utilizado en su elaboración.

En la producción del mezcal artesanal convergen técnicas prehispánicas y europeas a partir del conocimiento tácito de la variedad de agaves usados en ritos y ceremonias, complementándose con el proceso de destilación con alambique de cobre, traído por los europeos, el lugar donde se destila el mezcal se denomina palenque [Bautista, 2008: 13].

\section{PRODUCCIÓN INDUSTRIAL Y ARTESANAL DE MEZCAL}

El segundo eslabón de la producción de mezcal se realiza en los palenques [Jiménez y Pablo, 2011: 4], con la selección del maguey en los campos de cultivo y la jima de las pencas de maguey, se parten a la mitad las piñas de maguey para su traslado al palenque, donde otras personas tienen listo el horno, para cocerlas durante cinco días. Posteriormente, el maguey cocido se tritura mediante un mazo o con una rueda de piedra que es movida por un animal de carga, para luego colocarlo en barricas de madera para que se fermente, aproximadamente durante 10 a 15 días dependiendo del clima. Después, continúa el proceso de destilación, que se realiza en dos momentos; el primer líquido, que sale de la destilación es llamado por los mezcaleros "mezcal de punta" y tiene un alto grado de alcohol, mientras que lo último que sale es llamado "mezcal de cola" y tiene un menor grado de alcohol, de la mezcla de ambos obtienen un mezcal de alta calidad. ${ }^{3}$

Para Felipe González, ${ }^{4}$ el mezcal apenas empieza a ser apreciado, pues en general se encuentra devaluado, el consumidor lo

\footnotetext{
3 Información obtenida en julio de 2007 de la visita al palenque "La Concepción", en donde se elabora el mezcal tradicional Real Minero, y que se ubica en el municipio de Santa Catarina Minas, a siete kilómetros al sureste del distrito de Ocotlán, Oaxaca.

${ }^{4}$ Director comercial de Zignum, una marca de mezcal de la casa Armando Guillermo Prieto.
} 
considera por debajo en calidad y sabor con respecto al tequila [Aguirre, 2012: 3], en parte, porque mucha de la producción se realiza con métodos tradicionales. Cabe señalar que en este sector también hay unidades de producción que lo elaboran de forma industrial.

\section{Producción industrial}

En Oaxaca, las unidades económicas, en general, son micro-empresas. Un estudio realizado en la entidad señala que de 145107 unidades censadas, solo 107022 empleaban dos personas, mientras que 29160 ocupaban de tres a cinco, y se reportaron tres empresas que empleaban a más de 1000 personas [Jiménez y Pablo, 2011: 4-6].

Si se analiza la estructura de la industria conforme al número de empleos que generan y de acuerdo con la escasa información estadística disponible, se tienen seis grupos de empresas. ${ }^{5}$

\section{Cuadro 3. Personal ocupado en la industria del mezcal por tamaño de empresa 2009}

\begin{tabular}{l|c|c}
\hline $\begin{array}{c}\text { Tamaño de las empresas por } \\
\text { número de empleos }\end{array}$ & $\begin{array}{c}\text { Personal } \\
\text { ocupado total }\end{array}$ & $\begin{array}{c}\text { Personal } \\
\text { remunerado }\end{array}$ \\
\hline Total & 885 & 326 \\
\hline De 0 a 2 & 135 & 21 \\
\hline De 3 a 5 & 322 & 70 \\
\hline De 6 a 10 & 244 & 97 \\
\hline De 11 a 15 & 65 & 45 \\
\hline De 16 a 20 & 70 & 44 \\
\hline De 21 a 30 & 49 & 49 \\
\hline
\end{tabular}

Fuente: INEGI, censos económicos, 2009.

${ }^{5} \mathrm{La}$ información corresponde a los datos que proporciona el INEGI en su sistema de consulta de los censos económicos. 
La mayoría de las empresas de los dos primeros estratos son palenques pequeños y familiares que producen de manera artesanal, lo que explica la alta proporción de trabajadores no remunerados.

Considerando el volumen de producción anual se tienen cuatro grandes grupos de productores: pequeños, medianos, microindustriales e industriales [Pool-Illsley, 2004 e Illsley, 2010; 18]. ${ }^{6}$

Los pequeños y medianos productores de agave y de mezcal ${ }^{7}$ producen de 1000 a 10000 litros anuales, para el autoconsumo y la venta a granel. Algunos de ellos surten a los productores industriales de materia prima y de mezcal, que los últimos envasan y comercializan con su marca [Pool-Illsley e Illsley, 2010; 18].

\section{Producción artesanal}

La producción de mezcal se compone de dos tipos de unidades de producción: la artesanal tradicional y la que emplea agroquímicos y químicos.

El primer grupo de los productores pequeños tiene una organización de la producción básicamente familiar, elabora el mezcal de forma tradicional a partir del conocimiento tácito transmitido por sus antecesores, lo que hace de estos productos bebidas de alta calidad, pues se siguen estrictamente los pasos necesarios que la tradición ha probado para la elaboración de un mezcal sin alteraciones. Emplean agaves silvestres o cultivados de manera orgánica y realizan la fermentación de manera natural, sin aceleradores el contenido de alcohol es mayor a los 45 grados. El envase contiene la información sobre la especie de agave, la región de la materia prima, el nombre del "palenquero", la fecha y el volumen de la producción.

${ }^{6}$ Hay mayor información de la estructura productiva para este rubro, por lo que trabajamos con esta clasificación.

${ }^{7}$ Algunos se dedican a cultivar el maguey y otros además son productores de mezcal. 
Hay instituciones, investigadores y mezcaleros interesados en rescatar y valorar el mezcal, en especial el que se produce de manera tradicional, ya que estos productores cuidan cada una de las etapas de la cadena productiva del maguey-mezcal para producir uno bueno, han considerado la importancia de promover el mezcal artesanal, tradicional y orgánico con la finalidad de darle valor, como es el caso de Agustín Ochoa ${ }^{8}$ para quien: “... más que una bebida, el mezcal es un espíritu con su aroma ahumado y sus reflejos cítricos hacen que [se] le encuentre sabor a los pueblos, al maestro mezcalero, a las ollas de destilación y a la tierra".

El otro sector que elabora de manera artesanal o tradicional el mezcal es el que cultiva el maguey utilizando fertilizantes y herbicidas, además de aceleradores para reducir los días de fermentación, así pues, no todo el mezcal artesanal se produce cuidando el medioambiente.

Las empresas productoras de mezcal artesanal enfrentan una competencia desigual al no contar con capital suficiente o financiamiento [Jiménez y Pablo, 2011: 2], ya que son de producción familiar y, por ende, emplean pocas personas, su tecnología es básica, sus cultivos generalmente no están certificados, pues el costo de la certificación es muy alto y no cuentan con los recursos económicos, técnicos, ni con la información necesaria para llevarla a cabo. Los pequeños productores que han logrado certificarse, lo han conseguido por intermediarios y productores extraterritoriales con mayor capital económico y posibilidades de producción industrial, los cuales han llevado a cabo el proceso burocrático de la certificación y cubren los costos. La regulación ha fortalecido el papel de estos intermediarios para la venta legal y exportación del mezcal [Aguirre, 2012: 5].

La industria del mezcal, como ya se ha señalado, se ubica en distintos niveles. Están las microempresas, con dos trabajadores cada una, que asumen $12 \%$ del total de la producción, y otras empresas con inversión muy pequeña, que ocupan hasta cuatro trabajadores y en conjunto cubren $88 \%$ restante, pero producen

${ }^{8}$ Mixólogo mexicano formado en la costa Este de Estados Unidos. 
hasta 25000 litros de mezcal, siendo pocas las empresas que superan este volumen [Jiménez y Pablo, 2011: 4-6]. Los productores comercializan el mezcal en el mercado de Oaxaca, algunos cuentan con marcas registradas y certificación del Consejo Mexicano Regulador de la Calidad del Mezcal (Comercam) y otros con permisos para exportar parte de su producción a Estados Unidos, Europa y Asia. Otra parte, lo distribuyen en cavas, expendios, restaurantes y bares propios, en la ciudad de Oaxaca o en el Distrito Federal [Pool-Illsley e IIIsley, 2010: 18].

Las grandes empresas industriales tienen una producción superior a los 100000 litros anuales, cuentan con recursos económicos, capacidad organizativa, redes sociales que facilitan la comercialización, acceso a beneficios (programas de fomento, apoyos y subsidios), una escala de producción que reduce los costos y riesgos de exportar y de certificar; y concentran los beneficios de la venta nacional y de la exportación [Pool-Illsley e Illsley, 2010: 19].

El mezcal industrializado es producido con tecnología avanzada, maquinaria, equipo y personal calificado, como ingenieros químicos, quienes controlan la calidad de la producción de agave y mezcal, para que el destilado cumpla con las normas mexicanas de calidad. Estas empresas se apoyan en una gran infraestructura, lo que hace que el volumen de su producción sea mayor, lo mismo que su acceso a financiamientos. Además, no solo producen mezcal con los magueyes de cultivo propio, también le compran la materia prima a otros productores que cultivan el maguey o bien adquieren el mezcal para luego envasarlo con su marca.

\section{LA INVERSIÓN PRIVADA Y PÚBLICA}

EN LAS EMPRESAS PRODUCTORAS DE MEZCAL

Un estudio señala que los productores del mezcal industrializado se agrupan en clústeres, la mayor parte se ubican alrededor de Santiago Matatlán, en el valle de Tlacolula y dominan los mercados de Oaxaca y el país, cuentan con capacidad organizativa, 
redes sociales que facilitan la comercialización y el acceso a programas de fomento, apoyos y subsidios, es decir, se benefician de fondos y políticas de promoción del mezcal, programas para pequeñas y medianas empresas, como la feria anual del mezcal ${ }^{9} \mathrm{y}$ otras que se realizan local, nacional e internacionalmente. Además, reciben apoyo gubernamental para la exportación; 40 de estas empresas participaron con la Secretaría de Economía de Oaxaca en un recorrido de promoción en California, Estados Unidos. Su volumen de producción reduce los costos de certificación y de exportación, tienen mayores recursos económicos e influyen en las decisiones de la Comisión Reguladora del Mezcal [PoolIllsley e Illsley, 2010: 18-19].

De las empresas mezcaleras industrializadas, destaca en primer lugar la empresa productora de mezcal Benevá, ${ }^{10}$ la cual para 2006 tenía aproximadamente 200 trabajadores directos y unos 1500 indirectos, además de ocho personas en la administración que se encargaban de la contabilidad, del personal, de la exportación, de la promoción, de los insumos y de la logística. Ha desarrollado seis variedades de mezcales. Como parte de las actividades de promoción, en 1991 participó en ferias nacionales, en 1992 incursionó en ferias internacionales con apoyo del Banco Nacional de Comercio Exterior, en 1993 recibió un reconocimiento por exportar a Alemania, España, Francia, Escocia y Estados Unidos, para 1994 estaba enviando 1200 cajas de mezcal a Taiwán y para 2007, contaba con 15 palenques propios y otros tantos de maquila que generaban 60000 litros de mezcal mensualmente, con un cultivo de alrededor de 800 hactáreas de magueyes en los distritos de Tlacolula, San Carlos Yautepec, Ejutla Miahuatlán y Sola de Vega [Núñez, 2006; 1]. De acuerdo a la Cámara Nacional del Mezcal, la empresa Benevá cuenta con $20 \%$ de la producción del estado.

Con respecto a su exportación, no la lleva a cabo directamente, es por medio de un distribuidor, el cual se encarga de colocar

${ }^{9}$ Se realiza cada año desde 1997.

${ }^{10}$ En 1990, don Pedro Mateo López, originario de Santiago Matatlán, con dos amigos iniciaron una cooperativa y crearon la marca Benevá [Lopes, 2007]. 
el producto. Desde 2007 cuenta con una moderna fábrica con dos naves industriales de tecnología de punta. Ha obtenido apoyos del Programa Marcha Hacia el Sur (PMHS) de la Secretaría de Economía por un monto de 375000 pesos, otorgado en marzo de 2006 con el compromiso de generar 25 empleos. La marca tiene registro en México, Europa, China y Estados Unidos [Lopes, 2007].

Otra de las empresas de mezcal que destaca es la Casa Armando Guillermo Prieto (Casa AGP), de reciente creación, por una alianza entre las casas productoras Señorío y Zignum, ${ }^{11} \mathrm{e}$ inaugurada en agosto de 2008 [Aguirre, 2012: 3], en Lanacci, Oaxaca, con una inversión entre 48 y 60 millones de dólares en la construcción de la fábrica. Su meta de producción era de 15000 litros por día y para 2010 llegó a 20000 litros al día, lo que significa que dicha empresa cuenta con tecnología [Davies y Fish, 2010: 1-2; Aguirre, 2012: 3] y con amplios recursos económicos [Pool-Illsley e IIIsley, 2010: 19] para producir tal cantidad diaria. De reciente creación es Cha cha chá, de los inversionistas Ilan Bielak y Alan Zeichner, quienes en 2007 invirtieron 250000 dólares para crear su propia marca con la idea de convertir a Santiago Matatlán en la capital mundial del mezcal; compran 3000 litros mensuales a los artesanos, pretendiendo posicionar su marca en 60 restaurantes del Distrito Federal [Aguirre, 2012: 4].

También destaca el mezcal Sinai, bebida orgánica, premiada con dos primeros lugares, como "la mejor bebida reposada" y "el mejor mezcal", de acuerdo con "San Francisco World Spirits Competition en 2011", de la Unión de Productores de Maguey y Mezcal de San Dionisio Ocotepec, Oaxaca, empresa social que agrupa a 10 socios, genera 11 empleos, ha recibido apoyo del gobierno federal mediante el Fondo Nacional de Apoyo para Empresas en Solidaridad (Fonaes) y la Secretaría de Agricultura, Ganadería, Desarrollo Rural, Pesca y Alimentación [Sagarpa], con lo cual ha realizado cambios para hacer más eficientes los procesos productivos. Actualmente tiene tres destiladoras, que

11 De la planta procesadora de propiedad de Purita Rivera, heredera de Cimsa, la distribuidora de refrescos más fuerte en el sureste mexicano. 
producen más de 10000 litros mensuales. El representante de la empresa, Ignacio Martínez García, comenta: “Antes éramos simplemente productores, vendíamos a granel y otras personas lo envasaban por nosotros y lo revendían. Ahora somos nosotros los que producimos el mezcal, lo envasamos y lo vendemos”, además de que realizan ventas a Canadá.

Así, aun cuando en los últimos años se han multiplicado las marcas de mezcal de empresarios mexicanos - de cinco que había en 2005 a más de 150 a la fecha-, Benevá y otra de las marcas destacada de mezcal oaxaqueño, Zigmun, suman $10 \%$ de la producciónb total de las 150 marcas que integran el padrón de productores del Comercam, sin embargo, su capacidad instalada es de 600000 litros anuales, $80 \%$ de su producción la exportan y el resto la comercializan en el país. Para Zeiner, en unos 10 años habrá muchas marcas de mezcales [Aguirre, 2012: 5], lo que significa que el mercado tendrá una gran competencia, claro que el poder adquisitivo es determinante para acceder a una bebida de mejor calidad. Por ello encontramos en el estado de Oaxaca a productores de mezcal cuyo volumen de producción anual apenas es de 1000 a 10000 litros por año y, por otro lado, a empresas con una capacidad instalada de 600000 litros anuales [Aguirre, 2012: 5].

El primer foro estatal de la Cadena Productiva de MagueyMezcal de Oaxaca concluyó que la filosofía de trabajo de los magueyeros, no es "productivista", más bien tiende a ser "conservacionista” [Jiménez y Pablo, 2011: 6]. Pero esta no es la generalidad, hay quienes no solo son "productivistas" sino también competitivas y para serlo han dejado de conservar los recursos naturales.

\section{COMERCIALIZACIÓN DEL DESTILADO}

El cuarto eslabón de la producción del mezcal corresponde a la comercialización del destilado [Jiménez y Pablo, 2011: 4]; algunas empresas compran el destilado a pequeños productores, lo 
envasan y comercializan en el mercado local, nacional e internacional, respetando la norma oficial mexicana; este es el eslabón que proporciona más empleos en las comunidades [Jiménez y Pablo, 2011: 4]. Para algunos productores artesanales no es fácil incorporarse a todas las etapas del proceso de producción y distribución, debido a su poca capacidad organizativa, económica y tecnológica.

Para los productores expertos en mezcal, un buen producto es aquel que tiene más de 45 grados de alcohol, existiendo productos con más de 70 grados. De ahí la importancia de la información que debe contener la etiqueta de la botella: de dónde proviene la materia prima y cómo está cultivada, el proceso de elaboración y quién lo elaboró, todo eso dará certeza al consumidor y estimulará el interés por visitar los lugares en donde se produce y observar el proceso de elaboración de lo que está consumiendo.

En la ciudad de Oaxaca se observan expendios en los que se comercializa el mezcal a precios bajos y a granel, el cual es revendido en las localidades rurales. No todos los mezcales son de buena calidad, los de bajo precio, generalmente, son bebidas adulteradas y muchos consumidores ignoran que lo que ingieren no es mezcal, lo seleccionan por el bajo costo, lo que significa que en estas poblaciones rurales no tienen acceso en realidad al mezcal sino a una bebida adulterada [Noticiasnet.mx, 2012: 1].

Como lo señala Prisciliano Espinoza Rojas, ${ }^{12}$ algunos mezcales sufren procesos de adulteración que los consumidores no perciben y se comercializan entre 15 y 20 pesos el litro, en tanto que el destilado $100 \%$ natural oscila entre 100 y 200 pesos el litro, en ocasiones alcanzan precios más altos. Debe ser una bebida de buena calidad cuando se exporta, seguramente habrán mezcales de alta y baja calidad: habría que ver de qué depende, si de la materia prima o del proceso de elaboración, por otro lado, también sería interesante investigar si ha habido acciones gubernamentales para impulsar el desarrollo de las empresas mezcaleras oaxaqueñas.

${ }^{12}$ Presidente del Comité Regional de Recursos Naturales de la Zona Centro (Correnac) de Huajuapan de León, Oaxaca. 
La promoción de cursos y degustaciones ha permitido que el consumidor esté cada vez más informado, por lo tanto, no consumirá un mezcal de calidad inferior aún cuando el precio sea bajo, como lo señala Alan Zeichner [Aguirre, 2012: 5], lo cual está relacionado con la información que haya adquirido por medio de las degustaciones que se hacen en exclusivos lugares, lo que le daría el conocimiento sobre los mezcales. ${ }^{13}$

De acuerdo con algunos autores, en 2004 comenzó a despegar la comercialización del mezcal en Estados Unidos y, casi al mismo tiempo, se daba la apertura en la Ciudad de México de una docena de locales dedicados a la venta de este producto en zonas residenciales de ingresos altos como Polanco y La Condesa. Para finales de la primera década del siglo XxI, el mezcal ya era una bebida apreciada entre consumidores que conforman los grupos de mixólogos, con conocimientos sobre características de los agaves, los antecedentes de la bebida, los procesos de producción y calidades del mezcal [Aguirre, 2012: 2].

\section{Cuadro 4. Exportaciones de mezcal, 2009-2011}

\begin{tabular}{c|c|c|c}
\hline \multicolumn{1}{c|}{ Concepto } & 2009 & 2010 & 2011 \\
\hline Litros [38\% alcohol vol.] & 414607.67 & 610685.20 & 647988.99 \\
\hline Variación/año anterior & N.D. & $47.29 \%$ & $6.1 \%$ \\
\hline
\end{tabular}

Fuente: Informe del Consejo Directivo del Consejo Mexicano Regulador de la Calidad del Mezcal, A. C. [Comercam, 2012].

${ }^{13}$ En 2007 tuve la oportunidad de asistir a un curso sobre mezcales tradicionales y ahí me enteré de que hay una variedad de mezcales en la República mexicana, cuyo sabor y aroma están íntimamente ligados al tipo de vegetación y al proceso de elaboración, así como el grado de alcohol que debe contener un buen mezcal. "Curso-taller: Los mezcales tradicionales de los pueblos de México”, del 21 al 25 de mayo de 2007, impartido por Cornelio Pérez, en la Vicerrectoría de Educación Continua, Programa de Extensión Universitaria, Universidad del Claustro de Sor Juana.) 


\section{LA DENOMINACIÓN DE ORIGEN,}

\section{LAS REGULACIONES Y ACCIONES GUBERNAMENTALES}

Tener la certificación y pertenecer a la Comercam les permitiría a los productores de mezcal artesanal, participar en la toma de decisiones y acceder a los fondos públicos disponibles para el sector, generalmente quienes tienen los recursos económicos son líderes locales y regionales con amplias redes sociales y capacidad de movilización. En 2009 la Secretaría de Economía del estado de Oaxaca informó que en 2005 entregó un fondo de más de 126 millones de pesos a 764 productores, en 2006 más de 68.5 millones a 117 productores y en 2008 poco más de 200 millones de pesos a 110 productores [Pool-Illsley 2004 e Illsley, 2010: 25].

De acuerdo con Juan Carlos Segundo, director general del Comercam, la Secretaría de Agricultura tiene programas de certificación, misiones comerciales por medio de ProMéxico y proyectos de promoción con el programa Apoyos y Servicios a la Comercialización Agropecuaria (Aserca), pero hace falta capacitación para que los productores puedan acceder a estos programas, lo cual no es una tarea fácil porque se enfrentan a factores como la falta de tecnología para modificar los palenques, de infraestructura, de conocimientos administrativos y la poca preparación de los dueños del palenque para fortalecer su pequeña empresa rural, así como factores culturales de las familias. Además, aún cuando el Instituto de Capacitación y Productividad para el Trabajo del Estado de Oaxaca puede ofrecer cursos de capacitación en estas áreas, con frecuencia las empresas artesanales del mezcal no tienen información de ello o carecen del tiempo para capacitarse [Jiménez y Pablo, 2011: 6]. Asimismo, señala que en Oaxaca trabajan 115 productores certificados, pero la falta de recursos económicos, como de conocimientos de los procesos para poder tener acceso a los fondos de los programas ha obligado a algunos productores a abandonar la actividad [Aguirre, 2012:3].

El tequila, el mezcal y el bacanora se elaboran de agave, sin embargo, no son los únicos mezcales, hay muchas especies, pero 
estas tres son las que cuentan con una declaratoria de denominación de Origen (DO), en el caso de la del Mezcal, ${ }^{14}$ solo protege a cinco especies en siete estados de la República [Colunga, 2012: 1]: Oaxaca, Guerrero, Hidalgo, Zacatecas, Durango, San Luis Potosí y Tamaulipas [Bautista, 2008: 10-11; Illsley et al., 2009: 20], excluyendo el resto de los estados, en donde también se encuentra el agave mezcalero. La palabra agave no es un signo distintivo de las bebidas bajo DO, es un término científico que designa al grupo de plantas que en español mexicano se llaman magueyes.

Hay alrededor de 200 especies, de estas más o menos 39 se utilizan para la elaboración del mezcal tradicional, las cuales se encuentran en 24 entidades del país, por lo menos desde hace 400 años. Para otros autores, 39 especies se localizan en 26 entidades de la República mexicana [Colunga, 2012: 1].

Poco se conoce sobre la relación entre la producción del mezcal y las acciones gubernamentales para fomentar o potenciar el desarrollo de su producción, quizá porque es común pensarla como un proceso artesanal, de bajo estatus en calidad, consumo y valor. Esta situación refleja el desconocimiento de la importancia de esta industria para el país y de la alta calidad que tienen los mezcales tradicionales, tanto es así, que hay autores que comparan el mezcal producido de manera artesanal con el coñac.

Así, no se cuenta con una política nacional para atender a los productores de mezcal de manera integral, en la que se incluya a todas las regiones mezcaleras del país, o una DO que abarque la diversidad los agaves mezcaleros, para que los pequeños productores tengan la posibilidad de aprovechar este recurso si así lo desean.

Hay una serie actividades en materia de política para el desarrollo de la industria del mezcal: desde las privadas, que invierten millones de dólares en infraestructura, en gestiones y comercialización, lo que les ha permitido posicionar el mezcal en los mercados nacional e internacional, hasta las instituciones públicas que han elaborado una serie de programas de financiamiento y

${ }^{14}$ La Denominación de Origen del Mezcal fue emitida por el Instituto Mexicano para la Propiedad Industrial [IMPI] en 1997, modificada en 2003 [Illsley et al., 2009: 20]. 
ferias para promover el mezcal. Sin embargo, es necesario conocer los procedimientos para acceder a los apoyos, y en muchas ocasiones los pequeños productores, que son la gran mayoría, desconocen los procesos, mismos que suelen ser burocráticos. Los apoyos terminan beneficiando únicamente a las empresas con capacidad instalada, las industrializadas.

Muchas de las empresas de producción artesanal quedan excluidas de los financiamientos, pues hay una ausencia de acciones gubernamentales para ofrecer apoyos reales a las micro empresas. Los productores de mezcal requieren que se preserva la producción artesanal y los conocimientos tradicionales, también que se impulse el desarrollo de los pequeños productores en la entidad, ya que al no contar con los recursos suficientes terminan abandonando la actividad por la falta de capacidad para mantenerse en el mercado y por lo tanto, terminan vendiendo su producto a muy bajo precio a empresas que a la larga son las que obtienen mayores beneficios.

Hay propuestas como la de la Comisión Nacional para el Conocimiento y Uso de la Biodiversidad (Conabio), que plantea la necesidad de actualizar la información taxonómica, sistemática y biogeográfica de los agaves, la caracterización de la diversidad genética y la documentación de procesos comunitarios de conservación y desarrollo [Larson y Neyra, 2004: 6]. Dicha instancia ha reunido toda la información existente y ha realizado investigación original sobre los mezcales mexicanos, sentando con ello las bases para un sistema de indicador geográfico (IG) en función de la diversidad de mezcales y territorios [Illsley et al., 2009: 23]. Para la Conabio, la investigación básica y la comprensión de su relación con los procesos sociales de apropiación pueden apoyar el diseño de políticas públicas que promuevan la diversidad: muchos magueyes, muchos mezcales, muchas regiones [Larson y Neyra, 2004: 6]. Sus resultados y propuestas no han sido incorporados en la legislación [Illsley et al., 2009: 23]. 


\section{Conclusiones}

La elaboración del mezcal en el estado de Oaxaca es una de las actividades más importantes del sector manufacturero de la entidad, con frecuencia la principal entrada de recursos económicos para las regiones productoras.

La mayoría de las unidades de producción son microempresas que deben enfrentarse en el mercado con el estrato poco numeroso de empresas grandes, las cuales producen a menor costo, cuentan con recursos económicos, y redes sociales para obtener apoyos financieros, y tienen la capacidad tecnológica y capital humano para acceder al mercado exterior e incluso incidir en las políticas y normas aplicadas por el Estado.

En México la DO del mezcal debe incluir a las regiones y entidades federativas que se dejaron fuera, es necesaria una norma que proteja la diversidad de agaves como parte de nuestra diversidad biológica y riqueza cultural, hay que protegerla, como el maíz, frente a otros, y se requiere de una política incluyente.

Asimismo, es muy importante que las instituciones encargadas de apoyar a este sector diseñen programas accesibles para las microempresas, adecuados a estas, como es el acompañamiento y apoyos financieros para poder certificarse, asesoría sobre los procedimientos para acceder a los apoyos financieros que otorgan las instituciones gubernamentales y capacitación para la administración y mejora de los procesos.

Una política de fomento a lo largo de la cadena productiva es importante, pues las empresas grandes, además de contar con los recursos económicos para invertir en tecnología, capacidad instalada y redes sociales para conseguir los apoyos son las que se benefician, compran el agave o el mezcal a precios muy bajos, el cual envasan con su propia marca, de modo que no hay derrama económica ni encadenamientos productivos que permitan la generación de empleos directos e indirectos que pudieran repercutir en el desarrollo local en los estados productores. 


\section{REFERENCIAS}

Aguirre, A. [2012], "Detrás de la 'mezcalmanía'. El mezcal podría contribuir a que las bebidas de agave acaparen 10\% del mercado mundial de licores", en Poder $360^{\circ}$, <http://www. poder360.com/article_detail.php?id_article $=6494 \& p a g=1>$, 28 de noviembre.

Bautista, J. A. [2008], "Estrategias de producción y mercadotecnia del mezcal en Oaxaca", en El Cotidiano, Distrito Federal, México, Universidad Autónoma Metropolitana-Azcapotzalco, 23(148): 113-122, marzo-abril.

y J. Ramírez J. [2005], "Sostenibilidad y pobreza en las unidades socioeconómicas campesinas de la región del mezcal en Oaxaca", Wences Reza et al., (coord.), Problemática territorial y ambiental en el desarrollo regional, México, D.F., Asociación Mexicana de Ciencias para el Desarrollo Regional/ Universidad Autónoma de Guerrero, 519 pp.

[2008], "Agricultura y pluriactividad de los pequeños productores de agave en la región del mezcal, Oaxaca", en Agricultura Técnica en México, México, 34(4): 443-451, octubre-diciembre.

Calvillo, A. [2012], "En defensa del mezcal frente a los ataques tequileros", Los Especialistas, Sin Embargo, mayo 7, <http:// www.sinembargo.mx/opinion/07-05-2012/6767>, 27 de noviembre.

CNSPMM [2012], "Integración de la Cadena Productiva Maguey Mezcal de México, A.C. Durango, Guerrero, Oaxaca, Tamaulipas, San Felipe Guanajuato, San Luis Potosí, Zacatecas. Plan anual de fortalecimiento 2012", <http://www.sientemezcal.com/docs/Plan_anual_de_fortalecimiento_2012.pdf >, 25 de enero 2013.

Colunga, P. [2012], "La desaparición delos mezcales artesanales tradicionales", Opinión, La Jornada, México, 21 de enero, <http:// www.jornada.unam.mx/2012/01/21/opinion/021a2pol>, 21 de agosto. 
Comercam [2012], "Informe del Consejo Directivo del Consejo Mexicano Regulador de la Calidad del Mezcal A.C.”, abril 2009-abril 2012, disponible en: <http://www.comercam.org/ files/INFORMEANUA2009-2012.pdf>, 22 de noviembre.

Davies, N., y E. Fish [2010], "Coca-Cola incursiona en la industria del mezcal. La agro-industria absorbe la tierra y agua de Oaxaca para las ganancias privadas. Los tanques de acero inoxidable remplazan lo artesanal", en Narco News, 15 de febrero, <http://www.narconews.com/Issue64/articulo4045. html>, 22 de noviembre de 2012.

Illsley, C. [2004], "El mezcal papalote del Chilapan: una marca colectiva campesina", <http://www.raises.org/PFNM-documentos.htm>, 27 de junio de 2012.

Illsley, C. et al. [2004], "Manual de manejo campesino de magueyes mezcaleros silvestres", México, Grupo de Estudios Ambientales A.C., pp. 89-103.

Illsley, C., D. Giovannucci y C. Bautista [2009], "La dinámica territorial de la zona mezcalera de Oaxaca entre la cultura y el comercio", Grupo de Estudios Ambientales A.C./Territorios con Identidad Cultural/Dinámicas Territoriales Rurales, <ttp://www.rimisp.org/FCKeditor/UserFiles/File/documentos/docs/pdf/DTR-IC/Propuestamexicoparalawebconlogos. pdf>, 19 de abril de 2012 .

Instituto Nacional de Estadística y Geografía [2009], Censo Económico, México, INEGI.

Jiménez, Ma., y K. A. Pablo [2011], "La microindustria del mezcal y el empleo en Oaxaca”, $16^{\circ}$ Encuentro Nacional sobre Desarrollo Regional en México, Amecider/Universidad veracruzana-Campus Xalapa, 18 al 21 de octubre.

Larson, J., y L. Neyra [2004], "Programa Recursos Biológicos Colectivos", Boletín bimestral de la Comisión Nacional para el Conocimiento y uso de la Biodiversidad, México, (53), marzo.

Lopes, Ma. E. [2007], "Industrias de alimento y bebidas oaxaqueñas”, proyecto PAPIIT (IN306406), Análisis de casos de gestión de la innovación en empresas mexicanas innovadoras 2006-2007, IIEc y Ccadet-UNAM. 
Noticiasnet.mx [2011], "Instalar consejo regional del mezcal, reto. Sueñan mixtecos con fábricas mezcaleras", <http://www.noticiasnet.mx/portal/principal $/ 94532$-sue $\% \mathrm{C} 3 \% \mathrm{~B} 1$ an-mixtecos-f\%C3\%A1bricas-mezcaleras>, 27 de agosto de 2012.

Núñez, Abundio [2006], "Mezcal Benevá, de lo artesanal a la industrialización”, El Financiero, 6 de marzo.

Pool-Illsley, E., y C. Illsley [2010], "La dinámica territorial de la zona mezcalera de Tlacolula-Ocotlán en Valles Centrales de Oaxaca: entre la cultura y el comercio", Desarrollo Territorial Rural con Identidad Cultural, RIMISP-GEA, https:// www.myctb.org/wst/rimisp/comunidadDTR/taller-coordinadores/taller-santiago-2010/Documentos\%20compartidos/ GRUPO\%204/Mexico\%20-\%20Oaxaca.pdf, 20 de agosto de 2012.

Ramales, M. C. [2004], "La industria manufacturera dentro de la estructura y la dinámica de la economía oaxaqueña", <http:// www.eumed.net/cursecon/ecolat/mx/2004/mro-oax.pdf >, 17 de mayo de 2012. 


\title{
Capítulo 10 \\ Políticas PÚBlicas PARA EL DESARROLLO DE LA INNOVACIÓN Y LA COMPETITIVIDAD DE LA INDUSTRIA MANUFACTURERA
}

\begin{abstract}
Gerardo González Chávez,* Melissa Said Gayosso,** Yarel Esparza García,*** Óscar Alejandro Gómez Romero****
\end{abstract}

\section{INTRODUCCIÓN}

El establecimiento del modelo de acumulación neoliberal, con su fundamentalismo del mercado como mecanismo de solución de los problemas económicos, es contradictorio en sus planteamientos y en la relación entre los países, ya que a las economías subdesarrolladas se les impone la liberalización de sus mercados a los productos de sus empresas trasnacionales y se sugiere el alejamiento del Estado de la actividad económica, evitar los subsidios y la protección de su industria, entre otras medidas, en tanto que los países desarrollados mantienen la participación estatal directa con firmes barreras arancelarias proteccionistas y les proporcionan grandes subsidios públicos a la industria, entre otras políticas que fortalecen su competencia. En estas economías se da una participación creciente del Estado en la gestión

* Académico del iIEc-unam. Coordinador del proyecto de investigación PapitT IN305610. Correo: <gerardog@unam.mx>.

** Participante en el proyecto PAPIT IN305610. Correo: <melissagayosso@gmail.com>. *** Participante en el proyecto PAPIIT IN305610. Correo: < bebeyarel@hotmail.com>.

***** Participante en el proyecto PAPIIT IN305610. Correo: <alexgomez romero@ hotmail.com>. 
económica. Así, se rechaza toda acción pública para los otros, pero se estimula el traslado de recursos sociales hacia la acumulación de las grandes empresas por medio de la participación estatal.

La política liberal critica y sataniza al Estado como interventor o participante directo de la gestión económica y le exige redistribuir el gasto público en lo social, la privatización y descentralización de los servicios de salud y seguridad se confrontan con la necesidad de rescatar las empresas para capitalizarlas y luego nuevamente venderlas. Sin embargo, los ideólogos del sistema hacen a un lado estos principios y claman la ayuda pública para salir de la crisis. Le reclaman al Estado más apoyo para enfrentar la competencia, mayor compensación ante el ajuste, etcétera.

De un lado está el lento crecimiento, o de plano el estancamiento, de la mayoría de las empresas que no se han podido enganchar a la apertura externa o que fueron severamente afectadas por la forma en que esta apertura tuvo lugar, y del otro, el apoyo a las grandes empresas que controlan el mercado mundial. En estas economías, el gobierno desempeñó un papel activo, no solo en la promoción de la educación, el ahorro y en la redistribución de la renta, sino en la tecnología avanzada [Stiglitz, 2004: 276].

La doble moral del liberalismo queda descubierta cuando estalla la crisis y el mercado por sí mismo no puede resolver los problemas. Los ideólogos del Estado neoliberal buscan la estabilidad en la acumulación capitalista por medio de la intervención estatal, en contra de sus propios principios que dicen defender, se despliegan planes de inversión en diversos aspectos a los que antes se oponían, tales como el impulso de la infraestructura, el fomento a la investigación y al desarrollo de las universidades, los centros de capacitación, la organización para la investigación y demandan el rescate de las instituciones financieras para lograr la estabilidad del sistema.

En este apartado se analiza el contraste entre los países que siguieron las exigencias de los organismos financieros internacionales y aquellos que se alejaron de esas políticas públicas, lo cual tiene efectos en el desarrollo de la innovación y la competitividad de la industria manufacturera de cada país. 


\section{EL PAPEL DEL ESTADO LIBERAL EN LA ECONOMÍA}

Como ya fue señalado en apartados anteriores de este libro, el modelo neoliberal en México se aplicó desde mediados de la década de los ochenta mediante la transformación del modelo de industrialización sustitutiva de importaciones (ISI) con un Estado intervencionista que había funcionado durante varias décadas, por otro, que coloca al mercado como la solución de la crisis económica la cual se vio agravada por lo que se conoció como la crisis de la deuda.

Esta etapa se llamó la "década perdida” y llevó a que los países de la región se vieran obligados a buscar una salida al complejo escollo a partir de la adopción de los lineamientos concebidos en el "Consenso de Washington”. En ese sentido, a medida que en la región se fueron consolidando los programas de apertura externa de las economías, la desregulación de múltiples mercados y la privatización de grandes sectores de actividad industrial (previamente dominados por empresas estatales), se abrió una nueva etapa en el ingreso de capitales extranjeros. El modelo económico de la década de los noventa, basado en la tríada desregulación, apertura y privatización, tuvo un notable éxito en materia de atracción de capitales extranjeros. En este marco, gran parte de los capitales que ingresaron a la región fueron destinados a la compra de empresas públicas [Bianco et al., 2012: 217].

A los países dependientes se les obligó a cumplir al pie de la letra los principios liberales definidos por las instituciones financieras internacionales que: ${ }^{1}$

${ }^{1}$ Los propios empresarios que se vieron afectados por este proceso señalan que para que exista una verdadera política industrial activa deben converger: la intención estatal de reconocer explícitamente que, mediante la acción espontánea de las fuerzas del mercado, no se alcanzará el nivel de calidad, fortaleza tecnológica y oportunidad que demanda el comercio internacional de los bienes y servicios nacionales, así como la puesta en marcha de mecanismos financieros y fiscales acordes con los que utilizan nuestros principales socios comerciales, al mismo tiempo que las cámaras emprendan una intensa campaña de reestructuración de su organización, acciones y servicios [Mújica, 1997: 344 ]. 
Los gobiernos neoliberales han aplicado con fuerza creciente la reforma de la protección social, debilitando primero el presupuesto de sus instituciones, privatizando los servicios de mantenimiento, limpieza, preparación de alimentos, etc., instituyendo cuotas de recuperación en los servicios médicos asistenciales, promoviendo seguros de salud privados, complementarios a los servicios médicos del Instituto de Seguridad y Servicios Sociales de los Trabajadores del Estado (ISSSTE) y, recientemente, privatizando las pensiones a cargo del IMSS, así como preparando el camino para la privatización de los servicios médicos de la seguridad social [Rueda, 2009: 99].

En este sentido también destacan las políticas de flexibilidad laboral impulsada con mayor fuerza a partir de la firma del Tratado de Libre Comercio de América del Norte (TLCAN). Es importante subrayar que estos principios del liberalismo económico o el evangelio de la globalización y de la competencia global se hicieron para los "otros", porque en el caso de las principales potencias económicas no fueron aplicados y la actividad del Estado en el fomento y protección de su economía se mantuvo y fortaleció como forma de controlar su mercado interno, además de establecer toda una serie de barreras no arancelarias que protegen a sus empresas. ${ }^{2}$

Uno de los principales críticos de esta situación señala que:

La ideología del libre mercado resultó ser una excusa para nuevas formas de explotación. "Privatización" significó que los extranjeros pudieran comprar minas y campos petrolíferos en los países en desarrollo a bajo precio. También significó que pudieran embolsarse enormes beneficios de monopolios o casi monopolios como ocurrió en las telecomunicaciones. "Liberalización del mercado financiero y de capitales" significó que los bancos extranjeros pudieran obtener retornos altísimos por sus créditos, y cuando los créditos iban mal, que el Fondo Monetario Internacional (FMI) obligase a socializar las pérdidas, apretando las clavijas de poblaciones enteras para devolver los préstamos a los bancos extranjeros. [...] La

${ }^{2}$ Joseph E. Stiglitz y otros autores hacen un análisis crítico de este problema [Stiglitz, 2002: 17, 33 y 46; 2004: 252; 2006: 121-122; 2010: 76; y Cordera, 2011: 14]. 
liberalización del comercio significó también que las empresas extranjeras pudieran borrar del mapa industrias nacientes, impidiendo que se desarrollase el talento emprendedor. Mientras que el capital circulaba libremente, los trabajadores no lo hacían, excepto en el caso de los individuos más talentosos, muchos de los cuales encontraron empleo en el mercado global [Stiglitz, 2010: 266].

En este sentido, la liberalización del comercio sirvió solo para que las grandes empresas trasnacionales expandieran sus mercados hacia los países más débiles y pobres.

La globalización ha significado una prosperidad sin precedentes para las grandes empresas trasnacionales y la mayoría de los países:

... exitosos se desarrollaron a la sombra de barreras proteccionistas; algunos críticos de la globalización acusan a países como Japón y Estados Unidos, que han trepado por la escalera del desarrollo, de querer derribar esta escalera para que otros no puedan seguir el mismo camino [Stiglitz, 2006: 82, 105].

Uno de los temas esenciales en este proceso es la política de los subsidios para el desarrollo de la industria y el sector agrícola como uno de los factores más importantes para la competitividad internacional, en tanto los países dependientes los retiraban.

... Estados Unidos los duplicó en 2002: la agricultura recibía subsidios de miles de millones de dólares cada año. En 2006, 27000 granjeros acomodados productores de algodón se repartieron 2400 millones de dólares a través de un programa que violaba las leyes del comercio internacional y perjudicaba a millones de campesinos pobres de África, América del Sur e India. Había otros sectores subvencionados, algunos solo hasta cierto punto, otros de forma masiva, otros abiertamente, otros de forma encubierta a través de la fiscalidad [Stiglitz, 2010: 244].

Los acuerdos de liberalización comercial sostenían que no había que permitir que los países en desarrollo subvencionaran sus industrias nacientes, en tanto se buscaban los argumentos para justificar las: 
... subvenciones masivas a la industria del etanol a partir del maíz, que se introdujeron en 1978, con el argumento de que se trataba de una "industria naciente" y de que las ayudas serían temporales, hasta que pudiera competir por sus propios medios. Pero el recién nacido se negó a hacerse mayor [Stiglitz, 2010: 244].

Las políticas públicas de apoyo al sector industrial fueron claramente intervencionistas y se contraponen a los principios ideológicos que se manejaban en el contexto internacional, por lo que:

No es de extrañar que la gente de los países en desarrollo cada vez se convenciera más de que la ayuda occidental no tenía motivaciones altruistas. Sospecharon que la retórica del mercado libre -el "Consenso de Washington", como se la conoce taquigráficamente [sic]- solo era una tapadera para los viejos intereses comerciales. La propia hipocresía de Occidente no hacía sino reforzar esa sospecha. Europa y Estados Unidos no abrían sus mercados a la producción agrícola del Tercer Mundo, que muchas veces era lo único que esos países podían ofrecer, en lugar de ello, obligaban a los países en desarrollo a eliminar las subvenciones destinadas a crear nuevas industrias, al tiempo que ofrecían subvenciones masivas a sus propios granjeros [Stiglitz, 2010: 266].

Esta política propició un mayor atraso, la destrucción de cadenas productivas y mayor subordinación a los centros de poder internacional para los países que como México siguieron al pie de la letra las políticas liberalizadoras. Sin embargo, algunas naciones no siguieron este camino e impulsaron una política para el desarrollo industrial que les permitió un relativo desarrollo y pudieron competir en otras condiciones en el mercado globalizado.

\section{AlgunOs CASOS DE ÉXITO EN EL DESARROLLO INDUSTRIAL}

Cuando analizamos la evolución de las naciones de Asia oriental, ${ }^{3}$ encontramos que su éxito se debe, en gran medida, a la aplicación

${ }^{3}$ Una reflexión calificada señala que, sin la intervención directa del Estado, muchas de las "nuevas" industrias establecidas en Corea y otros "Estados de políticas industriales" 
de una política de innovación y competitividad distinta a la sugerida por los organismos financieros internacionales para lograr el desarrollo tecnológico y proteger sus mercados, el sistema financiero nacional permitió encauzar los préstamos y subsidios hacia ciertos sectores "estratégicos" y le dieron un tratamiento especial a la fuerza de trabajo. El papel del Estado se concentró en:

[reconocer] la importancia de la tecnología y la educación en el mercado competitivo global y $[\ldots]$ fortalecer sus ya voluminosas inversiones en educación -en la actualidad Asia triplica el número de nuevos graduados en ingeniería y ciencia de Estados Unidos. Su reto consiste en mejorar la calidad al mismo tiempo que la cantidad [Stiglitz, 2006: 74].

También se desplegaron rígidos mecanismos de control sobre el flujo de capital, las inversiones directas extranjeras y los préstamos del exterior [véase Chang, 1996: 103-104]. Su éxito se basó en que aplicó una estrategia distinta a las sugeridas por el "Consenso de Washington". Estas economías le asignaron una función más amplia al Estado, a diferencia del papel minimalista que define el liberalismo económico.

Las economías de China, Brasil, India y Corea son muy ilustrativas en este sentido, ya que, de acuerdo con el planteamiento de Stiglitz, se alejaron de las recetas del FмI y el Banco Mundial (вм) para seguir una política pública más independiente que les permitiera impulsar el desarrollo nacional y no solo aplicar programas de apertura económica para las grandes trasnacionales o crear las condiciones para el pago de los compromisos de la deuda, sino fortalecer el control del sistema financiero y las posibilidades de su autonomía.

del este de Asia no habrían podido organizar sus finanzas, por no mencionar las dificultades que habrían enfrentado para ser competitivos en el mercado mundial mediante el desarrollo tecnológico y de la mercadotecnia [Chang, 1996: 131]. 
El caso de China es muy importante en este sentido ya que:

... desde sus inicios como nación, más concretamente desde principios de los años 70 , sus dirigentes han optado por una estrategia de incorporación capitalista a través de la seguridad alimentaria, que en momentos de mayor incertidumbre ha rayado incluso en autosuficiencia alimentaria al nivel de aldea rural [Rodríguez y Rodríguez, 2012: 224].

Desde 1978, cuando inició su florecimiento científico y el desarrollo industrial le permitieron su expansión.

... En 1992, el 40\% de las exportaciones totales estaban integrados por artículos de confección, calzado, juguetes, bienes de escaso valor agregado y tres años después las exportaciones de productos de alta tecnología crecieron $50 \%$, en especial el sector de electrónicos, maquinaria y equipo [Martínez, 2012: 283].

También sentaron las bases y la estrategia de fortalecimiento del país mediante la inversión en ciencia y educación con lo que:

China va por el desarrollo acelerado de las nuevas industrias, como la informática de última generación, nuevos materiales, biofarmaceútica y biogenética, entre muchas otras. [...] gracias a su acervo educativo China ha construido en los últimos 20 años las bases necesarias para ser un líder mundial en los profesionales de la investigación y el desarrollo y estar dentro de los cinco países que más registran anualmente patentes ante la [Organización Mundial de la Propiedad Intelectual] omPI en Ginebra [Garza, 2012: 52-53].

Se fortalece el mercado interno:

... para mantener activa su economía sin tanta necesidad del exterior. La economía china va a dar a su población más dinero para que consuman más y se conviertan en una sólida clase media. En 30 años, China ha logrado avances importantes, tanto en materia militar y aeroespacial, como civil e industrial, sin dejar de lado la investigación y el desarrollo agropecuario. Al tiempo que logra 
concebir y operar la supercomputadora más importante y avanzada del mundo, mantiene como hace 2000 años sus proyectos de irrigación de las zonas norteñas con agua del sur [Garza, 2012: 55].

Su prioridad sigue siendo la alimentación como parte de su posicionamiento global de tal manera que:

Los años transcurridos desde el inicio del siglo XXI no han sido una excepción a la regla de que la seguridad alimentaria sea el factor clave que hay que tener en cuenta cuando se diseñan las políticas para la agricultura y el sector rural. Y si se examina esta situación desde un punto de vista global, queda claro que China debería ser vista como un factor de estabilidad en lo que al mercado internacional de alimentos se refiere [Rodríguez y Rodríguez, 2012: 224].

En los últimos años, China ${ }^{4}$ ha fincado su desarrollo hacia una estructura capitalista, encaminando sus esfuerzos a fortalecer los sistemas de propiedad privada de los medios de producción y el establecimiento de un mercado de trabajo:

[con una] mano de obra altamente disciplinada, muy trabajadora, pero sobre todo con un costo laboral muy bajo, en donde su control se da por un sistema político que se muestra rígido, estable y capaz. El atractivo por la mano de obra se complementa con la potencialidad de un enorme mercado que resultaba sumamente sugestivo para las empresas foráneas que recién se instalaban: si China despegaba económicamente -como efectivamente sucedió-, entonces surgiría una nueva clase media que representaría un nuevo mercado nada despreciable para las compañías que siempre buscan maximizar sus beneficios. El resultado fue una clase asalariada de millones de personas, pero también [...] un círculo de nuevos millonarios,

4 "Las transformaciones económicas se han acompañado con reformas legales. Se calcula que desde 1978 se han establecido setecientas nuevas leyes nacionales y más de 2000 leyes locales. Cabe mencionar que los cambios legales han enfatizado de manera significativa las libertades civiles en el terreno de las relaciones laborales, permitiendo por ejemplo, la posibilidad de cambiar de trabajo o contratarse con aquella empresa que ofrezca mejores beneficios económicos, pero aún falta un largo camino por recorrer para adoptar una legislación similar a la vigente en los países occidentales en cuestión de derechos laborales" [Lemus, 2011: 85]. 
así como por la presencia de las compañías multinacionales chinas, junto con el crecimiento en la infraestructura y la consolidación de múltiples ciudades que ofrecen una visión de la nueva modernidad [Lemus, 2011: 56,105 y 205].

Como parte de las reformas económicas orientadas a consolidar las actividades de investigación y desarrollo, se invirtió en la generación de fuerza de trabajo especializada, para la exportación de productos de alta y nueva tecnología buscando atraer empresas extranjeras de tecnología de punta e impulsar la incubación y desarrollo de empresas chinas para aprovechar la tecnología endógena en la producción y distribución de los productos para el mercado mundial. La apertura a la inversión privada con altos grados de control estatal, así como la creación de una infraestructura de las más importantes del mundo, les permitió una producción capitalista muy dinámica, ${ }^{5}$ así como la consolidación de una clase empresarial ${ }^{6}$ que prácticamente había desaparecido al triunfo de la Revolución comunista y colocó

${ }^{5}$ En 1997, el congreso del Partido Comunista decidió acelerar la reforma de las empresas estatales vendiendo las pequeñas empresas manejadas como conglomerados en los principales sectores industriales y capaces de transformarse en empresas multinacionales [Lemus, 2011: 55, 79]. Muchas empresas estatales, con alto grado de especialidad, se privatizaron y “... el gobierno decretó que las empresas debían concentrarse en sus industrias claves como la electricidad, el petróleo, el acero, las telecomunicaciones, la banca y la minería, entre otros sectores. [...] el número de empresas públicas se redujo considerablemente. A partir del ingreso de China a la OMC, se incrementó aún más la ied. En 2007 fueron registradas 1840524 empresas privadas, ya sea de capital chino o foráneo, que en conjunto dieron empleo a 460595000 personas, mientras que las empresas estatales y bajo control estatal sumaron 200680 y emplearon a 174290000 personas" [Lemus, 2011: 192, 194].

6 "Para el año 2003, en China existían 26.57 millones de empresarios empleando a más de 200 millones de personas. En el caso de Pekín, la ciudad se ha proyectado en tiempos recientes no solo como cuna de una burocracia, sino también como lugar significativo para el surgimiento y expansión de una nueva clase empresarial, nacida bajo el cobijo del Estado. Así, los pekineses se han sumado vigorosamente a la nueva ola capitalista de China, que genera oportunidades y desafíos para una nueva clase empresarial, que ha hecho suya la frase de Deng Xiaoping: es glorioso ser rico. El surgimiento y consolidación de una clase empresarial ha ido de la mano del avance vertiginoso de las exportaciones chinas y su vinculación con la economía globalizada así como el indudable crecimiento económico" [Lemus, 2011: 163-164]. 
... a China como una potencia tecnológica, cuyas compañías y productos no descansen en su ventaja competitiva exclusivamente en la mano de obra ni en la copia de diseños, marcas y productos, sino que aspira a generar un modelo de innovación endógena para hacer de este país un puntero en las nuevas fronteras del conocimiento y que sus empresas multinacionales sean capaces de competir eficientemente, en una economía mundializada [Lemus, 2011: 56].

El sistema financiero ha sido otra de las variables de máxima prioridad para China al considerarlo:

[un] ancla para controlar la inflación y equilibrar la economía para hacerla más dependiente del consumo interno y menos de las exportaciones. China está utilizando sus cuantiosas reservas internacionales, aproximadamente 3.2 billones de dólares, de las cuales dos tercios son en moneda estadounidense y 1.2 billones están invertidos en deuda del Tesoro de Estados Unidos. El banco central del país asiático compra dólares para limitar la subida de su divisa. Esta práctica ha convertido a China en el mayor poseedor de bonos del Tesoro estadounidense. ${ }^{7}$ Asimismo, el banco central chino está aumentando sus reservas de oro y otros metales preciosos contemplando, por otro lado, globalizar el yuan [Martínez, 2012: 284-285].

En China se aplicaron algunas políticas de corte neoliberal pero se mantuvo un estricto control de su mercado interno, lo que le permitió una fuerte expansión de las exportaciones, así como la presencia de compañías con capital foráneo y captación de inversión extranjera directa (IED). También se preocuparon por la transferencia de tecnologías de punta, el apoyo gubernamental para alinear las actividades de ciencia y tecnología a las

${ }^{7} \mathrm{Al}$ respecto Stiglitz señala que “... Asia -de donde actualmente procede la mayor parte del ahorro mundial- ya está desarrollando sus propios centros financieros. Ya no somos la principal fuente de capitales del mundo. Actualmente los tres primeros bancos del mundo son chinos; el banco estadounidense más grande ha bajado a la quinta posición” [Stiglitz, 2010: 240]. 
necesidades del mercado, los incentivos fiscales y apoyos gubernamentales en ciertas áreas claves para el desarrollo, la formación de recursos humanos especializados orientados a las nuevas áreas del conocimiento y el retorno de chinos que estudiaron en el extranjero [Lemus, 2011: 190 y 218]. Esta situación le permitió a China competir con Estados Unidos, no solo con bajos salarios de sus trabajadores, sino con una mano de obra cada vez más calificada y grandes inversiones en infraestructuras con producción a bajo costo y logística moderna para asegurar la entrega de las cantidades ingentes de bienes materiales que los consumidores de Estados Unidos demandaran.

En las cuestiones internacionales, China ha fomentado una política de acercamiento con México e Hispanoamérica por medio de la capacitación de personal diplomático que:

[en] la actualidad son, consejeros, académicos y empresarios, fueron formados en El Colegio de México. Su dominio del español y sus conocimientos sobre la historia, la cultura y el presente de Hispanoamérica representaron una importante ventaja en sus relaciones con nosotros. Mucho antes de abrir sus puertas al mundo, visionariamente, más de veinte instituciones académicas importantes de China tenían licenciaturas en español y literatura hispana, donde expertos españoles y latinoamericanos enseñaban lengua, historia, literatura, etcétera [Arsovska, 2012: 169].

En 2009, la economía china rebasó a la economía japonesa colocándose como la segunda del mundo, solo atrás de la estadounidense. Los pronósticos son que para la próxima década China sea el primer mercado del mundo. El FMI pronostica que en 2016 superará el PIB de Estados Unidos en términos de paridad de poder de compra. Asimismo, China ha aprovechado con sagacidad la crisis occidental para ganar terreno político y económico a costa de Estados Unidos y la Unión Europea. [...] China ha desplazado a México como el segundo exportador a Estados Unidos, solo superado por Canadá [Fernández de Castro y Cándaro, 2012: 277]. 
El caso de Brasil es también muy ilustrativo ya que es una economía que se negó a seguir al pie de la letra la política liberal. ${ }^{8}$ Impulsó la producción de petróleo, la minería y la aeronáutica, entre otros. Si bien, utilizó las medidas liberales dictadas por los organismos financieros internacionales durante la época de la crisis, se observa que en los últimos años sus principales gobernantes aplicaron una política económica encaminada a la generación de crecimiento mediante el impulso e inversión de sus sectores estratégicos, así como de la intervención del Estado con una política económica potenciada por las instituciones nacionales que tratan de posicionar a sus industrias y sectores económicos en el mercado mundial para generar ganancias que permitan reducir la desigualdad y la pobreza existente en su población.

Las políticas públicas se concentraron en la generación de nuevas tecnologías y la innovación de nuevos productos para el mercado.

El etanol está disponible en todas las gasolineras del país y todos los fabricantes producen este tipo de motores flexibles. Este energético es resultado del interés del gobierno brasileño, a partir de la crisis del petróleo de 1973 de lograr la autosuficiencia energética y también de la investigación agrícola de Embrapa, el instituto gubernamental fundado ese mismo año. A Embrapa se debe también la transformación de Brasil en una potencia agrícola resultado del aumento de un $150 \%$ en la productividad en este sector en los últimos treinta años. Según Pedro Antonio Pereira, director de Embrapa, en ese periodo la tierra dedicada a la agricultura solo aumentó en un 20\%. Para el 2025, el objetivo de Brasil es llegar a ser el mayor exportador de productos agrícolas del mundo, desplazando a Estados Unidos y sin perjudicar el medioambiente [Casanova, 2010: 443].

${ }^{8}$ La crisis económica de 1980 implicó grandes problemas al país: endeudamiento, altos índices inflacionarios, pérdida de crecimiento industrial, disminución de la capacidad adquisitiva de su población, desempleo y reducción en la protección social. “... el entonces senador Fernando Henrique Cardoso (FHC) lideró, en la posición de ministro de Hacienda, una exitosa estrategia de estabilización. A partir de 1994, con el Plan Real, se consiguió revertir el cuadro de inflación descontrolada. Además, fue profundizada la estrategia de liberalización económica" [Moreira, 2010: 181]. 
Brasil ha procurado generar una menor dependencia de las potencias dominantes:

Tradicionalmente era el mundo desarrollado el que exportaba productos nuevos e innovación en general al mundo en vías de desarrollo. Sin embargo, se ha comenzado a hablar de innovación al revés, es decir, desde el mundo emergente a Occidente. El microcrédito, la tarjeta prepago de los teléfonos móviles y el etanol a base de caña de azúcar, son algunas de las innovaciones que han revolucionado el sector financiero, las telecomunicaciones o los biocombustibles en los países emergentes y desde allí se han exportado a Europa y Estados Unidos. La empresa aeronáutica brasileña Embraer, por ejemplo, tiene un modelo de negocios que algunos especialistas llaman tercerización al revés. En la planta de São José dos Campos se diseña y se hace el ensamblaje final del avión con las partes que se han manufacturado en Europa o en Estados Unidos. Los ingenieros aeronáuticos brasileños que provienen del Instituto Tecnológico de Aeronáutica (ITA), una de las mejores escuelas en su especialidad del mundo, próxima a Embraer, son excelentes y comparativamente más baratos. Así Embraer consigue calidad a bajo costo [Casanova, 2010: 443].

Brasil se ha transformado en un país generador de innovación y ha comenzado a adquirir empresas internacionales.

En el 2006, la minera brasileña Vale, la mayor exportadora mundial de mineral de hierro, adquirió la canadiense Inco, especializada en níquel. Esta fue una de las adquisiciones que marcó un hito por su valor (18 900 millones de dólares) y porque fue un audaz movimiento de una empresa emergente hacia el mundo desarrollado. Se creó así lo que llamo empresas latinas globales, es decir, empresas que han logrado entrar con éxito en Europa o en Estados Unidos. [Asimismo,] dominó la escena siendo el origen de cinco de las diez mayores transacciones. Cuatro de ellas fueron fusiones dentro de Brasil que reforzaron sus "campeones nacionales": la empresa de carne bovina JBS lideró el ranking con la adquisición de Bertin en Brasil por 6300 millones de dólares, Perdigão, dentro del mismo sector, adquirió Sadia por 4100 millones formando Brasil Foods, Globex utilities 
(Pão de Açúcar) compró Casas Bahia por 2200 millones de dólares reconquistando el liderazgo dentro del sector de retail brasileño y Votorantim Celulose e Papel se fusionó con Aracruz Celulose para formar Fibria Celulose en una transacción de 1980 millones de dólares. El banco suizo UBS vendió su filial brasileña al grupo financiero brasileño BTG, UBS Pactual por 2500 millones de dólares. La entidad resultante, BTG Pactual es el mayor banco de inversión de los países emergentes. Detrás de esta operación estaba André Esteves, la misma persona que había vendido Banco Pactual a UBS en el 2006 por la misma cantidad [Casanova, 2010: 441].

Por todo esto, Brasil se ha convertido en una de las mayores economías del mundo y posee recursos naturales estratégicos para su desarrollo en las próximas décadas:

... una autosuficiencia energética, ahora potenciada por la creciente capacidad de exportar energías renovables (etanol) y no renovables (petróleo), la existencia de una frontera agrícola aún por ser explorada, lo que hace del país una de las pocas regiones con potencial de expansión de la oferta de alimentos bajo bases ambientalmente sostenibles (si los recursos fueran utilizados racionalmente), esto se asocia a la existencia de agua en abundancia y de un amplio abanico de recursos minerales [Moreira et al., 2010: 194].

El fortalecimiento capitalista de la economía ha sido posible porque Brasil aplicó una política pública de desarrollo capitalista apoyando:

La recuperación de un mayor dinamismo en términos de crecimiento comenzó con el drive exportador, beneficiado por la expansión de la economía mundial y por un tipo de cambio más competitivo después de la mudanza de régimen cambiario en 1999 [Moreira et al., 2010:189].

Entre 2001 y 2003, la demanda externa presentó una contribución positiva y superior a la demanda doméstica, mientras que, después de 2004, la expansión del gasto doméstico pasó a 
liderar el crecimiento. Se verificó una sensible recuperación del empleo, de la masa real de ingresos del trabajo y del crédito. Con ello, el consumo de las familias pasó a expandirse en un nivel sensiblemente superior al verificado en los años anteriores.

La formación bruta de capital, cuando se considera el indicador trimestral, pasó a presentar el mejor desempeño en más de dos décadas. El crecimiento económico, con generación de puestos formales de trabajo -y que, por eso, contribuyen con la financiación al sistema de seguridad social- hizo que, después de muchos años, el déficit de la seguridad social se estabilizara. La deuda pública (neta y como proporción del PIB) disminuyó desde el $52.4 \%$ en 2005, hasta el $42.3 \%$ en 2007, con resultados corrientes cada vez mejores, dado que el déficit nominal, que incluye el pago de interés, pasó de un 6.9\% del PIB, en 1997, a un 2.3\% del PIB, en 2007 [Moreira et al., 2010: 185].

Su producción se ha fortalecido en el mundo con la fabricación de motores híbridos que pueden funcionar con gasolina, etanol o cualquier combinación de los dos. "La multinacional alemana Volkswagen fue la primera en comercializar vehículos con estos motores. El año pasado esta tecnología se extendió a las motocicletas y fue la japonesa Honda, la primera en lanzar una con estas características" [Casanova, 2010: 443]. Esta política ha sido atractiva para la inversión extranjera directa y proyectarse desde ahí al mercado mundial de manera exitosa.

La participación del Estado en la economía ha sido fundamental para el crecimiento de estos productos e industrias. El gobierno poco a poco trata de sustituir algunos productos indispensables que son importados, mediante la generación de productos nacionales que posibiliten la autosuficiencia y, por lo tanto, el término de la dependencia de la compra de productos en el exterior y además poder colocar dichos productos en el mercado global. La política pública integra el uso y generación de nuevas tecnologías y promueve la innovación de nuevos productos. Todo esto es posible con la modificación de la inversión en innovación y desarrollo mediante los incentivos a la educación y 
la expansión del gasto a largo plazo.

En la cuestión financiera se aplica una relajada política monetaria, estímulos fiscales, expansión del crédito, ampliación de la inversión pública y programas sociales que han permitido extender el mercado interno, ${ }^{9}$ reducir la desigualdad y los niveles de pobreza. Se impulsó un modelo exportador que ha ayudado a la dinámica brasileña en el mercado internacional, al permitirle incrementar el comercio con otros países, en especial con China.

El salto de las inversiones brasileñas en el exterior tuvo su inicio en 2004 (US\$ 9.8 billones) como resultado de la fusión de Ambev con el grupo belga Interbrew, que representó una inversión en el exterior de US $\$ 4.5$ billones, mientras que en 2005 la mayor operación de capitales brasileños en el exterior fue la adquisición de la empresa argentina Loma Negra por US\$ 1 billón por parte de Camargo Correa. Fue recién en 2006 cuando las inversiones brasileñas en el exterior alcanzaron su mayor expresión (US\$ 28.2 billones), cristalizado en un aumento significativo que alcanzó el $2 \%$ del total mundial [Bianco et al., 2012: 228].

Las inversiones totales procuraban ser destinadas "principalmente a la adquisición de firmas en sectores como petróleo $(71.7 \%)$, minería $(15 \%)$, energía eléctrica $(12.1 \%)$, y en menor medida en agroindustria. El resto de las inversiones anunciadas fueron del tipo greenfield y se encontraban principalmente orientadas a la siderurgia [Bianco et al., 2012: 250].

Se tienen programas públicos de inversión en transporte, caminos, vías de tren, puertos y transporte por agua y aeropuertos, energía, generación y distribución de electricidad petróleo y gas, desarrollo urbano, saneamiento, transporte urbano, y caminos urbanos, desarrollo social urbano, viviendas, agua y luz para todos.

${ }^{9}$ Según el Ministerio de Finanzas, Brasil ha fortalecido su mercado interno mediante el crecimiento de la clase media , que para el año 2003 era de 65.9 millones de personas, mientras que para el 2011 se incrementó a 105.5 millones de personas, por lo que se ha visto reducida la población de ingresos bajos que pasó de 96.2 millones de personas de 2003 a 63.6 millones de personas para 2011 [Ministry of Finance, 2012:7]. 
... Salvo algunos matices observados en 2008 por motivos de crecimiento económico doméstico, el proceso de internacionalización productiva durante el periodo posterior a 2006 siguió las tendencias generales del resto de los inversores mundiales. El punto más crítico se verificó en 2009, el peor año en materia de ambiente de inversión para la economía mundial, cuando Brasil incurrió en un proceso de repatriación de capitales, interrumpiendo así una importante tendencia de creciente internacionalización productiva [Bianco et al., 2012: 250].

La expansión capitalista ha sido exitosa desde la perspectiva de la acumulación. Sin embargo, las contradicciones del sistema han profundizado la polarización entre capital y trabajo, las leyes económicas siguen funcionando, por un lado se da la concentración y centralización de la riqueza generada con este modelo, al tiempo que por el otro hay una distribución más inequitativa de la riqueza a favor de la expansión del capital y la profundización de la pobreza.

La economía de Corea, al igual que en los casos anteriores, se orientó hacia las exportaciones como forma de recuperarse de la crisis financiera mundial. Se aplicaron políticas dirigidas a mejorar la competitividad internacional de las exportaciones de manufacturas y en apoyo principalmente de los grandes conglomerados empresariales, cuyos productos manufacturados siguen representando la mayor parte de las exportaciones $(85.3 \%$ en 2011) [OMC, 2012: 7.17]. Corea ha propiciado la llegada de IED para fomentarla en zonas y lugares especializados. Sin embargo, tres sectores siguen estando completamente cerrados a los inversionistas extranjeros y en 29 se aplican restricciones parciales [OMC, 2012: 20].

La agricultura sigue estando solo parcialmente incluida y algunos productos agrícolas sensibles, como el arroz, están excluidos de la liberalización impulsada por los acuerdos de libre comercio. Se han reforzado las medidas de ajuste para compensar a los productores y empresas nacionales que parecen muy perjudicados por la competencia de las importaciones inducidas por los acuerdos de libre comercio. Se mantienen licencias y 
prohibiciones de importación, principalmente para la protección de la moral y la salud públicas, la higiene y el saneamiento, la protección de los animales y los vegetales, la conservación del medio-ambiente y la preservación de intereses básicos de seguridad. Corea ha tomado medidas antidumping contra importaciones, sobre todo de productos químicos, papel kraft, plásticos, acero inoxidable y tableros de partículas, ha iniciado ocho asuntos nuevos y mantiene en vigor 31 medidas definitivas sobre las importaciones procedentes de 13 países, principalmente asiáticos [OMC, 2012: 23]. También aplicó distintas medidas de fomento, como donaciones, desgravaciones fiscales o préstamos a bajo interés, para apoyar la producción y el comercio de muchos productos y estimular a las pymes ${ }^{10}$ y las actividades de investigación y desarrollo y protección del medioambiente. El Estado sigue interviniendo en la economía, ya que las iniciativas de privatización dieron pocos resultados, pese a la determinación del gobierno de desprenderse de sus inversiones [OMC, 2012: 31].

Las políticas públicas (incluidos aranceles, incentivos fiscales y rebajas del precio de la energía) han favorecido a las manufacturas frente a los servicios, que suelen ser mucho menos comercializables que las primeras. La protección en frontera consiste casi totalmente en aranceles y derechos de ajuste. A partir de 2009, la ayuda se centró en las actividades denominadas "nuevos motores de crecimiento", con el objetivo de incrementar las exportaciones de productos ecológicos (por ejemplo, automóviles eléctricos) de las principales industrias. Se concedieron otras ayudas para ramas de producción específicas, a fin de aumentar la competitividad general del sector de partes de automóviles, mejorar el sector siderúrgico, ayudar a Corea a recuperar la condición de principal país del mundo en construcción naval

10 "Si bien, estos conglomerados han sido tradicionalmente la columna vertebral de la economía coreana y de su crecimiento basado en las exportaciones, preocupa que, debido a su tamaño, estén sofocando a las pymes del país, que concentran el 90 por ciento aproximadamente del empleo y que, por consiguiente, estén polarizando la economía" [OMC, 2012: 99]. 
en 2011 y fomentar la expansión de la industria farmacéutica [OMC, 2012: 60].

En cuanto a la política monetaria, con el fin de mitigar los riesgos sistémicos para la economía coreana, generados por las voluminosas y volátiles entradas de capital, por medio de la inversión de cartera y, presumiblemente, para disipar la inquietud de que pudieran dar lugar a una excesiva volatilidad del tipo de cambio y aumentar la vulnerabilidad del sector financiero (y posiblemente también teniendo en cuenta la competitividad internacional de las exportaciones de productos manufacturados de los grandes conglomerados de empresas), en 2010 las autoridades aplicaron tres medidas macroprudenciales. ${ }^{11}$ Esas medidas incluyeron la retención de impuestos sobre los ingresos por intereses y sobre las ganancias de capital de los tenedores no residentes de bonos de estabilización monetaria y del tesoro.

Corea se ha beneficiado con su política fiscal prudente, que ha dado lugar a constantes superávits fiscales modestos (que han contribuido al superávit por cuenta corriente) y, por ende, a una baja deuda del gobierno central (de tan solo 31.9\% del PIB) en 2010. En particular, permitió que el gobierno contrarrestara la crisis de 2008 con un conjunto de medidas de estímulo equivalente a 6.1\% del PIB [OCDE, 2010: 8-10]. Los incentivos fiscales y los aranceles de importación han sido durante mucho tiempo uno de los principales instrumentos de la política industrial destinados a proteger a determinadas industrias nacionales contra la competencia de productos extranjeros y ayudar a los fabricantes nacionales. En el aspecto del mercado laboral, su política se ha centrado en aumentar la inversión en actividades que requieren una gran cantidad de mano de obra, en particular los servicios, para elevar así la productividad del trabajo, reforzar la red de seguridad social e incrementar la participación de las

${ }^{11}$ Las autoridades sostienen que el objetivo principal de esas medidas era reducir la volatilidad de las corrientes de capital, no los tipos de cambio, y que éstas no tienen ningún efecto para la competitividad internacional de las exportaciones de manufacturas de los grandes conglomerados. 
personas de mayor edad y las mujeres en la fuerza de trabajo [OMC, 2012: 63].

El último ejemplo que queremos destacar es el caso de India, que es una de las economías más grandes del mundo por su tamaño de población y el crecimiento económico de los últimos años. Este país aplicó un importante conjunto de medidas de estímulo para el desarrollo capitalista consistente en un aumento del gasto, la reducción de derechos de aduana e impuestos sobre el consumo y medidas de apoyo. Se le dio prioridad a la agricultura para asegurar la alimentación y convertirse en un exportador mundial de alimentos con el uso de tecnologías, variedades de semillas, fertilizantes y sistemas de riego. Los principales impulsores del crecimiento fueron los servicios y las manufacturas, mientras que la agricultura creció de forma mucho más lenta. Se desarrolló la ingeniería automotriz, la producción de acero, alimentos, automóviles y camiones, además de los planes de desarrollo de proyectos militares, autopistas, aeropuertos y ferrocarriles en el largo plazo.

En las últimas dos décadas el país asiático vivió el periodo probablemente más próspero de su historia en la época capitalista.

Los centros comerciales se convirtieron en los nuevos templos y oasis de la novedosa clase media, las hamburguesas de Mc Donald's se unían al picante menú local y las carreteras se llenaban de Toyotas, Audis y Fords. No se discutía si la India se convertiría en una superpotencia, sino cuándo [León, 2013].

Las políticas públicas se encaminaron a lograr el crecimiento económico mediante la diversificación de la agricultura, la industria y los servicios. El Estado invirtió en educación básica y en la innovación y el desarrollo tecnológico, lo que le permitió colocarse en un papel privilegiado para la exportación de conocimiento y el desarrollo de su mercado interno, con una fuerza de trabajo muy grande, calificada y barata. Se desarrollaron los servicios de alta especialidad en la red de telecomunicaciones, en la electrónica, la informática y el software. Se dio un prodigioso aumento de las exportaciones de servicios de tecnologías de la 
información (STI) y una producción industrial para la exportación masiva de productos (por ejemplo, en el sector del automóvil).

Se llegaba incluso a mencionar que la India (y no China) era el país con mejores perspectivas en el mundo, gracias a sus ventajas estructurales, como un adecuado perfil demográfico, un sector privado empresarial muy activo nacional e internacionalmente, unas instituciones democráticas arraigadas y un sistema judicial independiente, además de una buena preparación, gracias al sector de STI, para la sociedad de la información del siglo XXI [Bustelo, 2012: 1].

Se crearon las condiciones para atraer la inversión extranjera directa de las grandes empresas para la era digital y de servicios de comunicación aprovechando la transferencia de tecnología, nuevas formas de organización del trabajo y el aumento de las exportaciones con un control de las inversiones externas. En este aspecto se ofrece fuerza de trabajo calificada, recursos naturales, fortalecimiento de un amplio mercado interno y niveles elevados de crecimiento económico dirigido por el Estado. Aunque también se encaminaron sus esfuerzos en el desarrollo de la manufactura, la industria farmacéutica, la biotecnología, la nanotecnología, las telecomunicaciones, la construcción naval, la aviación y el turismo.

El resultado se plasmó en altas tasas de crecimiento del PIB entre 2003 y 2007 y luego, superada la primera fase de la crisis financiera internacional, en 2010 y 2011 mostró un país dinámico y con un gran futuro. "Por ejemplo, en 2010 la tasa de crecimiento del PIB llegó a alcanzar el 10.6\%, un porcentaje mayor que el correspondiente a China $(10.4 \%)$ " ${ }^{12}$ Esto fue posible por la aplicación de políticas públicas que combinaron la liberalización económica de algunos sectores; la privatización de empresas del Estado, la apertura comercial, el control del sistema financiero, etc., con las facilidades para la acumulación del capital

${ }^{12}$ En el artículo de Pablo Bustelo [2012] se plantea un análisis crítico de la situación de la India. 
privado, particularmente las importaciones y la inversión extranjera directa. No se vendieron todas las empresas del Estado y están obligadas a competir con el capital privado.

A pesar de la crisis del 2008, el crecimiento del PIB en India siguió siendo alto, de entre 8 y $8.5 \%$. Aunque, al igual que para el caso de Brasil, los importantes avances en la generación de empleos y la disminución de la pobreza con los altos niveles de crecimiento y la estabilidad social no han sido suficientes para abatir los elevados márgenes de analfabetismo y pobreza de la población, el crecimiento del desempleo que comparativamente con otros países representa la suma de varios de sus socios en el mundo atenta contra la estabilidad social. Se menciona que hay:

... (1) graves desequilibrios macroeconómicos (en 2011-12, un déficit corriente del $4 \%$, déficit presupuestario del $6 \%$, déficit comercial del 10\%, inflación del 7\%, etc.), (2) progreso social limitado, sobre todo en comparación con China-por ejemplo, la tasa de alfabetización de adultos es del $63 \%$ y apenas supera el 50\% entre las mujeres, la pobreza extrema afecta al $41 \%$ de la población (con ingresos diarios inferiores a 1.25 dólares) y nada menos que al $75 \%$ si el umbral es de 2 dólares-, (3) escasa generación de empleo, por la prioridad dada al sector de STI y la todavía relativamente escasa exportación industrial, (4) problemas graves de seguridad energética, ya que se prevé que el país importe en 2030 el 90\% del petróleo que necesitará, (5) unas infraestructuras subdesarrolladas, sobre todo en comparación con China y (6) una todavía escasa integración en la economía mundial, salvo en el sector servicios y algunos segmentos de la industria manufacturera, como los automóviles [Bustelo, 2012: 3].

Las leyes capitalistas siguen funcionando, si bien con un mayor grado de independencia, el capital trasnacional en la India se impone con la exportación de capitales, el abaratamiento de la fuerza de trabajo calificada, la innovación tecnológica, la flexibilización laboral y el incremento del desempleo como factores que permiten la mayor concentración y centralización de la riqueza y el aumento de la tasa de ganancia de las empresas trasnacionales. 


\section{CRISIS Y PARTICIPACIÓN DEL ESTADO}

En contraposición con la ideología neoliberal, que rechaza la participación directa del Estado, cuando estalló la crisis en 2008 los ideólogos sistémicos perdieron su identidad y demandaron la actuación del Estado para salir de la misma, pidieron una acción inmediata para rescatar al sistema financiero y trasladar los costos a la sociedad en su conjunto por medio de las contribuciones. El gobierno de Estados Unidos desempeñó un papel esencial en la distribución de miles de millones de dólares para rescatar al capital privado; el presidente Bush de inmediato, aplicó una política de apoyo al sistema financiero a pesar de que ellos habían sido los responsables del colapso económico:

Después de la caída de Lehman Brothers, de la nacionalización de Fannie Mae y Freddie Mac y del rescate de AIG, Bush se apresuró a ayudar a los bancos con un rescate masivo de 700000 millones de dólares, bajo un programa eufemísticamente denominado "Troubled Asset Relief Program" (TARP) [Programa de Alivio de Activos Depreciados] [Stiglitz, 2010: 62].

Se salvó a los bancos pero se ignoró a los millones de trabajadores que no pudieron pagar sus hipotecas y perdieron sus viviendas. Es decir:

... Los banqueros, que en gran parte habían precipitado el problema, se aprovecharon del pánico resultante para redistribuir la riqueza -para sacar dinero de las arcas públicas a fin de enriquecerse ellos-. En todos los casos, a los contribuyentes se les decía que el gobierno tenía que recapitalizar los bancos si se pretendía que la economía se recuperase [Stiglitz, 2010:74-75].

Este autor describe cómo ocurrió el traslado de recursos públicos en beneficio de los grandes bancos:

En realidad, Estados Unidos estaba dando ayuda exterior a otros países ricos (Francia, Alemania) en vez de a los países pobres que 
lo necesitaban mucho más. Y la magnitud de esta ayuda era de hecho mayor que la que se prestó a toda África. (La ayuda al desarrollo estadounidense oficial a toda África fue de 6500 millones en el año fiscal 2008, la mitad de la cantidad que fue a parar a una única empresa, Goldman Sachs, a través del rescate de AIG) [Stiglitz, 2010: 381].

La política de rescate se extendió a varias empresas, por ejemplo:

A finales de 2008, dos de los "Tres Grandes" fabricantes de coches, General Motors y Chrysler, estaban al borde del colapso. La preocupación era que hubiera un efecto en cascada: sus proveedores irían a la quiebra, el desempleo aumentaría y el desplome económico empeoraría [Stiglitz, 2010: 76].

También se incluyó a la industria petrolera y la minería, que recibieron miles de millones de dólares en subvenciones encubiertas de los contribuyentes. Aunque muchas de las industrias más exitosas de Estados Unidos se han visto beneficiadas históricamente con la presencia del gobierno en sus negocios.

Internet, sobre el que se ha basado tanta prosperidad reciente, se creó con fondos públicos, incluso el prototipo de navegador Mosaic fue financiado por el gobierno. Fue comercializado por Netscape, pero Microsoft utilizó su poder monopolístico para aplastar a Netscape por un procedimiento que todos los tribunales del mundo han considerado como un abuso de poder monopolístico [Stiglitz, 2010: 244].

Es claro que:

Estados Unidos usa con frecuencia sus gastos de defensa para conceder subvenciones a las industrias. Boeing se benefició de los gastos militares en diseño aeronáutico, y la industria de programas informáticos también lo ha hecho enormemente con una serie de gastos públicos que contribuyeron a desarrollar internet e incluso los buscadores. De hecho, una de las justificaciones que suelen esgrimirse a favor del alto nivel de gastos en defensa es que producen beneficios comerciales. Estados Unidos es lo suficientemente rico 
para permitirse una política industrial ineficaz que lo oculta tras lo militar, los países en vías de desarrollo no, y deberían ser libres de elegir, si así lo deciden, para tener la que fuera adecuada a sus circunstancias [Stiglitz, 2006: 121-122].

Se utiliza al Estado:

... como herramienta a favor de los intereses de las minorías dominantes, no en pro del bien público, protege a los ricos de los rigores del mercado e instrumenta el terror del "mercado libre" contra los indefensos, de este modo acaba efectivamente con el sistema de seguridad social, lo que se refleja en la reaparición de enfermedades y el recorte en gastos educativos [Chomsky y Dieterich, 1999: 139]. No es de extrañar que los países que estaban más abiertos, más globalizados, fueran los más afectados [Stiglitz, 2010: 282].

Anteriormente señalamos que China, Corea, India y Brasil enfrentaron la crisis financiera de distinta manera, por ejemplo, en el primer caso:

... no tardó en ajustar las políticas macroeconómicas, siguiendo el principio de ampliar las demandas internas y aumentando las importaciones al mantener el volumen de exportaciones para contribuir al equilibrio del comercio exterior. Como resultado de las políticas, el superávit comercial de China registró una obvia caída, pasando de un valor máximo de 300000 millones de dólares $(6.5 \%$ del PIB) de 2008 a 107100 millones (2.2\% del PIB) de los primeros tres trimestres de 2011, lo cual se encuentra en una franja razonable a la vista internacional" [Zhimin, 2012: 117-119].

Una característica esencial de los distintos ejemplos arriba presentados es la forma en que se enfrenta el proceso de competencia internacional y la manera en que se gestiona la distribución de la riqueza en la globalización, con la aplicación de políticas económicas claramente discriminatorias que ejercen los países desarrollados en contra de los subdesarrollados, mediante la protección de sus mercados internos que les permite enriquecerse cada vez más y empobrecer al resto de las economías. Se 
cuestiona que, en el mercado internacional, los países más liberales promueven posturas políticas de apertura y mecanismos de mercado, en tanto que en su mercado interno las sugerencias son contrarias a las que defienden externamente, es el caso de las políticas de privatización de la seguridad social, el equilibrio presupuestal contraccionista y expansionista, el apoyo a los deudores de sus países y la imposición de una rigidez extrema al control inflacionario, así como la exigencia de pago de la deuda a los países dependientes.

\section{PolítiCAS PÚBLICAS PARA EL DESARROLLO}

En la gran mayoría de los países subdesarrollados se ha observado una falta de estímulos y de participación del Estado en la definición de las políticas económicas que contemplen una estrategia que integre y fomente el crecimiento nacional de las empresas y sectores estratégicos para cubrir la demanda de productos para el consumo nacional e internacional con el fin de generar competencia y presencia en los mercados globales. El desarrollo capitalista se da en aquellas economías que se han resistido a seguir al pie de la letra la política neoliberal, además de impulsar una participación del Estado distinta a la sugerida por los organismos financieros internacionales. Las políticas públicas desplegadas por los países emergentes buscan posicionar a sus industrias, su agricultura y el desarrollo de los servicios como factores competitivos en el mercado mundial, lo que revalorizó el desempeño del Estado en el proceso de globalización, desafiando la concepción del libre mercado sostenida por los economistas neoliberales, la política de distanciamiento con los organismos financieros internacionales plantea una posición más social en comparación con la impuesta a los países pobres.

La política económica que se sigue aplicando en los países subdesarrollados debe cambiar y el Estado debe ejercer un papel más activo en la economía, similar a la instrumentada por los países industrializados en lo que se refiere a la regulación, a 
los impuestos y subsidios o en la participación directa en las actividades productivas como proveedor de servicios esenciales relacionados con la educación y la salud. En concreto, hay una serie de bienes de utilidad pública que pueden promover un rápido crecimiento económico y que el Estado tiene que tomar en sus manos con una perspectiva de desarrollo social, por ejemplo, a la iniciativa privada no le interesa suministrar una cantidad suficiente de bienes y servicios esenciales para la población más pobre como alimentación, agua potable, alfabetización y salud pública, transporte, vivienda y comunicaciones de bajo costo.

Para producirlos se requiere una sólida capacidad administrativa y vínculos institucionalizados con las partes interesadas, como las empresas privadas, en ese sentido, solo el Estado es capaz de establecer las bases económicas y sociales que permitan una buena gestión de la economía, servicios básicos de educación y de salud e infraestructura [Banco Mundial, 1997: 60 y 186].

Como se observa, no son elementos nuevos, son problemas que han estado presentes desde la implantación del modelo neoliberal y que el propio Banco Mundial viene planteando como sugerencia para solventar los problemas de diversos países del mundo en donde la situación es cada día más complicada.

Los países que no siguieron las instrucciones del FMI y el BM dan el ejemplo de que no se pueden liberar por completo los mercados de capitales ni la apertura de sus economías al mundo, ya que esta fue lenta y gradual, la privatización no fue total y mantuvieron una fuerte presencia presupuestaria, etc. Estos países estuvieron en mejores condiciones para enfrentar la crisis en relación con aquellos que sí liberalizaron sus economías, es una evidencia cada vez más clara cuando se observan los niveles de crecimiento y desarrollo de sus economías. Los países antes analizados lograron mejores niveles de crecimiento y enfrentaron en mejores condiciones la crisis económica, ya que pudieron aprovechar la globalización para expandir sus exportaciones y, como consecuencia, crecieron más rápidamente. No desmantelaron 
sus barreras proteccionistas, cuando fue necesario disminuirlas, lo hicieron de manera cuidadosa. Se aseguraron de que hubiera capital disponible para la creación de nuevos empleos y empresas, incluso adoptaron un protagonismo empresarial para la promoción de nuevas empresas, combinaron altas tasas de ahorro, inversiones públicas en educación y una política industrial dirigida por el Estado. Asimismo, pusieron énfasis en la promoción de las exportaciones y protegieron su mercado interno.

\section{Propuesta de POLÍTICAS públiCAS PARA MéXICO}

Al contrario de lo descrito sobre los países exitosos en el apartado anterior, en México se han seguido al pie de la letra las políticas liberales y se ha carecido precisamente de los factores de estímulo y participación del Estado que se han observado en las economías emergentes. Se adoptaron plenamente las políticas sugeridas por los organismos financieros internacionales: no se atienden los problemas fundamentales del mercado interno, no hay un fomento a las pequeñas y medianas empresas y los sectores estratégicos que pudieran cubrir la demanda de productos como la gasolina, para el consumo nacional y exportar un producto con valor agregado, se han descuidado en la medida en que esta forma de organización de la producción es muy redituable para las empresas productoras trasnacionales y que tienen suficiente capacidad para cubrir la demanda de sus clientes pero no para el país en donde se rompieron las cadenas productivas y se cancelaron muchos empleos con el control de las empresas trasnacionales.

Es necesario redefinir esta política y orientarla al beneficio nacional para dar solución a los graves problemas que la política económica liberal ha profundizado. Se deben aprovechar las ventajas de la globalización para lograr el desarrollo económico, compartiendo los costos y beneficios de manera más equilibrada, lo que conduce al establecimiento de una política fiscal que grave las utilidades, redistribuya el gasto en el orden social con 
la creación de mecanismos como el seguro de desempleo, de modo que, cuando los individuos pierdan su trabajo, puedan encontrar uno nuevo, pero partiendo del beneficio social sobre el interés privado.

Tenemos que poner en marcha políticas que conduzcan a un aumento de los salarios, especialmente de los más bajos. Estos solo pueden aumentar si se incrementa la productividad, lo cual precisa mayores inversiones en tecnología y educación. Por ejemplo [...] si la banca privada no establece sucursales en el medio rural para depositar ahorros, el Estado debe intervenir. Si la banca privada no ofrece créditos a largo plazo, el gobierno debe intervenir. Si la empresa privada no proporciona las materias primas básicas para la producción -como acero y plástico- el Estado debería intervenir si no es capaz de hacerlo de manera eficaz [Stiglitz, 2006: 64-65].

Debe quedar claro que estas propuestas son plenamente factibles para la expansión capitalista y no es una política que ponga en jaque el sistema económico, es simplemente reclamar condiciones de igualdad a las que aplica Estados Unidos o los casos antes mencionados. Es incompresible que:

En el mismo tiempo en el que nosotros desmantelamos nuestros ferrocarriles, China invierte en el sector y ahora es capaz de producir decenas de trenes de alta velocidad y de detentar ya el récord mundial de velocidad sobre rieles con $486.1 \mathrm{~km} / \mathrm{h}$ [Martínez, 2012: 52 y 53$]$.

Debemos exigir los mismos derechos y obligaciones a los países con los que realizamos inversiones, por ejemplo, con el capital chino en México, debe recibir el mismo trato que nos den en aquel país.

... hasta el mes de noviembre de 2011, tenemos registradas $41 \mathrm{em}$ presas chinas en México, con una inversión acumulada de 614 millones de dólares; dentro de estas empresas, están cuatro del sector petrolero y de contratación de construcción portuaria, dos de telecomunicación, diez de minería, dos del sector textiles y de prendas 
de vestir, una de fabricación de tubo de cobre, una de agricultura, una ensambladora de televisores, dos de planchas de impresión, dieciséis empresas comerciales, una de inspección de calidad para los productos de exportación a China y una oficina representativa de un banco de China [Yuming, 2012: 31].

Debemos exigir las mismas facilidades para la inversión y los sectores que abarca, para que no exista una desproporción tan profunda en su balanza de pagos.

De acuerdo con estadísticas de la Aduana de China, el volumen del comercio entre China y México en 2010 fue de 24690 millones de dólares. Las exportaciones de China a México totalizaron 17870 millones de dólares, mientras que las importaciones de China desde México sumaron 6820 millones de dólares. Los principales productos de exportación de China para México son, entre otros, computadoras, productos de tecnologías de telecomunicación, instrumentos y medidores, equipos para procesamiento automático de datos y sus compuestos, tejidos e hilados y productos textiles terminados. Entre los productos que China importa desde México se destacan principalmente computadoras y productos de comunicación, cobre y condensados, circuitos integrados, automóviles (incluyendo autopartes), petróleo crudo, maquinarias y equipo, hierro y condensado [Yuming, 2012: 31-32].

Es decir, las importaciones de China que consisten principalmente en bienes de capital e intermedios:

... participaron con el $91 \%$ de las importaciones de China, en tanto la participación de las importaciones de bienes de consumo (y que compiten directamente en el mercado doméstico con otras exportaciones y/o con la producción nacional) es inferior que del resto de las importaciones. El tema es crítico para comprender la importancia de China en México y su aparato productivo [Dussel, 2012: 84].

Al igual que en China, debemos poner en práctica políticas de incentivos para alentar las exportaciones: 
Para ello hay que reconocer que las pymes necesitan apoyos decididos e información amplia, veraz y actualizada que solo las instituciones mexicanas pueden proporcionar. También reconocer que es imperativo culminar las negociaciones de protocolos para el acceso de mayor número de productos agropecuarios. En el terreno de la minería, China, por su parte, podría venir en auxilio de los mineros descapitalizados que no pueden poner en operación sus concesiones y así diversificar la inversión extranjera en este campo. ... México podría participar en proyectos específicos en los campos de nanotecnología, materiales de alta conducción, biotecnología y exploración espacial, con inversión y recursos humanos, que le permitirían no solo disfrutar de los beneficios, también explotar los resultados de las investigaciones. El turismo representa otra gran oportunidad de expandir la relación económica bilateral con China. Sin embargo, es imprescindible crear la infraestructura turística necesaria para hacer sentir al viajero de este país oriental bienvenido a nuestro territorio [Ley, 2012: 62].

Se tiene que rescatar la producción de bienes y servicios para evitar el acelerado proceso de desindustrialización, para generar empleos y nuevas inversiones que sean lo suficientemente grandes como para contrarrestar el efecto del incremento del desempleo por la innovación tecnológica, o bien, que una parte importante de las nuevas inversiones se canalice a industrias intensivas en fuerza de trabajo, como la de confección de ropa, que además requiere una alta proporción de trabajadores poco calificados. Otra industria con estas características es la construcción y las obras de infraestructura que permite movilizar más eficientemente el aumento de la producción. Todas estas actividades son altamente generadoras de empleos tanto en esta como en las industrias que la abastecen de insumos. Dinamizar estas industrias y, en general, un desarrollo industrial que se traduzca en mayores empleos y mejoras económicas para la mayoría de la población requiere una decidida participación estatal, como ya lo señalamos para el caso de China, Brasil, India y Corea.

Es importante la inversión en educación, aunque es necesario generar los empleos en los que puedan ocuparse: de poco 
sirve tener individuos muy calificados si no existen puestos de trabajo para ellos.

Sin los empleos adecuados, los países en vías de desarrollo perderán este capital intelectual tan necesario, sus hijos más brillantes, en quienes han invertido tanto a través de la educación elemental y secundaria y en algunos casos también de la universidad, porque se marcharán a países desarrollados. [...] Esto suele denominarse fuga de cerebros, otra manera que tienen los países en vías de desarrollo de acabar subvencionando a los desarrollados [Stiglitz, 2006: 82].

También debemos profundizar en el aprovechamiento de:

nuevas tecnologías, como la biotecnología, mecatrónica y la nanotecnología, en los diversos aspectos que amerite: Inversión en la investigación de dichas tecnologías, apoyo a las empresas y universidades, fomentando la formación de profesionales y el estudio de las mismas. [...] que la acumulación se dé en condiciones menos depredadoras y más equilibradas entre los países desarrollados y los subdesarrollados [Stiglitz, 2002: 124-125].

En este aspecto las sugerencias de Carlota Pérez son adecuadas en el sentido de:

... promover una política de modernización para América Latina, que impulse desde ahora una especialización continental que nos permita incorporarnos, con ventaja y preparación, a la próxima oleada tecnológica (biotecnología, nanotecnología, nuevos materiales, etc.), cuya gestación ya está teniendo lugar y cuya irrupción articulada probablemente ocurrirá en dos o tres décadas. Ello supondría una especialización consciente en la producción y máxima potenciación tecnológica de los recursos naturales, minerales y biológicos para convertirnos en los proveedores globales especializados en insumos a todos los niveles, desde los más estandarizados (cosa que ya hacemos) hasta los más especializados y tecnológicamente sofisticados. Para ello la región tendría que desarrollar una estrategia conjunta de formación de capital humano de altísimo nivel y desplegarlo hacia esas áreas de especialización, al mismo tiempo 
que debe establecer alianzas con empresas globales metalúrgicas, agroindustriales, químicas, biotecnológicas, de nuevos materiales, etc., para aportar, desde acá, nuestra rica variedad de tales recursos y la importante experiencia asociada [Pérez, 2009: 39].

Se debe desarrollar una política de gasto canalizada a fomentar ciertas actividades, de carácter primordial, como las del campo, con el objeto de lograr la autosuficiencia alimentaria, evitando que la canasta básica de los mexicanos dependa de las importaciones. Además del apoyo al campo, es necesario que se distribuya de forma más eficiente y en mayor medida el gasto dirigido a la educación y a la innovación tecnológica, con el propósito de lograr un desarrollo tecnológico, que impida que estas políticas de apoyos y subsidios se vuelvan eternas, y esto genere grandes cargas fiscales, logrando la eficiencia y competitividad de nuestras empresas sin necesidad del subsidio. La política de desarrollo impulsada por el Estado propiciaría una mayor producción con una mejor calidad y competitividad, que nos daría mejores elementos para la exportación y la apertura de fuentes de trabajo en el sector industrial, con el restablecimiento de los encadenamientos productivos hacia delante y hacia atrás para recuperar el mercado interno y la formación de nuevos mercados y productos.

El Estado, como motor del desarrollo y del crecimiento, tendría la responsabilidad de que se estabilice el ciclo económico por medio de las políticas monetaria y fiscal, además de adoptar políticas equitativas que contribuyan al crecimiento y la distribución del ingreso en términos macroeconómicos. Pero también es esencial el apoyo a las actividades manufactureras o artesanales de orden comunitario, que promocione la producción de ciertas mercancías como las bebidas nacionales, los cultivos de café y cacao orgánicos, con la idea del "comercio justo", para beneficiar a los productores, con el objetivo de lograr elevar su nivel de vida. Asimismo, se requiere el apoyo a las pequeñas empresas cooperativas, las cuales deberán ser protegidas por el Estado de la competencia internacional para que no sean aniquiladas por 
las importaciones de productos con precios más bajos, para impedir los desequilibrios en la balanza comercial que afectan a las empresas nacionales y generan desempleo. Es necesario motivar e incentivar a las empresas para que retomen la producción nacional, fomentando el mercado interno e incrementando el empleo, los salarios y la capacidad de compra de los trabajadores.

El impulso a la producción nacional se puede hacer mediante incentivos fiscales a los empresarios, pero también con una recuperación del poder adquisitivo de los trabajadores que fortalezca el mercado interno, o incluso con cargas impositivas a los importadores. Los incentivos deben estar dirigidos únicamente a la actividad productiva que garantice la creación de más empleos, con ello más salarios y que en forma global aumente el ingreso nacional, lo que a su vez incrementará la recaudación tributaria, evitando que se genere algún desequilibrio fiscal por los mismos incentivos.

La IED es importante para el desarrollo, pero debe ser contralada y coordinada por el Estado, como se hace en los casos de China, Brasil, India o Corea, además de asegurar que las utilidades que se generen sean reinvertidas para permitir la expansión de la actividad productiva y restringir la inversión del capital financiero especulativo.

Un Estado de este tipo incentiva la inversión privada al tiempo que cubre los reclamos sociales desplazados con las políticas neoliberales, los gastos sociales, considerados como excesivos por las críticas más extremas del neoliberalismo, se tendrán que recuperar y verlos ahora no solo como componentes insustituibles de los estabilizadores macroeconómicos, sino como factores esenciales para el mantenimiento del orden político nacional de cara a la globalización y a las contradicciones políticas nacionales e internacionales, así como las movilizaciones sociales y culturales que han propiciado la globalización tal y como ha ocurrido hasta ahora.

Una política distinta que tenga como motor al Estado hace imprescindible la calificación permanente de la fuerza de trabajo y el fomento de grandes inversiones para la educación, pero 
también se requiere la protección de los mercados internos. Estas políticas son las que normalmente aplican los países desarrollados, lo que en conjunto nos conduce a pensar en un regreso al punto de partida en el que el Estado estará en el centro del debate como elemento clave para el buen funcionamiento de la acumulación capitalista, entonces, la búsqueda del máximo beneficio posible para el propietario capitalista estaría mediado por la intervención social del Estado como factor esencial de equilibrio del propio sistema.

Un Estado que atienda los reclamos sociales y propicie el desarrollo económico requiere reformas para una mejor redistribución de la riqueza bajo el capitalismo, sin olvidar la ley básica de la valorización y la apropiación de la riqueza en el sistema capitalista que seguirá existiendo, incluso con el Estado más democrático y popular posible. La transformación del modelo de acumulación liberal por otro que ponga el bienestar de la sociedad como objetivo esencial es un problema político, de confrontación entre los poseedores de los medios de producción y los que solo cuentan con su fuerza de trabajo para la sobrevivencia, de modo que el Estado tendrá que crear mejores condiciones para la venta de esta fuerza de trabajo y evitar un estallido social que ponga en cuestionamiento todo el sistema de apropiación capitalista.

\section{REFERENCIAS}

Arsovska, L. [2012], "La enseñanza del chino en México: qué, cómo, y para qué”, Enrique Dussel Peters (coord.), 40 años de la relación entre México y China: acuerdos, desencuentros y futuro, México, FE-UNAM, pp. 169-178.

Banco Mundial [1997], Informe sobre el desarrollo mundial. El Estado en un mundo en transformación, Estados Unidos de América, Oxford University Press para el Banco Mundial, 292 pp.

Bianco, C., G. Bittencourt, E. Dussel et al. [2012], "La transnacionalización en el mundo, en China y en América Latina”, G. 
Bittencourt (coord.), El impacto de China en América Latina: comercio e inversiones, Montevideo, Uruguay, Red Mercosur, $195-262 \mathrm{pp}$.

Bittencourt, G., G. Carracelas, N. Reig L. y A. Doneschi, A. [2012], "Estimaciones econométricas de la competencia por IED entre China y América Latina", G. Bittencourt (coord.), El impacto de China en América Latina: comercio e inversiones, Montevideo, Uruguay, Red Mercosur, 263-299 pp.

Bustelo, P. [2012], "India: ¿el final de la edad dorada del crecimiento económico?", en: <http://www.realinstitutoelcano. org/wps/portal/rielcano/contenido?WCM_GLOBAL_ CONTEXT=/elcano/elcano_es/zonas_es/ari56-2012>, consultado el 13 de enero de 2014.

Casanova, L. [2010], "Las multinacionales latinoamericanas en los albores de una gran oportunidad", en Administración de empresas, México, 50(4): 439-455, octubre-diciembre.

Chang, Ha-Joon [1996], El papel del Estado en el cambio económico, México, Ariel/Fe-UnAM, 212 pp.

Chomsky, N., y H. Dieterich [1999], La sociedad global, México, Joaquín Mortiz, S.A. de C.V., 197 pp.

Cordera C., R. [2011], "Estado y política social: ¿qué hacer?”, en Economía UNAM, México, UNAM, 8(22): 7-14, enero-abril. Dussel P., E. (coord.) [2012], 40 años de la relación entre México y China: acuerdos, desencuentros y futuro, México, FE-UNAM, $436 \mathrm{pp}$.

Fernández de Castro, R., y D. Cándano L. [2012], "China: una relación prioritaria para México en el futuro inmediato", Enrique Dussel, 40 años de la relación entre México y China, acuerdos, desencuentros y futuro, México, FE-UNAM, pp. 277-280.

Garza Limón, Cecilio [2012], "México ha dejado de soñar: no perdamos lo mejor que tiene un país, su juventud", Dussel P. Enrique (coord.), 40 años de la relación entre México y China: acuerdos, desencuentros y futuro, México, FE-UnAm, pp. 49-57. Gómez I., J. [2012], "La hostilidad racista de México contra el ser chino", Enrique Dussel (coord.), 40 años de la relación entre 
México y China: acuerdos, desencuentros y futuro, México, FE-UNAM, $436 \mathrm{pp}$.

Lemus D., D. [2011], Innovación a la China, México, LID Editorial Mexicana, 278 pp.

León, Jaime [2013], "India: adiós al sueño de ser superpotencia económica", Proceso, <www.proceso.com.mx/?p=353315, 20 de septiembre.

Levy-Dabbah, S. [2012], "La minería: el puente de plata estratégico entre México y China”, Enrique Dussel (coord.), 40 años de la relación entre México y China: acuerdos, desencuentros y futuro, México, FE-UnAM, pp. 201-210.

Ley L., S. [2012], "Algunas reflexiones sobre el futuro de la relación México-China”, Enrique Dussel (coord.), 40 años de la relación entre México y China: acuerdos, desencuentros y futuro, México, FE-UNAM, pp. 59-64.

Martínez Cortés, José Ignacio[2012], La participación de China en la política internacional a través de su poder nacional", Dussel P. Enrique (coord.), 40 años de la relación entre México y China, acuerdos desencuentros y futuro, México, FE-UNAM, pp. 281-285.

Ministry of Finance [2012], "Brazilian Economic Outlook", <http://www.fazenda.gov.br/portugues/documentos/ 2012/ Apresentacao_Guido_Mantega_Economist_Conferences. pdf $>, 3$ de diciembre de 2012.

Moreira C., A., D. Magalhaes P., y S. Bichara, S. [2010], "La economía brasileña: su nuevo papel en el sistema financiero internacional", en América Latina Hoy, España, 54: 67-197, Universidad de Salamanca.

Mújica R., A. [1997], "Las cámaras empresariales como sustento de la política industrial activa", Enrique Dussel, Michael Piore y Clemente Ruiz Durán, Pensar globalmente y actuar regionalmente: hacia un nuevo paradigma industrial para el siglo XXI, México, UNAM/Jus, pp. 327-350.

Organización para la Cooperación y el Desarrollo Económicos, OCDE [2010], “OECD Economic surveys: Korea:2012”, <http:// www.oecd-ilibrary.org/economics/oecd-economic-surveys-k 
orea_19990707;jsessionid=15u8eo77scp3i.epsilon $>, 6$ de enero de 2012.

Organización Mundial de Comercio [2012], "Examen de las políticas comerciales", Organización Mundial de Comercio, http://www.wto.org/indexsp.htm, 3 de diciembre de 2012.

Pérez P., C. [2009], "Innovación y crecimiento. Comprender la dinámica y el cambio de las oportunidades para América Latina”, Adriana Martínez Martínez et al., Innovación y competitividad en la sociedad del conocimiento, México, Consejo de Ciencia y Tecnología del Estado de Guanajuato/Plaza y Valdés, pp. 21-42.

ProMéxico [2010], Síntesis de la relación México/China, $<$ http// paginas.tol.itesm.mx/Alumnos/A01181595/China.pdf, 2 de mayo de 2014.

Rodríguez y Rodríguez, M. T. [2012], “China. Políticas agrícolas antes y después de la crisis alimentaria de 2008”, Enrique Dussel (coord.), 40 años de la relación entre México y China: acuerdos, desencuentros y futuro, México, FE-UNAM, pp. 217-229. Rueda P., I. [2009], La creciente desigualdad en México, México, UNAM-IIEc, $185 \mathrm{pp}$.

Stiglitz, J. E. [2002], El malestar en la globalización, España, Taurus, 314 pp.

[2004], Los felices 90. La semilla de la destrucción, España, Taurus, 415 pp.

[2006], Cómo bacer que funcione la globalización, México, Santillana Ediciones Generales, 433 pp.

[2010], Caída libre. El libre mercado y el bundimiento de la economia mundial, México, Santillana Ediciones Generales, 423 pp.

Subbarao, D. [2009], "Impact of the global financial crisis on india collateral damage and response", The Global Economic Crisis and Challenges for the Asian Economy in a Changing World, <http://rbidocs.rbi.org.in/rdocs/Speeches/PDFs/ Speech\%20-\%20as\%20sent-\%20Modified\%20_4_.pdf >,14 de noviembre de 2012 . 
Yuming, C. [2012], "Relaciones económicas y comerciales bilaterales entre China y México", Enrique Dussel (coord.), 40 años de la relación entre México y China: acuerdos, desencuentros y futuro, México, FE-UnAm, pp. 31-34.

Zhimin, Y. [2012], "Cooperación económica y comercial entre China y México: elevando el nivel desde una óptica estratégica”, Enrique Dussel (coord.), 40 años de la relación entre México y China: acuerdos, desencuentros y futuro, México, FE-UNAM, pp. 107-120. 


\title{
CONCLUSIONES GENERALES
}

\author{
Angelina Gutiérrez Arriola \\ Gerardo González Chávez
}

En los dos últimos modelos de acumulación de capital, la participación del Estado ha sido un factor esencial para entender el desarrollo industrial de los países, en los cuales la utilización de las tecnologías propias de cada fase ha jugado un papel central tanto en la organización de la producción como del trabajo.

De principios del siglo pasado y hasta la década de los setenta, el patrón de acumulación basado en un Estado proteccionistakeynesiano, regulador del desarrollo, desplegó las condiciones generales para el modelo basado en la industrialización sustitutiva de importaciones. La intervención directa del Estado en la economía por medio de las políticas públicas que este modelo fomentaba, como es el caso de los programas de infraestructura, comunicaciones y transportes, servicios de salud, educación y vivienda, propiciaron un crecimiento acentuado de la economía y el desarrollo de núcleos importantes de la población. El Estado creó empresas en áreas estratégicas como la siderúrgica, los fertilizantes, el petróleo y la electricidad, etc., los cuales fueron fundamentales para impulsar el desarrollo capitalista al generar las condiciones para estimular la expansión del capital privado, nacional y extranjero, sobre todo en aquellos sectores donde 
esta última, por sí sola, no podía asegurar un desarrollo mínimo. Las políticas públicas propiciaron el desarrollo de una fuerza de trabajo, cuya regulación quedó plasmada en las leyes de protección del trabajo que dieron normatividad a la relación capital/ trabajo estabilizando el empleo, salarios y duración de la jornada de trabajo, además de la creación de organismos de protección en salud y seguridad social que permitió un abaratamiento social de los costos laborales. Se propiciaron condiciones para desarrollar la forma de organización de la producción fordista que favoreció el aumento de la plusvalía absoluta y relativa para incentivar la acumulación capitalista sustentada en la oferta con orientación directa al mercado interno.

La participación de los trabajadores se dio mediante una estructura corporativa controlada por el Estado, con el surgimiento del sujeto social para la conformación del sindicato y su reconocimiento por parte del Estado y del capital.

A partir de la década de los setenta se hizo cada vez más evidente la necesidad del capital de establecer mecanismos que contribuyeran a revertir la caída de la tasa de ganancia, por lo que había que establecer distintos mecanismos que restringieran los derechos de los trabajadores, aumentaran la intensidad y productividad del trabajo y liberaran los mercados de las áreas en que participaba el Estado. La reestructuración del capital coincidió con el acelerado desarrollo tecnológico que se enfrentó a la estructura de organización fordista del trabajo; se requería abatir todos los obstáculos para la expansión y circulación del capital.

El patrón de acumulación neoliberal establece las nuevas condiciones de acumulación por medio del establecimiento de las políticas públicas de apertura, desregulación y privatización, necesarias para la reestructuración del capital, las cuales fueron aplicadas y supervisadas por los organismos financieros internacionales como el Banco Mundial (BM) y el Fondo Monetario Internacional (FMI).

En esta reestructuración del capital cambian los métodos y técnicas de organización de la producción y del trabajo con base 
en la flexibilidad laboral, el fraccionamiento y la segmentación del proceso productivo a escala global, mediante la subcontratación que incorpora empresas proveedoras especializadas en el ámbito mundial y que adquieren un papel relevante. La producción se realiza mediante una red de cadenas de valor a las que son integrados proveedores especializados de diversos países y regiones, en función de la demanda y, sobre todo, para el mercado internacional. Se impulsa la individualización de las condiciones de trabajo, el control salarial, la fragmentación de la mano de obra, la temporalidad laboral, el desmantelamiento de los contratos colectivos, la disminución de los subsidios y demás obligaciones que el Estado había desempeñado en la fase anterior.

La política industrial se encaminó a mejorar la competitividad para ubicarse en los mercados internacionales y en apoyo principalmente de los grandes conglomerados empresariales. Con la nueva división internacional del trabajo, las grandes empresas presionaron para liberar la circulación de capitales y mercancías, se especializó a cada país y región en determinadas fases del proceso productivo orientando la producción de los insumos a la exportación para la elaboración del producto final, apoyados en la nueva organización de la producción, en el cual las nuevas tecnologías de la comunicación facilitan la aplicación del justo a tiempo y la circulación de mercancías se vuelve más dinámica.

La necesidad de la liberación impulsó la firma de diversos tratados comerciales para permitir la integración regional auspiciada por los países desarrollados, al eliminar una gran cantidad de barreras legales y arancelarias que establecían límites a los esquemas de producción compartida y al comercio intrafirma. Así, la lógica de la integración ha estado regida principalmente por la disolución de las barreras al flujo de capitales y mercancías requerido por la libre operación de las empresas trasnacionales, pero no para el desarrollo nacional. En este sentido, los acuerdos comerciales no fueron ni libres ni justos con economías claramente asimétricas, pues abrían los mercados de los países subdesarrollados a mercancías procedentes de los países industriales avanzados sin que se diera una plena reciprocidad. Se mantu- 
vieron multitud de barreras comerciales sutiles, pero eficaces. Esta forma de organización de la producción benefició claramente a las empresas trasnacionales, como son los casos de las industrias automotriz, textil, petroquímica, editorial, agroalimentaria y electrónica.

La aplicación de los principios neoliberales muestra contradicciones claras, ya que mientras los países desarrollados mantienen las barreras arancelarias proteccionistas, proporcionan grandes subsidios públicos a su industria y propician una participación creciente del Estado en la gestión económica, la situación es diferente en los países subdesarrollados. A estos últimos se les impone la apertura, se critica y sataniza al Estado como interventor o participante directo de la gestión económica, se les impone el endeudamiento financiero sujeto a los cambios estructurales en beneficio de las trasnacionales y se exige la disminución del gasto público en lo social, la privatización de empresas paraestatales y de los servicios de salud y seguridad social y se impone la política de rescatar las empresas quebradas para capitalizarlas y luego nuevamente venderlas, en tanto estimulan el traslado de recursos sociales hacia la acumulación y el incremento de las ganancias de las grandes empresas.

Las pequeñas y medianas empresas nacionales, generadoras de gran número de empleos, fueron desplazadas del proceso productivo y se rompieron los escasos encadenamientos productivos al enfrentarlas con grandes empresas que reciben subsidios y el apoyo de sus países para competir en el mercado internacional, por lo que se resquebrajó la competitividad de las primeras.

La participación del Estado para orientar la acumulación capitalista es fundamental cuando apreciamos las políticas públicas aplicadas en algunos países subdesarrollados que no siguieron al pie de la letra los lineamientos de los organismos financieros internacionales. Los resultados que reportan países como China, Brasil, India y Corea ejemplifican cómo el proceso de acumulación capitalista puede ser menos depredador, ya que esos países obtuvieron mejores resultados en el desarrollo y crecimiento económico, aprovechando la globalización para expandir sus 
exportaciones y protegiendo su mercado interno. No desmantelaron sus barreras proteccionistas, cuando fue necesario disminuirlas, lo hicieron de manera cuidadosa. Combinaron altas tasa de ahorro, inversión pública en educación y una política industrial dirigida por el Estado asegurándose de que hubiera capital disponible, incluso adoptaron un protagonismo empresarial para la promoción de nuevas empresas y creación de empleos. $\mathrm{Su}$ competitividad se basó no solo en los bajos salarios de sus trabajadores, sino en una mano de obra cada vez más calificada combinada con grandes inversiones en investigación y desarrollo, obras de infraestructura y modernización de su planta productiva, para disminuir costos y ampliar sus mercados, además de garantizar las materias primas para la producción y asegurar el mercado de consumo.

En el caso de México, el Estado se alejó de la función productiva y se concentró en la estabilidad financiera: promovió las políticas de apertura, desregulación y privatización del patrón de acumulación neoliberal que llevó a cabo en forma irrestricta, aplicando reformas y adecuaciones del marco jurídico para favorecer el arribo de la inversión extranjera, la liberalización de mercados y la flexibilidad del trabajo necesarias para la valorización del capital. Con la apertura, si bien algunas grandes empresas nacionales tuvieron la capacidad para integrarse al mercado global, otras caracterizadas por su atraso tecnológico, escasez de capital y bajo nivel de productividad -principalmente pequeñas y medianas-, sufrieron una profunda crisis. Por otra parte, la cancelación de los subsidios para el desarrollo de la industria nacional propició un mayor atraso, la destrucción de cadenas productivas nacionales y una mayor subordinación del país a los centros de poder internacional. Simultáneamente, el Estado redujo el gasto social y aplicó programas asistencialistas para amortiguar la enorme deuda social que esa misma política produjo afectando con ello a la mitad de la población que fue sumida en una creciente pobreza.

Este proceso afectó de manera diferente a los diversos sectores económicos. La competencia asimétrica y la reestructuración 
productiva en un contexto de globalización son elementos claves para entender los diferentes comportamientos de las grandes, medianas, pequeñas y microempresas que, dependiendo de la rama y sector económico en que se ubican, aplican estrategias que les permiten adaptarse a las nuevas condiciones con mucha fragilidad, como se puede apreciar en los capítulos que componen este libro relativos a la industria automotriz, textil y confección, editorial o la del mezcal. En conjunto representan un universo heterogéneo, ya que la composición de capital, tecnología y organización de sus procesos de producción y trabajo es de lo más diverso. La producción de automóviles está totalmente controlada por empresas trasnacionales, seguimos desempeñando un papel subordinado de maquiladores y exportadores de productos que tienen un escaso encadenamiento productivo, la sobrevivencia de la industria textil cada vez está más cuestionada por la competencia trasnacional subsidiada y protegida por sus naciones, la industria editorial que también se ejemplifica es un sector totalmente controlado por el capital externo tanto en su inversión como en las distintas fases de producción y circulación de productos. Hay algunas esperanzas en la producción en cooperativas y en la elaboración artesanal del mezcal, no obstante, el Estado tiene que desplegar una política de fomento para estos sectores que tienen un gran potencial de encadenamiento productivo e importancia en la generación de empleo. 
Políticas públicas para el desarrollo y la competitividad en la industria manufacturera es una obra del Instituto de Investigaciones Económicas de la Universidad Nacional Autónoma de México. Se terminó de imprimir el 21 de abril de 2015. Se tiraron 1000 ejemplares en impresión offset en los talleres de Fuentes Impresores, Centeno 109, col. Granjas Esmeralda, 09810, México, D. F. La formación tipográfica estuvo a cargo de José Dolores López Sánchez; se utilizaron fuentes Simoncini Garamond Std, ITC Berkeley Oldstyle Std, Verdana de 11:13, 12:14.3, 13:14.3, 10:12, 9:11 y 8:10 puntos sobre papel cultural de $75 \mathrm{~g}$ y los forros en cartulina couché de $250 \mathrm{~g}$. El cuidado de la edición estuvo a cargo de Graciela Reynoso Rivas. 